A 6 A

ampranum (a) ancmeme Aanamic

\section{ananham} ana MMAA MMAAA chananenth

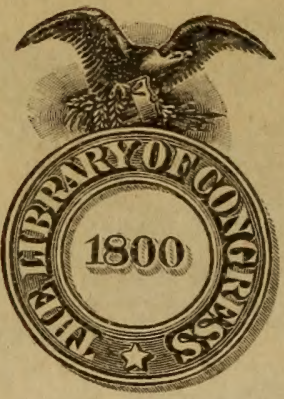

$$
\text { Class SF } 753
$$

Book. C 6

$$
1848
$$

AATAAAA ATAMAMA

- AARAลA MAAATAล:

MANAMATA WAATAACA

MAARAAAAT Anthant

AANAATAA:

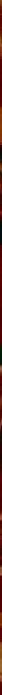

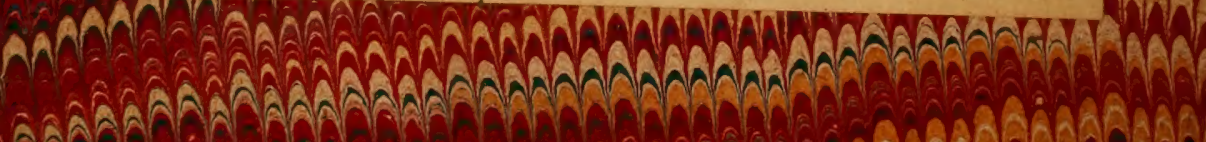
aran

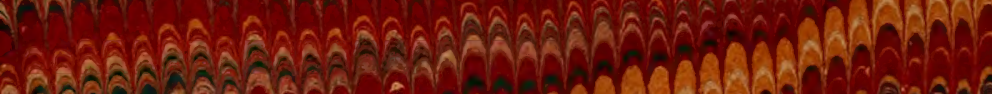

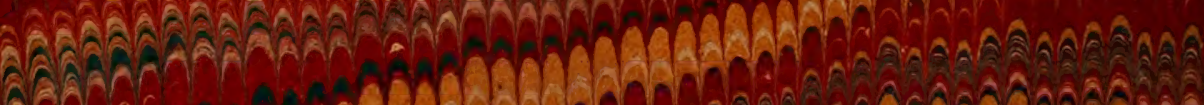

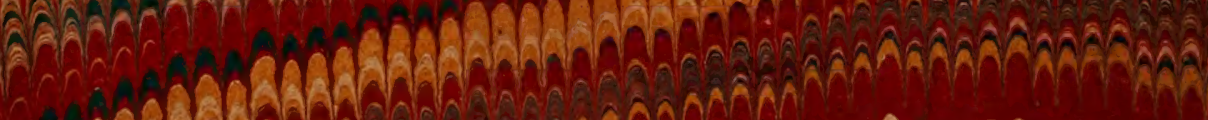
MMMAM MAMA

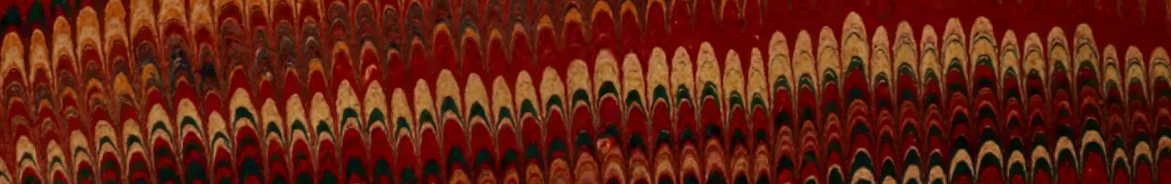

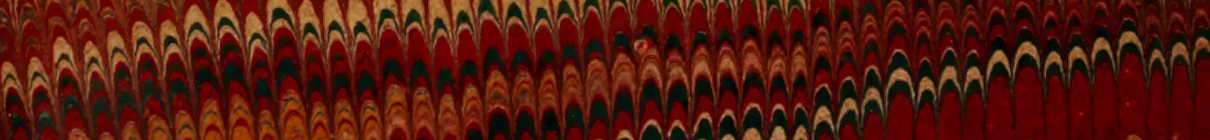
MA 


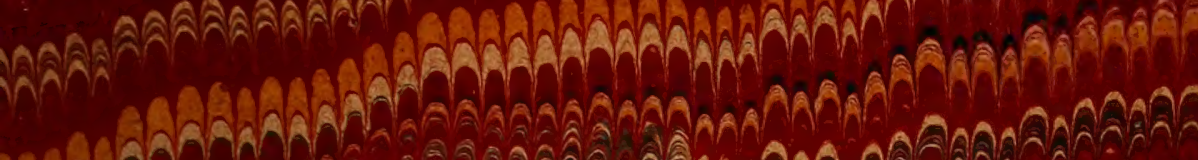
1.ค月ล

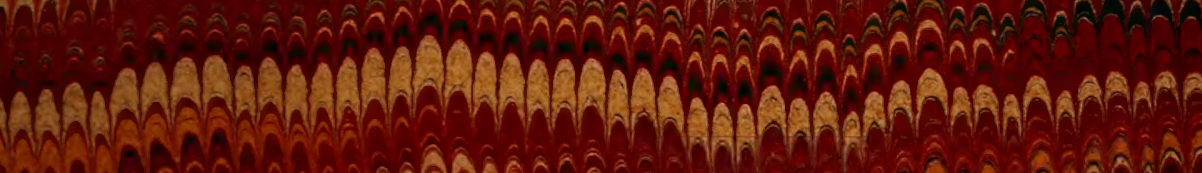

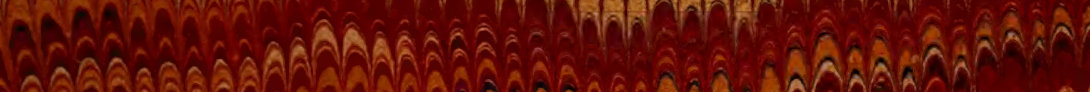
ÂÂÂA

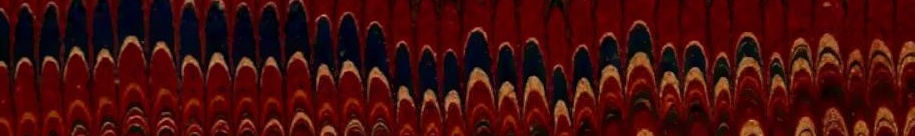

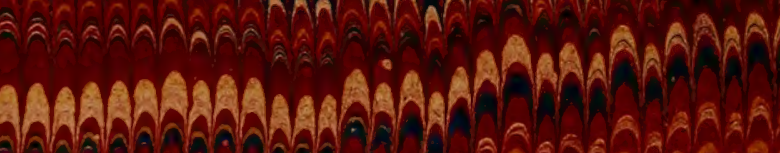

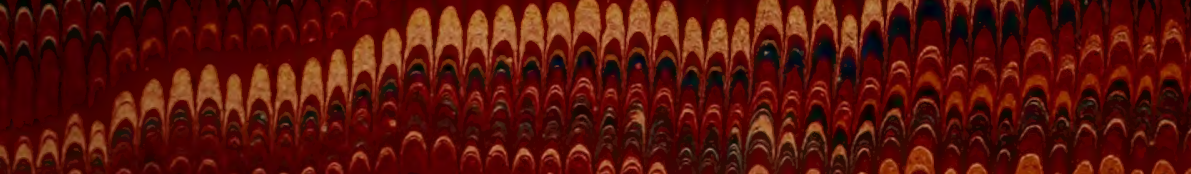

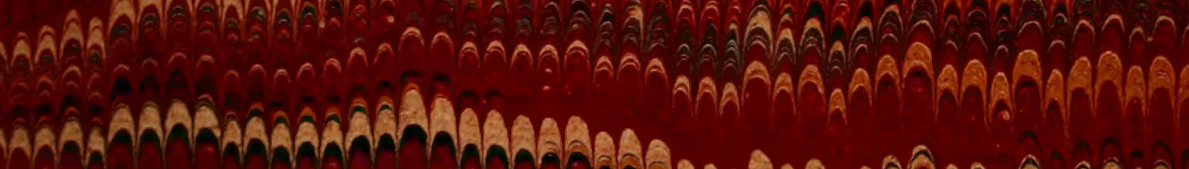

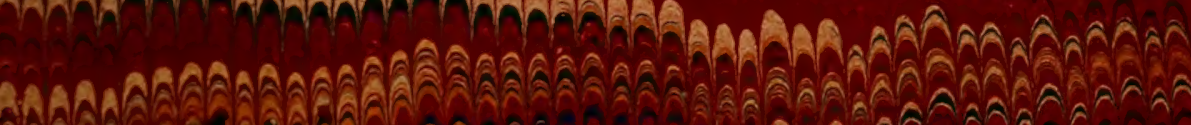

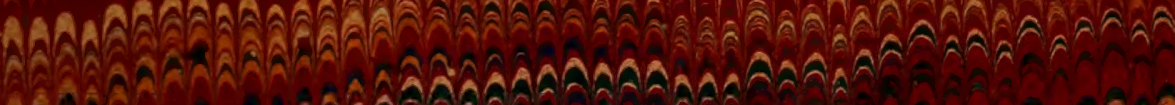
ลลลลลลลลลลคด

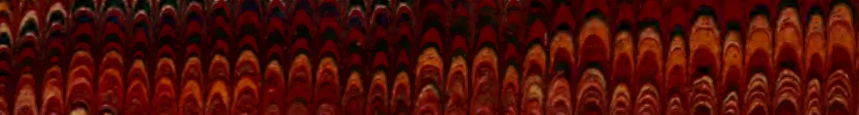

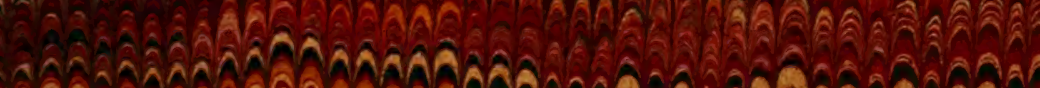

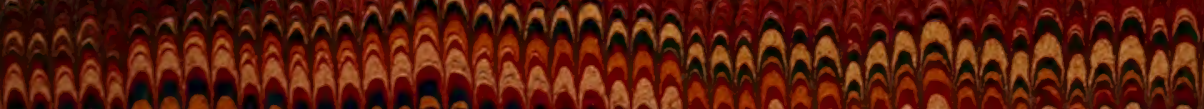

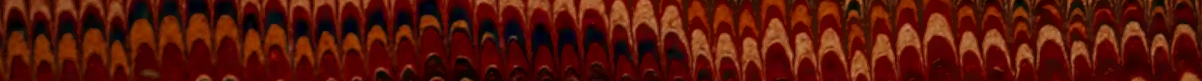

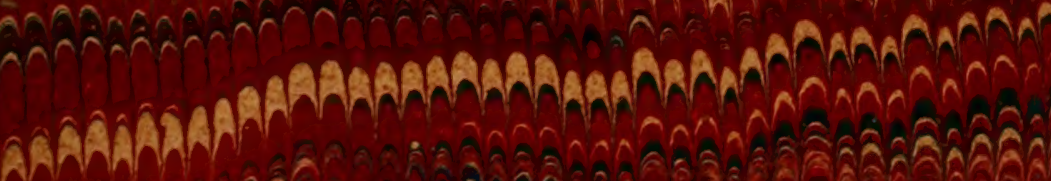

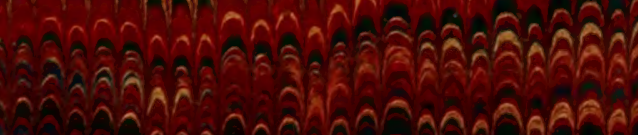

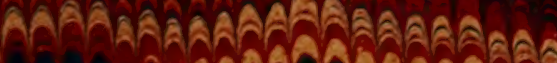

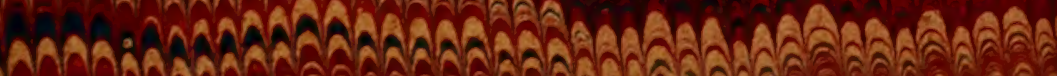
AAAAA 






\section{EVER Y M N}

\section{HIS OWN CATTLE DOCTOR: \\ C ONT AIN I NG}

THE CAUSES, SYMPTOMS, AND TREATMENT OF ALL THE DISEASES INCIDENT TO

OXEN，SHEEP，AND SWINE; AND A SKETCH OF THE

ANATOMY AND PHYSIOLOGY OF

NEAT CATTLE.

BY FRANCIS ÇLATER.

EDITED, REVISED, AND ALMOST REWRITTEN

BY WILLIAM YOUATT, A UTHOR OF “THE HORSE," \&C.

WITH NUMEROUS ADDITIONS, E M B R A CI N G

AN ESSAY ON THE USE OF OXEN, $\triangle N$ D $T$ H E

IMPROVEMENT IN THE BREED OF SHEEP, \&c.

BY J. S. S KINNER, ASSISTANT POSTMASTER GENERAL.

WITH NUMEROUS CUTS AND ILLUSTRATIONS,

P H I L A E L P H I :

LEA A N D LA N CHARD. 1848 . 


\section{VAIIISVA}

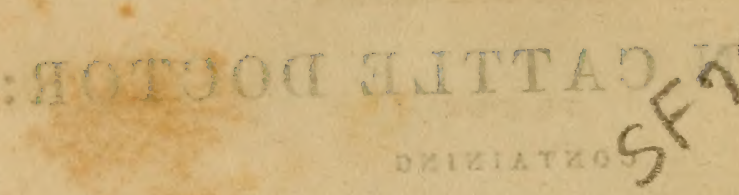

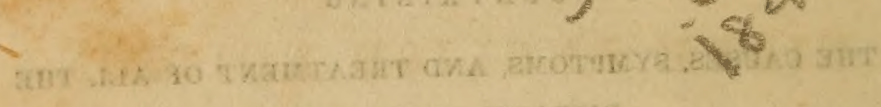

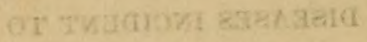

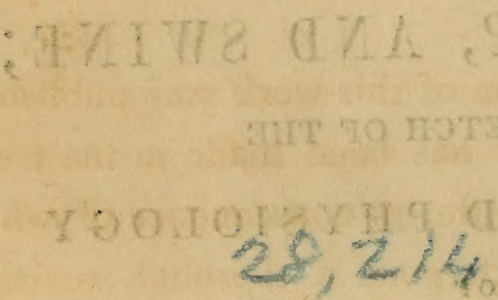

\section{8,214}

Entered, according to the Act of Congress, in the year 1844, by

\section{LEA AND BLANCHARD,}

in the clerk's office of the district court of the United States in and for

- the eastern district of Pennsylvania.

By trenefor som

Qt. Betce Lis.

L. phit 1914.

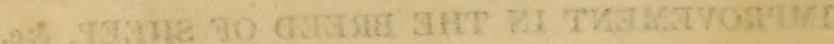

Printed by T K. \& P. G. Collins. 


\section{ADVERTISEMENT}

T 0 THE

\section{NINTH ENGLISH EDITION.}

Since the Eighth Edition of this work was published, considerable improvement has been made in the treatment of the diseases of cattle, in consequence of which this volume has again undergone a thorough revision, and several new chapters have been added. The proprietors for this purpose have placed the work in the hands of a Veterinary Surgeon of extensive experience, and they trust the desire they have evinced of rendering it still more worthy of public patronage will meet with a corresponding support.

August, 1842. 


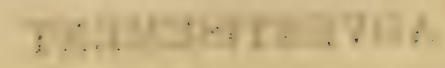

\section{:}

\section{. $\begin{gathered}4 \\ 4\end{gathered}$}

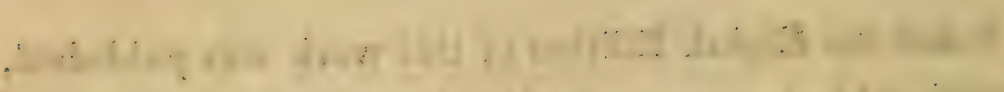

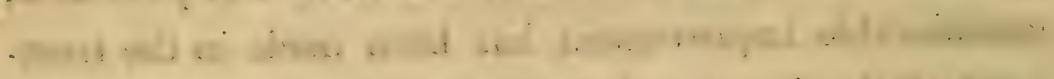
1\% :

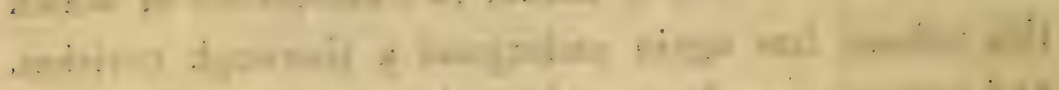

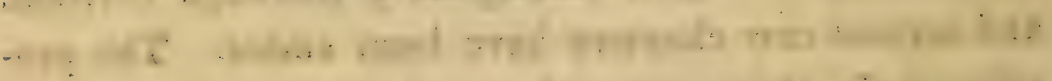

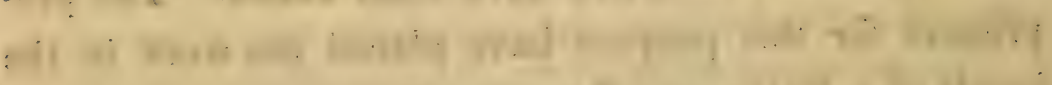

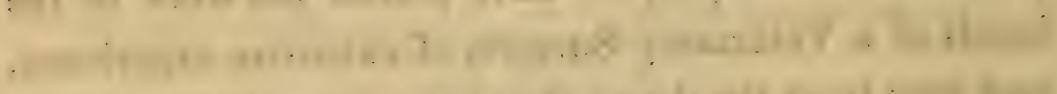

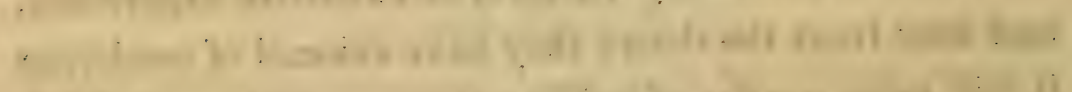

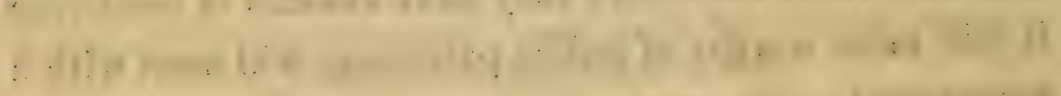
$x_{\infty}+1+1+2$ A14 , wa. $\because$.

I. 


\section{P R E F A C E}

TO T H E

\section{SEVENTH ENGLISH EDITION.}

Since the publication of the last edition of this work, a kind of revolution has taken place in Cattle Medicine. Veterinary practitioners had been strangely forgetful of the proper extent of their professional duty, and the treatment of the diseases of cattle had, with few exceptions, (but among which we may justly rank the original author of " Every Man his own Cattle Doctor,") remained in the hands of the uneducated and the ignorant. It has now, however, begun to be understood that all domesticated animals are the legitimate objects of the veterinarian's care; and veterinary surgeons of no mean eminence do not think it a degradation to practise on the diseases of cattle, and sheep, and dogs, and swine. Public lectures on these subjects are at length delivered, in the University of London, and at Edinburgh, and a knowledge of this branch of veterinary medicine has wonderfully increased.

Under such circumstances the proprietors of this work have endeavoured to discharge their duty to the public. A new edition being required, they have obtained the assistance of an eminent practitioner of both horse and cattle medicine, who, while he has retained all that was useful in the former edition (and there was a great deal that was truly valuable, and particularly with regard to the symptoms of diseases), has endeavoured to keep pace with the progress of the art. The book is in a manner re-written; and the additions on the diseases of swine, now for the first time thrown into a regular and scientific form, in the English language, will be found peculiarly valuable.

June, 1832. 


\section{7}

\section{.

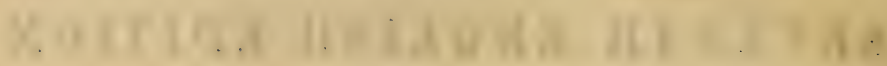

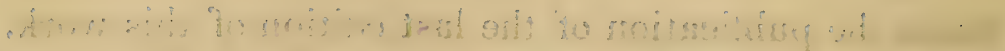

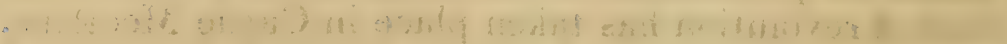

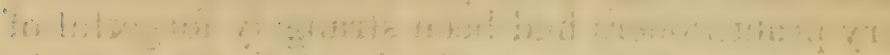

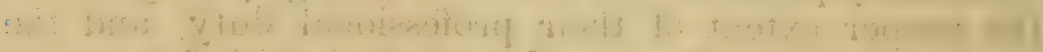

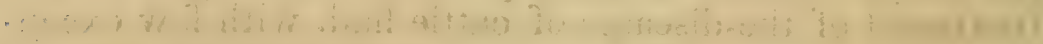

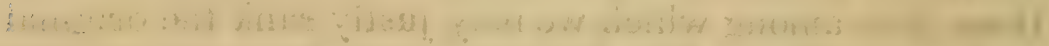

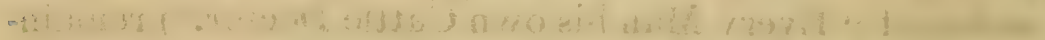

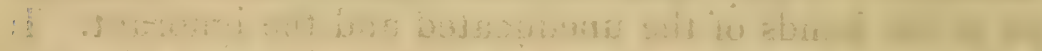

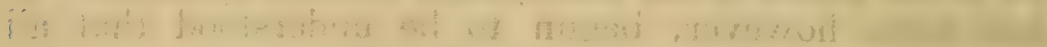

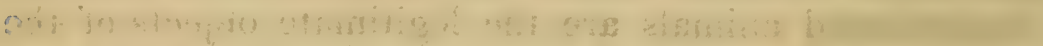

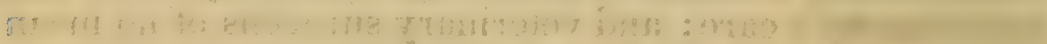



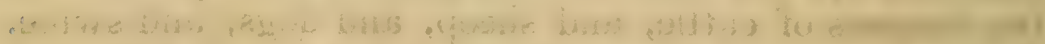
e

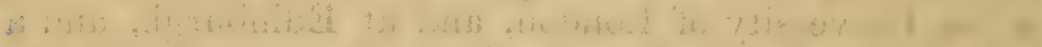

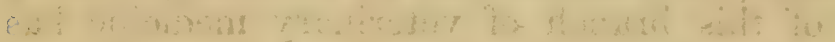

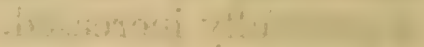

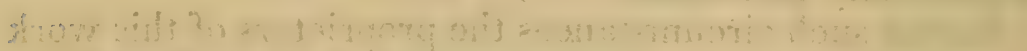

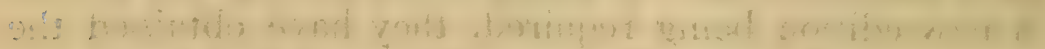

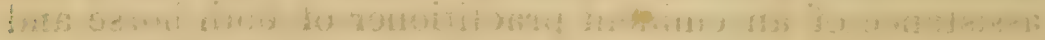

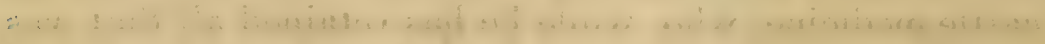
|

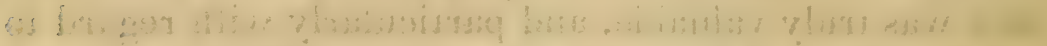

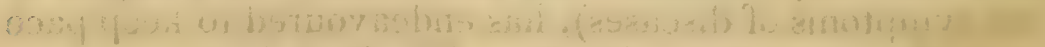

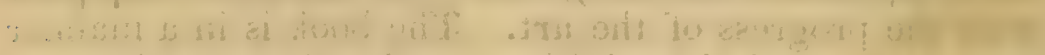

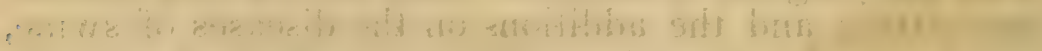

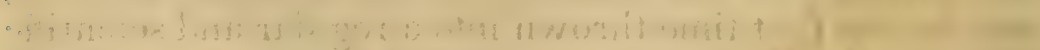

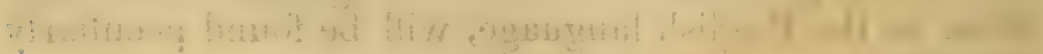




\section{P R E F A E}

TO THE

\section{FIRST AMERICAN EDITION.}

"There are two great sources of the mortality of cattle and sheep, and the oss of agricultural property; and it is difficult to say which is the worst,-the ignorance and obstinac $f$ of the servant and the cow-leech, or the ignorance and supineness of the owner."

YouatT.

THE beneficence of an all-wise Providence in so organizing man as to secure him dominion over animals of inferior physical construction, imposes on him the obligation to exercise that emtnent advantage in a spirit of mercy, and in mitigation of the pains and disorders of the brute creation; and both the obligation and the necessity to do so, are enhanced by the consideration, that in being domesticated and made subservient to our uses, animals lose in a great measure that instinct which enables them to distinguish what is noxious from that which is wholesome, and become, as does the human race in the process of civilization, liable to numerous and complicated diseases to which they are comparatively strangers when roaming in the simple habits and unrestrained freedom of nature.

Assuredly, there is no great charity in the creed which would teach that of all the variety of God's creation that make up his animal kingdom, some of them displaying high cu.ture and fine affections of mind and heart, he should care alone for the present and future happiness of man!

" Know Nature's children all divide her care;

The fur that warms a monarch warmed a bear;

While man exclaims, 'See all things for my use :'

'See man for mine,' replies a pampered goose :

And just as short of reason must he fall

Who thinks all made for one, not one for all." 
To the sparseness of our agricultural population, we may probably attribute, in a great measure, the absence of a class of persons, well supported in Europe, who profess to treat scientifically, the diseases of domestic animals. There, the study of comparative anatomy has served to illustrate and improve the science of medicine. More especially was it subservient to that end in past ages of superstition, when the dissection of the human body was regarded as sacrilegious. The discovery, says Doctor Rush, of the salivary glands in an ox - of the fallopian tubes in an ewe - of the thoracic duct in a horse - of the lacteals in a kid - and of the pancreas in a turkey, led to the discovery of the same parts in the human body; and it is well known that the circulation of the blood and of the peristaltic motion of the bowels, in man, were first suggested by experiments and observations on animals of the lower order. Their physical structure and complaints have, in fact, for years past, been the subject of regular lectures by the ablest Professors in the Universities of London and Edinburgh; and hence it is, that there, improvements in the veterinary have kept pace with the progress of other useful arts, until it has reached, in practice, a high degree of certainty, and of honour as an intellectual profession. Under such auspices, and assurances of authority and excellence, has this ninth edition of "Clayter's every man His own Cattle Doctor" been published in England-compounded, not by ignorant cow-leeches, and made up of nostrums to be administered without judgment or discretion, but embodying the mature results of careful and scientific research.

In tne hands of the American Editor, the work now presented has undergone no alteration of matter or arrangement. He has not presumed to disturb what he could not hope to amend; but some additions have been made in the confident hope of rendering this edition more acceptable by making it more useful to the American reader. These additions will be found to consist of essays and illustrations intended to diffuse such information on 
the general subject, as may well be coveted by every Gentleman Farmer, and to lead to important practical reforms. He has endeavoured particularly to impress his own persuasion, that a more general use of oxen in place of horses, would be highly expedient and economical, accompanying his reflections on this topic with ample instructions as to breeding, breaking, and gearing them.

Deeming familiarity with the names of every part of the animal frame essential to an intelligent treatment of accidental injuries or disorders to which it is constantly exposed, anatomical delineations have, for that purpose, been introduced, which are not given in the English work. For the same purpose, and illustrated in like manner, certain instruments and contrivances there only referred to, as necessary in the administration of relief in certain dangerous cases of common occurrence, will be found in this American edition - viz: the stilet probang, for relieving cattle that are choked, and Read's Patent Veterinary Syringe or Stomach Pump, to be used for the extraction of gas, when cattle get hoven, as often happens, by over-feeding on green and wet clover, or other deleterious substances.

To the medical part of the work in the shape of notes, some recipes have been appended, consisting of elements more simple or more easily procured than those prescribed in the text; but only such have been thus inserted as seemed to be either innocent in themselves, or recommended on alleged experience and respectable authority.

To say nothing of the duty which common humanity enjoins on every one, to be prepared with common medicines, and directions for the use of them, which may enable him to extend prompt relief to speechless suffering; on the sordid score of selfinterest alone, the most calculating, it may be supposed, will not hesitate to provide himself with a book which in teaching him 
to be his "own Cattle Doctor," may enable him to save the life even of the meanest animal on his estate. In a word, the want of some such work would be an obvious defect in every farmer's library, however small it may be, and this one is of the highest and most recent authority in a country where the subjects of which it treats have been most carefully investigated and are best understood. To have been revised and sanctioned by $\mathbf{M r}$. Youatr, as it is believed to have been, is of itself a sufficient titie to public confidence.

J. S. S.

Washington, April, 1844. 


\section{O N T E N TS.}

Advertisement to the ninth English edition, - - - Page vii Preface to the seventh English edition, - - _ - - ix Preface to the first American edition, by J.S. Skinner, Esq. xi

- CATTLE.

Introduction-Anatomy and Physiology of Neat Cattle, - 19 Number of Neat Cattle in each of the United States, according to the census of $1840, \quad-\cdots-\ldots$ Skeleton of the Ox, and Explanations, - - - - 38, 39

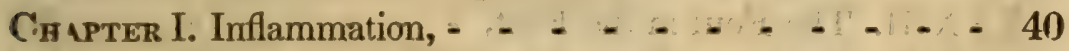

II. Bleeding, its utility - and in what cases neces-

III. On Physic,

IV: On Setoning, - - - - - - - 45

V: Cold-Cough-Hoose, $-\cdots \cdots$

VI. Inflammation of the Lungs, - - - - 50

VII. Rheumatism, or Joint Fellon, - - - - 51

VIII. Inflammation of the Liver, _ - _ - - 53

IX. The Yellows, or Jaundice, - - $\ldots \ldots$

X. Inflammation of the Brain, - - - - - 56

XI. Inflammation of the Bowels, with Costiveness, 59

XII. Diarrhœa, or Purging, - - - - - - - 61

XIII. Dysentery, Slimy Flux, or Scouring Rot, - 62

XIV. Red-water, - - $\quad-\quad \cdots \quad 65$

XV. Garget, or the Downfall in the Udder of Cows, 68

XVI. Treatment of the Cow, before and during

Galving, - . . - 71

XVII. The Milk Fever, or the Drop, - - - - $\quad 76$

XVIII. The Brain, \&c., - - . . . - - 80 
XIX. The Blood, Blood-striking, Black-leg, Quarter

Evil, or Black-quarter, - - - - - - 82

XX. Murrain, or Pestilential Fever, - - - - 85

XXI. The Epedemic of 1840 and 1841, - - - 91

XXII. Inflammation of the Bladder, - - - - - 94

XXIII. Stone in the Urinary Passages, or Bladder, - 96 XXIV. Diseases of the Eye, - - - - - - - - 97

XXV. The Hoove, Hoven, or Blown, - - - - 101

XXVI. Choking, - - - - - - - - - 108

XXVII. Locked Jaw, - _ - - - - - - 110

XXVIII. Poisons, - - - - - - - - - - - 112

XXIX. Wounds, - - - 113

XXX. Strains and Bruises, : - - - - - - 114

XXXI. Cancerous Ulcers, - - - - - - - - 121

XXXII. Angle Berries, - - - - - - - - - 122

XXXIII. The Foul in the Foot, - - - - - - 123

XXXIV. To Dry a Cow of her Milk, - - - _ - 124

XXXV. The Mange, - - - - - - - - 125

XXXVI. To produce Bulling in the Cow, and Treat-

ment of Bull-burnt, - - - - - 127

XXXVII. The Cow-pox, . - - - - - - - - 128

XXXVIII Clue-bound-Fardel-bound, - - - - - 130

XXXIX. Rabies-Hydrophobia, - - - - - - - 130

XL. The Diseases incident to Young Calves, - 131

Postscript to the Diseases of Cattle, by J. S. Skinner, Esq. 138 Essay on the advantages of the Use of Oxen in the Hus-

bandry of the United States, by J. S. Skinner, Esq., . - 142

SHEEP.

Sheep Husbandry - Diseases of Sheep, by J. S. Skin-

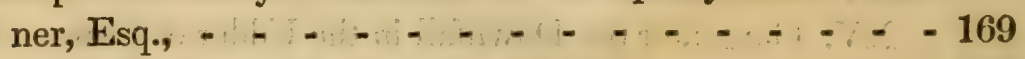

ON the Diseases of Sheep, $-z_{-}-c_{-}-193$

Sect. I. The Lambing Season, - - - - - - - - 194

II. The Diseases of Young Lambs, - - - - 198

III. Red-water, - - - ... - - - - - 202 
IV. The Blood, - - - - - - - - - - 203

V. Sturdy, Giddiness, or Water in the Head, - 204

VI. Inflammation of the Brain, - - - - - - 206

VII. Cold-Inflammation of the Lungs-Influenza, -. 207

VIII. Blown, or Blast, - - - - - - - - - 209

IX. The Yellows, or Jaundice, - - - - - 210

X. The Rot, - - - - - - - - - - - 211

XI. The Foot Rot, - - - - - - - - - 218

XII. The Scab, - - - - - - - - - - - 223

XIII. Lice, Ticks, and Flies, - - - - - - - 228

XIV. Sore Heads, - - - - - - - - - - 232

XV. Diarrhœa, or Purging, - - - - - - - 233

XVI. Indigestion and Debility, - - - - - - 234

XVII. Blindness, - - - - - - - - - - - - 235

XVIII. Fractures, Wounds and Bites, - - - - 237

XIX. General Cautions, - - - - - - - - 239

S W I N E.

On the Diseases of Swine, - - - - - - - - 241

Inflammation of the Lungs, - - - - - - - - 241

Apoplexy and Inflammation of the Brain, - - - - 242

Measles, - - - - - - - - - - - - - - 243

Mange, - - - - - - - - - - - - - - - 244

Sore Ears, - - - - - - - - - - - - - - - 244

Pigging, - - - - - - - - - - - - - - 244

Quinsy, - - - - - - - - - - - - 245

Costiveness, - - - - - - - - - - - - - - 246

Inflammation of the Bowels, - - - - - - - - 246 


\section{N T R ODUCTION.}

\section{ANATOMY AND PHYSIOLOGY}

$05^{5}$

\section{NEAT CATTLE.}

The term Neat Cattle comprehends all the varieties of the $\mathbf{O x}$ This animal belongs to that numerous order termed Ruminants, from their singular property of bringing back their food into the mouth, after the first swallowing of it, in order that it may undergo a second and more perfect mastication.

Their distinguishing characteristics are the absence of front teeth in the upper jaw, whose place is supplied by a callous par; the division of the stomach into four distinct compartments discharging essentially different functions; and the feet being cloven.

The ox, whether domestic or wild, and varying materially in appearance from difference of breed and climate and food, possesses certain characteristics, which separate him from all other ruminants : these are the strength and squareness of the skull-the horns, where there are any, invariably growing from the crest or ridge of the forehead, projecting first laterally, and being composed of a horny case covering a porous or cellular bone-the muzzle being broad, and devoid of hair, and moist-no mane on the neck-the dewlap generally deep-only thirteen pairs of ribs-the tail reaching down almost to the heels, and the ndder containing four teats, forming a kind of square. It will be advantageous to take a rapid view of the different parts of the structure of the ox.

The bones are the most solid portions of the frame: they sustain the soft parts, give shape to the animal, and protect the most important organs, as the brain, lungs, \&c., from injury.

'The bones, although solid, are perfectly organised, having bloodvessels, absorbents, and nerves: they are composed of a gelatinous matter, in which an earthy substance, phosphate of lime, is deposited, and to which they are indebted for their hardness. 
The centre of almost all the bones is more or less hollow, and contains marrow. This substance seems to be necessary to the health of the bone, and it may be a reservoir of nutriment in case any particular state of the constitution should require it.

The bones are covered by a membrane called the periosteum, which gives attachment or hold to the muscles by which the bones are moved. The ends of the bones, forming the joints, are tipped with cartilage, which is a polished elastic substance, facilitating the motions of the heads of the bones upon each other, and preventing bad effects from concussion. Still more to avoid friction or concussion, these cartilages are lined by a membrane, which secretes an oily fluid,- the joint oil or synovia. The heads of the bones are held together by ligaments, and thus joints are formed. These ligaments are white, fibrous, and tough; possessed of sufficient elasticity to accommodate themselves to the various motions of the joints, but not enough to endanger their strength.

The Head.-The head, comprehending the skull and face of the animal, is composed of numerous bones closely united to each other. The skull contains and defends from injuries that important organ, the brain; and in it are found four of the organs of sense, which minister so much to the enjoyment of the animal, viz. those of hearing, sight, taste, and smell.

The Teeth.-Neat cattle have eight fore teeth in the lower jaw, and none in the upper one: twelve grinders in the lower jaw, and as many corresponding ones in the upper one. Each tooth has its body and root: the body is all that part appearing without the gurn, the root or fang is covered by the gum, and lies deep in the bony socket. The front teeth are composed of two substances, - the internal bony part, and its covering, the enamel. This latter is exceedingly hard, and gives to the front teeth their cutting edge. The sides of the backteeth are also covered with enamel, and columns of enamel are let down into the bady of these teeth. While the bone is gradually worn away, the enamel is scarcely touched, and so there is formed a rough and uneven surface on the top of the grinders, admirably adapted for breaking down the food.

The teeth, although of firmer structure than the rest of the bones, are also plentifully supplied with nerves and blood-vessels.

How to ascertain the Age of Neat Cattle by their Teeth.-The calf is usually born with two fore or eutting teeth, and at a month old the whole eight are cut. The age is then guessed at by the wearing down of these teeth until the calf is eight months old, when they begin to become narrower and smaller. At eight months the two centre teeth are smaller than the rest; and from that time until eightees months the others gradually diminish, until the whole are very cor siderably lessened in size and stand apart from each other.

At two years old the two middle teeth are pushed out, and succeeded by two permanent ones; at three there are four permanent teeth; six at four years; and all the eight at five, when the animal 
is said to be full-mouthed; but he is not actually so until six years old, when all the eight are level.

A good judge of cattle will generally determine the age with considerable accuracy for many years after that. From six to nine he will be guided by the wearing down of the teeth, and after that by the diminution in their bulk, as in the milk teeth. At nine the two middle fore teeth are evidently smaller and narrower than the rest; at ten the two next are so; and so or until twelve, when, as in the steer of two years old, the teeth again begin to stand singularly apart from each other.

Age by the Horns. - The surface of the horn continues nearly smooth until the expiration of the second year of the animal's life, when a wrinkle or circle of thicker horn begins to be formed around the base. This is fully completed in a twelvemonth, and another ring then begins to appear, so that if the perfect rings or circles are counted, and two added to them, the age of the beast is supposed to be ascertained. These rings, however, are not always clear and distinct, and it is very easy to remove one or two of them with a rasp, at least to the unpractised eye, when the animal begins to be unmarketably old. In addition to this a well-known fact should be stated, that if a heifer takes the bull at about two years old, the first ring is formed a twelvemonth before its usual time, and, consequently, she would always appear to be, reckoning by her horns, a twelvemonth older than she really is.

After all, the age, as denoted by the horn, can only be calculated in the cow: these rings do not begin to appear in the ox or bull until the animal is five years old, and then they are frequently too confused to be accurately counted.

Young Cattle are, for the most part, best understood by the following names:-The Bull, while sucking, is called a Bull-Calf; and from one to two years old a Stirk or a Yearling Bull; every year afterwards he is called a Bull of three, four, five, and six years old, beyond which period he becomes aged. A young castrated male, after the first year, is called a Stot-Calf or Stirk-Stot, and then a Steer : at four years old he receives the name of a Bullock. A female is at first called a Quey-Calf, and then a Heifer until the age of four years : she afterwards takes the name of a Cow, which is retained as long as she lives.

The Neck of the ox is comparatively shorter than in the horse. It consists of seven bones, each of which, although widened, is shortened and roughened, for the accumulation of more flesh and fat.

The Chest is the large bony cavity containing and defending from injury the heart and lungs. It is formed of the thirteen rack bones of the back, thirteen ribs on each side, and the breast-bone below and before. The ribs are so articulated with the spine as to allow of some little motion in respiration. It is of much importance that the chest should be wide and full, and at the same time deep in the girth, otherwise there will not be sufficient space without for the 
attachment of flesh, or room within for the heart and lungs to play. It is very desirabie that the chest shall not be drawn up immediately behind the elbow. The accumulation of fleshy and fatty substance under the chest, and projecting before it, and which is called the brisket, is also an important point-is an earnest of a propensity to accumulate flesh and fat everywhere.

Breadth across the loins is a valuable conformation, and more particularly length in the quarters, leaving space for plenty of muscle and fat being put on these places, where the meat is of the finest grain and fetches the highest price.

The Fore Legs. - The Shoulder Blade is a broad, flat, and triangular-shaped bone, situated on the outside of the fore ribs. It is comparatively larger and more upright in the ox than in the horse. It is, however, a fault when the shoulders are too heavy; for there is then generally a deficiency about the choice parts.

The Shoulder Bone is a short and very strong bone extending from the cup of the shoulder blade to the fore arm.

The Leg Bone, or Fore Arm, is situated between the shoulder bone and knee, and it is the longest bone of the fore extremities. At the upper and back part of it is the process called the elbow. The fore arm should be large and muscular, and regularly tapering towards the knee.

The Knee consists of two rows of small bones, forming a compound joint of considerable strength, and allowing likewise of extensive motion.

The Fre Leg, or Shank, reaches from the knee to the upper pastern bones. It is of much consequence that it should be clean, fine, short, and small.

The ley is divided at the bottom of the shank-bone, and there are two sets of pasterns, and two hoofs, to each leg. The pasterns should be small, and not too long: the feet, especially in working oxen, should point straight forward, and should be sound; and they should not be too close to each other, for this would indicate a narrow chest, that would be unfavourable to speedy fattening.

The Hind Legs.-The Thigh Bone is a large and rather short bone, extending from the cup-like cavity of the hip-bone to the stifle. It is inclined obliquely forwards, and its lower end articulates with the leg bone at the stifle. This part constitutes the quarters, which should be deep and large. The longer the thigh bone is, compared with those below it, the better; indeed, it is of advantage that the flesh should extend down even to the hocks.

The Leg Bone reaches from the stifle to the hock, inclining obliquely backwards.

The Hock is a compound joint, being, like the knee of the fore extremities, composed of two rows of small bones. The hocks naturally approach each other much nearer in the ox than in the horse, and the hind legs diverge from each other below the hock, and stand considerably apart. In some cattle this is carried to such an extent 
as to become a great deformity-it indicates weakness and unthriftiness.

It will be unnecessary to describe the remaining bones of the hind ley and foot, as they closely resemble those of the fore leg, and have also the same names.

The Skin.-The hide or skin consists of three layers; the first and outermost called the scarf shin, the central mucous substance, and the innermost or true skin.

The Scarf Skin is the outermost layer. It is thicker on some parts than on others, as on the back and legs, and, being insensible, it defends the true skin from much injury. The scarf skin is separated from the parts beneath in the act of blistering.

The Mucous Substance is thin, delicate, and soft, resembling in toxture fine net-work. It is this that gives colour to the skin in the human subject; but it is precisely of the same hue in all oxen, whatever be the colour of the hair. It adheres more firmly to the scarf skin than to the true skin, and separates with it, when the hide is prepared by the tanners.

The True Slin is a thick, dense, and elastic substance, and is that from which leather is made.

The Hair.-The skin is covered with hair, which is not only an ornament to the beast, but tends to keep the body warm. 'The hairs arise from bulbous extremities in the skin, and receive their nourishment from these roots. 'The feeling of the skin, and the appearance of the hair, should be carefully observed. A softness and suppleness of the skin, and a kind of glossiness in the coat, not only indicate present health, but a disposition to thrive; while a hard dry skin, clingin $r$ to the ribs, and a coat staring in exery direction, show that there is sonething wrong in the constitution, and that it will be labour in vain to attempt to fatten such a beast. 'The eyelashes and the hair within the ears seem principally designed to protect those parts from insects, moisture, or cold. The hairs at the end of the tail are longer than those of the rest of the body, in order the better to drive insects away from the skin.

Inmediately under the skin is the feshy panicle, or rhine. It is a thin inuscle, extending over the whole of the trunk, and partly down the extremities. It is well supplied with nerves, and capable of very extensive rnotion; and its chief use is to corrugate the skin for the purpose of shilking off flies, or anything that may annoy the animal.

The Fat.-On removing the hide and fleshy panicle, the fat comes intn view, which is sometimes in considerable quantity, particularly on the rump. loins, and ribs. There are also layers of it, in heasts in gond condition, not only between the muscles, but the fihres of the sinfe muscle, giving a peculiar marbled appearance to the flesh.

Within the belly the kidneys are chiefly surrounded with it; the oncutum, or caul, comtains a large quantity of it; and there is, also, a grest dral about the intestines. It guards many parts that would be irigured hy pressure: it fills up a viriety of intersteces, and forms 
a reservoir of nutritive matter for the support of the animal undel any accidental want of nourishment.

Connected with the fat is the cellular membrane, formed likewise of membranous cells, but which communicate with each other through the whole of the body. There is sufficient but disgusting proof of this in the blowing up of the calf just killed. The crackling heard when the skin of cattle labouring under inflammatory fever is pressed upon, is another proof, for the gas which was produced by the commencement of putrefaction is forced into the neighbouring cells.

The cellular membrane is the connecting medium between almost all the componerit part of the frame,

The Muscles.-The muscles are accumulations of fibres or cords, running parallel to each other, and bound together by cellular membrane, and by the tightening or contraction of which the various parts of the body are moved. They arise from some fixed point, and are inserted either by a diminution of their substance, or in the form of a tendon, into a bone or part that is movable. Nervous fibrils are sent to all these museles from the spinal cord, by the influence of which they contract or shorten, and the bone or movable part into which the tendon is inserted is acted upon; and if both the parts from which they arise, and into which they are inserted, are movable, both change their place.

There are other muscles, as those of the heart and the intestines, which are moved by nervous influence not arising from the spinal cord and the brain, and not under the influence of the will. It is proper that the powers of circulation and digestion should be perfectly independent of the will. The sources whence these powers are derived will be presently spoken of.

The Brain.-The brain is a pulpy substance contained in the cavity of the skull. By means of the spinal cord (which is a continuation of its substance), and the nerves which proceed from the spinal cord, it holds correspondence with the whole frame, imparting sensibility everywhere, and giving motion to every part that is capable of voluntary action.

'The five senses, viz., vision, hearing, feeling, tasting, and smelling, so necessary to the animal's existence and well-being, are all situated in the head, and not far distant from the brain. The organs of these senses are the eyes, ears, lips, tongue, and the internal parts of the nose. These have nerves sent to them from the brain, by which the impressions made upon them by external objects are immediately communicated to that important organ, and the animal is rendered conscious of surrounding objects, and their forms and qualities.

Nine pairs of nerves arise from the hase of the brain, and proceed, through holes in the skull, to the face and head principally; but some of them wander farther, for the purposes of feeling and motion. The first pair are the nerves of smelling; they pursue a short course to the nose. 'The sccond pair go to the eyes, and are the nerves of vision: the third and fuurth pairs are distributed to the muscles that move 
the globe of the eye. The fifih pair are very extensive nerves: they divide into three separate branches, which ramify into numerous filaments or twigs, and are distributed over the whole of the face, and in some degree give the various muscles the power of motion, but more particularly confer on the parts to which they go the faculty of feeling. The sixth pair go to the muscles of the eye. One division of the seventh pair is distributed over the internal parts of the ear, and on it depends the sense of hearing: the other portion is that from which the muscles of the face mainly derive their power of motion. The eighth pair are principally distributed over the organs contained in the chest and belly: they give the power of motion, but motion altogether independent of the will ; and they have nothing to do with sensation. The ninth pair go to the tongue, and give it the faculty of taste.

These nine pairs of nerves proceeding in regular succession from the brain, may be readily seen by gradually raising that organ from the fore part of the cavity of the skull.

The Spinal Marrow. - When the brain passes out through the large opening at the back part of the skull into the canal ci the spine, it is called the spinal cord or marrow. It extends through the whole length of the spine, and gives origin to numerous nerves, which pass through notches formed between the junction of each of the bones, and are distributed over the whole of the exterior and to some of the internal organs of the body. They convey to the whole machine the power of feeling and of moving.

The Organs of Circulation. - Every part of the body is supplied with blood by means of the heart and the vessels arising from it; and the regular course in which it flows from the heart and back to it again is denominated the circulation of the blood.

The Heart is situated about the middle of the chest, rather inclining to the left side, and rests upon the breast-bone.

It may be considered as double; and it consists of two cavities on either side. The upper one, on the right side, the auricle, so called from its supposed resemblance to a dog's ear, receives the blood which has circulated through the frame, and pours it into the lower one, the ventricle. As soon as that is filled, it contracts upon its contents; and, as it closes, a membrane or valve rises, which prevents the return of the blood into the auricle, and forces it into vessels that carry it into the lungs, where it undergoes that purification which is necessary to sustain the life of the animal. Having been thus purified, it is returned to the heart, and enters the left auricle; thence it is poured into the left ventricle, and, that contracting, and a similar membrane or valve rising, to prevent its flowing back into the auricle, it is sent into the main trunk of the arteries, and thus distributed over the whole of the frame.

The blood flows through the arteries by the force impressed upon it by the heart. This is felt in the pulsations of the arteries, which correspond with the contractions of the heart, and indicate not only 
the number but the nature of these contractions, whether propelling a greater or smaller quantity of blood. By the number and the force of the pulsations the degree of fever is indicated with considerable certainty. The heat of the mouth, and of the base of the horns, will be important guides; but a much safer one, and more clearly ascertaining the extent and the nature of the fever, is the action of the heart faithfully represented by the pulse. Wherever the finger can be placed on an artery that is not too thickly covered by cellular membrane or fat, and that has some firm substance beneath, the pulse may be felt; but most conveniently so where, at the back part of the lower jaw, the artery comes from the channel between the jaws, and passes over the edge of the jaw-bone, to ramify on the face.

The natural pulse of the full-grown ox varies from 50 to 55 beats in a minute, but is quicker in milch cows than in oxen, and partioularly towards the period of parturition. A pulse much quicker than that here stated denotes fever or inflammation; whilst one much slower indicates sluggishness of the circulation, or debility.

There are other circumstances, however, to be taken into the account, - as the force or the weakness of the heart's action, - strong and bounding at the beginning of inflammatory fever, and weak and scarcely to be felt when that fever is assuming a putrid form. The regularity or irregularity of the pulse is also an important consideration as characterising the kind of irritability under which the heart labours. They who have to do with cattle will find it of immense advantage to study the pulse, and especially in reference to the propriety of bleeding; for a large bleeding will, in some cases, cut the disease short at once, while at other times it would destroy the remaining strength of the animal, and ensure and hasten its death.

The blood flows through the arteries principally by the impulsive jower of the heart. The arteries, however, possess a controlling influence independent of the heart, and can, under circumstances of necessity or disease, supply a deficiency of action in the heart, or neutralize its too violent efforts.

At the termination of the arteries, and branching from them at every point of their course, are other vessels as small as a hair, or a thousand times smaller, through which the blood must find its way. These are the crpillaries, and in them, or in the glands into which they enter, or which they compose, all the important offices of secretion and nutrition are performed. These offices being discharged, and the various portions of the frame being built up, the blood has matcrially changed. From being of a scarlet colour it has become black - from being capable of supporting life it is poisonous - from arterial it is changred to venous-and, these capillary vessels running into each other and gradually enlarging, we begin to recognise the veins. The veins commence where the arteries terminate, and by them the black blood is collected, and carried back to the heart, to be thence pumped into the lungrs, for the purpose of re-purification. 
The blood traverses the veins also by the power of the heart, but exerted in a different way. When the ventricle of the heart, after having contracted upon its contents, opens again, it forms a vacuum into which the neighbouring blood flows by a mechanical principle, viz. the pressure of the atmosphere. 'T'he fire-engine is supplied with water from the reservoir by the same principle, although the pipe through which it flows may be a quarter of a mile in length. Besides this, where there are muscles by the action of which the vein may be compressed, provision is made that the flow of blood shall be assisted and not retarded; for there are numerous membranous valves, which open in the natural direction of the current, and would close if the current were to take a retrograde course. All the veins connected with the muscles are abundantly supplied with such valves, so that, by every contraction of the muscle, or motion of the limb, the blood is forced on more rapidly in its natural course, and the possibility of retrograding is prevented. This accounts for the incrensed flow of blood on exercise, and the greater rapidity with which the blood escapes in venesection, when the jaw of the ox is moved by introducing the finger in to the mouth.

The Organs of Respiration:-Respiration is so absolutely essential to the life of quadrupeds, that, if it is suspended for a few minutes, the animal dies suffocated. The act of respiration is the alternate reception and expulsion of air into and from the lungs, and, during which, the blood traverses a set of vessels in the lungs, where it is exposed to the action of this air, and changed by it, and rendered capable of supporting animal life. 'The air which is to effect a salutary change in the blood is received partly through the mouth, but mostly through the nostril in cattle, and enters

The Windpipe, a long tube situated in the fore part of the neck, and leading from the back of the mouth to the lungs. On the top of it is a triangular cartilaginous substance, which permits the passage of the air either way, but closes the mouth of the windpipe when the animal swallows its food, and so prevents any substance from getting into this tube, and annoying, or perhaps destroying, the beast.

The windpipe consists of numerous circular rings formed of dense cartilage, and these are connected together by a strong ligamentous substance which is very elastic: this peculiar structure not only renders the windpipe very flexible, but keeps it eonstantly open. The whole passage is lubricated with a viscid fluid, secreted from the membrane lining its internal surface.

Immediately before it arrives at the lungs, the windpipe divides into two distinct tubes, and these, as soon as they enter into the lungs, subdivide until they are too minute to be traced by the naked eye, and at length terminate in an innumerable series of minute cells. Upon the membrane lining these cells the vessels which have conveyed the venous blood to the lungs ramify, and there is nothing interposed between the air and the blood but the membrane forming the cells, and the thin covering of the blood-vessels. 
The air is introduced into these cells in the following manner:The chest and the belly are divided from each other by a very strong muscular expansion called the diaphragm, or midriff, or skirt. In its natural state it is of an arched form, and bulges considerably into the chest. When it is excited to action, it contracts ; it becomes straighter; the bulging into the chest is diminished, and the cavity of the chest proportionally increased; and if, at the same time, the muscles which are between each rib, and which have the power to elevate or depress the ribs, likewise act and raise them, the cavity becomes yet more enlarged ; and the consequence of this necessarily is, that there would, if possible, be a vacuum between the lungs and the walls of the chest. To prevent this, or, more properly speaking, forced by the inequality of atmospheric pressure thus produced, air rushes into the nose, passes down the windpipe, inflates and fills up the lungs, and is thus brought into contact with the blood. After a short time the diaphragm and the muscles of the ribs cease to act, and the former begins to bulge again into the chest, and the latter to fall, and the cavity of the chest is contracted, and the lungs are squeezed into their former bulk, and the air which had entered is pressed out again.

A most important process, however, has been performed during this entrance and expulsion of the air. Both the air and the blood have been changed : the air has become poisonous, and the blood has become capable of supporting life. A great quantity of what used to be termed pure air, oxygen, is taken from that which was inhaled; a portion of it unites with the poison of the blood - the carbon - and forms carbonic acid gas - fixed air - and which is expelled when the air is returned in the act of expiration; while another portion of it enters into the composition of the blood, and either remains there unchanged, or becomes combined with some of the multifarious substances that make up the blood. The air has taken carbon from the blood, and communicated oxygen to it.

This change, both of the air and the blood, is not so marked in the ox as in most other animals. He does not seem to have so much poison to get rid of, nor needs he to steal so much vital air from the atmosphere, and therefore the cow-house, however close, is seldom offensive. The breath of the cow is even pleasant, and consumptive persons have fancied that they have derived benefit from inhaling it.

'The inside of the chest, and of the diaphragm, and also the whole external surface of the lungs, are covered by a smooth membrane called the pleura, which secretes a serous fluid, which in its natural quantity preserves the surfaces moist, and prevents friction, but in undue and unhealthy quantity constitutes dropsy of the chest.

The Organs of Digestion. - The food received by all animals affords, by the process of digestion, a nutritious fluid of a milky colour, called ehyle; which is absorbed into the system, and soon enters the circulating mass of blood, and becomes itself converted into blood: thereby repairing the waste that this fluid suffers in nourishing the body, and also supplying the materials for all the 
strangely varinus secretions. The orcans of digestion in neat catile are more complicated than in the horse, or in man; for the latter have only one stumach, but these have four stomachs. 'This, probably, renders them more liable, particularly in their present domesticated state, to diseases of the digestive orcrans.

The gullet is a thick fleshy canal that receives the food from the mouth, in its passage into the first stomach, and having afterwards returned it to the mouth for the purpose of re-mastication, once more receives it, and conveys it into a canal at its base.

The grass is crnpped, and having been slightly chewed, is covered by the mucus of the mouth, and formed by the tongue into a lind of pellet that can be swallowed. It then passes down the gullet, and arrives at this canal. If this canal were pursued it would lead on to the manypiies, or third stomach; but its floor is curiously constructed. It is formed of two ronnded muscular bands, which may be held together or divided - which may form a tube through which a liquid will scarcely penetrate, and so carry on the food to the third stomach, or which mily diride and sutior it to fall through into the rumen or palunch, of the root of which, and also of the reliculum, or second stomach, these bands form a part.

'The pellet of food pisses down, and partly by its own weight, and a sisictul also by the contraction of the muscles of the gullet, and its course also in some ineasure depending on the pleasure of the animal, it brealis throurh the floor and enters into the paunch; and there it remains, and pellet after pellet descends until the paurch is nearly or quite fillod. 'The animal then lies comfortably down. The food has all this time been macerating in the paunch, the inner membrane of which is lined with numerous little prominences or capillary glands, thit secrete an alkaline fluid, which prevents or limits the process of firinentation, when fresh succulent vegetables are exposed to the united influence of warmth and moisture. While this has been going forivaril, the muscles which compose one of the coats of the paunch have been constantly acting, and the food has travelled through the various compartments of the stomach, and every portion of it has been exposed to the influence of this fluid; and finally, that which was swallowed first, or which had been in the stomach many an hour befire, and which has been considerably softened, and duly prepared, is ready to present itself first to be returned.

By a slighily convulsive act, a portion sufficient to form a pellet of the proper size to be returned passes on from the paunch into the sirennd stomach, which is connected with the first under the floor of thr cancl. 'This stomach is possessed of a strongly muscular coat, and it rontrarts immediately on this mass, presses out the fluid which it contains, and sends it clong the canal through the third into the fourth stumacir; at the same time it forms the more solid part into a pre fer strape to be returned, and covers it with a mucous fluid, priviled ly numerus little glands in the honcycomb-cells, and which rent rs its return through the gullet more easy. 
By another slight convulsive effort of the animal the pellet is made to break through the floor of the canal, and is carried to the base of the gullet, where it is embraced by the spiral muscles of that tube, and returned to the mouth; or it may be more correctly said that the same effort which sends the prepared pellet from the second stomach into the gullet, to be re-chewed, forces a fresh portion from the paunch into the second stomach. The animal now ruminates at his leisure, and the pellet having been perfectly broken down by the grinding action of the teeth, and softened by an additional secretion from the glands of the mouth, is almost a semi-fluid mass; and, when it is again swallowed, it either has not sufficient solidity to force itself through the floor of the canal, or the beast does not choose that it shall, and it passes on, over the roof of the paunch and the honeycomb, and enters into the third stomach or manyplies.

A very important hint here suggests itself with regard to medicines, and which has not been sufficiently attended to by the cow-leech or the veterinary surgeon. We may, to a very great extent, send medicine into what stomach we please. We may give it in a ball, and it will fall into the paunch, and thence go the round of all the stomachs; or it may be exhibited in a fluid form, and gently poured down, and the greater part of it passed at once into the third and fourth stomachs. That which is meant to have a speedy action on the constitution or the disease should be given in a fluid form. 'That also which is particularly disagreeable should be thus given, otherwise it will enter the paunch, and be returned again in the process of rumination, and disgust the animal, and, perhaps, cause rumination to cease at once. This would always be a dangerous thing, for the food retained in the paunch would soon begin to ferment, and become a new source of irritation and disease.**

The third stomach, called the manyplus or manyplies, or manyleaves, is, at its base, a continuation of the canal already referred to, and through which fluid food would pass at once into the fourth stomach; but there are suspended from its roof numerous curious leaves, floating loose in the canal, furnished at the edges with numerous little hooks, which intercept and take up everything that may have escaped the action of the teeth, and continues to retain a solid form. The general surface of these leaves is studded with littie hard prominences on either side, and, these rubbing against each other, the hardest food is gradually reduced to a fit state for digestion. This being accomplished, the food arrives at last at the fourth or true digestive stomach-a long pouch or bag, more abundantly supplied than any of the others

* It has, however, been ascertained by experiment, that if a quantity of liquid, nuch as linseed tea, be given to a heast just before it is slaughtered, the greater por. tion will be found in the rumen. The fluids, however, do not require to be ruminated, and therefore they are squeczed out by the action of the second stomach, and thus pass on wards to the third and fourth stomachs, whilst the solid fond is returned to the moth and re-masticnted. Even after this all the ruminated fond does not ne. cessarily pass into the third stomach, but the harder portion again enters the rumen, and is again ruminated. 
with blood-vessels, and secreting the gastric juice - the principal agent in digestion, and by means of which the food is converted into a uniform half fluid mass, called chyme.

From the presence of this gastric juice, the fourth stomach has the property of curdling milk. The dried stomach or maw of calves is called rennet. It will be seen, as we go on, that this property of curdling milk is, in some states of the stomach or the milk, an occasional source of disease.

The food, being thus prepared, passes through the lower orifice of the stomach into the intestines; and these are of enormous length, in order that every particle of nutriment may be extracted. They are twenty-two times the length of the body of the ox.

The food has not passed far into the first intestine ere it undergoes a new change. The secretions from the liver and the pancreas-the bile and the pancreatic juice-mingle with the food; and at the same time, and possilly influenced by these, the mass which has passed the stomach begins to separate into two parts, the one a white matter, constituting the nutritive portion, and called the chylc-the other, that which is afterwards to be expelled from the system. The separation is at first but partial: more and more nutritive matter is extracted as the mass rolls on, and, at length, nothing that is usefnl remains.

This nutritive matter, the chyle, is not suffered to pass far along the intestinal canal, but is taken up or absorbed by numerous minute ressels that open on the inside of the bowels, and is conveyed by them into the circulation, where it is mixed with the blood, and converted into blood, and prepared for building up the various portions of the frame. All along the small intestines,-the dundenum, jejunum, and ileum, - this separation continues to be made, and these vessels at length convey away all the useful portion of the food.

The residue, having arrived at the larger intestines, which now succeed, and containing no longer anything that can be thus changed into chyle, these vessels, the lacteals, are no longer found in cattle; but nevertheless there are other vessels, absorbents, which take up the fluid parts of the fæces, and extract from them what may ultimately contribute to nutriment. It is on this account that, when an animal is unable to eat, we can support him for a considerable period by means of nutritive fluids injected into the bowels, and which can only reach to the large intestines.

In most herbiverous animals there is a provision made by a curious cell-like structure of the colon and cxcum, (the most considerable of the large intestines), for the retention of the residue of the food in them; but, in the ox and other ruminants, the food is so thoroughly prepared by the complicated mechanism of the four stomachs, and the course of the sinall intestines is so lengthened, that this structure of the colon and cocum is not needed, and they are neither of extraordinary size nor formed into cells 
All nutriment of every kind being extracted, and the residue having reached the last intestine, the rectum, it is hurried on to be expelled.

Several diseases to which the intestines of cattle are exposed having reference to, or being seated in, different coats or membranes of these vessels, it will be necessary to speak briefly of them. In the first place, they are all wrapped up in a very thin membrane or bag, yet one that possesses considerable strength, called the peritoneum. It secretes a serous fluid, and thus prevents friction in the natural motion of the bowels over or among each other; and, encircling them all, it retains each pretty much in its place, and restrains too extensive or dangerous motion. The outer coat of the intestines is composed of a reflection or expansion of this membrane, and is liable to a peculiar inflammation. The second coat is muscular, and is composed of a double layer of fibres, by the action of which the food is conveyed or pressed along the canal, and which is called the peristaltic motion. The inner coat is the mucous one, so called from the jelly-like substance by which it is covered; called also the villous coat, from its velvet-like construction. It is thickly set with innumerable glands pouring out this mucus, and it is the seat of inflammation in over-purging.

The Mesentery, or that membrane by which the intestines are enfolded from beginning to end, and through the folds of which the blood-vessels and nerves that supply the intestines, and the veins, and the lacteals pass, is only a duplicature of the peritoneum. In different parts of the mesentery, various glandular bodies are seen: they are the mesenteric glands, the precise use of which is not known, except that they are connected with the passage of the chyle. The enlargement or obstruction of them is sometimes attended with very serious disease, and even with death. The omentum, or caul, is also a portion of the peritoneum. The use of it has never been satisfactorily explained.

The Liver is a large gland, of a dark-red colour, situated in the belly on the right side, and secreting a bitter fluid named bile, or GALL. It receives the blood that returns from all the contents of the belly, and which is probably so loaded with carbon that it could not all be discharged by the lungs; the quantity of atmospheric air that can be introduced into the lungs in the act of breathing not containing sufficient oxygen for the purpose. The blood is, therefore, sent into the liver, where it undergoes a process of purification to a certain extent. This inflammable matter, the carbon, is separated in the form of bile; and when that is conveyed into the bowels, in order that it may be expelled, it is rendered exceedingly useful there, either by separating the chyle, or quickening the passage of the food, or both. 'The yellows in cattle is caused either by too great an increase of bile, or by obstruction of its passage into the intestines. In the first case the surplus quantity is taken up by the absorbents, and enters into the circulation and tinges the blood yellow; and in the other case, accu- 
mulating in the liver, or the obstructed ducts, it is at length taken up by the vessels of those parts, and is carried over the frame.

The bile is received into a kind of reservoir called the gall-bladder, in which it is stored up for use: at the same time it is probably improved in activity by the absorption of some of the fluid parts of it.

The pancrens, or sweetbread, is a large gland, of a whitish colour, adhering to the upper portion of the first small intestine, and which secretes a fluid-like saliva, termed the pancrcatic juice, that is poured into the intestines, and assists in the process of digestion. Of the precise nature, however, of this fluid, or the manner in which digestion is promoted by it, we have no certain knowledge.

The spleen, or mill, is a large and oblong substance of a dark purple hue, situated upon the paunch, being between it and the midriff. Of the office discharged by the spleen we have no satisfactory information.

The Absorbents. - Every part of the body is continually changing. The worn-out portions are dissolved, and taken up by the absorbent vessels, and carried, like the chyle, into the circulation. They mingle with and form part of the blood, and are converted again into nutritive matter, or expelled by means of the liver, or in some other way. These absorbents, or, as they are sometimes called, lymphatics, are small transparent, elastic tubes, opening upon every surface, and every portion of the body, external and internal.

The trunks of the absorbents are arranged into two systems, one of which lies near the surface of the body, and the other is more deeply seated; and both follow the course of the neighbouring veins. They have valves like the veins, and pour their contents into the circulation at the same point with the veins.

The lymphatic glunds form a prominent part of the absorbent system. They answer some valuable purpose, for every absorbent, in performing its course, passes through one or more of these glands. They are seen in the mesentery when the animal is opened, and they can be plainly felt in the neck and under the jaw.

The Blood.-The blood is incessantly circulating in the heart and arteries and veins, and through every part of the body, supplying materials for its nourishment and growth, and for the various secretions. The different parts of the system are constantly receiving and appropriating to themselves those elements of the blood which are proper to supply the waste they sustain from the necessary actions of life; conseyuently the health and vigour of the body require a new, daily, and liberal supply of fresh blood. That supply is in some measure derived from the absorbent vessels generally, but chiefly from the chyle, which is separated from the food in the process of digestion.

Blood, received into a vessel in the act of bleeding, snon separates into two parts; one of which is fluid, and called serum, the other solid, and called red clot, or cale, or crassamentum.

Serum is the watery part of the blood, and surrounds the red clot. 
When it is heated to 160 degrees of Fahrenheit's thermometer, it coagulates like the white of an egg ; but it has no appearance of be ing organised.

Red (lu/, cr Crassamentum, coagulates spontaneously ; and is found to consist of two parts, namely, a fibrons substance called congulable lymph and resembling very closely the muscular fibres, and a great number of extremely small red globules, which give colour to the blood.

Secretion.-There are separated from the general mass of blood, by certain organs denominated glands, different kinds of fluids, subservient to various purposes; and the process by which they are formed is termed secretion.

The glands on the internal coat of the stomach secrete the gastric - juice, the liver secretes the bile, and the saliva is derived from the glands of the mouth. In some cases it seems to be a mere filtration or separation of certain substances from the blood: in others it is the formation of a new substance that did not previously exist there. With regard to the structure of the glands, there is considerable obscurity. They consist of a great number of small arteries which convey the blood to be operated upon, and of corresponding minute veins that return the blood when the operation is complete; but of the intermediate substances or sets of vessels, and of the nature of the action which is going forward in them, we are perfectly ignorant.

The secretions are exceedingly numerous, very different in their chiracter, and all subservient to some useful purpose. The most important secretion connected with the cow is that of milk, which is formed in that large and complicated gland, the udder, to which so many blood-vessels are directed.

The functions of the glands are much affected by disease. The secretion is sometimes suspended. In dropping after calving, and in constipation, the secretions of the udder and the bowels partially or entirely cease. At other times the fluids which they afford are considerably increased. In purging, the glandular follicles of the bowels pour out a great quantity of aqueous fluid. Occasionally the character of the secretion is changed. 'The discharge of mucus from the nose, under some diseases, and the fluid which escapes from the bowels in dysentery, are very acrid and irritating.

Perspiration. - A fluid is continually passing off from the surface of the body in the form of an invisible vapour; and when, from exercise or other causes, the quantity is increased, it becomes visible like a thick stream, and collects upon the skin and wets the hair, or falts in drops. This is the perspiration or sweat. It is necessary to health that a considerable quantity of fluid should escape in this way. When, from sudden exposure to cold, this discharge from the skin is suppressed, either generally, or in a particular part, rheumatism, or honse, or catarrh, is the result. Various states of the constitution, and various diseases, will also materially influence the discharge. A cessation of it is by turns the consequence and the cause of disease. 
When the coat stares, it is owing to the scales of the outer skin becoming dry from the stoppage of perspiration, and turning the hair in dufferent ways: when the coat is smooth and glossy, it is caused by the perspiration rendering the skin moist and supple, and thus permitting the hair to take its natural direction. We judge with considerable accuracy of the health of the animal by the appearance of the coat, because in health the perspiration flows naturally, and in disease it is unduly increased, or oftener suspended.

The Organs of Urine.-The lidneys are two in number, of an oblong shape, situated in the loins on each side of the spine, and imbedded in fat. They are of a red colour, and divided externally into between twenty and thirty distinct lobes, or portions.

A great quantity of blood is continually circulating through them, and they, being glandular bodies, separate from it a fluid, called urine. The peculiar ingredient of the urine, urea, contains a great quantity of a poisonous substance or gas, called nitrogen. It would therefore seem that the kidney is the organ by which any dangerous excess of nitrogen in the constitution is removed. Besides the urea, nearly twenty different salts and compounds, more or less injurious, have been discovered: so that the kidney is a gland of immense importance in preventing the unhealthy accumulation of these inatters. It likew ise is ready to act instead of any other part of the frame that may happen to be diseased or out of order. When the absorbents are unable to carry off the fluid received into the stomach, or the lungs or the skin refuse to throw off their share of perspirable matter, the kidneys supply their place, and by an increased flow of urine prevent disease and danger.

The urine is conveyed from the kidneys into the bladder by two canals called the ureters, and it is retained until a sufficient quantity is collected to excite that organ to contract, and to expel its contents.

The Periloneum and Caul.-The peritoneum is a strong and extensive membrane, lining the internal surface of the belly, and covering all the organs contained therein. It secretes a fluid which keeps the surface of the intestines moist, and thus allows free motion between thein; yet at the same time enwrapping them on every side, each is kept in its proper situation, and strength and support are given to the whole.

The (Juen/um, or Caul, is a broad and fatty membrane formed from the peritnneum, and particularly from those portions of it that are reflect 1 from the paunch. It covers the four stomachs and some of the jutestines. Its use is probably somewhat similar to that of the peritoneu:n: it supports the intestines, and it prevents them from being injured in the various motions of the body.

The Iterus a ad Pregnancy.-Reaching from the external parts of generation in the cow, the body of it projecting beyond the bladder, and the two prolongations or horns of it floatirg loose in the belly, is the uterus or womb, in which the unborn calf is contained and nourished. At the extremity of each of the horns of the womb is a small 
canal or tube, conducting to an oval body of the size of an egg, containing numerous little vesicles or bladders called ova, or eggs; and the collection of them is denominated the ovaries. At the time of conception one of these ova escapes, and slowly descends the tube and enters the womb. It is the germ of the future animal, but scarcely larger than a pea. Arrived in the womb it floats there for a while, and at length becomes attached to some portion of it. When it de. scended it was enveloped by two membranes or coats, and two others now rapidly form over it from the uterus. They are exceedingly vascular, and by means of them, and the vessels proceeding from them, not only is nourishment conveyed to the fœtus, but the blood which has circulated through its little frame is purified.

At the fourth week it has attained the size of a mouse, and every limb is to be seen nearly perfect, although in miniature. It has eyes, although at present it sees not, and a mouth, but no food enters it: the lungs perform no office, and the stomach receives no nourishment; but the blood of the mother is sufficient for its nutriment and its growth.

In the cow and other ruminant animals there are a vast number of red prominences between the membranes, consisting of thousands of convolutions and ramifications of blood-vessels : they were designed, probably, more completely to purify the blood, and render it more fit for the nourishment and rapid growth of the quadrupeds that are destined to contribute to the food of man.

In the fourth month the fotal calf is large, but the skin is not covered with hair. About the sixth or seventh month the hair has spread over it, and at the expiration of nine months the animal is sufficiently well formed and strong to change its mode of existence. The womb has now attained its greatest degree of distention: it becomes irritated; - its muscular fibres begin to contract; labour comes on, and, assisted by the diaphragm and abdominal muscles, the calf and its membranes are expelled, and the young animal is born.

As the pelvis, from its horizontal position, may safely be much larger in these animals than in the human female, parturition is, generally speaking, not dangerous or very painful in the quadruped. Difficult labours, however, and false presentations will sometimes occur, of which notice will be taken in the proper place.

The Udder. - The udder is a large glandular organ, destined to secrete milk for the nourishment of the young calf. As the produce of the cow is confined to one, or at most to two calves at a birth, the udder would perhaps have been only double, as in the mare, were it not that this animal is intended to yield the greater part of her milk for the nourishment of man. The bag is therefore quadruple, or there are four distinct partitions of it.

The udder is made up of numernus minute branches of arteries, from the exuremities of which the milk is secreted. This secretion is always going on. The bag of a milch cow is always gradually filling, yet a considerable proportion of that which is given is secreted at the 
time of milking : for it must be evident to the most careless observer, that the udder could not possibly contain one-half of the milk which a good dairy cow will sometimes yield. The milk is also given in greater or less quantities at the will of the animal. A cow will sometimes not yield a drop of milk to a stranger calf, while to her own she will pour it out in abundance. In this she is perhaps assisted by the valves which are placed over the orifice of each teat, in order to prevent the milk from running out. When the calf is sucking, he is seen to push the teat upwards, he then lifts these valves: the dexterous milk-maid is well acquainted with the method of accomplishing the same object.

\section{NUMBER OF NEAT CATTLE IN EACH STATE,} ACCORDING TO THE CENSUS OF 1840.

1. Maine, ..............................27,255

2. New Hampshire, ....................275,562

3. Massachusetts, $. \ldots \ldots \ldots \ldots \ldots \ldots \ldots \ldots . \ldots 282,574$

4. Rhode Island, .................. 36,891

5. Connecticut, .....................238,650

6. Vermont, ......................384,341

7. New York, .................... 1,911,244

8. New Jersey, ..................220,202

9. Pennsylvania, ................... 1,172,665

10. Delaware, .................... 53,883

11. Maryland, ..................... 225,714

12. Virginia, .................... $1,024,148$

13. North Carolina, ....................617,371

14. South Carolina, ................. 572,608

15. Georgia, ...................... 884,414

16. Alabama, ...................668,018

17. Mississippi, ....................6 623,197

18. Louisiana, ....................... 381,248

19. Tennessee, .................... 822,851

20. Kentucky,..................... 787,098

21. Ohio, ....................... 1,217,874

22. Indiana, ...................619,980

23. Illinois, $\ldots \ldots \ldots \ldots \ldots \ldots \ldots \ldots \ldots \ldots \ldots 626,274$

21. Missouri, ....................4 433,875

25. Arkansas, ................... 188,786

26. Michigan, .................... 185,190

27. Florida, .................... 118,081

28. Wisconsin, $\ldots \ldots \ldots \ldots \ldots \ldots \ldots \ldots \ldots \ldots, 30,269$

29. Iowa, ...................... 38,049

30. District of Columbia, .............. 3,274

Total, .................... 14,971,586 


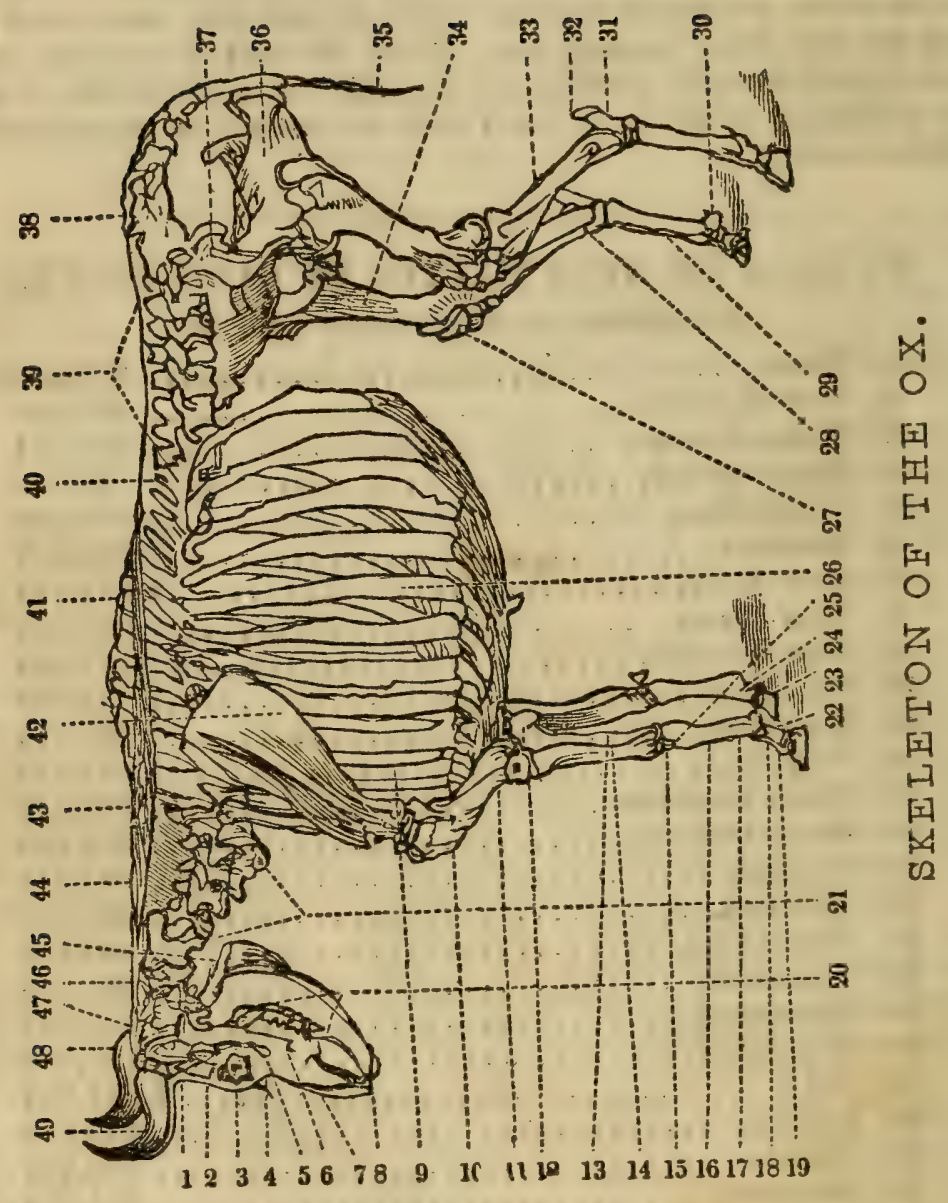

(38) 


\section{EXPLANATIONS OF THE OPPOSITE CUT.}

1. The temporal bone.

2. The frontal bone, or bone of the forehead.

3. The orbit of the eye.

4. The lachrymal bone.

5. The malar, or cheek bone.

6. The upper jaw-bone.

7. The nasal bone, or bone of the nose.

8. The nippers, found on the lower jaw alone.

9. The eight true ribs.

10. The humerus, or lower bone of the shoulder.

11. The sternum.

12. The ulna, its upper part forming the elbow.

13. The ulna.

14. The radius, or principal bone of the arm.

15. The small bones of the knee.

16. The large metacarpal, or shank bone.

17. The bifurcation at the pasterns, and the two larger pasterns to each foot.

18. The sessamoid bones.

19. The bifurcation of the pasterns.

20. The lower jaw and the grinders.

21. The vertebræ, or bones of the neck.

22. The navicular bones.

23. The two-coffin bones to each foot.

24. The two smaller pasterns to each foot.

25. The smaller or splint-bone.

26. The false ribs, with their cartilages.

27. The patella, or bone of the knee.

28. The small bones of the hock.

29. The metatarsals, or larger bones of the hind leg.

30. The pasterns and feet.

31. The small bones of the hock.

32. The point of the hock.

33. The tibia, or proper leg-bone.

34. The thigh-bone.

35. The bones of the tail.

36. The haunch and pelvis.

38. The sacrum.

39. The bones of the loins.

40. The bones of the back.

41. The ligament of the neck and its attachmente.

42. The scapula, or shoulder-blade.

43. The bones of the back.

44. The ligament of the neck.

45. The dentata.

46. The atlas. 47. The occipital bone, deeply depressed below the crest, or ridge of the
head.

48. The parietal bone low in the temporal fossa.

49. The horns, being processes or continuations of the frontal bone. 


\section{THE DISEASES}

\section{OF \\ HORNED CATTLE.}

\section{CHAPTER I.}

\section{IN FIA M M A T ION.}

Inflammation is the most frequent diseased condition to which neat cattle are subject. This may be owing to their peculiar organization in respect to the four stomachs, in which the food is completely prepared and digested, so as to yield all its nutriment. This complicated apparatus was necessary in the animals that were destined to afford us so much liquid nutriment while living, and good fat and flesh when dead; and who must therefore be disposed to an occasional redundancy of blood in the system, and consequently to inflammation.

External inflammation is known by the part being swollen, tender, and hotter than in its natural state. In garget or downfall of the udder, which is an inflammation of one or more quarters of the bag, the affected parts are swollen, tender, and hot.

If this state of the bag is neglected, matter or pus will probably be formed. This is one of the consequences of inflammation, or one of the methods by which the part, and the constitution generally, are relieved, and which is usually denominated the suppurative process.

Should, however, the downfall be judiciously treated, the swelling subsides, and the heat and tenderness gradually vanish : the inflammation in this case is said to be resolved. This is most to be wished for, and should always be attempted in inflammatory complaints.

In black-leg, a disease frequent in young cattle, the affected part loses its sensibility, and becomes dark-coloured, and is said to be mortified. It is then speedily separated, or ought to be separated from the living portions around. Mortification is usually the result of violent inflammation, by which the texture of the part is speedily broken down, and its vitality destroyed. 
External inflammation most frequently proceeds from wounds, or bruises, or other accidents to which cattle are liable. These produce different degrees of disease, according to the severity of the injury; and when the inflammation runs high, or continues long, it affects the whole system, and brings on fever; or, in other words, a certain degree of inflammatory action pervades the entire frame.

External inflammation sometimes results from causes which affect the whole system, but the chief mischief of which is determined to particular parts, from previous weakness in them, or disposition to take on inflammation. This is the case with inflammation of the udder of cows, or the joints of young cattle. The whole frame had been exposed to cold; but the udder of the cow that had lately calved was very much disposed to inflammation, and the joints of young cattle had not acquired their full strength. In inflammatory fever, also, the inflammation will settle in particular parts, from causes which it is impossible to explain, as in the tongue in blain, and in the limbs in quarter evil.

The swelling of the inflamed part is principally to be ascribed tc the increased quantity of blood passing through it. Every little vessel is distended by the additional fluid it is compelled to carry ; and there is likewise a greater deposition of fluid and solid matter in the cellular texture of the inflamed part: for every secretory vessel is doing increased duty in proportion to the blood with which it is supplied.

In the minute ramifications of the vessels, the blood is changed from arterial to venous; and it is while this change is effecting that animal heat is extricated or produced. In inflammation, a great deal more than the natural quantity of blood is passing through these vessels: a great deal more is changed from arterial to venous; and a great deal more heat must necessarily be evolved.

The lenderness is caused by the unnatural distension of the vessels, and by their pressure on the neighbouring parts, and also the pressure of the natural deposit produced by inflammation. The nerves of sensibility likewise unite very freely with the nerves of another order that supply the capillaries; and when the nerves of the capillaries are irritated, those of sensibility will hecome irritable too, and the part will become so tender as not to be touched without extreme pain.

\section{Internal Inflammation.}

Internal inflammation is characterised by other and often more indistinct symptoms. We can here seldom ascertain the heat or tenderness or swelling of the part, and can usually only judge of the complaint by the effect which it produces on the system. Every internal irflammation does, however, soon affect the system. There is no inflammation of any important internal part that is not quickly accompanied by fever; and that fever and the degree of it are easily ascertained, by the heat of the breath and the mouth and the base of the horn, by the redness of the eye, and the frequency and hardness 
of the pulse, the loss of appetite, and, often, the cessation of rumination.

The symptoms of internal inflammation will be related as the inflammation of each part comes before us.

Whether inflammation is internal or external, resolution is to be attempted, or, in other words, the inflammation is to be subdued.

When it seizes any important organ, as the brain, lungs, bovels, kidneys, eyes, udder, or womb, bleeding is to be immediately had recourse to ; and, after bleeding, a purging drink is to be administered: sometimes it is necessary to insert a seton in the dew-lap.

In external inflammation from severe bruises, wounds, and other accidents, fomentation with warm water, poultices made of linseed meal - when they can be applied - and the purging drink (No. 2), give much relief. If external inflammation is considerable, it will always be necessary to bleed the beast.

\section{CHAPTER II.}

\section{BLEEDING, ITS UTILITY - AND IN WHAT CASES NECESSARY.}

BLEEdivg is a most useful and powerful remedy in the cure of inflammatory complaints. It lessens the quantity of blood in the vessels, and diminishes nervous power. The following are the chief diseases in which bleeding is required:-

1. Where animals in a thriving state rub themselves until the hair comes off, and the spot is covered with a dry scab; while at the same time the eyes appear dull, languid, red, or inflamed, the breath hot, and the veins puffed up, and considerably larger than usual.

2. In all kinds of inflammatory diseases, as of the brain, lungs, kidneys, bowels, eyes, womb, bladder, shape, and udder, or in swelling of the joints.

3. In the disease called blain, and in which bleeding, not only general but local, and local far more than general, has the best possible effect, the tumefaction usually almost immediately subsiding, and the beast speedily recovering.

4. When the glands or kernels between the jaws, or those of the throat, are enlarged, and especially if they are only recently affected, immediate recourse should be had to bleeding, for otherwise the lungs will probably become diseased, and dangerous or consumptive hoose will speedily ensue.

5. In bruises, hurts, wounds upon the head, strains in different parts, and all other accidents that may occur to the animal, and in which there is reason to apprehend considerable inflammation, bleeding will be proper.

6. In violent catarrh or cold, bleeding is employed; but, in slight eases, a few fever drinks will restore the animal. 
7. The yellows, when attended with feverish symptoms, or constipation of the bowels, requires bleeding.

The manner of performing this operation is too well known to require any description.

The Fleam is an instrument in general use for oxen, and the jngular or neck vein is that which is mostly opened. Local bleeding is, however, in many cases particularly serviceable. In inflammation of the eye, the eye-vein is frequently cut; in foot-halt, we sometimes bleed at the toe; and in inflammation of the bowels, or the udder, or even of the chest, blood is advantageously taken from the milk-vein.

The quantity of blood that it may be proper to take away at one time cannot here be determined; but must be regulated by the size, strength, and condition of the animal, and the disease under which he labours. In many inflammatory complaints too much can hardly be taken, provided the bleeding is stopped as soon as the patient appears likely to faint or to fall down. A strong healthy beast will bear the loss of five or six quarts of blood, without the least injury. Larger cattle, that are attacked with inflammatory complaints, will profit by the abstraction of a greater quantity ; seven or eight quarts may be taken away with decided advantage : but when it is necessary to repeat the bleeding, the degree of fever and the strength of the beast will regulate the quantity. The blood should flow from a large orifice, for sudden depletion is far more powerful in its operation than when the blood is suffered slowly to trickle down. The blood must never be suffered to fall upnn the ground, but should be received into a measure, in order that the quantity taken may be known. No absolute quantity of blood should ever be prescribed, but when extensive bleeding is demanded, the stream should flow until the pulse falters, or intermits, or the animal begins to heave violently, or threatens to fall, or other circumstances show that the system is sufficiently affected. The beast should not be permitted to drink cold water immediately after bleeding, nor to graze in the field: the former has sometimes induced troublesome catarrh, and the latter may cause the orifice to open again. If this operation is performed in the summer season, it will be most prudent to fetch the cattle out of the pasture towards evening, in order that they may be bled; and, after that, to let them stand in the fold-yard all night, and drive them back to the field on the following morning.

\section{CHAPTER III.}

ON PHY $\mathrm{IIC}$.

Purgivg medicines operate by increasing the evacuation of freces from the bowels, and thus often removing a very considerable source of irritation. They augment the secretion of the exhalent vesede 
situated on the internal coat of the intestines, and thus, by producing watery stools, lessen the quantity of fluid circulating through the system. They divert the increased flow of the blood from the affected organ, and determine it to the bowels, which is well elucidated in red water; and they have a peculiar influence on the nervous system, augmenting the energy of the nerves distributed to the intestines, but diminishing it in other parts of the system.

The chief purgatives in use for neat cattle are Glauber's salts, Epsom salts, Barbadoes aloes, Linseed oil, and Sulphur. In obstinate constipation of the bowels, ten or fifteen grains of the farina of the Croton nut, freshly prepared, may be added with gond effect. One pound of Glauber's, or Epsom salts, will purge a full-sized beast. Aloes are very properly getting into disuse : they are uncertain in their effect, they require very considerable doses of them to be given in order to act alone, and if they should be received into the rumen they are apt to disgust and nauseate the animal. Half an ounce, or six drachms of them, however, may be added to the salts in particular diseases. Where there is considerable fever, or the attack of fever is apprehended, there is no purgative so beneficial as the Epsom salts. In bad cases, twenty-four ounces may be given at a dose, and eight ounces of sulphur every six hours afterwards, until the full purgative effect is produced. Linseed oil is rapidly superseding the more expensive and the more uncertain castor oil : the dose is from a pint to a pint and a half. As a mild aperient, and in cases where there is no great degree of fever, and a violent purge is not required, there are few better things than Sulphur. Where nothing else is at hand, and the case is urgent, Common Salt is no contemptible medicine: a pound of it dissolved in water will produce a very fair purgative effect, but it should not be given if the animal labours under fever. The following are the cases in which purgative medicines are found useful :-

1. I have known some graziers who, when feeding old cows (during summer), have given them a purging drink about every six weeks, by way of keeping off the downfall, which in general has had the desired effect, and has even caused them to fatten more rapidly.

2. A purging drink is very properly given to cows soon after calving, in order to prevent the milk fever.

3. Neat cattle are naturally of a greedy and ravenous disposition, and their appetite is hardly ever satisfied. Milch cows in particular, if feeding on herbage, or other food agreeable to their palate, will often continue to graze until they are in danger of suffocation. Thus the powers of digestion become over-burdened, and the animal appears dull and heavy, and feverish symptoms are induced. Purgatives will give the most effectual relief in these cases, and if the appetite does not return soon after the physic, a cordial ball will be useful in restoring it.

4. Cows that are turned into fresh pastures sometimes become bound in their body, in which case a purging drink must be imme- 
diately administered, and repeated every twelve hours, until tho desired effect is obtained : a clyster should be given, if the first drink does not operate. If the costiveness is accompanied with pain and feverish symptoms, inflammation of the bowels is to be suspected, and must be treated accordingly.

5. When red-water is recent, a purging drink or two will often completely remove it.

6. In the yellows it is generally necessary to give a purging drink, and, after that, cordial tonic drinks, in order to invigorate the digestive organs.

7. When medicines are given to prevent cows from slipping their calves, they are generally preceded by physic.

8. In all inflammatory complaints, a purging drink should be administered after the bleeding.

9. If external inflammation, occasioned by wounds, bruises, and other causes, runs high, and affects the whole system, purgative medicines are absolutely necessary.

\section{CHAPTER IV. \\ ON SET TQNING.}

The utility of setoning for the cure of several diseases incident to neat cattle cannot be doubted. There are many localities in which, if farmers did not adopt this precaution, they would lose great numbers of their young from the black leg.

In some districts the hoose in calves is very prevalent and fatal : where this is the case, they should all be setoned when they are getting into condition, and before they are attacked by the disease. This will either lessen the violence of the complaint or prevent it altogether.

In joint evil, I have frequently inserted a seton in the dewlap with decided good effect.

Setoning will be often prescribed, in the course of this treatise, in inflammatory complaints; and it acts by exciting a new and artificial inflammation in the neighbourhood of the former one, and thus lessening its intensity. This plainly proceeds on the principle of diverting to another part a portion of the blood which was determined to the original one, while also a new direction is given to a portion of the nervous influence or power which was concentrated on it. This is in accordance with the generally reccived medical maxim, that no two violent inflammations, of different character, can exist in neighbouring parts at the same time; and that in proportion to the intensity of the one the other will be diminished.

By the discharge which a seton produces it will likewise relieve the overloaded vessels of a neighbouring inflamed part. 
Mode of inserting a Seton.-The seton is commonly made of tow and horse hair plaited together, or cord or coarse tape alone, or leather. It should be tolerably thick, and eight, ten, or twelve inches in length. Before inserting the seton, it should be dipped in oil of turpentine. 'The seton being now prepared, an assistant is to hold the animal, while the seton-needle, with the cord affixed to it, is plunged into the upper edge of the brisket or dewlap, and brought out again towards its lower edge: the space between the two openings should be from four to eight inches 'The seton is to be secured by fastening a small piece of wood, or tying a large knot at either end of the cord. Matter will begin to run the second day, and, after that, the cord should be drawn backwards and forwards two or three times every day, in order to irritate the parts, and by this means increase the discharge.

When setoning is had recourse to in inflammatory complaints, the cord should be dipped in the following blistering ointment:-

Blistering Ointment.-Take yellow basilicon, one ounce; cantharides, in powder, three drachins; spirit of turpentine, two fluid drachms.

This ointment will be found to act efficaciously and quickly in stimulating the parts to action, and hastening on the suppurative process.

The root of the common dock forms a very good seton, and one that will act speedily and powerfully; but the best of all, where a sonsiderable effect is intended to be produced, is the root of the black hellebore. This will very quickly cause considerable swelling as well as discharge.

\section{CHAPTER V.}

COLD AND COUGH-HOOSE.

A sIMPIE cold, attended by slight cough and discharge from the nostrils, is easily removed. Warm housing, a few mashes, and the following drink, will usually succeed :-

\section{RECIPE (No. I).}

Cough and Fever Drink.-Take emetic tartar, one drachm; powdered digitalis, nalf a drachm; and nitre, three drachms. Mix, and give in a quart of tolerably thick gruel.

There are few things, however, more dangerous, if neglected, than cough or hoose; and there are few maladies that are so often neglected.

The farmer will go into the cow-house, or into the pasture, again and again, and hear some of his cows coughing, and that perhaps hardly, or hollowly, or painfully; but, while they continue to chew the cud, and do not waste in flesh, he thinks little about it, and suffers them to take their chance. 
The inflammation is slight; the animal is scarcely ill at all; the cough remits and returns, with or without his observation. He adds to it, perhaps, by improper treatment. He exposes the beast unnecessarily to cold or wet; or he crowds his cattle into stables shamefully small compared with the number of the animals, and the air is hot and nauseous, and charged with watery fluid thrown off from the lungs and from the skin. The cough increases, it becomes hoarse, and harsh, and painful; and that affection is established which oftener lays the foundation for consumption and death than any other malady to which these animals are exposed.

That farmer is inattentive to his own interests who suffers a cough, and especially a hoarse, feeble cough, to hang about his cattle longer than he can help. He should be warned in time, before his cows are getting off their feed, and becoming thin, and are half dry; for then it will generally be too late to seek for advice, or to have recourse to medical care: the disease has fastened upon a vital part, and the constitution is undermined.

Cough occasionally assumes an epidemic character-from sudden changes of the weather, chiefly and particularly in the spring and the fall of the year: it then spreads over a great part of the country, and is often particularly severe.

The symptoms of epidemic cold or catarrh, or influenza, as it is sometimes called, are frequently serious. The beast is dull and heavy, with weeping at the eyes, and dry muzzle; the hair looks pen-feathered, or staring; the appetite fails; the secretion of milk is diminished; there is considerable heaving of the flanks; the pulse is from 60 to 70 , and the bowels are generally costive or sapped.

Cattle that have been tenderly managed during the winter, and cows after calving, are very subject to it, especially if they have been poorly fed, or driven long distances, and exposed to a cold, piercing wind.

It will be necessary to commence the treatment of this disease with bleeding. From four to six quarts of blood should be taken, and then a dose of physic administered. The following will be a good purgative medicine in such a case :-

\section{RECIPE (N⿴, 2).}

Purging Drink.-Take epsom salts, one purund; powdered caraway-seeds, half an ounce. Dissulve in a quarı of warm gruel, and give.

After that the drink No. 1 should be given morning and night, the drink No. 2 being repeated if the howels should be costive.

It will be proper to house the beast, and especially at night; and a mash of scalded bran with a few oats in it, if there is no fever, should be allowed. It is necessary carefully to watch the animals that are labouring under this complaint; and, if the heaving should continue, or the muzzle again become or continue dry, and the breath hot, more blood should be taken away, and the purging drink repeated. At the close of the epidemic catarrh, the animal will sometimes be left weak 
and with little appetite. It should be well ascertained whether the fever has quite left the beast, because listlessness and disinclination to move, and loss of appetite, and slight staggering, may result as much from the continuance of fever as from the debility which it leaves behind. If the muzzle is cool and moist, and the mouth not hot, and the pulse sunk to nearly its natural standard, or rather below it, and weak and low, the following drink may be ventured on; but No. 1 must be returned to if there is the slightest appearance or increase of cold or fever.

RECIPE (No. 3).

Take emetic tartar, half a drachm; nitre, two drachms; powdered gentian ront, one drachm : powdered chamomile flowers, one drachm; and powdered ginger, half a drachm. Pour upon them a pint of boiling ale, and give the infusion when nearly cold.

When the beast begins to recover, he should not be exposed in any bleak situation, or to much rough weather.

In some years this epidemic disease destroys a great many cattle. In the winter of 1830 , and in the spring of 1831 , thousands of young cattle perished in every part of the country. Some of them were carefully examined after death, and the membrane lining the windpipe was found to be inflamed, and the inflammation extending down to and involving all the small passages leading to the air-cells of the lungs.

In a great many instances the windpipe was nearly filled, and the small passages of the lungs were absolutely choked by myriads of little worms. These cattle had had their flanks particularly tucked up, and had stood and coughed with a violence that threatened every moment to burst some blood-vessel; and well they might cough thus violently, when the delicate and sensitive lining of the air-tubes was incessantly irritated by the motion, if not by the bites, of these worms. The origin of the worms no one has satisfactorily ascertained. There is no doubt that there are innumerable little eggs of various animalculæ, too small to be seen by the unassisted eye, always floating in the air, and only waiting for some proper situation or nest in order to be nursed into life. 'The proper nidus or nest of these animals is probably the mucus of the air-passages, and they are plentifully lodged upon it in the act of respiration.

I scarcely know what to advise in the treatment of these aggravated cases. The violent cough is an effort of nature to expel the parasites. Can we assist her in accomplishing that expulsion? There are certain medicines which afford us much relief when we have difficulty in expectorating a quantity of thick viscid phlegm. After a dose or two of liquorice or squills we find the cough considerably loosened, or, in other words, the phlegm is a great deal more fluid, and easily got rid of. The same effect, although not to such an extent, is produced in cattle, and a few, at least, of the worms are expelled. The following prescription may be tried with advantage:- 
RECIPE (No. 4).

Expectorant Drink.-Take liquorice root, two ounces; bruise, and boil in a quart of water until the fluid is reduced to a pint; then gradually and carefully adrpowaered squills, two drachms; powdered gum guaiacum, one drichm; tincture of balsam of Tolu, half an ounce; honey, two ounces. Give it morning and night.

There is another way in which the worms may with greater certainty be got rid of. There are some substances which are immediately destructive to worms when brought into contact with them. Some of these medicaments may be taken into the circulation of the animal with perfect safety to him, and probably death to the worms. Among those which most readily enter into the circulation after being swallowed is the oil or spirit of turpentine. The breath is very soon afterwards tainted with its smell, which shows that a portion of it has passed into the lungs. Therefore, when other means have failed, and the continuance of the violent cough renders it extremely probable that worms are in the air passages, the following prescription may be resorted to:

\section{RECIPE (No. 5).}

Turpentine Drink for Worms.-Take oil of turpertine, two ounces ; sweet spirit of nitre, one ounce; laudanum, half an ounce; linseed oil, four ounces., Mix, and give in a pint of gruel.

This may be repeated every morning without the slightest danger; and even when we are a little afraid to give it longer by the mouth, it may be thrown up in the form of an injection. A pint of lime water every morning, and two table-spoonfuls of salt every afternoon, have also been administered with advantage when worms are present in the windpipe.

Before I quit the subject of hoose, I must repeat my caution against the use of spices and cordials for the cure of this disease. Hundreds of animals are yearly lost by this mode of treatment. As easily may a fire be put ont by pouring oil upon it, as hoose, attended with fever (and it is so attended nine times out of ten), be subdued by the farrier's comfortable, or, in other words, highly stimulating, and almost intoxieating drink.

Should the case appear to he obstinate, the exhibition of half doses of physic every second or third day will often be useful, with the following drink, morning and night, on each of the intermediate days:-

\section{RECIPE (No. 6)。}

Take digitalis, one scruple; emetic tartar, half a drachm; nitre, three drachms; priwered squills, one drachm; npium, one scruple. Mix, and give with a pint of gruel.

A seton in the dewlap should never be omitted; and if the disease seems to be degenerating into inflammation of the lungs, the treatment must be correspondingly active.

The termination of hoose that is most to be feared is consumption. That will be indicated when the discharge from the nose becomes purulent, or bloody, and the breath stinking, and the cough continues to be violent, while the beast feeds badly, and tho eyes begin to ap- 
, pear sunk in the head, and he rapidly loses flesb. The best remedy here, so far as both the owner and the animal are concerned, is the pole-axe of the butcher; for in the early part of the disease the meat is not at all injured, and may he honestly sold. If, however, it is wished that an attempt should be made to save the animal, the cough and fever drink (No. 1, p. 46) may be given daily; more attention should be paid to the warmth and comfort of the beast; and, if the weather is favourable, it should, after a while, be turned into a salt marsh, either entirely, or during the day.

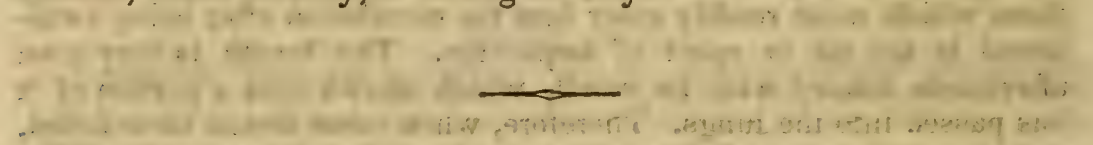

\section{CHAPTER VI.}

IN F L M M TION OF THE LUNGS.

WhEN common catarrh has been neglected, it will sometimes run on to inflammation of the lungs, or the beast may be attacked with this disease without any of the previous symptoms of catarrh. This is a very serious complaint, and requires the most prompt and decisive treatment.

7 The symptoms are dulness, shivering, and cough that is particularly sore; the ears, roots of the horns, and legs are sometimes cold, : but not invariably so, as the quantity of cellular membrane about the legs is often sufficient to keep them warm in spite of the nature of the complaint; the breath and mouth are hot; the mouth is generally open, and there is a ropy discharge from it; the beast will often lie down, and can scarcely be induced to move; the flanks heave very laboriously, and the head is protruded, showing the great difficulty - of breathing. The pulse is not always much increased in number, but is oppressed, and can sometimes scarcely be felt.

Inflammation of the lungs is caused by the perspiration being obstructed from sudden and great changes of the weather, especially when accompanied with wet. Cattle that are driven long distances, and then exposed to the cold and damp air of the night, are particularly liable to it. In most cases it can be traced to the cattle being imprudently exposed to cold ; but when the cause is not so apparent, it oftenest attacks those that are in good condition.

Young cattle, and particularly calves, are more subject to this disease than older ones; and in them it must be principally attributed to their being in a state of plethora, that is, having a redundancy of blood in their systems.'

Sometimes the membrane covering the lungs and lining the chest is the part principally attacked; the disease is then termed pleurisy, and is in this form often complicated with rheumatism, but it is inore usual for the substance of the lungs to be affected in common with their envelopments: 
Copious bleeding is the remedy most to be depended on for subduing the inflammation, and shoulu be had recourse to as soon as the disease is discovered. 'The beast should be put into a cool cow-house well littered, and immediately bled. If the difficulty of hreathing and other symptoms are not much relieved in six or eight hours after the first blecding, it should be repeated.i A third or fourth bleeding may in bad eases be requisite. In this disease, more than in any other, the person who attends the eattle should be present when the beast is bled. It is impossible, by looking at the patient, and considering the symptoms, to say what quantity of blood ought to be taken away; but as a general rule, and especially in inflammation of the lungs; and at the first bleeding, the blood should flow until the pulse begins to falter, and the animal seems inclined to faint. The faltering of the pulse will regulate the quantity of the after-bleedings. Littie bleedings of two or three quarts, at the commencement of inflammation of the lungs, can never be of service; from six to eight quarts must be taken, or even more, regulated by the circumstances that have been mentioned, and the blood should flow in a large full stream.

A seton should be set in the dewlap immediately after the first bleeding, and the purging drink (No. 2, p. 47) given. Four drachms of nitre, two of extract of belladonna, and one of tartarized antimony, may afterwards be administered twice a day in a drink.

In very severe cases the chest has been fired and blistered with advantage.

Warm water and mashes must be regularly given two or three times a day.

When the beast has recovered, it will be proper, as much as possible, to avoid all those causes which induced the complaint. The animal should for a short time be housed during the night, and, if the weather is very unsettled, kept up altogether, or turned out for a few hours only in the middle of the day.

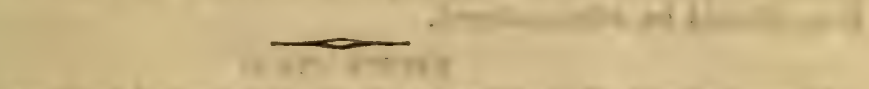

\section{CHAPTER VII.}

\section{RHEU MATISM, O R J INT-FELLON.}

Tue early symptoms of this complaint are those of common catarrh, with no great cough, but more than usual fever: by degrees, however, the animal shows some stiffness in moving, and if the hand is pressed upon the chine or any part of the back, the beast will shrink, as if this gave him pain. When the complaint goes no farther than this, it is called chine-fellon in many parts of the country; but generally, in two or three days, the animal appears stiffer in the joints; - these afterwards begin to swell, and are evidently painful, particu larly when he attempts to move. Sometimes the stiffness extends al' 
over the body, and to such a degree that the beast is unable to rise without assistance.

This is generally termed jnint-fellon. Old cows are very subject to it, and especially a short time before ealving; but milch cows and young cattle are oftener attacked by it at the spring of the year. It is mostly occasioned by the animal being kept in a state of poverty during the winter, and suddenly exposed to the vicissitudes of the weather in the spring, or to the inclemency of the north or northeasterly winds, especially in low situations.

This disease sometimes comes on suddenly, and is present in a very acute form, being in fact a severe chill: these acute symptoms may subside, and be succeeded by others, milder but more obstinate. Sometimes abscesses will form amongst the muscles, or the sheaths or bodies of the tendons; and the capsular ligaments of the joints are often distended with synovia. These symptoms are particularly unfavourable.

In this disease we find the same class of membranes, viz., the serous, diseased throughout the body, and an examination after death sometimes exhibits, in addition to the diseased appearances before noticed, the membrane lining the heart, the chest, and the abdomen, considerably affected, either wholly or in part, and sometimes a considerable effusion of water in these cavities.

As soon as the disease makes its appearance, the beast must be taken to a warm cow-house or stable, or some situation sheltered from the severity of the weather. The following purging drink should then be given :-

RECIPE (No. 7).

Sulphur Purging Drink.-Take sulphur, eight ounces; ginger, half an ounce. Mix with a quart of warm gruel. This drink should be repeated every third day if the bowels appear to require it.

The bowels having been gently opened, a drink which may cause some determination to the skin, and increase the insensible perspiration, should be administered.

RECIPE (No. 8),

Rheumatic Drink.-Take nitre, two drachms; tartarized antimony, one drachm; spirit of nitrous ether, one ounce; aniseed powder, an onnce. Mix with a pint of very thick gruel, and repeat the dose morning and night, except when it is necessary to give the sulphur purging drink (No. 7).

If there should be much fever at any period of the complaint, the sulphur drink must be exchanged for the purging drink (No.2, p. 47), and three or four quarts of blood taken away.

If any of the joints should continue swelled and painful, they should be rubbed twice a day, and for a quarter of an hour each time, with a gently stimulating embrocation.

RECIPE (No, 9).

Rheumatic Embrocation.-Take neat's foot nil, four ounces; and camphorated nil, spirit of turpentine, aud laudanum, each one ounce; oil of origanum, one drachm. Mix. 
Should a scaly eruption break out on the joints, or any part of the lecrs, after the beast his apparently recovered, an ointment composed as follows will gemerally clear off the scurf, heal the cracks or sores, and cause the hair to grow again.

RECIPE (No. 10).

Hecling Cleansing Ointment.-Take lard, two pounds; resin, half a pound. Melt them together, and when uearly cold, stir in calamine, very finely powdered, half a pound.

If stifiness or swelling of the joints should remain after the inflammation and tenderness are removed, the joints should be well rubbed morning and night with a gently stimulating embrocation. The following will be as good as any :-

\section{"Q⿱艹}

Camphorated Oil.-Take camphor, two nunces, and break it into small pieces; put it into a pint of spermaceti or common olive oil, and let the bottle, being closely stopped, aud shaken every day, stand in a warm place until the camphor is dis. solved.

When a beast has had one attack of rheumatism, he will be always subject to its return, and therefore should be taken more than usual care of in cold variable weather; and should he appear to have a slight catarrh, or to walk a little stiffer than usual, he should be housed for a night or two, and should have a warm mash, and the following cordial rheumatic drink; which, however, would be very improper in hoose or cold, or rheumatism connected with any degree of fever.

$$
\text { RECIPE (No. 12). }
$$

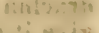

Cordial Rhcumatic Drink.-Take rhododendron leaves, four drachms; and boil it in a quart of water until it is diminished to a pint ; strain the decoction, and to half of the liquid, warm, aild gum guaiacum, finely powdered, two drachms; powdered caraway-sreds, two drachms; and powdered aniseed, two drachms, mixed with half a pint of warm ale.

$\therefore=$

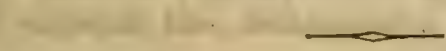

CHAPTER VIII.

\section{IN FL,A M ATION OF.THE'LIVER.}

Turs is a disease to which cattle are oftener subject than is magined, and particularly those that are in high condition and stall-fed: the symptoms, however, are usually sufficiently distinct, to guide the attentive observer.

When the milch cow is attacked, there is a diminution of the milk, and it has a ropy appearance and saltish taste after being separated from the cream. The animal has a heavy appearance, the eyes being dill, the countenance depressed, with a stiffened, staggering gait; the appetite is impaired, and the membrane of the nostrils and the skin is of a yellow colour. Sometimes the respiration is much disturbed; at others, it appears tranquil ; but the pulse, though unusually $5 *$ 
quickened, is rarely hard or full. The howels are generally constipated, though sometimes purging exists. Rumination is usually disturbed, and occasionally altogether suspended. To these will occasionally be added the characteristic symptoms of pain on pressure on the edge of the short ribs on the right side. In acute inflammation of the liver, the most frantic pain has been exhibited; but this is rarely the case.

A high degree of fever will indicate the propriety of bleeding, but it should not be carried to too great an extent, but may be repeated. After bleeding, one or two drachms of calomel, with a scruple of opium, and two drachms of ginger, may be given in gruel, and a few hours afterwards twelve ounces of Epsom salts and half a pint of linseed oil. The calomel and opium may be repeated twice a day, and the purgative also until the bowels are sufficiently operated on. If, however, purging be present from the first, a few ounces only of Epsom salts should be given, but a drachm each of calomel and opium repeated twice a day; and if the purging continue, the case may be treated as one of diarrhœa. The sides in this disease should be blistered, and setons may also be inserted.

Inflammation of the liver frequently leaves after it a great deal of weakness, and tonics are clearly indicated. The best medicine that can be given is the following:-

RECIPE (No. 13).

Tonic Drink.-Take gentian root, powilered, half an ounce; ginger, powdered, one irachm; epsom salts, two ounces. Mix the whole with a pint of warm gruel, and give it morning and night.

No hay, and little corn, should be given in inflammation of the liver; but the diet should consist of mashes and green meat.

... When a beast dies of this disease, all the contents of the chest and the belly will often be found to be considerably affected. The lungs in almost every case exhibit inflammation, and there are patches of inflammation in the bowels.

It has been stated that fat beasts, or such as are in good condition, are very liable to this disease, and particularly those that have been fed much on oil-cake. It is more frequent in hot than in cold weather, and in store cattle that have been over-driven, or worried in woodland pastures by the flies. Sudden change of weather; the exposure to considerable cold, of a well-fed beast that had been well housed, or indeed anything that has a tendency to excite fever, will produce inflammation in an organ that has been over-worked, or is disposed to disease from the undue secretion of bile in the rapid accumulation of flesh and fat. Chronic inflammation of the liver is characterized by symptoms similar but more moderate than those detailed. The debility gradually increases, and death often succeeds. The same treatment should be pursued, with the exception of bleeding. 


\section{CHAPTER IX. \\ THE Y ELLOWS, OR JAUNDICE.}

Tuis is a far more common disease than the last, and almost as dangerous, because, although it is not marked by any acute symptoms, or accompanied by much fever, it creeps on insidiously, and fastens itself on the constitution, beyond the power of medicine to eradicate it; or it is the consequence and the proof of some disease of the liver, which is equally difficult to cure. It may be produced by inflammation of the liver, or too great secretion of the bile, or stoppage of the vessels through which the bile should flow into the bowels. If its passage is obstructed, it is thrown back again upon the liver, and there taken up by the absorbents, and carried into the circulation, and communicates a yellow colour to the blood; and as the blood, by means of the capillary vessels, is carried to every point and part of the body, so the yellow hue of the disease spreads over the whole of the frame.

This obstruction is sometimes effected by the undue thickness of the bile; sometimes by hardened bile or gall-stones; and in not a few cases it is caused by a greater secretion of bile than can find its way into the intestines, and which, consequently, accumulates in the liver, until it is taken up by the absorbents, and carried into the frame in the manner that has just been described.

At the beginning of the disease there is considerable dulness and languor, and loss of appetite. The cow wanders about by herself, or is seen standing by the side of the hedge or the fence in a most dejected manner. The quantity of milk is generally lessened; the bowels are costive; and the fore-teeth are sometimes loose: milch cows are more subject to it than oxen, and particularly in the latter end of the year. Sudden change of weather frequently gives rise to it, and especially if the animal has previously exhibited symptoms of ill-health.

The treatment and the hope of cure depend upon the causes and degree of the disease, and which should be most carefully ascertained. If it has followed symptoms of fever, probably indicative of inflammation of the liver, it may be difficult to remove, because it is an indication of the ravages which disease has made in the organ. Should the pulse be strong as well as quick, moderate bleeding will be judicious, but not otherwise. The bowels should then be freely opened by means of the purging drink (No. 2, p. 47), and kept open by half-doses of it administered as occasion may require. In this disease, oftener than in any other to which cattle are subject, stomachics are useful to rouse the digestive organs to their proper tone and power. Mingled with them, or at other periods of the day, medicines may be given which are supposed to have a direct effect on the 
liver, and a tendency to restore its healthy action; therefore, while the tonic drink (No. 13, p. 54) is given in the morning, the following may be given at night:

\section{RECIPE (No. 14).}

Drink for the Yellozos. -Take, of calomel and opium, a scruple each : mix and suspend in a little thick gruel.

If, on pressing the sides, the animal evinces pain, we may suspect some inflammation of the liver; and a blister on the sides, but particularly the right side, will be useful.

After the yellowness is removed, and the beast restored to health, the tonic drink (No. 13, p. 54) should be given twice in the week for a month. This will contribute to restore the weakened appetite, and particularly will bring back to the cow the proper flush of milk.

\section{CHAPTER $\mathrm{X}$.}

\section{IN FIAM M T ION OF THE.BRATN.}

This is not a very frequent, but a most frightful disease. It is . commonly known by the names phrenzy or sough. It is most prevalent among well-fed cattle, and particularly in the summer months. In the early period of it the beast is dull and stupid. He stands with his head protruded, or pressed against something for support. He refuses to eat, ceases to ruminate, and is, in a manner, unconscious of surrounding objects. Now and then he will stand motionless for a long time, and then suddenly drop; he will start up immediately, gaze around him with an expression of wildness and fear, and then sink again into his former lethargy. All at once, however, his eyes will become red, and seemingly starting from their sockets; the countenance will be both anxious and wild; the animal will stagger about, falling and rising again, and running unconsciously against everything in his way: at other times he will be conscious enough of things around him, and possessed with an irrepressible desire to do mischief. He will stamp with his feet, tear up the ground with his horns, run at every one within his reach, and with tenfold fury at any red object; bellowing all the while most tremendously, and this he will continue until nature is quite exhausted: a sudden and violent trembling will then come over him, he will grind his teeth, and the saliva will pour from his mouth; he will fall, every limb will be convulsed, and he will presently die.

Causes,-It proceeds most commonly from a redundancy of blood in the system, called by farmers an overflowing of the blood; and this is induced by cattle thriving too fast when turned on rich pasture-grounds, or their being fed too quickly in order to get them into condition for show or sale. It is sometimes occasioned by the intense 
heat of the sun, when cattle have heen turned into the fields where there has been nothing to shade them from its influence. It may be brought on by severe contusions on the head, or by the cattle being harassed and frightened, when driven along the road or through large towns.

Very few weeks pass in the metropolis in which cattle are not driven into a state of absolute madness, either by the brutality of the drovers, or by a set of miscreants whose sport it is to abuse and infuriate the animal, and endanger the lives of the passengers.

The chief or the only cure is bleeding. The neck vein should be opened, on each side, if possible, and the blood should be suffered to flow until the animal drops. It is absurd to talk of quantities here; as much should be taken as can be got, or, at least, the blood should flow until the violence of the symptoms is quite abated.

To this a dose of physic should follow. The following may be administered :-

\section{RECIPE (No. 15).}

A Strong Physic Drink.-Take, Epsom or Glauber's salts, half a pound; the kernel of the croton nut, ten grains : take off the shell of the croton nut, and weigh the pro. per quantity of the kernel. Rub it down to a fine puwder; gradually mix it with half a pint of thick gruel, and give it, and immediately afterwards give the salts, diseolved in a pint and a half of thinner gruel.

If the violence or even the wandering should remain, another bleeding should take place six hours afterwards, and this also until the pulse falters ; and the purging should be kept up by half-doses of the powder (No. 2, p. 47).

Although it is very difficult to produce a blister on the thick skin of the ox, it should be attempted if the disease does not speedily subside. The hair should be closely cut or shaved from the upper part of the forehead and the poll, and for six inches on each side down the neck, and some of the following ointment well rubbed in:-

\section{RECIPE (No. 16).}

Blister Ointment.-Take, lard, twelve nunces; resin, four ounces; melt them toge. ther, and, when they are getting cold, add oil of turpentine, four ounces; and pow. dered cantharides, five ounces; stirring the whole well together.

When the blister is beginning to peel off, green elder or marshmallow ointment will be the best application to supple and heal the part. A little of it should be gently smeared over the blistered surface morning and night.

A seton smeared with the above ointment may be inserted on each side of the poll in preference to the application of a blister.

Although the violence of the disease, and of its remedies, will necessarily leave the beast exceedingly reduced, no stimulating medicine or food must on any account be administered. Mashes and green meat, and these in no great quantities, must suffice for nourishment, or, if the animal, as is sometimes the case, is unable to eat, a few quarts of tolerably thick gruel may he horned down every day; but ale and gin, and spices, and tonic medicines, must be avoided as downright poisons. There is not a more common or a more fatal 
error in cattle management than the eagerness to pour in comfortable; I would rather say, poisonous drinks. Even the treacle and the sugar in the gruel must be prohibited, from their tendency to become acid in the debilitated stomach of the animal recovering from such a complaint.

Every symptom of the disease having vanished, the beast may very slouly return to his usual food; but, when he is turned out to pasture; it will be prudent to give him a very short bite of grass, and little or no dry meat. Nature is the best restorer of health and strength in these cases; and it is often surprising, not only how rapidly the ox will regain all he has lost, if left to nature, and not foolishly forced on, but how soon and to what a considerable degree his condition will improve beyond the state in which he was before the complaint.

'The ox that has once had inflammation of the brain should ever afterwards be watched, and should be bled and physicked whenever there is the least appearance of staggers or fever. The safest way will be to send him to the butcher as soon as he is in sufficient condition.

Sometimes the disease does not run its full course. There is but a slight degree of inflammation, or there may be sudden determination or flow of blood to the head from some occasional cause, and without inflammation. This is known by the name of

\section{STAGGERS, OR SWIMMING IN THE HEAD.}

The symptoms are heaviness and dulness; a constant disposition to sleep, which is manifested by the beast resting its head upon any convenient place; and he reels or staggers when he attempts to walk. If this disease is not checked by bleeding, purging, and proper management, it will probably terminate in inflammation of the brain or inflammatory fever.

It mostly attacks those cattle that have been kept in a state of poverty and starvation during the winter season, and in the spring of the year have been admitted into too fertile a pasture: hence is produced a redundancy of blood in the system, which, on the slightest disturbance, or even naturally, gives rise to the disease.

The cure must be attempted by taking four, five, or six quarts of blood from the animal, according to its size and strength; the purging drink (No. 15, p. 57) must then be administered, and (No.2, p. 47) continued in half-doses every eight hours, until the full purgative effect is produced. If the animal is not relieved in the course of two hours from the first bleeding, the operation must be repeated to the same extent, unless the beast should become faint; and the bowels must be kept in a loose or rather purging state by No. 2. As soon as the bowels are opened, the fever drink (No. 1, p. 46) should be given morning, noon, and night, until the patient is well. Nothing more than a very little mash should be allowed, and all cordials should be avoided as absolutely destruetive to the beast. 
When the animal appears to be doing well, he must very slowly be permitted to return to his usual food. He should for some weeks be put into short and scanty pasture; the seton should be continued in the dewlap, and occasional doses of Epsom salts administered.

$+1 \cdot 1 \cdot 3: 1218$

\section{CHAPTER XI.}

\section{INFLAMMATION OF THE BOWELS, WITH COSTIVENESS.}

INFLAMMATION of the bowels is by no means an uncommon disease among neat cattle, and frequently proves fatal to them from injudicious treatment. It is a complaint easily recognisable on account of the peculiar symptoms by which it is attended.

The animal is continually lying down and getting up again immediately, and, when up, he strikes at his belly with the hind feet. The bowels are obstinately constipated: the dung, if any is roided, is in small quantities-hard, covered with mucus, and that sometimes streaked with blood-and the urine is generally voided with difficulty. The pulse is quiclier than natural, and there is much heaving at the flanks.

It is distinguished from colic by the great degree of fever that evidently attends it, the muzzle being dry and the mouth hot. The animal becomes speedily weak, he falls or throws himself down suddenly, and when he rises he does it with difficulty, and he staggers as he walks. The lowness and wealnness appear more speedily and decidedly than in almost any other disease.

The attack is sudden like that of colie. The animal quits his companions, and hides himself under the hedge. If he is in the plough, he all at once becomes deaf to the voice of the driver, and insensible to the goad. He trembles all over-his skin becomes hot - his back and loins are tender-his ears and horns hot. Every thing indicates the highest degree of local inflammation and general fever.

The disease mostly arises from sudden exposure to cold; and especially when cattle go into rivers or ponds after being heated and faticued. It is sometimes produced by change of pasture, and feeding ton much on dry and stimulating diet.

The first thing to be done, and that which admits of no delay, is to bleexl; from six to eight quarts of blood at least should be taken away. Inmediately afterwards the purging drink (No. 15, p. 57) should be administered, and its effect promoted by half-doses of No. 2. given every six hours. This is a very dangerous discase, and the measures pursued must be of the most decisive kind. The symptoms sueceed each other rapidly, and if one day is suffered to pass without proper means being taken, the beast is irrecoverably lost.

The third stomach or manyplus will generally be found, after 
death, choked up with dry food, hardened between the leaves of which that stomach is composed. It will be necessary to wash this well out before the proper path to the fourth stomach can be opened. In order to effect this, plenty of thin gruel, or water with the chill taken off, should be given; or, if the beast will not drink it, several quarts of it should be horned down. Clysters of warm water, or thin gruel, with a purging powder dissolved in them, should likewise be administered.

After having bled the animal once copiously, and, if the fever has not subsided, a second, or even a third time, the farmer should in this disease of high inflammation of the bowels, and strangly obstinate costiveness, found his only hope of saving the animal in producing purging, and to this purpose his whole attention should be directed.

If it should not be accomplished after the third dose of the medicine, a pound of common salt may be given. The water or other liquid which the beast will probably be induced to drink will assist in purging him. Should not this succeed, a pound and a half of castor-oil must be administered.

The patience of the attendants will sometimes be almost worn out - they must, however, persist. Clysters, numerous, and great in quantity, must be administered. The Epsom salts and the castor-oil will not do harm in whatever quantities they are given: it will not be prudent, however, to repeat the common salt. During the whole of this time the cordial drink of the cow-leech must be avoided as a dose of poison.

The farmer or the attendant must not be deceived by the passage of a little liquid dung in a small stream, for that shows that there is yet much hardened freces clinging round the intestines, and which must be removed, and therefore he must pursue the measures recommended until the dung is expelled in considerable quantities, and in a large full stream, and without much straining. There has generally been something more than usually wrong in the food or management when this sad constipation is observed. Either the animal has been kept too much and ton long on dry food; or he has heen turned into fresh pasture (and particularly in the autumn) in which there are oak-trees or some astringent vegetables. The cause must be removed, or the disease will return.

The state of the bowels of a beast that has once been sapped should be observed for some time afterwards, and gentle aperients occasionally administered; cold water should not, for a little while, be permitted, and strict attention should be paid to the diet.

Inflammation of the bowels, however, will in a few cases occur without all this costiveness, and yet produced by nearly the same causes. The other symptoms are the same, but the danger is not so great. The beast should be bled and physicked, kept tnoderately warm, and have warm water with bran mashes. 


\section{CHAPTER XII.}

DIARRICE, OR PURGING.

Purging is produced by various causes; by change of food, from dry to green meat, or from short to luxuriant pasture; by poisonous plants, bad water, or unknown atmospheric agency.

It is not always to be regarded as a disease, nor should the farmer be always anxious to stop it. It may be an effort of nature to discharge something that is injurious; it may exist while the beast enjoys almost perfeet health, and is even thriving.

'The farmer will not regard an occasional fit of purging; he will only attack it if it is violent, or if it continues too long. In the first case it indicates some disordered state of the bowels, or the presence of some offending matter in them, and he will endeavour to remedy this; not, as is too often done, by attempting to arrest the discharge as speedily as he can-not by the exhibition of astringent medicine - but by giving a mild dose of physic, in order to assist nature in her effort to get rid of some evil. Nothing so much distinguishes the man of good sense from the mere blunderer as the treatment of purging,

From half to three-quarters of a pound of Epsom salts should be. given with the usual quantity of ginger. The next day he may probably adininister a little astringent medicine. The following will be efiectual, and not too powerful:

RECIPE (No.. 17).

Aatringent Drink.-Take prepared chalk, two ounces; oak bark, powdered, one nunce; cateclu, powdered, half an ounce; opium, powdered, two scruples; ginger, powlered, two dravhms.' Mix, and give in a quart of warm gruel.

In the second case also, when purging has long continued, and the animal is beginning to become thin and weak, the practitioner; must begin with physic. There is probably some lurking cause of intestinal irritation. He should give the quantity of Epsom salts just recommended - or perhaps he will more prudently give from half a: pint to a pint of castor-oil. It will usually be a good practice to give: a rather smaller dose on the following day; and, after that, he may: safely have recourse to the astringents: the animal should be brought? into a cow-house or enclosed yard, where it can be shel tered from the weather, and kept partly or altogether on dry meat.

It is of great consequence that diarrhœa or simple purging should be distinguished from another disease with which it is too often confounded. They are both characterized by purging. That which has been just considered is the discharge of dung in too great quantity, and in ton fluid a form; but that which will form the subject of the next chapter, dysentery, is the evacuation of the dung, mingled with: mucus, or mucus and blood. In diarrhora the dung is voided in large 
quantities, and in a full stream; it has sometimes an offensive smell, and is occasionally bloody : but dysentery is often accompanied by a peculiar straining; the dung is not so great in quantity, and it is more offensive, and more highly charged with blood.

The one is an accidental thing - not always to be considered as a disease - and often ceasing of itself when the purpose for which nature set it up, - the expulsion of some acrid or injurious matter from the alimentary canal, - has been accomplished; the other is an indication of an inflammatory affection of the larger intestines, difficult to be controlled, often bidding defiance to all means, and speedily destroying the animal. Diarrhoa occurs at all times of the year, and particularly after a sudden and great change of pasture; dysentery is a disease almost peculiar to the spring and autumn alone. It must be confessed, however, that diarrhoea is sometimes the precursof of dysentery in its worst form.

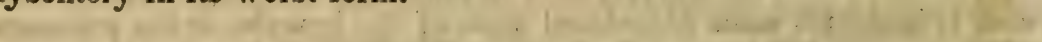

DYSENTERT, SLIMY FLUX, OR SCOURING ROT.

IT has been just observed that this disease is most prevalent in the spring and autumn, particularly in low, wet, and swampy situations. It is one of the most fatal diseases to which oxen, and dairy cows in particular, are subject, and destroys more than any other malady.

It begins with frequent and painful efforts to expel the dung, which is thin, slimy, stinking, and olive-coloured. The animal, as appears from his restless state, suffers much pain, frequently lying down and soon rising again. There is also a frequent rumbling noise in the intestines. If the disease is neglected, or improperly treated, the beast gradually gets thin, although for a while he retains lis appetite, and continues to ruminate; at length he evidently begins to get weak, rumination is imperfectly performed, and the food passes from him half digested. As this disease is often the consequence of a previous affection of the liver, considerable tenderness will be discovered on the spine, a little beyond the shoulders. This is one of the methods, and a very good one, by which the farmer endeavours to ascertain whether a beast which he is thinking of purchasing has the scouring rot. As the disease proceeds, the dewlap hangs down and has a flabby appearance; the dung runs off with a putrid and offensive smell, and, as it falls upon the ground, rises up in bubbles, and a membranous or skinny-like substance is often seen upon it: this is occasioned by the natural mucus, which was given to defend the bowels, being discharged. In proportion to the quantity of mucus that mingles with the frees, the whole is rendered more adhesive, and the bubbles are larger, and remain longer on the dung. When this is the case the disease is always obstinate, and generally fatal. 
The hair all over the body soon appears pen-feathered or staring. Feverish symptoms also accompany the complaint: the eyes become dull and inflamed, there is much working of the flanks, and the pulse is quick.

The causes of this dreadful malady are - taking cold at the time of calving; long journeys; exposure to sudden vicissitudes of the weather; and, after being over-heated in travelling, being turned into damp pastures, \&c. Poor keep is a very frequent cause, and especially when connected with exhaustion from constant milking; and it is inore especially the consequence of the cows being badly fed in the winter. Some cold wet lands are particularly liable to give the rot; yet where the land and treatment are similar it prevails more in snme dairies than in others, depending much on the breed of the cattle. Old cows that are fed on sanded pastures are very subject to this complaint.

In all cases the animals should be taken from grass, and put into a jarge cow-house, or an open yard, where they can be sheltered from the weather, and kept on dry food, such as good hay, ground oats, barley, and beans. An equal proportion of each of the three last articles and of linseed cake will make an excellent food for cattle labouring under dysentery. A quantity proportionate to the size and appetite of the patients should be given two or three times a day, or if they are much reduced and their appetite is quite gone, a thick gruel should be made of these ingredients, and administered three or four times a day.

This disease consists in inflammation of the lining membrane of the large intestines. It will then be evident that bleeding, proportioned to the suddenness and violence of the attack, and the apparent degree of fever, should be first resorted to.

If the eyes are inflamed, with heaving of the flanks, and painful twitchings of the belly, accompanied by severe straining and apparent gripings in the expulsion of the excrement, the abstraction of blood is indispensable.

The purgative drink (No.2, p. 47) should precede the use of every other medicine, in whatever state the bowels may be. It will prepare for the safer use of astringents. In almost every case there will be something in the bowels, which, if it did not cause the disease, contributes to keep it up. The proprietor of cattle, and he who professes to treat their diseases, should know that there can be nothing more dangerous than to attempt suddenly to stọp a violent purging, especially one that assumes the character of dysentery. Let that which offends in the bowels be first got rid of, and the disease will sometimes cease of itself, or, if it does not, astringents may then be administered with safety.

The safest and the most effectual astringent mixture for the scouring rot is that which was recommended in page 61 . 'It may be given once or twice in the day, according to the violence of the complaint. Ale should never be given in these cases. The astringents may be 
commenced twenty-four hours after the purgative has been administered.

If the disease does not speedily yield to this treatment, it will not be prudent to continue the use of such large quantities of astringent medicines for any considerable time. The following drink may then be given, and continued morning and night for five or six days :-

$$
\text { RECTPE (No. 18). }
$$

Astringent Drink irith Mutton Suet.- T'ske mutton suet, nne ponnd new milk, two quarts; boil then together until the suet is dissolved; then adu opium, powderer, half a drachm; gingir, one Urachm, having previously well mixed thein with a spoouful or two of fluid.

When the dysentery is stopped, the beast should very slowly and cautionsly be permitted to return to his former green food. Either during the night or the day, according to the season of the year, he should be confined in the cow-house, and turned out twelve hours only out of the twenty-four. Water should be placed within reach of the animal, in the cow-house, and, if possible, in the field; for there are few things more likely to bring on this disease, or more certain to aggravate it, than the drinking of an inordinate quantity of water after long-continued thirst.

These precautionary measures should be continned for a considerable time; for there is something very treacherous in this malady, and it will often suddenly return several weeks after it has been apparently subdued.

In those eases, and they are much too numerous, which totally resist the influence of the medicines already recommended, other mears should be tried. The alum whey has sometimes succeeded, and is thus prepared :-

\section{RECIPE (No. 19).}

Alum Whey.-Take alum, half an ounce; milk, two quarts. Boil them together for ten minutes, and strain.

This may be administered twice every day.

The disease may not yield even to this. It will then be evident that it is the consequence of some other disease, and, probably, of the liver, the vitiated bile secreted by which is keeping up the purging. It is almost a forlorn hope to attack such a ease; but the beast may be valuable, and, at all everts, we cannot be worse off. The only medicine that can have power here is mercury, for it seems to exert its chief influence on the liver and the discharge of bile. The mildest, and at the same time the most effectual, form in which it can be administered, is that of the blue pill, half a scruple of which may be given morning and night, rubbed down with a ittle thick gruel. There is very little danger of salivation: yet it may be prudent to give half a pound of Epsom salts every fifth or sixth day; and most certainly to give them every second day, and discontinue the blue pill, if the mouth should become sore, or the breath stinking, or there should be a more than usual discharge of saliva from the mouth.

In many cases there is found a schirrous state of the third and fourth stomachs in cattle that have died of, or been destroyed for, this disease. 
(10.9.

\section{CHAPTER XIV.}

R E D - W A T ER.

THE nature of this disease has been very much misunderstood. It consists of a discharge of high-coloured urine, and therefore has been attributed to an inflammatory affection of the kidneys. It will generally be found to begin in another organ, the liver, and to be connected, in the first stage at least, far more with disease of that gland than of the kidney.

There are evidently two distinct species of red-water.

One, but which occurs most seldom, begins with decided symptoms of fever. 'There is shivering, succeeded by increased heat of the body ; the muzzle dry ; working of the flanks ; urine of a red colour, evidently tinged with blood, and occasionally consisting almost entirely of blood, discharged in small quantities, and frequently with considerable pain; loss of appetite. As the disease proceeds, the animal loses strength; the bowels become constipated or very loose; and the urine of a dark colour, approaching to black.

Very early in the complaint the loins become exceedingly tender, and the animal shrinks when they are pressed upon; some heat is likewise felt there, showing evidently the seat and nature of the disease. It sometimes proceeds from cold, particularly when beasts are turned into low pasture grounds at the spring of the year. It also frequently seizes young cattle that are feeding, or in good condition; for a fulness of blood in the system renders them more liable to the complaint.

Sometimes inflammation of the kidneys proceeds from external injuries; such as a violent bruise across the loins, in consequence of other beasts ramping on them, or a severe blow in the region of the kidneys.

The discharge of bloody urine may either proceed from inflamma. tion of the kidneys or a rupture of some of the blood-vessels, and in either case blood is discharged with the urine, and may be often detected in clots; whilst in the other kind of red-water, although the urine is dark in colour, it does not contain blood. The former disease is more frequent with bulls and oxen, and the latter with milch cows.

When the kidneys are inflamed, and the animal evinces tenderness on pressing the loins, the treatment should consist of blood-letting, purging, and the application of sheep-skins and stimulants to the loins. But in some cases where blood is discharged with the urine without any inflammatory appearances, the exhibition of astringents and stimulants, such as the following, have effected a cure:-

RECIPE (No. 20).

Take oil of juniper, two to four drachrns; tincture of opium, one ounce; ail of eurpentinf, one ounce. Mix, ard give in a pint of linseed tea, once or twice a day. $6 *$ 
True red-water is a disease of the digestive organs, principally of the liver; and the dark colour of the urine is owing to the presence of vitiated bile, probably loaded with carbon, and not to blood, as used to be supposed.

The more frequent causes are connected with the nature of the pasture. There are some farms, or particular parts of the farm, where red-water is almost sure to follow when cattle are turned upon them. Low marshy grounds are apt to produce 1 , and also pastures with much woodland, and especially in the latter part of autumn, when the leaves are falling. Some have said that elm-leaves are apt to cause red-water; others attribute the disease to the oak; and many more to some of the numerous species of ranunculuses that abound in our marshy and woodland pastures. . The truth of the matter, however, is, that no one knows what plant is most concerned in the affair ; and all that the farmer can do is to observe what pastures most frequently produce red-water, and at what season of the year, and to use them as much as he can for other stock in the dangerous seasons.

A removal from a poor to a luxuriant pasture, or from a low marshy situation to a dry and lofty locality, are frequent causes of red-water; and it often oecurs after a long succession of dry weather.

Cows that are dried of their milk are often attaeked by it, when put into luxurious pasture, while, perhaps, it does not affect those that are still milked. The reason of this is plain enough:-the superfluous nutriment not being carried off by the udder in the form of milk, the digestive organs are deranged, and the secretions of the liver become vitiated.

Some breeds of cows are more disposed to red-water than others, and especially if they are brought from a distance, and the quality of their pasture materially changed, whether from good to bad, or from bad to good. A cow that has once had an attack of red-water is very liable to a repetition of the complaint. The farmer is obliged to take a great deal of care properly to manage the change of pasture with her, and, notwithstanding all his care, she will probably have two or three attacks of the disease every year. It will behove him to consider how far it is prudent to keep such an animal. No beast that is subject to periodical complaints of any kind should be kept, for it may easily be prepared for the butcher, and disposed of with little or no loss to the farmer.

The symptoms of red-water are at first purging, which is usually followed by constipation; the appetite is impaired; the pulse and breathing quickened; and the former, though bounding at the heart, is often weak. The membranes of the nostrils and eyelids are pale, and the legs cold; the milk is diminished, and rumination ceases. The urine, from being brown, often becomes black, and the disease is, in this state, often denominated black-water.

The red and the black water are diseases that require prompt and careful treatment; for, although, in some slight cases, the beast does not seem to be much affected by either, and wotks or yields her milk 
29 well as ever, yet ere long it preys upon the constitution, and the animal gradually wastes away.

It is folly to wait in order to see whether nature will effect a cure. Except in beasts suddenly put upon more than usually rich pasturage, it never is or can be a salutary discharge. It must be preying upon the system and wasting the strength, and the sooner it is got rid of the better. It attacks mileh cows oftener than others, and it is more injurions to them than to others. While it lasts, it often materially lessens the quantity of milk, and, even after it is removed, the animal is slow in returning to her former strength.

The first thing to be done is to remove the cause of the disease. The pasture should be changed.r A more open and a drier situation should be fonnd, and where the grass, although succulent and nutritious, is not very plentiful. If there is considerable fever, or the animal should appear to be really ill from the discharge, she should be taken under shelter, and fed on mashes, with a very little hay; or a few turnips or carrots may be allowed her if they are in season.

Bleeding is often necessary at the onset of this disease, but it should always be practised with moderation, and in many cases abstained from altogether. About two hours after bleeding, the following drink should be administered :-

\section{- RECIPE (No. 21).}

Take epsom, or glauher salts, one pound ; ginger, half an ounce ; carhonate of am. monia, half an ounce. Pour one quart. of boiling water upon the ingredients, stir them well, and give when new.milk warm.

A quarter part of this drink may be given every six hours, until the bowels are freely opened, and the medicine may be assisted by clysters. The successful treatment of the disease very much, or altogether, depends on early and thoroughly opening the howels. If this is early accomplished, the animal will almost certainly recover. If it is neglected, or the constipation cannot be overcome within the first two or three days, the termination will probably be fatal.

When the howels are properly acted on, mild stimulants may be exhibited, such as-

\section{RECIPE (No. 22).}

Take ginger, onc drachm; gentian, one drachm; and spirit of nitrous ether, one ounce. Mix, and give in a pint of gruel.

If, with the amendment of the other symptoms, the urine should appear black, a diuretic,- - such as one ounce of nitre, $\rightarrow$ may be given with the above drink, or even the more powerful stimulant, spirit of turpentine, in doses of one or two ounces.

If, after the bowels have been well opened, and the fever is somewhat abated, the discharge of blood still continues, and in as great a quantity as before, it will be right to have recourse to astringents, yet such as will not irritate and stimulate the kidneys; and even these shonld he administered cautionsly. Constipation attended the earlv ani most violent stage of the disease-some remission, at least in the 
fever and the pain, if not much diminution of discharge, attended the removal of the constipation: it must; therefore, be dangerous to confine the bowels again. The following prescription will be as efficacious as any :-

\section{RECIPE (No. 23.)}

Take, oak bark, powdered, half an ounce; powdered catechi, two drams; and opium, powdexed, half a scruple: mix. together in a pint of gruel or warm water.

This may be given morning and night, for a week, cautiously watching the state of the bowels, and suspending the astringent, and even having recourse to physic, if the bowels should again be confined.

The recovery of the animal is denoted by the restoration of the pulse and breathing to the natural standard, and the return of the appetite, together with the healthy appearance of the urine. It is essential, however, to exercise the greatest caution with regard to the food for some little timè, bearing in mind that the digestive organs have been greatly impaired.*

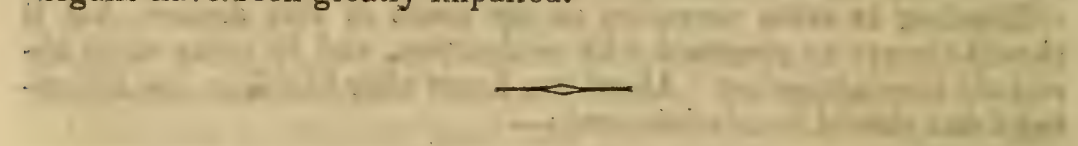

\section{CHAPTER XV.}

GARGET, OR THE DOWNFALI IN THE UDDER OF COWS.

Tins is a disease of the utmost consequence to the owners of neat cattle. Young cows in high condition are most liable to it, especially at the time of calving. Such as are aged are chiefly subject to it during hot and sultry weather, particularly those which are fattened for the shambles; when this is the case, the loss is considerable, for a summer's keep is generally thrown away.

This disorder makes its appearance in one or more quarters of the udder, which become swollen, hard, hotter than usual, and painful when pressed. If the patient is a milch-cow, the secretion of milk is

* [RED W ATER, - Charles Waistell, in the London Farmers' Journal, says: For a fullgrown cow dissolve two pounds Epsom salts in two or three pints of boiling water, and give it when new milk warm; then keep her six or eight hours without food. If then the salts should not have operated, give four or five quarts warm water, and drive her ahout gently; in a quarter of an hour it will operate; then give her as much warm water as she will drink, and turn her out to graze, if the weather be dry. "My brother, J. Waistell, of West Park, has used the above remedy for upwards of thirty years, and has not in all that time lost one beast by the red water. Before he commenced using it, he almost invariably lost cattle annually by that disease. His cattle were less frequently afflicted than formerly, which he attributes to his having underdrained a great part of his farm, which was wet and boggy. The remedy was communicated to him by a relation, Mr. Kendall, a cow-keeper, who for many years kept many cows, and occupied part of Mary-le-bone Park, at London." 
lessened, and mingled with blood, pus, and corruption. At other times the flow of milk is totally stopped, and the tumefied quarter proceeds to a state of suppuration. It not unfrequently happens that the hind extrenitics, at the same time, become swollen and inflamed, especia!ly about the hip joint, hock, and fetlock, which disables the animal from getting up, almost from moving.

It is inflammation of one or more quarters of the udder, and is mast commonly induced by the animal catching cold. It particularly attackis those cows that have a redundancy of blood in the system, or are of a gross babit of body. Young heifers are not always exempt from it.

It will be necessary, as soon as the downfall is discovered, to bring the animal out of the pasture, and take away from three to five quarts of blood, aocording to her size or strength. If she is bled at night, it will be proper on the next morning to give her the purging drink, No. $2,(p .47)$, or if a stout beast, No. 15, (p.57).

The cow should be sparingly fed for a day or two on mashes with a little liay, and afterwards turned on rather short pasture. As this is a disease either confined to, or most violent and dangerous in, cows that are in high condition, it will be quite necessary to keep the patient for a while on spare diet. The ground oats, and barley, and cluver-hay, and oil-cake, that are sometimes given, cannot fail to aggravate the complaint.

The following ointment should be well rubbed into the affected quarter, immodiately after milking, but it must be carefully washed off again with warm water hefore the milk is drawn.

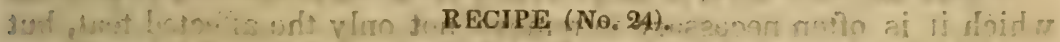

Mercurial Garget Ointment.-Take soft soap, one pound; mercurial ointment, two ounces; camplor, rubbed down with a little spirit of wine, one ounce: rub them well together.

This ointment will penetrate into the diseased part of the udder, and be of very great service.

In ohstinate cises the iodine has been applied to the indurated udder with great success.

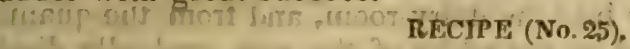

Joline Oinfment.-Take, hydriodate of potash, one dram; and lard, seven drams: rab them well together.

A portion, varying from the size of a nut to that of a filbert, according to the extent and degree of the swelling and hardness, should be well rubbed into the affected part morning and night.

It may sometimes be advisable to give the hydriodate internally, and from eight to twelve grains may be administered morning and night in a little gruel, with very good effect.

During the continuance of the disease, the bowels mnst be kept open with half-doses of No. 2, (p. 47). The fever drink, No. 1, (p. 46), will also be useful, or one more decidedly diuretic, as

\section{RECIPE (No.26).}

Diuretic Drink-Take, powdered nitre, nne ounce; powdered resin, two onnces; - ginger, two Jrans: wix them well together in a little treacle, and give them 1 warm gruel. 
After the purulent and bloody discharge has ceased, and the teat seems to be free from inflammation, and nearly of its natural size, colour, and softness, it will be prudent to continue the ointment daily, and this last drink occasionally for two or three weeks at the least.

Cases, however, will occur, either neglected at the beginning, or the beast being too fat, and very much disposed to inflammation, in which the teat and the whole quarter will long continue hard and swelled, and tender, and will get worse and worse: 'The whole of the affected part must then be carefully examined, to ascertain whether there is matter within, and whether it is pointing, $i$. e., whether there is a part a little more prominent and softer than the rest. If this is detected, it should be freely opened with a lancet or penknife, the matter suffered to flow out, and the wound dressed with Tincture of Aloes or Friar's Balsam. Slight incisions with a lancet, where matter cannot be detected, will often be serviceable. The flow of blood should be encouraged by fomentations with warm water. 'The teats are sometimes cut off in obstinate cases of this kind; but that should, if possible, be avoided, for the quarter will be lost, and there will be a serious diminution in the quantity of milk as long as the cow lives. The teat may be cut deeply in order to let out the matter. This wound will readily heal again, and the quarter will be as useful as ever.

If the udder appears gangrenous, it should be scarified with a lancet, and a solution of chloride of lime applied, whilst the strength of the animal should be supported by tonic medicine.

When the cow dies, it is generally from mortification, to prevent which it is often necessary to remove not only the affected teat, but the whole of the quarter. A skilful man, mure competent than, a common cow-leach, should be employed for this purpose.

A frequent but unsuspected cause of this disease is the hasty and careless mode of milking which is often adopted. A considurable quantity of milk is left in the bag, particularly when a cow gives her milk slowly. This is not only a loss to the farmer, from so much less milk finding its way into the dairy-room, and from the quantity. of milk regularly secreted in the udder of the cow gradually diminishing; but the milk curdles in the teats, and produces swellings, and - lays the foundation for garget.

The Sore Teats to which some cows are subject is a very different disease, and often a very troublesome one. It usually occurs a little while after they have calved. If it happens in the summer, the animals are so sadly tormented by the flies, that it is difficult to milk them; and the discharge from the cracks and wounds passing through the hand in the act of milking, and mingling with the milk, renders it disgusting, if not unwholesome.

The following ointment will generally be found effectual :-

RECTPE (No. 27).

Ointment for Sore Teats, - Take, older nintment, six nunces ; bees' wax, two ounces: mix them together, and add an ounce each of sugar of lead and alum, in fine powc' - stir them well together until cold. 
A little of this should be rubbed on the teats morning and night after milking; and if the flies tease the animal much, a small quantity of aloes or assafoetida may be mixed with the ointment. The latter is the more effectual, but its smell is very unpleasant. . . . : : .

The teats are sometimes so sore that it is necessary to hobble the cow, in order to make her stand; but this is seldom effectual; for the legs of the cow get sore, and she kicks worse than ever. Kindness and patience are the best remedies. It is never of any use to beat or ill-use a cow for this fidgetiness at milking. She will either at the time do mischief in return, or she will at some other opportunity take her revenge:

There is another variety of disease to which the udder of cows is liable, somewhat different from that deseribed: in Scotland it is termed $W e e d s$. It is attended by considerable fever and constitutional disturbance, commencing with a shivering fit, which, after some hours, ? is succeeded by a hot fit, in which all the symptoms of fever are present, - the cow hangs her head and refuses to feed, and the udder is: painful, hot, and swollen. . If relief is not soon obtained, an abscess? forms, and one or more quarters become cold, black, and insensible; the udder becomes disorganized, and the animal is lost.

The first thing to be done is to administer a warm stimulant, such as-

RECIPE (No. 28).

Take, ginger powderen, half an ounce; caraway-seeds, six drams; allspice, half an ounce: in a quart of warm water or mild ale.

Sometimes this draught alone will effect a cure, but the body should be clothed and the cow well nursed. On the following day, if the bowels are constipated and the cow appears dull, a purgative should be given. The udder inust be fomented with warm water for an hour at a time, several times a day, and if it is much swollen, it should be suspended with cloth passing over the loins. It may also. be rubbed with a liniment composed of hartshorn and oil. It is of mueh importance that the fomentations should be as hot as can be borne, and applied in good earnest to the part affected, and for a long time together.

\section{CHAPTER XVI.}

TREATMENT OF THE COWW BEFORE AND DURING CALVING.

Ir is an old and true saying, and the truth of it is nowhere more evident than in the treatment of the milch-cow, that the prevention of an evil is better than the cure. The difficulty of calving, and the mortality afterwards, are in a great measure to be traced to the improper management of the cow. So far as the udder is concerned, 
there is a plan ustially adopted, and a very grecessary one-the cow is dried six or eight weeks before calving. Two reasons are given ir far this : the first is, that after as long period of milking, the strength : and constitution of the cow require a little respite.; a more important: reason, however, is, that from some eause that has never been fully explained, the mixture of the old milk, and the new secretion that? nature prepares for the expected calf, produces frequently great irri-: tation and inflammation in the udder, and obstinate garget is apt to: ensuer asitis lliw orl?

During the early period of gestation the animal may, and should be, tolerably well fed, for she has to provide milk for the dairy and. nearishment for the foetus; yet even here there should be: moderation and care; but when she is dried, her food should be considerably: dinainished. She should not be too fat or full of blood at the time of ealving, for that is the frequent cause of difficult labour, garget, milk fever, and death. There are few things in which the farmer errs more than in this. There may be an error in starving her before she calves, but it is a much mere dargerous one to bring her into too high: condition.

Some cows are apt to slink their calves, or to produce them dead s before their time. This generally happens about the middle of their pregnancy. If about that time a cow is uneasy, feverish, off her food, or wandering about in search of something for which she seems te have longing, or most greedily and ravenously devouring: some particular kind of food, she should be bled and physicked (No. 2, p ' 47). If she is not quieted, she should be bled and physicked again in the course of three or four days. She should be immediately removed from the other cows; for should she slink her calf among them, it is not improbable that:some, or even all, of the others will do the same. This is not easily aceounted for, but it is perfectly true. The cow that slinks her calf will often require much attention. She should al ways be physicked, and in most cases bled, and, after that, the best thing to be done with her is to fatten her for the butcher ;' for she will probably do the same again, and teach others the habit.

"When the ninth calendar month is nearly expired,* the cow should: be diligently looked after. She should be brought as near to the house as can be conveniently done; she should lose three or four quarts of blood, unless she is very poor; and she should most certainly be physicked. It will be better if she can be separated from the other cows; and although it may not be prudent to house her entirely, there should be some shed or shelter into which she may go.

When it appears that labour is close at hand, she should be driver. gently to the cow-house, and for a while left quite alone. She will do better by herself than if she is often disturbed by one and another

* The average period of gestation in the cow has been ascertained by Earl Spencet to be 244 or 225 days. The longest period under his observation was 313 , and the shortest 220 days. He also fourd that when gestation was longer than the average the greater proportion were bull calves,-IVhitc q! Calle Medicine, by W. C. Speaner, 
looking in upon her and watehing her. If, however, she is discovered in the act of calving in the homestead, she should not be moved, however exposed may be her situation. It would sometimes be dangerous to drive her even a hundred yards.

The usual symptoms of the approach of calving are uneasiness, slight lifting of the tail, lying down and getting up, the evident labour-throe, gentle at first, and increasing in force, and the commencement of the protrusion of the membranes from her shape. The still earlier symptoms, and preceding the labour by a few days, are enlargement of the udder, and redness of the space between her shape and the udder.

The labour having actually commenced, the membranes will more and more protrude, until they break, and the fluid by which the calf was surrounded will escape. If her pains are strong, the cow should for a while be scarcely meddled with ; but if an hour or more elapses, and no portion of the calf presents itself, the hand, well greased, should be introduced, in order to ascertain the situation and position of the calf. The natural position is with the fore feet presenting, and the muzzle lying upon the fore-legs. If the fotus is found in this position, and advanced into the passage, some time longer should be allowed to see what nature will do; and the strength of the anirnal may, if necessary, be supported by some gruel, with which a pint of warm ale has been mixed, being horned down. As soon, however, as the throes begin to weaken, and before that, if no progress has been made, manual assistance must be rendered.

Here it will be recollected that there are two objects to be accomplished,- the saving of the lives of both the mother and the young one, and that, consequently, the means at first employed should be gentle. The hand should be introduced, and the fore-legs of the calf laid hold of and drawn down, the efforts of the operator being employed at the moment of the throes of the mother. If the legs are brought forward a little way, care should be taken that the head is accompanying them. The hand will sometimes be sufficient for this purpose. If the head cannot be moved by the hand, a cord must be procured with a slip knot at the end, which is to be passed carefully into the passage, and, the mouth of the young animal being opened, fastened round his lower jaw. The end of this must be given to an assistant, who should be instructed to pull gently, but firmly, at the moment of the throes, while the principal operator is endeavouring to draw on the feet.

Should not this succeed, it will appear that, either from the narrow- ness of the pelvis, or the size of the fœetus, there will be difficulty and danger in accomplishing its extraction. The operator must then begin to think less of the safety of the calf, and endeavour to secure that of the mother. Two other large cords or ropes must be procured, and one fastened round each leg. The service of two assistants will now be required. One should pull at the head, and the other the feet, while the operator asceitains the progress that is made: too much 
force, however, should not immediately be used, for the chance of saving the young one must not yet be given up. 'This not succeeding, greater power must be applied, until the assistants begin to use their full strength, pulling steadily, and with the pains of the cow, if they still continue.

In the natural position of the calf, the young one is almost uniformly extracted by these means, and its life is preserved; for both the mother and her progeny will, without serious injury, bear the employment of more force than would by some be thought credible. When the womb is unable to discharge its contents, and the throes are diminishing, or perhaps ceasing, much benefit may be derived from the administration of the ergot of rye, which appears to act as a stimulus specifically on the uterus: two drachms of this medicine, finely powdered, may be given in a pint of ale, and repeated several times, if required, with intervals from half an hour to an hour.

The foetus is not, however, always presented naturally, and it is the duty of the operator to ascertain its exact position in the womb. This he will not find much difficulty in accomplishing.

The most usual false position is the presentation of the head, while the feet of the calf are bent and doubled down under his belly, and remain in the womb. A cord must be passed as before around the lower jaw, which is then to be pushed back into the womb. The operator now introduces his hand, and endeavours to feel the situation of the feet. He is generally able to find them out, and to fix a cord round each pastern, or at least about the knee, and then he can usually bring them into the passage. The head is next to be brought forward again by means of the cord; and, the three cords being afterwards pulled together, the foetus is extracted. Should the calf have been long fixed in the passage, and be evidently much swelled, it is certainly dead; the head may then be opened in order to lessen its bulk, and the extraction accomplished as before.

When the feet present, and the head is doubled under the rim of the passage, the case is more difficult, and the calf is very rarely saved: indeed it may be reckoned to be dead if it has remained in this position for any considerable time. Cords are first to be placed round the feet; the hand must be afterwards passed into the womb, and the situation of the head exactly ascertained, and the cord passed round the lower jaw. 'The ealf being then pushed farther back into the womb, the head must be brought into the passage, and, the three ropes being pulled together, the delivery effected as quickly as may be, without the exertion of more force than is necessary.

The last false presentation I shall mention is that of the breech, the tail appcaring at the mouth of the shape. The hand is to be passed into the uterus, and the cords fastened round each hock. The calf is then to be pushed as far back as possible into the womb, and the hocks, one after the other, brought into the passage, the ropes being shifted as soon as possible to the fetlock. With the exertion 
of considerable force, the ealf may now be extracted, and sometimes without serious injury.

By studying these cases the operator will be enabled to adapt his measures to every case of false presentation; and they are numerous. Great force must sometimes be used to effect the extraction of the calf. The united efforts of five or six men have been employed, and (although such practice ean scarcely be defended in any case), a horse has sometimes been attached to the cords. The fotus has been necessarily destroyed, but the mother has survived : too often, however, she has evidently fallen a victin to this unnecessary violence. If by the united force of two or three men the foetus cannot be brought away, any ruder and more violent attempt must always be fraught with danger, and will often be fatal. 'The safer way for the mother,yet that is attended with considerable risk, -is to cut off some of the limbs of the foetus. One or possibly both shoulders may be separated, slipped, and then the head and trunk may, without much difficulty, be brought away. The knife must be one that can be concealed in the hand, and that is hooked at the end, and rounded and thick at the back; but, notwithstanding that, there is much danger of wounding the womb, which is forcibly pressing on the hand of the operator.

Labour is not unfrequently prevented by the diseased state of the entrance or neck of the womb, which becomes hard and scirrhous, and thus prevents the calf escaping. When this is found by examination to be the case, an operation should be performed, which consists in dividing the contracted entrance by means of a small knife passed up, protected by the hand and fingers. Considerable caro must be exercised so as not to cut too deeply; and it is better to divide the stricture slightly in several places.

From the violent efforts of the cow, or from unnecessary artificial violence, the uterus, or calf-bed, may protrude, and be absolutely inverted. The case is not desperate. The part must be cleaned from blood and dirt, and supported by a sheet; then, the operator beginning at the very fundus or bottom of the womb, it may be gradually returned by the union of some little ingenuity and a great deal of patience. The animal should be copiously bled before this is attempted, in order to relax the passage; and the application of cold water for a considerable time may contract the womb itself, and render its return more easy. A stitch or a couple of stitches should be passed through the lips of the shape, in order to prevent a repetition of the protrusion, and the following anodyne draught administered -

RECIPE (No. 20).

Anodyne Drink. - Take powdered opium, half a drachm; sweet spirit of nitre, two minces. Rub them together, alding the fluid by small quantities at a time, and give the mixture in a pint of warm gruel.

If the cow has calved unscen and unattended, she will, like every other quadruped, set diligently to work to devour the cleansing, and lick the new-born animal clean. This, howcver, is often carefully prevented when there is the opportunity of so doing. The calf is 
taken immediately away, and the cleansing thrown on the dung-heap. We act contrary to nature in this. She would not have given to herbivorous animals this propensity to eat the placenta, had not some useful purpose been effected by it. Cleanliness was one object, the next was either to support the strength of the animal, or to have an aperient or salutary influence on her. The mother and the young will be happier if they are left to pursue the dictates of nature. Many a cow has fretted herself into fatal fever from the sudden loss of her little one, and many a calf has died from the neglect of that cleanliness which the mother could best effect.

A great deal has been said of the necessity of cleansing the cow after calving, or the removal or expulsion of the placenta. There is much error in this. The placenta comes away with the calf; and it is that natural discharge from the womb, continued during several days, and which is observed to a greater or less extent in all quadrupeds, that gives the notion of anything being retained. Medicine, nevertheless, is necessary in order to prevent that access of fever to which the cow in high condition is liable; but that medicine should be administered, not in the form of a stimulating cordial, from the false supposition that the animal wants support after the fatigue and pain it has undergone, but in that of a purgative, in order to prevent an attack of fever to which the animal is so naturally exposed after parturition, and which is so often hastened and aggravated by absurd management.

The mother requires little care after calving, except that of protection from too great severity of weather, and this more especially if she had been much nursed before parturition. A warm mash may be given daily for a little while; but otherwise she may return to her previous and not too luxuriant feed. The state of her udder, however, should be examined : if it is at all hard, she should be milked twice every day, and the calf should be put with her several times in the day at least, if not altogether. Perhaps she will not let it suck, especially if it is the first calf, on account of the soreness of her teats, and her being unaccustomed to the duties of nursing. She must then be carefully watched at sucking time, and the bag, if it is very hard and kernelly, and sore, must be fomented with warm water, or, if necessary, the garget ointment (No.24, p. 69, or No.27, p. 70) must be rubbed into the part principally affected.

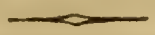

\section{CHAPTER XVII.}

THE MILK FEVER, OR THE DROP.

THrs is a disease almost peculiar to cows in high condition at the time of calving: whether young or old, all are liable to be attacked by it: they are, however, rarely attacked until after they have had 
neveral calves; and it is stated that the short-horned breed is more liable to it than others. Whenever it takes place, either at home or in the fivid, it is distressing to the animal, as well as troublesome to the owner; for the beast is seldom able to rise during several days. I'he ptierjeril or milk fever is most frequent during the hot weather of summer. 'The cows most liable to be attacked by this fever have large udders, that have been full of milk for several days before calving. It is a very dangerous disease when severe, and of ten proves fatal even under the most judicious treatment.

The milk fever most commonly appears about the second or third day after calving; but the cow is occasionally down within a few hours after parturition. It is first recognized by the animal refusing her food, looking dull and heavy; then follows protrusion of the eye, heaving of the flanks, restlessness, and every symptom of fever. In a few hours, or on the next day at the latest, the cow begins to stagger; is weak in the loins; palsy steals over the whole frame; and she falls, unable to rise again. It is in this advanced stage that the complaint is too often first observed; the previous symptoms are not taken notice of, and the beast is almost past cure before the owner is aware of her illness. From this seeming palsy of the hinder limbs, and sometimes of the whole frame, the disease is very appropriately called drupping afler calving.

There are evidently two varieties of this disease, one being considerably more dangerous than the other. In the severer kind, the brain, as well as the spinal marrow, is affected, whilst the milder disease is principally confined to the loins.

In the former kind, we first notice a staggering gait, the breathing then becomes irregular and disturbed, the eyes full and glassy, and the pupil dilated. 'The animal, after reeling about for some time, falls, and frequently never rises again. She then becomes, in great measure, unconscious; the head is turned on one side; sensation appears partially lost, so that, if liquids are given with the horn, they often enter the windpipe without occasioning coughing. The hind legs become entirely paralyzed, and the fore ones are sometimes affected in a similar manner. 'The pulse is generally very quick, but weak; the appetite is altogether lost; rumination ceases; and the bowels are obstinately constipated. If the animal dies, it is generally within forty-eight hours from the commencement of the symptoms, and indeed sometimes only a few hours afterwards. In some cases, the animal will lie in a state of insensibility; in others, she exhibits considerable pain and distress. The cow is unable to discharge either her urine or dung, the nerves influencing these offices being paralyzed. On examinirg the bodies of cows that have died from this disease, the principal mischief has been found in the brain and spinal cord: in the latter, chiefly at the region of the loins. The womb, in the greater number of instances, has been found in the same state as it isually is after parturition; but, in some cases, it presents the appearance of the most intense inflammation. In such cases, it appears ; * 
that the inflammation of the womb is superadded to the other disease.

In the milder form of this complaint, it is, to a greater extent, a local malady : the spinal cord at the region of the loins is affected; but the brain is comparatively exempt; and thus, though the hind extremities are paralyzed to a great extent, yet the insensibility is by no means general, and consciousness is retained. In both the severe and mild form the digestive organs are altogether deranged, and in fatal cases the third stomach is found loaded with hard indigestible food, and the other viscera are often found inflamed.

The cause of the disease has not been ascertained, but it appears connected with a high state of condition, and is best prevented by keeping the cow short of food some days previous to her calving.

The treatment of this disease must be modified according to the severity of the symptoms, and the fact of its being the milder or the severer affection. It is important also to ascertain whether the secretion of milk has ceased; as it has been ascertained that when this is the case the disease is fatal, and when not so the cow recovers. If the pulse is strong, it will be proper to bleed to the extent, perhaps, of four or five quarts. The principal expectation of relief, however, must be placed on the exhibition of powerful purgatives.

\section{RECIPE (No. 30).}

Take Epsom or Glauber's salts, twelve ounces; flour of sulphur, four ounces; powdered ginger, four drachms; spirit of nitrous ether, one ounce. To be dissolved in warın water.

One-half of this draught may be repeated twice a day until the bowels are properly opened. In the severer affection it will be proper to add from ten to twenty drops of the croton oil to the first draught, and even two drachms of carbonate of ammonia and ten grains of cantharides have been conjoined with advantage. It is of importance to administer the draught slowly and carefully; and when the cow is any way unconscious it will be better to give it by means of Read's syringe, putting the tube half-way down the neck, so as to prevent any of the medicine getting into the windpipe, where it has been known to produce fatal inflammation. The action of the physic should be assisted by frequent clysters, and the bladder should be emptied from time to time by a catheter. A blistering liniment should be rubbed on the course of the spine: in the milder disease it may be limited chiefly to the loins, but in the severer affection it should extend from the head to the tail, and be often repeated. It is astonishing what a vast quantity of purgative medicine may often be administered in this disease without producing any effect, the stomachs being in such a torpid state.

In the milder disease, the treatment must be similar in its nature, though not so powerful as that here recommended; the croton oil may be dispensed with, and the blistering application confined to the loins.

The cow should be made as comfortable as possible. A good bed 
of straw should be got under her, and her fore-quarters should be considerably raised, so that the dung and urine may flow away. It not unfrequently happens, that as soon as the cow begins thoroughly to purge she gets up and walks about, although still continuing for a while in a very weak state.

In order to make her as comfortable as possible, the cow should be shifted from side to side twice in the day; all filth of every kind should be carefully removed, a warm cloth thrown over, and warm gruel or linseed-tea frequently offered to her with mashes, if she will eat them.

It will be a very bad symptom if she begins to swell, and there are frequent belchings of very foetid gas. If the digestive powers are thus weakened there is but little hope. The following ball should then be given, still continuing the purgative medicine if necessary :-

\section{RECIPE (No. 31).}

Cordial Drink.-Take caraway powder, one ounce: gentian, powdered, half an ounce; ginger, powdered, balf an ounce; essence of peppermint, 20 drops.

This, in the form of a ball, will probably find its way into the paunch. Half the quantity of the above ingredients should also be given morning and night as a drink, in a pint of warm ale, and the same quantity of thin gruel.

If the cow should continue to swell, relief must be obtained by means of the flexible pipe for that purpose; and, if the proprietor has the pump which should accompany the pipe, some gallons of warm water in which a little ginger has been boiled may be thrown into the paunch, in order to wash out a portion of its contents. Should not the pipe be at hand, an opening may be made into the paunch at the flank with a sharp-pointed knife, in the usual manner; or, if the case is becoming absolutely desperate, the operator will be justified in enlarging the opening so as to admit the hand, and gradually take out the greater part of the undigested fond. The edges of the wound should then be brought together and held hy two or three stitches, the divided skin and the wall of the paunch being included in each stitch.

There is one thing that should not be omitted, and that is the attempt, two or three times every day, to bring back the milk, by diligently stroking the teats. As the drying up of the milk is the earliest symptom of the attack of the disease, so the return of it is the happiest promise of recovery.

If the cow does not get up on the third or fourth day, there is but little chance that she ever will. The case, however, should not be abandoned, for she has done well even after the fourteenth day.

If the udder is hard and knotty the camphorated oil (No. 11, p. 53) should be well rubbed over it twice every day ; and if it is very hot and tender, fomentations of warm water should be used, but no cold lotion is admissible in such a case.

As the cow is frequently unwilling, and sometimes unable, to tako 
sufficient nutriment herself, some nutritious food should be horned in; and there is nothing better than good thick gruel. 'Two or three quarts given four times every day will be enough. All sweet things, which farmers are so apt to give, should be omitted; the food in the paunch is sufficiently ready to ferment, without giving any sugar.

A cow labouring under milk fever should scarcely ever be left. She naturally gets very tired of coughing so long, and sometimes attempts to shift herself, and would get sadiy bruised if assistance were not afforded; besides which, in the early stage of the disease, and occasionally afterwards, there is some affection of the brain, and the animal is half unconscious of what she does, and would beat herself dangerously about if care were not taken of her.

I must again repeat that prevention is better than cure; and that the best preventive of milk fever is not to let her be in too high condition, but to take four or five quarts of blood from her, and give her a physic drink eight or ten days before the expected time of calving.

\section{CHAPTER XVIII.}

THE BLAIN, \& C.

This is by no means an unfrequent disease, and is commonly known by the name of blain, hawkes, or gargyse.

The animal appears dull and languid, the eyes red and inflamed, with tears trickling from them. A swelling begins about the eyes, and occasionally appears on other parts of the body; but the characteristic symptom is that there are generally blisters under the tongue, or at the back part of the mouth; the pulse is quicker than natural; there is more or less heaving of the flanks; and the bowels are sometimes constipated. When the complaint is not checked at the onset, there is often a copious flow of saliva from the mouth, mixed often with a purulent, bloody, stinking discharge; the beast becomes extremely weak and reduced, and is in danger of being suffocated by the great and rapid enlargement of the tongue.

Causes.-Those cattle are the most subject to this complaint that are in high condition, and feeding on rich pasture grounds. It appears in many cases to be brought on by a redundancy of blood in the system, or from the beast taking cold while in that state. It is most prevalent in the summer months, especially when the weather is hot and sultry, but it occurs at all times of the year, and in pastures of every kind, yet oftenest in low, marshy situations.

This is a disease which must not be trifled with for a moment. I have known it prove fatal in the course of one day; and when neglected at the beginning it has speedily assumed a malignant charaoter, which baffled every attempt to arrest its progress. 
The remedy, and often a very expeditious one for this disease, is to cut deeply, and from end to end, the bladders that will be found along the side of and under the tongue. They will appear to be filled with a glutinous matter, and, although there may not be much bleeding from them at first, considerable bloody fluid will gradually ooze out, the swelling of the mouth and head will subside, and the heast will be very much relieved. All the curious operations of thrusting sticks and tardown the throat have this for their object, to break these bladders, but which is most easily and completely effected by the knife.

If, however, much fever has accompanied the enlargement of the tongue, it will be prudent to take away five or six quarts of blood, and to give a physic drink, and particularly if, on the day following the operation, the beast should continue to be feverish. The mouth may likewise be washed with a solution of the chloride of lime in water, in the proportions of one drachm of the powdered chloride to a quart of water, while the mouth is very offensive; and with equal parts of tincture of myrrh and water afterwards, in order to promote the healing of the ulcer.

If the fever continues, the fever drink (No. 1, p. 46) may be given morning and night, and the bowels kept open by the purging drinks (No. 2 or 7, p. 47 and 52 ).

Should considerable weakness and loss of appetite remain when the fever seems to be subdued, the following tonic drink may be given:-

\section{RECIPE (No. 32).}

Tonic Drink.-Take gentian, two drachms; tartrate of iron, one drachm ; ginger, one drachm. Mix, and give in a pint of gruel.

This may be repeated daily, or twice a day, as circumstances may require.

It will sometimes happen that the animal will for some days refuse to eat, on account of the soreness of the mouth. Thin gruel should be always placed within his reach, and plenty of thick gruel administered with the horn.

The person who has to attend on cattle that have the blain should take care that none of the discharge from the mouth comes in contact with any sore place, for very troublesome ulcers have been produced by this means. If $t^{\prime}$ iere is any fear that a sore place has been thus inoculated, the lunar caustic should be applied to it. 


\section{CHAPTER XIX.}

THE BLOOD, BLOOD-STRIKING, BLACK-LEG, QUARTER EVIL, OR BLACK-

\section{QUARTER.}

'Tue disease which am now to describe is indicated by these curious names, and a great many more, in various parts of the country. Very few of these names, however, are misplaced, for they indicate some variety, or symptoms, or stage of this dreadful malady. It would be much better recognized by the title of Inflammatory Fever.

Its attack is confined almost entirely to animals that are in high condition, or rapidly improving; I should say, too high condition, and too rapidly improving. In some instances the disease will give some warning of its approach, but, generally, the beast appears to be to-day perfectly well, and to-morrow he will be found with his head extended, his flanks heaving, his breath hot, his eyes protruding, his muzzle dry, his pulse quick and hard - every symptom, in short, of the highest state of fever. He utters a low and distressing moaning; he is already half unconscious; he will stand for hours together motionless, or if he moves, or is compelled to move, there is a peculiar staggering referrible to the hind limbs, and generally one of them more than the other: by and by he gets uneasy, he shifts his weight from foot to foot, he paws faintly, and then lies down. He rises, but almost immediately drops again. He now begins to be, or has already been, nearly unconscious of surrounding objects.

There are many other symptoms from which the different names of the disease arose. On the back or loins, or over one of the quarters, there is more or less swelling; if felt when it first appears it is hot, and tender, and firm, but it soon begins to yield to the touch, and gives a singular crackling noise when pressed upon. One of the limbs likewise enlarges, sometimes through its whole extent, and that enormously. It, too, is at first firm, and hot and tender, but it soon afterwards becomes soft and flabby, or pits when pressed upon, $i$. e., the indentation of the finger remains. When examined after death, that limb is full of red putrid fluid: it is mortified, and seems to have been putrefying almost during the life of the beast. Large ulcers break out in this limb, and sometimes in other parts of the body, and almost immediately become gangrenous; pieces of several pounds in weight have sloughed away; three-fourths of the udder have dropped off, or have been so gangrenous that it was necessary to remove them, and the animal has been one mass of ulceration. The breath stinks horribly; a very offensive, and sometimes purulent and bloody fluid runs from the mouth; the urine is high-coloured or bloody, and the faces are also streaked with blood, and the smell troin them is scarcely supportable. 
In this state the beast will sometimes continue two or three days, at other times he will die in less than twelve hours from the first attack. In a few instances, however, and when the disease has been early and properly treated, all these dreadful symptoms gradually disappear, and the animal recovers.

Although much evil has resulted from the putrefied carcases of the beasts that have died of inflammatory fever be ng suffered to lie about, yet it does not appear that there is anything infectious in the disease. It is true that if one bullock on a farm dies of the blood, many will usually follow; but it is only because they have been exposed to the same exciting cause. Fortunately, also, for the farmer, it is almost confined to young cattle. Those that are between one and two years old are most subject to it; but some of three and four years are occasionally attacked by it, and I have seen others of double that age die under it. Milch cows, or lean eattle, are in a manner exempt from it.

It is to a redundancy, or overflowing of the blood, the consequence of the sudden change from bad to good living, that this disease most commonly owes its origin. It is most prevalent in the latter part of the spring and in the autumn; and very often, at those seasons of the year, proves destructive to great numbers of young cattle in different parts of the kingdom. It is sometimes, however, seen in the winter and the early part of the spring, when the cattle are feeding on turnips. Some situations are more subject to this complaint than others. It is most frequent in low, marshy grounds, and pastures situated by the side of woods.

It is a disorder of high condition and over-feeding. The times of the year and the character of the cattle prove this. It occurs in the latter part of the spring, when the grass is most luxuriant and nutritive, and the autumn, when we have the second flush of grass; and the animals attacked are those principally that are undergoing the process of fattening, and that have somewhat too suddenly been removed from scanty pasturage and low feeding to a profusion of herbage, and that of a nutritious and stimulating kind. The disease sometimes occurs when the cattle have been moved from one pasturage to another on the same farm; but more so when they have been brought from poor land, at a distance, to a richer soil. There are in the latter case two preparatory causes, - the previous poverty, and the fatigue and exhaustion of the journey.

Farmers may endeavour to account for it, if they please, from their beasts having fed on certain acrimonious or poisonous plants, as the different species of the crowfoot, or some others; but there cannot be a moment's doubt that the evil is to be traced to their own bad management, and to that almost alone. I will not say that there may not be some atmospheric agency. The blood is much more prevalent in some years than in others, and more fatal when it does occur; but if the fact is carefully examined, rapid vegetation has then succeeded to a cold and thriftless seasun, and thus the causes of which $I$ have spoken have been more powerfully called into action, while the influ- 
ence of the atmosphere may have materially modified the character of the disease after it had been produced.

In examining cattle that die of this complaint the affected part or parts are found mortified, and emit a peculiar cadaverous smell; and there is a glutinous or bloody ichorous fluid of a very offensive smell between the skin and flesh. In two instances I found the membranes of the brain mortified, being here and there of a livid colour, and easily torn:

This disease rarely admits of cure, but fortunately it may in general be prevented. If the malady is discovered as soon as it makes its appearance, the beast should be immediately housed, and then from four to eight quarts of blood taken away, according to the age and size. Two hours after bleeding give the following purging drink (No. 2, p. 47), which will be found of a proper strength for young cattle from the age of one to two years.

The bleeding should be repeated in three or four hours, if the animal is not materially relieved; and a third bleeding must follow the second, if the fever is unabated. There must be no child's play here; the disease must be knocked down at once, or it will inevitably destroy the beast. 'The physic likewise must be repeated until it has its full effect.

As soon as the bowels are well opened, the fever drink (No. 1, p. 46) should be administered, and repeated morning, noon, and night, all food except a little mash being removed.

At the first appearance of the disease, the part principally affected should be fomented several times in the course of the day with hot water, and for at least an hour each time. For this purpose there should be two or three large pieces of flannel in the water, that after one of them has been applied thoroughly hot and dripping to the part affected, another equally hot may be ready when this gets cold.

As soon as the fever begins evidently to subside, and the beast is more himself, and eats a little, the fever medicine must not be pushed too far. It should be remembered that this is a case of highly inflammatory disease, which soon passes over, and is often succeeded by debility almost as dangerous as the fever. The ox, therefore, must not be too much lowered; but, the fever abating, the following mingled tonic and fever medicine should be given:-

\section{RECIPE (No. 33).}

Mildest Tonic Drink.-Take gentian, two drachms; emetic tartar, half a draclum nitre, half an ounce; spirit of nitrous ether, half an ounce. Give in gruel.

If this does not bring back the fever, it may be safely continued once every day until the ox is well; or the quantities of tie gentian may be increased, and the emetic tartar lessened, and at length altogether omitted, the nitre being still retained.

A seton (of black hellebore root if it can be procured) should be inserted into the dewlap; and, if the beast can be moved, it should be driven to much scantier pasture.

Should not the disease be discovered until there is considerable 
swelling, and a crackling noise in some tumefied part, a cure is seldom effected. Bleeding, at this stage of the complaint, can seldom be resorted to, or, at least, one moderate bleeding only should be practised, in order to subdue any lurking fever that may remain. If a cure is in these cases attempted, the drink No. 13, p. 54, should be given, which may invigorate the system by its cordial and tonic powers, and prevent the mortification extending.

The swelled parts should be frequently bathed with equal portions of vinegar and spirits of wine, made as hot as the hand will bear; or, if ulceration seems to be approaching, slight incisions should be effected along the whole extent of the swelling, and the part bathed with spirit of turpentine made hot.

If ulceration has commenced, accompanied by the peculiar foetor that attends the disease, the wounds should be first bathed with a disinfectant lotion.

RECIPE (No. 34).

Disinfectant Lotion.-Take solution of chloride of lime in powder, a quarter of an ounce; water, a pint. Mix.

The hot spirit of turpentine should be applied immediately after this, and continued in use until either the mortified parts have sloughed off, or the sore begins to have a healthy appearance. The tincture of aloes or Friar's balsam may then follow.

Since so little can be done in the way of cure, we next anxiously inquire whether there is any mode of prevention. The account which I have given of the disease immediately suggests the prevention, viz., to beware of these sudden changes of pasture; now and then to take a little blood from, or to give a dose of physic to, those beasts that are thriving unusually rapidly, and, whenever the disease breaks out on the farm, to bleed and to purge, and remove to shorter and scantier feed every animal that has been exposed to the same exciting causes with those that have been attacked. The farmer should be particularly watchful during the latter part of the spring and the beginning of the autumn: he may thus save many a beast, and the bleeding and the physic will not arrest, but rather assist their improvement. He who will not attend to a simple rule like this will deserve the loss that he may experience.

\section{CHAPTER XX.}

MURRAIN, OR PESTILENTIAL FEVER.

Tars is not the fever which I have just described, more rapidly, and to a greater extent, assuming the typhoid and malignant form, although there is a considerable similarity between the diseases, but it is distinguished by some peculiar and fatal characters. It has from time to time destroyed immense numbers of cattle on every part of 
the continent of Europe. Its ravages have sometimes been dreadful in Great Britain. In the spring of the year 1714 more than 70,000 cattle died of this pest in England.

Fortunately of late years this destructive malady has been comparatively unknown among us, except that in some unfavourable districts a few cases have occurred every year. Its latest visitation, clothed with all its most dreadful attributes, was in 1768. It is thus described by Dr. Layard, an intelligent physician of that period:"6'The animal was found with its head extended, that its laborious breathing might be accomplished with less dread of suffocation; there was considerable difficulty in swallowing; enlargement of the glands under the ear, and frequently swelling of the whole of the head; uneasiness about the head; seemingly itchiness about the ears; dulness ; frequent, but not violent heaving. To these succeeded staggering and great debility, until the animal fell, and was afterwards either unable to stand long at a time, or to stand at all. A constant discharge of green bilious stinking fæces now appeared; the breath was likewise offensive; the very perspiration was sour and putrid; the head swelled rapidly; the tongue protruded from the mouth; and the saliva, at first stinking, but afterwards purulent, bloody, and more and more offensive, flowed from the mouth. A crackling was heard under the skin when the back or loins were pressed upon; tumours appeared, and abscesses were formed in various parts; they multiplied and they spread, and discharged a dreadfully stinking fluid.

"By and by a fresh access of fever seemed to supervene; the breath got hot, and the extremities were cold; the purging increased, and was even more offensive; the urine and the dung excoriated the neighbouring parts as they passed away; and on the seventh or ninth day the animal usually died."

If a milch cow was attacked her milk dried up gradually, her purging was more violent, and her debility more rapid than that of other cattle. Bulls and oxen were not so violently seized as cows and calves; and cows with calf, and weakly cow-calves, were most in danger. If cows slipped their calves they usually recovered. Calves received the infection from the cow, and the calf, on the other hand, often infected the cow.

'The disease was epidemic. It depended on some atmospheric influence, which we are unable to understand; but at the same time it was contagious, and that to a very great degree. If it once appeared on a farm, almost all the cattle were sure to be affected: yet it was ascertained that the power of infection did not extend more than a few yards; and that a hedge alone often separated the dead from the living. The murrain seemed mostly confined to cattle, for horses and sheep; and swine and dogs, lived in the midst of the infection and escaped, and even some neat cattle seemed to possess a security from infection.

The favourable symptoms were eruptions on various parts of the 
body, not indeed too numerous, and their breaking and discharging a considerable quantity of purulest matter. If from exposure to cold, or other improper treatment, the boils were repelled, or if they gradually lessened and disappeared, death was an almost inevitable consiquence. If the dung became more corisistent, and the urine not so hirgilly coloured, and the mouth cooler, and the beast hegan to brighten up, and look a little cheerfully around him, there was hope; but if the boils receded, and the scouring became constant, and the breath was hot, and the horns were cold, and the difficulty of breathing increased, and the animal groaned at every motion; if the eye sunk, and the pulse intermitted, and the beast was almost unconscious, and a cadaverous smell proceeded from him, it was seldom that lie escaped.

On examination after death, the whole of the cellular texture under the skin was found to be distended either by air or a sanious fluid, and in most eases partly by both. The air rushed out when the skin was punctured, and stunk inost abominably; and the cellular texture and the muscles were rendered livid and black by the dark fluid which they contained. 'The brain and its membranes were inflamed, and the ventricles filled and distended. The mouth and nose, and fauces and throat, and the frontal sinuses to the very tip of the horn, were filled with ulcerations and with pus. The lungs were inflamed in patches, and filled with tubercles. The liver was large, and so rotten that it was torn by the slightest touch. All the vessels of the liver and the gall-bladder were gorged with greenish fetid bile. The paunch was distended with wind, and uridigested and, generally, hardened food. The third stomach contained between its leaves a quantity of dry and hardened food, so hard and brittle that it might be almost powdered; and the fourth stomach, or rennet bag, was empty, but highly inflamed and gangrened in various places. The intestines were also beset with livid and black spots. 'The uterus of thnse that were in calf was gangrened, and the smell from the fluid which it contained was almost insufferable.

It seemed to be a high degree of fever, which had speedily run on to a typhoid and malignant form, and by which every part of the frame was poisoned.

We have not for a long while been visited to any great extent by this malady, and should it again occur, the veterinary art is far more advanced than it was many years ago, and there is reason to hope that it would not be so destructive as in times past.

The treatment would be, first, and the most important thing of all, to separate the diseased from the sound : to remove every animal that seerned to be in the slightest clegree affecterl to some isolated portion of the farm where contact with others would be impossible. It would be imprudent to remove those that appeared to be unaffected, because it would be impossible to know that the virus did not lurk in their veins, and thus the poison might be conveyed to other parts of the 
farm. The sick only should be taken away, and that as speedily as possible.

In the early stage of the disease there can be no doubt of the propriety of bleeding. The fever, which, according to every account, characterises the first attack, should, if possible, be subdued; otherwise its prolonged existence would aggravate, if it did not cause, the subsequent debility. 'The animal should be bled, in proportion to his size, condition, and the degree of fever: he should be bled, in fact, until the pulse began to falter or he began to stigger. 'The blood should be taken in as full a stream as possible, that the constitution inight be more speedily and beneficially affected. When the blood flows slowly, a quantity may sometimes be taken away before the animal begins to feel it, the loss of which would afterwards produce alarming debility; but if the blood flows freely, the beast will show symptoms of faintness - the effect we wish to produce - before onefourth of the quantity is drawn that would be lost if it ran in a slow stream. We want to attack and subdue the fever, without undermining the strength of the frame.

Then we should with great propriety administer a brisk purgative. If fetid and obstinate purging so sonn follows, we should be anxious to get rid, if we can do so, of a portion of the offending matter; and therefore a pound or twenty ounces of Epsom salts should be given in a sufficient quantity of thin gruel.

Next, as it is a disease so much and so early characterised by debility, we should attend to the diet. Green succulent grass would scarcely be allowed, because it would probably not a little increase the purging; but mashes of bran, with a little bean-meal, carrots, or sweet old hay, should be given in moderate quantities. The animal shuuld be coaxed to eat; for it is necessary that the constitution be supported against the dehilitating influence of such a disease. The animal should not be at first drenched, for this might produce nausea and disgust for food; but if two or three days should pass, and the beast should obstinately refuse to eat, plenty of warm thick gruel must be forced upon him. As for medicine, I scarcely know what to advise. The fact stands too clearly upon record, that nineteen animals out of twenty, seized with the murrain, have died. That on which I should put most dependence would be the following :-

RECIPE (No. 35).

Drink for Murrain.-Take sweet spirit of nitre, half an ounce; laulanum, half an ounce; chloride of lime, in powder, two ounces; prepared chalk, an ounce. Rub them well together, and give them with a pint of warn gruel.

This may be repeated every six hours, until the purging is considerably abated; but should not be continued until it has quite stopped.

The purging being abated, we must look about for something to recall the appetite and recruit the strength, and I do not know anything better than the following:- 
Tonic Drink for Murrain.-Take columba root, two drachms; canella bark, two drachus ; ginger, one drachm; sweet spirit of nitre, half an nunce. Rub them toge. ther, and give in a pint of thick gruel.

There cannot be a more proper means adopted than a seton in the dewlap, made with the black hellebore root. 'The mouth should be frequently washed with a dilute solution of the chloride of lime. The ulcerated parts, if they are fetid, should have the same disinfectant applied to them, and the walls and ceiling, and every part of the cowhouse, should be washed with it.

One caution should be used with respect to the food; while the beast should be coaxed to eat, in order to support him under the debilitating influence of the disease, it is only on the supposition that he ruminates his food. Until he begins again to chew the cud, we are only injuriously overloading the paunch by enticing the animal to eat. Until rumination is re-established, the food should consist of gruel, or any other nutritive fluid, and should be so administered that the greater part of it may pass on into the fourth stomach, without entering the first. When the animal appears to be recovering, he should be gradually exposed to cool arid open air, and very slowly permitted to return to his usual food.

When the disease is quite subdued, the cleansing of the cow-house should be seriously ucdertaken, and thoroughly accomplished. Let every portion of filth and dung be carefully removed, the walls, and the wood-work, and the floor carefully washed with water, or soap and water, and then every part washed again with a lotion, in the proportion of a quarter of a pound of the chloride of lime, in powder, to a bucket of water. This will be better than any fumigation that can be possibly applied. Should, however, the chloride of lime not be at hand, then a simple and cheap fumigation, on which very considerable dependence can be placed, may be resorted to.

RECTPE (No. 37), is i

Fumigation.-Take common salt, two pounds; oil of vitriol, one pound.

The salt should be put in an earthen vessel, and placed in the toiddle of the cow-house, and the oil of vitriol gradually poured upon it. They should be stirred well together with a stick, and the person preparing the thing should retreat as quickly as he can, to prevent himself from suffering by the fumes of the chloride, closing the door carefully after him, every window and aperture having been previously closed. In a few hours he may enter the cow-house again, and remove the vessel without any serious inconvenience.

There is every reason to hope that the murrain will never again thin our herds of cattle to any great extent, not only because veterinary scicnce is so much advanced, and the farmer can have immediate recourse to the assistance of a skilful practitioner, but because agriculture has been so much improved within the last century, and particulirly that important and most bencficial system of under8* 
draining has been introduced. When the murrain so sadly prevailed in foreign countries, and in England, it uniformly commenced in, and was chiefly confined to, some low marshy district. 'This was particularly the case in the murrain which prevailed in France in 1779. It was principally confined to the low meadows and marshes, and it appeared soon after an unusual inundation had subsided. In Italy, where the murrain has been more prevalent and fatal than in any other country, it always commences in some of the extensive and pestilential marshes with which the Italian coast abounds. In the account of a pestilence that carried off thousands of cattle in Hungary, it is said that the spring had been rainy, with great changes in the temperature of the atmosphere. This will afford a useful hint to the farmer as to the system of agriculture he should pursue, and the situation to which he should, if possible, remove his cattle when any pestilential disease breaks out. The infected cattle, and the herd generally, should not only be removed to some rather elevated and dry situation, but sheltered as much as possible from the sudden variations of the external air, at least by night.

It is to be hoped, too, that some legislative provision will be made to prevent as much as possible the spread of the disease; that every animal seriously affected shall be immediately consigned to the slaughter, and that no portion of the hide or carcass shall by any means be permitted to be used, but the whole deeply and speedily buried.

When the murrain was so prevalent in Holland, and it seemed as if every beast was destined to fall a victim to it, some speculative men had recourse to inoculation. The matter discharged from the nostrils, or from an ulcer of a beast not apparently affected with any very virulent form of the disease, was inserted under the skin of a sound animal. The disease was produced, sure enough, but with very doubtful and often lamentable effect. In some cases a worse malady was induced. In a few it was materially mitigated; a considerable proportion still died, and doubtless some who would have escaped the disease had it not been for the inoculation.

[Extract of a letter to the American Editor from J. E. G. Kennedy, Meadville, Pennsylvania.

"I received some months since, from a Hollander who purchased a farm a few years since in my neighbourhood, some povders for the cure of murrain in cattle. After having resided here a few years, the frequency of this disease induced him to send to Holland for the medicine mentioned, and which he avers was a certain remedy there within his own knowledge. The receipt for its manufacture is a secret, and lodged with one family in the Hague. Its reputation in Holland is very extensive. Mr. Kohler, who gave me the article, is a remarkably intelligent man, noted for his correct agricultural taste and knowledge among his friends, and I perfectly rely on his veracity. He would say nothing that he did not believe true; and as a proof of his standing in his own country, I might mention his having received, from a nobleman of Holland an invitation to become the manager of an extensive estate in that country, and the inducement such, that he has rented his farm and gone to 
Follund with his family. Before Mr. Kohler lef this country lie gave mie snme of the powders, and I have thought that possibly the chief ingredients might be detected by the experiments of an accomplished chemist. If you will undertake the task of having them submitted to the tests of such a person, I will send you a sufficient guantity to make trial with. If the experiments should result successfully, and the medicine prove valuable, the labour would be well expended, as I know of no sertain or plausible cure for murrain in cattle, a disease occasioning the loss of "housands annually in this country. The principal part of the article (whether the virtuous portion or not I cannot say) is mineral-judging from the weight."

Another extract.- I send you two papers of the murrain powder, being two doses. For fear of mistake I wrote the directions on them when I received them."

The two powders were placed in the hands of Professor Benjamin Hallowell-as eminent for scicntific attainments as he is remarkable for simplicity of manners and benevolence of heart. In a few days he was good enough to return the powder, with an exact duplicate of it, and the following memorandum:- "The powder contains 380 grains ; it is composed of 340 grains of nitrate of potash (salt-petre) and 40 grairis of bole armenian intimately mixed" - be it remembered that the above quantity makes two doses - and the directions are: "dissolve in a pint of water." It will be easy to try a remedy so strongly and plausibly recommended; and, if found effectual, the public will owe an obligation to all who may assist in diffusing a knowledge of it.

Thus we come at the following recipe for murrain:-Take nitrate of potash, 170 Erains; bole armenian, 20 grains. Dissolve in a pint of water, and give. $-\mathbf{S}$.]

\section{CHAPTER XXI.}

\section{THE EPIDEMIC OF 1840. AND 1841 .}

Since the last edition of this work was published a new disease has appeared amongst cattle and sheep, and for the last two years it has spread through the kingdom as an epidemic, scarcely sparing a single parish from its visitation. Though not by any means usually fatal in its effects, it has yet altogether destroyed a great number, and the pecuniary loss has been still greater from the debilitating effects which it has produced or left behind. It has been proved to be extremely infectious, and it is difficult to say whether the greater number of eases have been thus produced or spontaneously occasioned. It has sometimes appeared amongst the cattle of a farm, scarcely sparing a single case; and again, after some months' absence, it ha's re-appeared on the same farm amongst the sheep, or perhaps the swine. In some cases, and on some occasions, the symptoms of the disease have been very slight, and the cases have soon got well without any medical treatment; but in other cases the symptoms have been extremely severe, and attended with danger. It has usually happened that the earlier and the later cases have been somewhat slight, and the middle ones much more dangerous. In this respect it 
has resembled other epidemics. The cause of this disease is altogether unknown: it is probably owing to some atmospheric agency, the nature of which it is impossible to ascertain.

The disease is decidedly constitutional, though manifesting itself locally in a peculiar manner: its nature is that of a low fever, great debility quickly supervening, and sometimes exhibiting a tendency to putridity. If the very earliest symptoms are observed, it will generally be found that cold extremities, a staring coat, and indeed a cold fit is exhibited; but a reaction soon follows, in which the limbs become hot, and then saliva issues from the mouth, and the tongue is somewhat swollen. At the same time some degree of tenderness in the feet is manifested, and the pulse is quickened and the beast is altogether feverish. The soreness of the mouth and feet increases, small bladders are found on the tongue, the lips and other parts of the mouth, and likewise between the hoofs, and sometimes also on the teats. The animal gradually ceases to feed, from the pain experienced in the act, and sometimes the appetite itself fails. 'The bladders become opaque, and at length burst and discharge a watery fluid; and this increases the soreness of the parts. The flow of saliva increases, and in a few days the cuticle sloughs off. Sometimes there are swellings along the back and loins, which appear to contain air. The disease thus continues, becoming gradually more severe until four or five days from the commencement, when amendment generally takes place, and the beast gradually recovers. Sometimes, however, the complaint becomes complicated with inflammation of some organ - such as the lungs, and the danger is then much greater, or it may take on a low typhoid form, under which the animal may sink. In milch cows the udder is often affected, occasionally much inflamed, and attended with danger.

The treatment of this disease must be moderate in its character, and should consist in checking the fever, relaxing the bowels, healing the sores on the mouth and feet, and afterwards assisting the strength with tonics.

Bleeding should in general be abstained from, unless there is some severe local inflammation present, calculated to increase the debility; but the following laxative should be administered without loss of time:-

$$
\text { RECIPE (No, 38); }
$$

Take epsom salts, half a pound ; sulphur, two or four ounces ; nitre, half an ounce ; ginger, two drachıs; spirit of nitrous ether, one ounce. Dissolved in warm water or gruel, and repeated once a day for several days.

The following liniment may be applied to the mouth several times a day :-

RECIPE (No. 39).

Take alum and white vitriol, of each half an ounce; treacle, a quarter of a pint. Dissolved in a pint of warm water.

The feet should be carefully pared, and if much inflamed a poultice may be applied; but if not so, and there is a sore, equal parts of 
tincture of myrrh and butyr of antimony. One application of this canstic is generally sufficient, and the sore should afterwards be dressed once a day with the following :-

\section{RECIPE (No. 40).}

Astringent Powder. - Take blue vitriol, powdered, half an ounce; powdered alum, half an ounce; prepared chalk, two ounces; armenian bole, one ounce. Mix.

Linseed and oatmeal gruel should be offered to drink, and mashes with the best food that can be procured. If the weather is fine, it will be better to continue the cattle at grass; but if housed, they should be kept clean and dry. When the bowels are relaxed, and there appears much weakness, the following tonic should be given daily :-

\section{RECIPE (No. 41).}

Take powdered ginger, one drachm; powdered caraway seeds, one drachm; gentian, powdered, four drachms; spirit of nitrous ether, one ounce. 'T'o be mixed slowly with gruel.

If there should be any appearance of colic or spasm of the bowels, an ounce of laudanum may be given with the other medicine; and if the liver is affected, a drachm of calomel may be added, and a blistering application rubbed on the right side.

Should the lungs be inflamed, it will be proper to bleed and blister the sides, or insert setons in the brisket. If the udder is affected, it should be well and frequently fomented with hot water, and the milk should be drawn with great care.

The epidemic has sometimes appeared amongst sheep in so slight a form that they get well without assistance, or simply by the application of tar to the feet, no other part being affected. At other times, however, its appearance has been far more severe; the hoofs in many cases have come off, from the formation of matter underneath, and the poor animals have been altogether unable to stand. The mouth, however, in these animals is rarely affected, and the appetite there-fore is not greatly impaired. In wet weather the disease is more severe than in dry, and the feet are sometimes so bad as to resemble the worst form of foot rot.

The feet will therefore, in sheep, require the principal attention. The detached horn should be sufficiently cut away to afford exit to any matter that may be under; but the knife must be used with caution and sparingly, as fungus flesh is so apt to grow when the horn is removed.

The same medicine recommended for cattle should here be emplnyed, and the powder will be particularly useful. It will be desirable, unless the symptoms are slight, to administer the internal medicine, one-sixth or one-eighth part being sufficient for the sheep; and it will not be necessary to continue its use so long.

Pigs may be treated in a similar manner. 


\section{CHAPTER XXII.}

IN LAMMATION OF THE BLADDER.

This disease does not often occur in cattle, except from eating acrid and poisonous herbs, or when cows are near their time of calving. In the first case, there are frequent and violent, but ineffectual, efforts to stale. There is true and proper inflammation of the neck of the bladder. This may be occasioned by cold, but is more frequently produced by the animal having fed on heathy pastures, and on the hot and stimulating plants that abound there. "The broom is a frequent cause of this disease,

It is of much consequence to be enabled to distinguish this from inflammation of the bladder itself. In the early stage of inflammation of the neck of the bladder no urine will be voided, while it will be discharged much more frequertly than usual, and apparently in larger quantities in true inflammation of the bladder; and when at length, in inflammation of the neck of the bladder, urine is voided, it is after much straining, and is evidently and forcibly squeezed out from the over-distended but closed vessels. The most certain way, however, of distinguishing the one from the other, is to introduce the hand into the rectum; the distended bladder will then be plainly felt below. It may sometimes be detected by examination of the outside of the belly.

The course to be pursued is sufficiently plain - the bladder must be emptied, or more fluid will pour into it until it actually bursts. For some time before the fatal termination of the complaint in the rupture of the bladder, not only the constant straining, but the heaving of the flanks, the quickness of the pulse, the loss of appetite, the cessation of rumination, and the shivering fits, will sufficiently indicate the extent of the danger. The better way of emptying the bladder is, if possible, to relax the spasm of its neck. It is the spasmodic action of the sphincter muscle of the neck of the bladder that is the cause of the obstruction. A very large bleeding will sometimes accomplish this; but it must be a large one, and continued until the animal is exhausted almost to fainting.

To bleeding, physic should succeed, in order to lower the system, and relax the spasm; but no medicine must be given that would in the slightest degree increase the flow of urine. Sulphur, or aloes, or both combined, would be indicated here.

Should not the flow of urine be re-established, mechanical means must be resorted to. Here a skilful practitioner should be consulted. The water may be readily drawn from the cow by a catheter; but in the ox, from the curvature of the penis, this would be a very difficult affair. Some have recommended to cut down upon the penis, behind the bag, and lay open the urethra, ard so pass a catheter into the 
bladder; but this will produce a wound, difficult to heal from the passage and excoriation of the urine. Others would puncture the bladder through the rectum, and others through the belly; but both operations may be accompanied and followed by various unpleasant circumstances.

The catheter lately invented by Mr. Read, and which, by curiously accommodating itself to the curvature of the urethra in the horse, will readily enter the bladder and evacuate it without any painful or dangerous operation, is not applicable to the ox, at least in common hands; for there is a double curvature in his penis and urethra, through which no catheter, however flexible, will pass. A good veterinary anatomist, however, will overcome this difficulty; and to him, or to one well skilled in his profession, the proprietor of cattle. should have recourse in such a case.

The farmer, nevertheless, having fully ascertained the nature of the case, may often evacuate a great portion of the urine in a very simple way. The bladder of the ox lies more in the pelvis than does that of the horse-it is more easily fult than in the horse-it is more readily pressed upon by the hand-and the muscle at the neck of the bladder is much weaker: so that the hand being introduced into the anus, and gentle pressure made upon the bladder, a great quantity, or almost the whole, of the urine may be forced out, without danger.

A catheter may be introduced into the bladder of a cow without difficulty.

Inflammation of the bladder itself is a disease more frequent, and from the same causes, namely, cold and acrid herbs. Here the animal should be bled and physicked, and fomented across the loins, and every diuretic medicine carefully avoided. The following drink may be administered with good effect, after the bleeding and purging -

Drink for Inflammation of the Blndder. - Take, antimonial nowder, two drachms : powlered opiun, one scruple: rub thein well together with a small portion of very thick gruel, and repeat the dose morning and night.

It should not, however, be forgotten, that in cows that are near parturition this discharge of urine is not unfrequent, and arises from irritation of the bladder, caused by the pressure of the fotus, or from sympathy with the uterus, now much excited,-and not from actual inflammation. When she has calved, this will gradually cease; or a dose of salts, followed by one or two of the powders just recommended, will afford immediate and considerable relief. In some cows this incontinence of urine has been produced by the retention of a dead calf in the womb beyond the natural period, and it being at the same time in a state of putrefaction. The mingled influence of long-continued pressure, and of proximity to a large body in a state of decomposition, will occasionally produce a state of extreme irritability. The animal should have warm mashes once or twice daily.

Connected with this is a not unfrequent disease, and especially in the summer, and in cows in high condition, namely :- 
I N F L M MATION OF THE SHA PE.

The external parts are very much swollen, and pustules or boils appear about them, that break and discharge much matter; and there is also a considerable discharge of glairy fluid from the vayina.

This sometimes occurs after difficult calving, or from taking cold when the calving has been easy and natural : it has occasionally followed bulling, and it has been seen at other times, and arises from causes that could not be ascertained. Every action of the animal shows that she labours under extreme irritation, and suffers a great deal.

She should be bled and physicked. It will often be advisable to give a second dose of the physic, after an interval of three days. The shape should be well fomented several times in the day with warm water, until the swelling begins to diminish. A common goulardwash, consisting of one ounce of the extract of lead to a quart of water, with the addition of an ounce of spirit of wine, will then be serviceable.

An unpleasant gleet will often remain for a considerable time after the swelling has subsided and the ulcers have healed. An astringent injection will then be useful. The one that should be first tried is composed of six ounces of bruised oak bark, boiled in two quarts of water until it is reduced to three pints. If this should not succeed, a solution of alum, in the proportion of a quarter of an ounce to a quart of water, may be tried. A common injection syringe, of tolerably large size, will be the best instrument for throwing up the injection.

\section{CHAPTER XXIII.}

\section{STONE IN THE URINARY PASSAGES, OR BLADDER,}

There seems to be a greater disposition to the formation and retention of calculi, or stones, in the urinary passages of the $o x$, than of the horse. The manner in which cattle gather their food, the halfcutting, and half-tearing, by which the roots of a portion at least of the herbage are taken into the mouth and swallowed, and the propensity which almost all cattle have to swallow earth, in order to. prevent the acid fermentation of the food in the paunch-these things account for the more frequent collection of sand and gravel in the bladder of cattle than of horses.

This sand and gravel is the foundation of, or the preparation for, the future formation of stone in the bladder; and when the stone begins to form, it is far more likely to be detained, and to accumulate in size, in the bladder of the ox, than that of the horse, because the urethra is very much smaller and more curved in its course. 
Stone in the bladder may be suspected, when there is much fover, accompanied by a frequent turning of the head, and earnest gave on the flanks; when the hind limbs tremble, and there are ineffectual endeavours to pass urine, or it is evacuated in small quantities, and mingled with blood.

The suspicion may very easily be reduced to certainty, by examining the bladder with the hand introduced into the rectum, or last gut. The bladder of the ox, as has already been described, lying so much more in the pelvis than the bladder of the horse does, the stone cannot fail of being felt if there is one.

The presence of stone in the bladder having been thus proved, that farmer will pursue the most judicious course who sends the beast immediately to the butcher; for no medicine will dissolve it, and the animal will lose condition every day.

A skilful veterinarian is able, indeed, to remove the stone by the operation of lithotomy : but he must well understand the anatomy of cattle; and, after all, the operation would be attended with some danger and considerable expense.

The retention of a small calculus in some part of the urethra occurs much oftener than is generally suspected. The symptoms would be nearly the same as those of stone in the bladder, except that the stoppage of urine would be more complete. On examination, the stone will be easily felt, and generally in the double curvature of the penis. An incision may be made upon it, and it may be thus easily extracted. Two or three sutures, according to the size of the calculus, having been passed through the edges of the wound, it will usually heal in a few days.

\section{CHAPTER XXIV.}

\section{DISEASES OF THE RYB.}

Oxes are very apt to receive injuries about the eye, as wounds penetrating into the orbit of the eye, or even fractures of the orbit. The principal thing is to prevent or abate inflammation, by fomentations or poultices, and a little physic, and to leave nature pretty nearly to herself. Either from injury, or from a disposition in the bullock to throw out tumours of every kind, there are frequently bony enlargements about the eyes of oxen. It will be easily seen how far they are a nuisance to the animal, or impede the sight: and if it is necessary to remove them, the aid of a professed practitioner on cat tle should be obtained, as an important vessel may be divided, or a

Soft fungous tumours sometimes grow out of the orbit, or from the bone around. These can only be got rid of by the use of the knife, and that should bo placed in a skilful hand: but even in the most 
skilful hands, the knife often fails; or rather, there is a disposition to reproduction in these tumours, which it is impossible to repress.

The eyelids of the ox are very subject to disease. Sometimes there is a scaliness around the edges; sometimes a row of pustules resembling the stye of the human being: both of these diseases are frequently a great source of annoyance. They appear early in the spring of the year, and continue during the summer and the greater part of the autumn, and disappear as winter comes on. A solution of white vitriol, in the proportion of a drachm to a pint of water, will often be a useful application. If this fails, the nitrated ointment of quicksilver may be smeared over the lid, taking care that none of it gets into the eye. It will, however, be necessary at times to prepare for the use of these by washing the part with a goulard lotion for a few days.

Young oxen are subject to warts, which are frequently sadly teasing. They would probably disappear after a while, but, in the meantime, they are unsightly, and much annoy the animal by getting between or within the lids. They may either be clipped off with a pair of scissors, touching the root afterwards with the lunar caustic, that the wart may not be reproduced; or - the best way when practicable-they may be removed by tying a ligature of fine strong silk tightly round the pedicle, or root.

The eye itself is not unfrequently inflamed, and sometimes very acutely. The horse has a little shovel, concealed in the inner corner of the eye, which he is enabled to protrude whenever he pleases over the greater part of the eye, and by aid of the tears to wipe and wash away the dust and gravel which would otherwise lodge in the eye and give him much pain. When the haw is swelled in disease, the ignorant farrier too often cuts it away, not knowing that it is the mere effect of inflammation, and that a little cooling lotion would probably abate that inflammation, and lessen the swelling, and restore the part to its natural size and utility. The ox has something of the same contrivance, but it is not so moveable or so effectual; and, when he travels over a dusty road in the heat of summer, he sadly suffers from the small particles of dirt and the insects that are continually flying into his eye. This is unobserved by the careless driver, and inflammation is established, and the eye weeps, and becomes dim, and sometimes blindness follows.

This portion of the eye, or this third eyelid, seems to-be peculiarly subject to disease. Little swellings, and ulcers, and fungous grow ths, appear upon it; and a fungus, like that just described, springs up, and almost covers the eye. This is sometimes in a manner epidemic on various farms.

But from other causes, and of the nature of which we know little, inflammation of the eye is produced, and goes and comes as in the horse, time after time, the attack being gradually more severe, and the intervils between the attacks shorter, until, as in the horse, the inflammation extends to the internal part of the eye, and the lens becomes opaque, and cataract ensues, and the ox is incurably blind. 
All these must be dealt with as other inflammations are. In order to combat general inflammation of the eye, bleeding, physicking, and fomentations, are the principal weapons employed. The blood should be taken from the jugular, for that is supplied by veins coming from the inflamed parts. If the bleeding is ever local, the lid should be turned down, and the lining membrane lightly scarified. A few drops of blood thus obtained will often do a great deal of good. The fomentation having been continued for a day or two, one of the two following lotions should be used, a few drops of it being introduced into the eye two or three times every day :-

RECIPE (No. 43.)

Sedative Fye Lotion (1).-Take, dried leaves of foxglove, powdered, one and a half nunce: infuse them in a pint of Cape or dry raisin wine, for a fortnight, and keep the infusion for use.

There cannot be a better sedative in the early stage of inflammation of the eyes.

In many cases this alone will effect the temporary or perfect removal of the inflammation; but should not the eye improve, or should it appear to become insensible to the influence of the tincture, try the next prescription:-

\section{RECIPE ( No. 44).}

Sedative Eye Lotion (2) - Take, extract of goulard, two drachms; spirituous tinc. ture of digitalis (made in the same manner as the vinous in the last recipe), two drachıns; tincture of opium, two drachms ; water, a pint : this should also be intro. duced into the eye. Two or three drops at a time will suffice.

The inflammation being subdued by the one or the other of these applications, or even bidding defiance to them, and assuming a chronic form, a lotion of a different character must be had recourse to.

$$
\text { RECIPE. (No. 45). }
$$

Strengthening Lotion for the Eye.-Take, white vitriol, one scruple; spirit of wine, a drachm; water, a pint: mix them together, and use the lotion in the same manner as the others.

When the inflammation runs high, the transparent part of the eye is apt to ulcerate, and a fungous substance sprouts, and sometimes protrudes through the lids. This should be very lightly touched with a solution of nitrate of silver, or, if it is very prominent, it should be cut off, and the base of it touched with the caustic.

A seton in the dewlap will always be beneficial in inflammation of the eye, and it should either be made of the black hellebore root, or a cord well soaked in turpentine.

Of one circumstance the breeder of cattle should be aware-that blindness is an hereditary disease, and that the progeny of a bull that has any defeet of sight is very apt to become blind.

If the rase is neglected, inflammation of the eye will sometimes run on to crncer, and not only the eye, but the soft parts around it, and even the bones, will be affected.

When this termination threatens, the globe of the eye will usually turn to a bottlo-green colour, then ulceration will appear about the 
centre of it, and either the fungus of which I have spoken will sprout, and the eye will become of three or four times its natural size, or it will gradually diminish and sink into the orbit. The fluid discharged from it will be so acrid that it will excoriate the parts over which it runs, and the lids will become swollen and ulcerated.

The radical cure, and the most humane method to be adopted with regard to the animal, is to remove the eye. Here the assistance of a veterinary practitioner will be indispensable.

If the owner does not think proper to adopt this method, let him at least try to make the poor beast as comfortable as he can. The part should be kept clean, and when there appears to be any additional inflammation, or swelling, or pain, the eye should be well fomented with a decoction of poppy-heads. Let none of the stimulating ointments or washes of the farrier be used. This would he cruelly punishing the animal, when no good purpose could possibly be effected.

Sometimes the centre of the eye is not so much affected as the haw at the inner corner of it. When that part merely enlarges from the inflammation of the eye generally, the digitalis or the Goulard wash will usually abate the swelling; and he would be both ignorant and cruel who would remove it on account of simple enlargement accompanying inflammation; but when it becomes hard and schirrous, and especially if fungous granulations begin to spring from it, the case assumes a different character. No sedative or other lotion will lessen the schirrous or the fungous tumour. It must be removed by an operation;-it must be cut away. The method of accomplishing this by a skilful practitioner is not difficult. The beast must be thrown, and the head held firmly down by an assistant. The operator then passes a curved needle, armed with a double strong silk, through the body of the tumour, and, drawing a portion of the silk through it, gives the needle and the end of the silk to be held by another assistant. $\mathrm{He}$ pulls the silk gently, but firmly, until he draws the tumour as far as possible from the corner of the eye, so that the attachment of its base may be seen. 'The operator then with a knife dissects it out, or with a pair of scissors snips it off. No bleeding of any dangerous consequence will follow, and the blood that is lost will abate the inflammation, and ease the pain which the animal had previously endured. The removal by ligature is a slow and not always effectual method of proceeding; for it may not be possible to apply it accurately around the very base of the tumour, and then the enlargement will probably be reproduced. It is also necessary to tighten the ligature every day, or every second day, and at each time the contest with the heast must be renewed if this mode of removing the tumour is adopted. 


\section{CHAPTER XXV.}

\section{THE HOOVE, HOVEN, OR BLOWN.}

This disease is a distention of the rumen, or first stomach, by the gas which is extracted from certain substances undergoing the process of fermentation within it. The herbage is hastily gathered at first, and received into the rumen, in order to undergo there a process of maceration, by means of which it may be more perfectly ground down, and all its nutritive matter extracted when it is subjected to a second mastication.

The rumen has been described as divided into various compartments, and its coats containing a strong muscular structure. By the action of these muscles the food is made slowly to traverse these compartments in the order in which it was received; and the journey, in the ordinary state of health, occupies sufficient time for the herbage to be to a certain degree macerated or softened, but not for that process of fermentation to be set up to which all vegetables are liable.

Supposing an ox to be suddenly turned into new and luxuriant pasture, he sets to work, and gathers the herbage rapidly and greedily; so much so that the stomach is unable to propel forward the different portions of food as they are received, but becomes overloaded and clogged, and at length ceases altogether to act upon its contents. 'The food remains longer in the stomach than nature designed that it should, and it begins to ferment; and while fermenting throws out a quantity of gas, which distends the stomach almost or quite to bursting. Thence arises the danger of sudden change of pasture from an inferior to a better quality, and the numerous cases of distension of the stomach and death which occur when the fog-grass is plentiful and succulent, or the beast has without preparation or care been turned upon clover or turnips.

Some animals, however, are subject to hoove, but in a slighter degree, without this change of pasture. Many a weakly cow has occasional swellings of the paunch where there has been little or no change of food. The stomach, also, is subject to disease-it sympathises with disease of every other part; and one of the first and most frequent results of an unhealthy state of it is the production of an acid, which wonderfully accelerates and increases the process of fermentation and the development of gas. Hence it is that distension of the stomach is an accompaniment of almost every malady to which rattle are liable. No case of difficult parturition, or of dropping after calving, or of milk fever, occurs without some degree of distension of the paunch, either from the stomach being so weakened as to be unathe to force the food along, or from its secreting this unnatural and unhealthy acid, so favourable to the progress of fermentation.

The symptoms of hoove are sufficiently known. The beast seems $9 *$ 
to swell, and that to an enormous extent; the breathing is very laborious, and the animal is evidently in great distress, and threatened with immediate suffocation, from the pressure of the distended stomach against the diaphragm diminishing the cavity of the chest, and rendering it impossible for the lungs to expand. The difficulty of rreathing increases with the distension of the stomach and the pressure on the lungs, and the animal is inevitably lost if relief is not soon obtained.

This relief consists, and can alone consist, in relieving the stomach from the distension. But how is this to be accomplished? Medicine seems to be almost or quite thrown away. If a drink is given, not a drop of it will find its way into the paunch, the entrance to which is so firmly closed that it seems scarcely possible that even a ball should now break through the floor. A very stimulating drink, passing into the fourth stomach, and exciting it, may, by sympathy, induce the paunch to act: yet it is difficult to conceive how that viseus can possibly act while its fibres are put thus violently upon the stretch.

- Something might have been done by way of prevention. If, when the cattle had been turned into the fresh pasture, they had been carefully watched, and removed again to the straw-yard, before the paunch had been too much gorged, and this had been repeated two or three times, the appetite would have been blunted and hoove prevented.

Some farmers, an hour or two before they have turned such cows as are of a greedy disposition into a fresh pasture, give them a cordial drink. The stomach is stimulated by this, and induced to contract in time upon its contents; and this contraction has reminded the animal of the necessary process of rumination, or has rendered it almost impossible for him to continue to feed until some portion of the contents of the stomach has been returned and remasticated.

If the farmer will adopt such a plan, the following drink is as good as any that can be given:-

\section{RECIPE (No. 46).}

Cordial Drink.-Take, caraway and aniseeds, in powder, of each an ounce ; ginger, half an ounce: mix with a pitt of good ale, made hot.

I must confess, however, that, although I would not absolutely condemn such a practice, I would much rather trust to simpler and more effectual precautions. I would take care that the change of food should not be too sudden nor too great. If there was an eviden difference in the nutritive quality of the two pastures, I would be carefully on the witch, and remove the beast to shorter grass, before material mischief could be effected.

Suppose, however, that the mischief is done; the stomach is distended, and the animal is evidently threatened with immediate suffocation. Nothing but mechaniral means will now be of avail.

Some drive the animal about. This is sadly cruel work; for he soems to be scarcely able to more, and appears as if he would be 
suffocated every moment. This has, however, been sometimes successful, especially if the beast is made to trot; for, by the motion and the shaking of the stomach thus produced, the roof of the paunch has been forced a little open, and a portion of the air has escaped, and some of the food with it, and the stomach has been relieved from a part of its distension, and has been enabled to act upon the remaining food, and the process of rumination has recommenced. It is, however, dangerous work; for in the act of moving with the stomach so distended, either it or the diaphragm upon which it is pressing is in danger of being ruptured.

Some have resorted to an operation. Midway between the last rib and the haunch-bone, the distended paunch will be felt pressing against the flank. A lancet or a pocket-knife has been plunged into the animal at that spot, which has passed through the skin and the wall of the belly, and entered the paunch. The vapour has then rushed out with a hissing noise, and steamed up four or five feet high, and some of the contents of the bowels have been forced up with the gas, and the flanks have fallen, and the beast has evidently become less, and has been so much relieved that he has begun to ruminate, and has done well. The wound is left open for a while, that any newly-formed gas may escape: it then soon heals of itself, or would almost immediately if its edges were brought together by a slip of adhesive plaster.

It, however, too frequently happens, that, al though present relief has been obtained, and the beast has ruminated and eaten, it has in a few days begun to show symptoms of indisposition, and has become feverish, and drooped, and died. We account for this by some of the gas, and, perhaps, a portion of the food, getting into the belly, between the paunch and the flank, and falling down among the intestines, and causing irritation and inflammation there.

Some have adopted even rougher and more effectual methods of remedying the evil. They have not contented themselves with simply puncturing the paunch, but they have cut a hole into it through the flank large enough to introduce the hand; and so they have not only liberated the air, but have taken out the fermenting food by pailfuls. They have even gone so far as to pour in water, and fairly. wash the paunch out. They have then brought the edges of the wound together by passing a few stitches through it, and including the substance of the flank and the wall of the paunch in each stitch, and afterwards covered the wound with adhesive plaster, and it has readily healed, and no bad consequence has ensued. In desperate cases, as when the paunch seems to be filled with a mass of food that will continue to ferment, and cannot be got rid of either by rumination or by physic, this bold mode of treatment may be adopted. The paunch has few blood-vessels, and little sensibility, and will bear great injury without ariy fatal consequence. But this expedient has not always succeeded. Inflarmation has ensued, and carried the animal off. Besides this, the paunch, being suspended by these stitches, and afterwards hang- 
ing thus from the flank, is kept permanently out of its place, and is unable freely and fully to contract afterwards upon its contents : thus inflammation has ensued; and the subsequent want of condition in some of these animals, and the difficulty of fattening them thoroughly, Is easily accounted for.

Some farmers go a little more judiciously to work. They thrust a flexible stick, or a cart-whip, down the throat, and through the floor of the passage beneath, and the roof of the paunch, and thus enable some of the gas to escape; and this, perhaps, would be effectual, if the stick could be kept there long enough, and the stomach did not close around it.

An instrument, first devised by Dr. Monro, and now brought to perfection by Mr. Read, of the Regent's Circus, is superior to every other method of relieving blown or hoven cattle. A kind of gag is placed across the mouth; with a hole in the centre of it, and a leather at each end to buckle round the horns. Through this is passed a hollow tube of stout leather, called a probang, with a perforated knob at the end of it, and containing (to render it firm enough to be thrust down the throat, and flexible enough to accommodate itself to the Dending of the passage) a stylet, or slender piece of cane or whalebone, extending through the whole of -its length. The tube, thus strengthened by the stylet, is forced through the roof of the paunch into that stomach. The stylet is then withdrawn, and the air rushes violently out, and sometimes a considerable quantity of fluid with it. The tube may be kept in the gullet as long as the operator pleases, or returned as often as may be necessary; and if it be passed down with a little caution, and not too rapidly and violently, no injury can possibly ensue.

Thus the gas and some of the fluid are liberated; but the solid contents of the stomách, the undigested food, may remain, continuing to ferment, and so nauseating the animal that he is disgusted in the act of rumination. Mr. Read has a contrivance to remedy this.* $\mathrm{He}$

* [Read's Patent Veterinary Syringe consists of a syringe (Fig. 1) to which tubes of different sizes are affixed, according to the purpose and kind of animal to be ope. rated npon. There is a long flexible tube for giving an enema (clyster) to horses and cattle, $a$, and a smaller one for dogs, $b$. To relieve hoven cattle, however, it is not only necessary to relieve the stomach from an accumulation of gas, but from the fermenting pultaceous mixture which generates it: for this purpose a tube, $d$, is applied to the extremity of the syringe, and then passed into the animal's stomach through the mouth, as in Fig. 2, and being put into action, the offending matter is discharged by a side opening. When the same operation is performed on sheep, a smaller tube, $\varepsilon$, is used. The characteristic excellency of this apparatus is, that there is no limit to the quantity of fluid that may be ejected or extracted. The same syringe is used for extracting poison from the stomach of man, for smoking insects, for extinguishing fires, and syringing fruit trees.

Another drawing represents a very useful instrument, and for which there is frequent occasion; a hollow probang, for relieving cattle choked with turnips, potatoes, \&c. It is armed with a stilet, which being passed into the throat of an animal 
TH E IIOOVE.

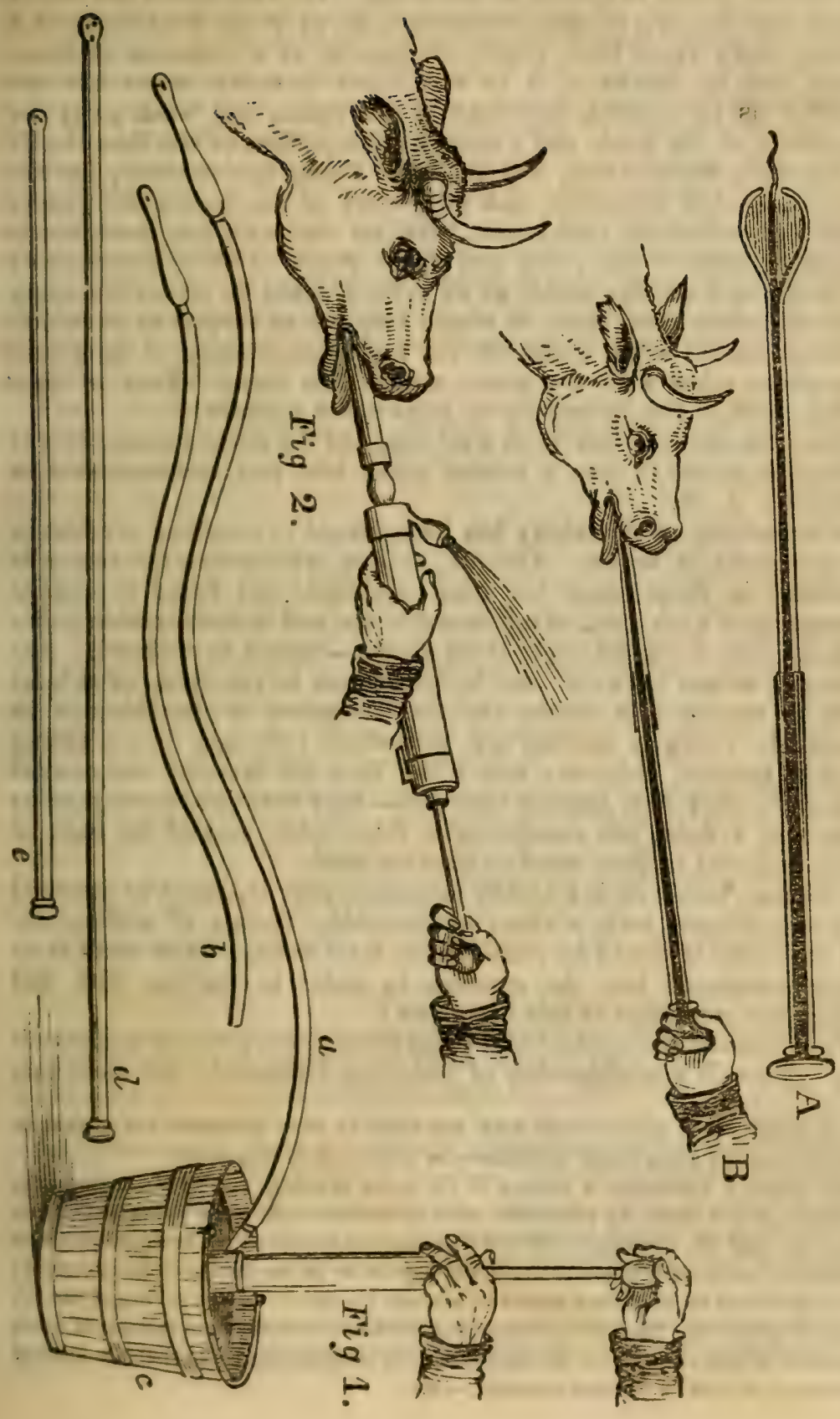


cannot, indeed, extract the food from the stomach by his tube, but he can do that which is almost as beneficial. He attaches to the tube a pump, that can in a moment be altered, so as to be used either as a forcing-pump like a little garden-engine, or as a common suckingpurnp, and by means of it he can inject as much water into the stomach as he pleases, and draw it out again, and wash away the impurities of the food, and a considerable portion of the food itself; or, by using warm water, and perfectly filling the stomach, he ean excite the act of vomiting, and so get rid of the nuisance at once. This is an admirable contrivance, and no one who has many cattle should be without the pump and tube. Some of these instruments are made on a smaller scale, so as to be adapted for sheep labouring under the same complaint, to which they are as subject as oxen are. Nothing can be better contrived for the administering of injections than these tubes with the pump attached to them. Two or three gallons of fluid can be thrown up in as many minutes.

After the stomach has been well emptied by these means, it will always be proper to give a cordial drink like that recommended in Recipe 31, p. 79.

A knowledge of chemistry has been turned to excellent account in the treatment of hoove. The air, or gas, with which the rumen is distended in these cases has been analysed, and found to consist principally of hydrogen, or inflammable air, and in combination either with sulphur or the principle of all plants-carbon or charcoal. Are there any means by which this hydrogen can be removed, or at least male to occupy less space, and the distension of the stomach be relieved? There is another gas for which hydrogen has a strong affinity, namely, chlorine; and when they are brought into contact with each other they rapidly combine - they hoth lose their gaseous form, and a fluid, not occupying a thousandth part of the bulk of either, is found in their stead - muriatic acid.

Chlorine, however, is a highly poisonous gas : it cannot be breathed in a very diluted state without a distressing feeling of suffocation, and undiluted it would be immediately fatal to life. How shall it be safely introduced into the stomach in order to combine with and change the properties of this hydrogen?

To a chemist the method of accomplishing this presents no difficulties. There is a combination of chlorine, fortunately for medicine,

that is choking by a piece of solid fond, too large to pass, perforates the snbstance, and allows of its being easily withdrawn or blown out in fragments.

The figure A represents a section of the stilet probang; the figure $\mathbf{B}$ shows the operation of the same, in extracting solid substances. By these inventions it has been truly said Mr. Read has conferred a permanent benefit on the breeder and feeder of domestic animals. These instruments should be in the hands of every farmer; their cost would be more than repaid by a single operation, by the saving of the life of one of his cattle. Their simplicity, ton, is such as to render them capable of being employed by any indivilual, the only necessary preliminary being that the head of the animul he held in a proper position. - S.] 
now well known and in extensive use - Chloride of Lime. 'The practitioner, then, after having, by means of Read's probang, got rid of the hydrogen already extricated, provides for the absorption or disappearance of any that may afterwards be formed, in the following manner:-he dissolves two drachms of the chloride of lime in the form of powder, in a quart or three pints of water, and injects this into the stomach by means of Read's pump. The chlorine has an affinity for lime-in virtue of that affinity it had combined with it and formed chloride of lime; but, having a much stronger affinity for hydrogen, it rapidly quits the lime and unites with the hydrogen, either then existing in the stomach, or as it may be afterwards extrieated during the process of fermentation, and forms muriatic acid; and by the wonderful diminution of bulk that follows this new combination of hydrogen, the distension of the stomach is at once, and, as it were, magically removed.

There are then left in the stomach muriatic acid and the lime which has lost its chlorine. These are highly caustic substances, and might threaten to be detrimental, but their continued presence in the stomach is beautifully provided against, for between the muriatic acid and the lime there is also a strong affinity; and these substances hasten to unite; and the result is a harmless neutral salt, muriate of lime.

The practitioner on cattle will highly prize this remedy for hoove, and will see other ways in which it may be usefully employed.

It is proper to observe that there are several other medicaments which have been found of great service in this disease, such as limewater, potash, hartshorn, and particularly sulphuric ether. About an ounce and a half of hartshorn may be given in a pint and a half of water, unless the symptoms are so urgent as to threaten immediate suffocation: then the flexible tube, if at hand, should be used; or, if not, the trochar, or the knife, plunged into the flank. If the symptoms should denote any inflammation, ether will be preferable as a inedieine, as it promptly condenses the gases: an ounce may be given in a pint of water. If the symptoms are produced by green food there is less probability of inflammation than if the food has been previously dry.

It is very important to distinguish between distension of the paunch produced by meteriozation, or the production of gas, and that occasioned wholly or in part by the large mass of food itself. The nature or the diet will in some measure assist our judgment. If it has consisted of roots, such as potatoes, the obstruction will probahly be me anical; and then, though the symptoms may not be so painful or sudden, the danger is yet greater. There is generally some inflammation of the digestive organs, and the pulse is usually small and frehle. On pressing the abdomen at the flank, we find that the stomach feels hard and firm, although even in this case it contains some gas.

It will be proper to arlminister ether or chloride of lime, to condense the gases, as before advised: then, if no relief can be obtained 
by this or the administration of purgatives, it will be proper to employ the trochar, and thus give exit to the gas, and ascertain positively the nature of the contents of the rumen. If they are found to be solid and in considerable quantity, it will be proper to make an opening in the flark five inches long, so as to insert the hand, and empty the stomach mechanically, taking especial care not to let any of the food escape from the wound in the rumen into the abdomen. The wound must afterwards be stitched up, and some blood may be taken and an oily laxative administered, and the food for some days given very sparingly. The operation is, of course, attended with much danger, and should therefore be employed in desperate cases only; but it has been performed with perfect success.

Cattle that have been once blown are subject to a repetition of the accident. The chloride of lime should be administered whenever they are turned into fresh and tempting pasture: they should be more carefully watched than others, and a cordial drink, mingled with a portion of physic, given them as soon as they appear to be in the slightest degree blown.

[A gentleman of Easton, Pennsylvania, once assured us that he had often seen a tarred rope tied in the mouth of cattle or sheep far this affection, and "never knew it fail." To prevent hoven, Lewis Saunders, an eminent cattle breeder of Kentucky. recommends - to "mix thoroughly one bushel of wood ashes, sifted to each bushel of common silt; this mixture to be used as salt for stock on a farm. At all times stoek ought to be sufficiently salted; but at the periods most likely to be attacked with hoove (early in spring or at the time of first frosts in autumn) increase the supply of salt and ashes. The alkali, says Mr. Saunders, destroys, from the ashes, the acidity of the stomach-preventing the accumulation of gas. 1 have thus used ashes with salt, for stock, for upwards of twenty years, and in all that time have lost but one animal by hoove, and that was supposed to have occurred in conse. quence of having omitted the ashes, in one or two saltings. I prefer salting on the ground, a double handful in a place twenty-five or thirty feet apart. I use the mixture for horse and hog stock, as well as for cattle and sheep."-Grass Hills, Kon. tucky, 1839. - S.]

\section{CHAPTER XXVI.}

\section{HOK I N G.}

Cattre are extremely liable to become choked when feeding on turnips or other roots, and many are in consequence destroyed. A round object, such as a potato, is more likely to occasion suffocation than a more irregular body, as it produces greater pressure on the windpipe, and is embraced more closely by the osophagus. 'The appearances attending choking can scarcely be mistaken. The animal evinces great distress, tries to bring up the obstructing body, slavers at the mouth, pokes its nose, and draws up the neck. After awhile 
the abdomen swells from the inflation of the paunch with gas. Sometimes the beast will die in a very short time, but the urgency of the case depends much on the situation and the size of the obstructing body.

If the rumen is so distended as to threaten immediate suffocation, it will be proper to puncture it ; but this, if possible, should be avoided. It will next be desirable to ascertain the situation of the obstruction. Sometimes it will be found that the body is impacted at the back of the inouth or beginning of the cosophagus : in these cases by using a balling-iron the object can frequently be removed by passing up the hand.

If, however, the substance is situated low down the tube, it will be desirable to force it onwards. For this purpose half a pint of oil should be given to lubricate the passage as much as possible, and then the beast, being properly secured, and a gag placed in the mouth, a flexible tube or rod, with a knob at the end, should be carefully passed down the esophagus until it reaches the body: a steady pressure should now be employed to force it onwards; but this should be done patiently, so as not to injure the parts. By alternately resting and trying again, the object will generally be removed.

If the object is situated near the mouth, but not sufficiently so as to be reached by the hand, it can best be removed by means of an instrument invented by Mr. Simonds, and which is constructed so as to embrace the obstructing body by a forceps, concealed in the bulb at the end of the tube, and thus to remove it upwards by the mouth.

After forcing the object into the stomach it will be desirable to let the probang remain a short time, if the animal is hoven, to afford an exit for the gas: and this may be assisted by pressing the flanks.

No solid food shonld be allowed for several days afterwards, as there is great danger of a repetition of the choking until the muscles entirely recover their tone. Sometimés, after all attempts of removing the body by the methods before described have failed, it will be proper to do so by means of an operation which has been performed with success; and this consists in making an incision through the skin into the œsophagus, sufficiently large to extract the body. Great care must be exercised so as not to injure the important nerves and bloodvessels situated near the part. The beast should be cast for the operation, and the wound carefully sewed up afterwards, and for several days the food should consist principally of gruel.

[A gentleman who has been much in Spain says that it is a common practice there, wien cattle get choked with apples, or other such substances, for two or three men to seize them and lay their neck over a log of wond, and then the operator fecling for the obstruction, strikes a smart blow immediately over it, with a mallet or billet of wood, sufficient to crush the apple to pieces, which instantly begins to be blown out, and the animal is relieved. The expedient appears to be practicuble, where the obstruction can be felt externally and come at in this way. The probang mentioned in this chapter has been exhibited by an appropriate drawing, page 104, In the belief that it is not of such familiar use, or so generally known among us, av in England. - 8.] 


\section{CHAPTER XXVII.}

\section{LOCKED JA W.}

Fortunately this is not a very frequent disease among cattle; but it is a very fatal one when it does occur. If the attendant is careful, he will observe the symptoms of this malady one or two days before it is thoroughly and incurably established. There will be a stiffness of gait in the beast-he will walk unusually wide behind-there will be difficulty of turning-permanent cocking of the tail, except when that is interrupted, or accompanied by a singular tremulous motion of it. The animal can scarcely, and, after a while, not at all, bend his neck to graze; but he will stand with his head protruding, and his ears stiffened, and unnaturally fixed in a somewhat backward direction. Rumination gradually ceases, or is performed slowly and painfully. At length the jaws become firmly closed, and the neck perfectly stiff. The eyes are strangely fixed, and with some degree of squinting, and the expression of the countenance is peculiarly anxious. The breathing is considerably affected, and there is much labour of the flanks.

The animal will linger on in this dreadful way for eight, or nine, or ten days, almost every muscle of the body being painfully cramped, and the poor creature unable to take a morsel of food, until at length it dies, exhausted by the violent contraction of the muscles and by starvation.

The usual cause of locked jaw is some neglected or unobserved wound, particularly in the feet. Working oxen, therefore, are most subject to it. Several weeks sometimes pass between the infliction of the wound and the appearance of this disease. Working oxen that have been exposed to cold and wet, after being heated in drawing, frequently have locked jaw. It has been said that locked jaw is occasionally produced by eating some poisonous plant, particularly the colchicum, the water-hemlock, or the yew. I much doubt the accuracy of this; and in many, and probably the majority of, instances the cause is altogether unknown.

The treatment is indicated by the nature of the disease. It is a most violent action of the nerves of motion, either of a part or the whole of the frame. The most likely means to quiet this is the loss of blood, and that in a large quantity. Therefore, the ox should be bled as soon as the complaint is discovered, and bled until his pulse falters, and he staggers, and threatens to fall. 'The bleeding will usually relax the muscles of the jaw to a certain degree, and for a little while; and advantage must be taken of this to give a strong physic drink. 


\section{RECIPE (No. 47).}

Strong Physic Drink for Locked Jaw.-Take Barbadoes alnes, one ounce and a half; the k.ruel of the croton uut, powdered, ten grains. Dissolve them in as mall a quantity as possible of boiling water, and give them when the liquid is sufficiently cool.

Generally the jaw will be now sufficiently relaxed to permit the introduction of the thin neck of a claret bottle into the mouth. The best method, however, of giving medicine in this case is by the assistance of Read's patent pump, the pipe of which, let the jaws be fixed as firmly as they may, can generally be introduced, close to and immediately before the grinders.

The bowels having been opened, those medicines must be resorted to which have the readiest and most powerful effect in quieting the nervous system. These are, as it regards cattle, opium and camphur.

\section{RECIPE (No. 48).}

Anodyne Drink for Locked Jax.-Take camploor, one drachm, rub jt down in an ounce of spirits of wine; to this ald powdered opium, oue dracho, and give the aixture in a small quantity of thick gruel.

This medicine should be administered three or four times every day; care being taken that the bowels are liept open, either by means of aloes or Epsom salts.

The bleeding should be repeated on the second day, if the animal is not evidently relieved; and as much blood should be agrain taken as the patient can bear to lose.

The stable or cow-house should be warm, and the animal covered with two or three thick rugs. If considerable perspiration can be excited, the beast is almost sure to experience some relief.

While all this is done to lower the action of the nervous system, the strength of the beast must be supported. He will not, or rather he cannot eat; but he often looks very wistfully at his food. Let a good mash, a little at a time, and moister than usual, be placed before him, a portion of which he will try hard to suck up. If he manages this tolerably well he needs not to be forced with gruel or any other nutriment; but if his jaws are too firmly fixed for this, the small end of the pipe of Read's pump should be introduced into the mouth, and as much thick gruel pumped down as the attendant pleases. When the poor animal has been hungry for two or three days through utter impossibility of eating, he will gladly enough submit to this operation. and almost offer himself for it.

It will be almost labonr in vain to endeavour to stimulate the skin, or to raise a blister. Two, three, or four setons in the dewlap have been useful; and benefit has been derived from shaving the back alnng the whole course of the skin, and cautrising it severely with the common firing-iron. If it should be found impracticable to administer either food or medicine by the mouth, they must be given in the furn of clysters. Double the usual quantity of the medicine must be given, on account of the probable loss of a portion of it, and the small quantity that the absorbents of the intestines may take up; out 
too much gruel must not be injected, otherwise it will probably be returned. A quart will generally be as much as will be retained, and the clyster may be repeated five or six times in the course of the day.

Should the progress of the disease have been rapid, and the symptoms violent; or should it be found to be impossible to give medicine by the mouth, or cause them to act by injection, the most prudent thing will be to have recourse to the butcher. The meat will not be in the slightest degree injured. for it is a disease that is rarely accompanied by any great degree of fever.

\section{CHAP'TER XXVIII.}

\section{POISONS.}

IN the early part of the spring, and before the different vegetables have attained their proper growth and smell, cattle are liable to be injured, and even destroyed, by eating poisonous plants; and especially when they are turned into fresh pasture. In some countries and in some seasons, when particular plants have prevailed, a great many cattle have been lost, and it has appeared as if some epidemic disease was raging, until a botanist, accidentally coming into that part of the country, has discovered the true cause of the malady. It is a great pity that farmers and graziers are not sufficiently acquainted with botany to know the different plants, wholesome and poisonous, that are growing in their fields. It is a pleasing study, and would be an exceedingly useful one to them.

The plants that are the most dangerous are the different species of hemlock, and particularly the water-hemlock, the fox-glove, the dropwort, and some of the species of crows-foot. These plants are not useful for any purpose, and it is to be lamented that the farmer is not able to recognize them, and root them all up. Young calves and lambs, until they have added some experience to the guidance of instinct, are occasionally lost in very great numbers.

The yew is a deadly poison, and many cattle have been destroyed by it; but they seldom browse upon it when green. The mischief, in the great majority of cases, is done by the half-dried clippings of some formal hedge-row or fantastic tree. In this state cattle are very apt to eat great quantities of the leaves or shoots.

Some have thought that cattle are poisoned by drinking from stagnant pools, full of venomous insects and of every kind of decomposition from animal and vegetable substances. I doubt the truth of this; ior the cow seems to be naturally one of the foulest drinkers among our domesticated quadrupeds. She will often choose the most filthy nuddle in the straw-yard in preference to the clearest running stream 
Nature would not have given her this propensity to foul and putrid drink if it was prejudicial to her.

The symptoms of empoisonment vary with the plant that has been Jevoured. In general the animal moans sadly, as if in dreadful pain; or a sudden stupidity comes upon it - or violent convulsions. After eating the yew-clippings, eattle are often perfectly delirious; and in almost every case the belly more rapidly swells than it usually does in hoove.

It is plain that there can be no case in which more speedy and decisive measures are needed; and yet very little can be done, except that useful instrument, far too little known, Read's patent pump, is at hand. The pipe should be introduced into the paunch, so that the extricated gas which causes the swelling may escape. After this a quantity of warm water should be thrown into the stomach, sufficient to cause sickness, and thus get rid of a part, at least, of the offending matter. Then, by introducing the pipe only a part of the way down the gullet, a physic-drink may he gradually introduced, which will thus pass on to the fourth stomach, and cause speedy purging. The aloes and croton (No.47, p. 111), will be the most effectual purgatives. It will usually be advisable to bleed moderately: drinks of vinegar and water, not exceeding half a pint of vinegar at a time, should be administered if it is suspected that the poison is of a narcotic kind, and the purging should be kept up by repeated small doses of the aperient medicine. When the poison seems to be nearly or quite evacuated, a cordial drink will be beneficial in giving tone to the stomach, and the Recipe 31 ( $p .79$ ) will be as good as can be given.

Cattle are exposed too much to the influence of poisons of another kind, used under the form of medicines. Corrosive sublimate and tobacco-water have destroyed many a valuable ox. An antidote is in these cases usually quite out of the question, for the constitution is fatally affected, before the owner knows anything of the matter.

Cattle in the neighbourhond of lead-mines have been dangerously affected from the effects of this ore in the grass. Difficult respiration with lond wheezing is one of the most prominent symptoms, the beast losing its appetite, pining away, and at length dying of suffocation or attacked by epileptic symptoms. Large doses of Epsom or Glauber's salts with linseed oil, and followed by opium, are the best remedies. 'The smoke from copper-mines has also produced sad disease amongst animals in the neighbourhood: it causes swellings of the joints of a painful description. An early removal to another soil forms the best treatment.

Ranking under the general term of poisons, we may mention the bites of venomous reptiles. Our country fortunately knows but one that is dangerous, and that is the viper, or adder; and it is very rarely that cattle suffer from its sting. The beast is generally stung about the head or feet, for it is most likely to disturb these reptiles either in the act of browsing, or as it wanders over the pasture. Cattle bitten $10 *$ 
in the tongue almost invariahly die. They are suffocated by the rapid swelling which takes place. 'The udder has occasionally been stung; but the supposed bites on the teats are, far oftener than otherwise, the effect of garget.

The country remedy is not a bad one, viz., to rub the part well with a bruised onion. Some follow this up by cramming another onion down the throat. A better application is the following :-

RECIPE (No. 49).

Embrocation for Bite of Viper.-Take hartshorn, and olive oil, equal quantities. Shake them well together, and rub the wound and the neighbouring parts well with the liniment morning and night.

A quart of olive oil should also be given to the animal, mixed with an ounce of hartshorn. Oil of turpentine may be used when hartshorn cannot be procured; but it is not so much to be depended upon.

The stings of hornets, wasps, and bees, in some cases produce much temporary swelling and pain. If the part is well rubbed with warm vinegar, the inconvenience will soon subside.

Leech-bites may be mentioned here. While the animal is drinking from some stagnant pool, a leech will occasionally fasten itself on the muzzle, and afterwards creep up the nostril, and produce a very considerable, and, in some cases, dangerous, bleeding by its bites. If the leech can be seen, or it is in a manner certain that it has insinuated itself into the nostril, a little strong salt and water should be injected up the nose, which will immediately dislodge the intruder, if it can be brought into contact with it.

\section{CHAPTER XXIX.}

W O U D S

From the horns of their companions, and from the brutal violence of those who look after them, cattle are often exposed to wounds. The treatment of them is generally simple enough, except in a joint, or the neighbourhood of one.

'The first thing is to clean the wound from all dirt and gravel, which would cause irritation, and prevent the healing of the part. A gond fomentation with warm water will effect this, and at the same time will help to abate any inflammation which may probably have arisen.

Next is to be considered the state of the wound. Is it a lacerated or punctured one? If it is a lacerated wound, we must try how neatly we can bring the divided parts together. If there are any portions so torn as to prevent us from doing this completely, they should be removed with a knife or a sharp pair of scissors. Then, when the edges are brought well together, they should be retained by passing a needle and strong waxed twine deeply through them, making two. or three, 
or more stitches at the distance of half an inch from each other. A surgeon's crooked needle, or a glover's large triangularly pointed needle, will be necessary for this purpose. A little dry soft clean tow should then be placed over the wound, and the whole covered by a bandage closely, but not too tightly applied. Let none of the farrier's abominable tents, or pledgets of tow, be introduced: the intervals between the stitches will be quite sufficient to permit the escape of any matter that may be formed. The wound should not, if possible, be opened for two days after the first dressing.

When it is at length examined, let none of the hot torturing applications of the farrier be used. If it looks tolerably healthy, and is going on well, it may be dressed with tincture of myrrh and aloes, or with the Healing Ointment, (No. 10, p. 53), or with both; a pledget of tow soaked in the tincture being put immediately upon the wound, and more tow, with the ointment spread upon it, placed over this.

If proud flesh should begin to spring, the wound should be first washed with a strong solution of blue vitriol, and then dressed with the tincture; or if the discharge is very offensive, the wound should be well bathed with the Disinfectant Lotion, (No. 34, p. 85), and then the tincture applied. It is high time for all the disgraceful torturing applications of the farrier and cowleech to be discarded, especially as Nature is much kinder to these animals than she is to us; and wounds that would in the human being puzzle the surgeon, heal readily in cattle, almost without any application.

- If it is a punctured wound, its direction and depth must be carefully ascertained. Fomentations of marsh-mallows, or poppy-heads boiled in water, should be applied for a few days, in order to abate inflammation, and the tincture of aloes and myrrh should be injected into the wound morning and night; the injured parts being covered if the flies are troublesome, but otherwise left open. If the wound runs downwards and the matter cannot escape, but collects at the bottom, and seems to be spreading, a seton should be passed into the original orifice, and directed as far as the very lowest part of the sinus, or pipe, and there brought out. There is never occasion for the introduction of lint into these wounds: if they are well syringed with the tincture to the very bottom, and a seton passed through the sinus, should one happen to be formed, they will do very well.

From the yoke being too heavy, or not fitting the neck, the shoulders of oxen will sometimes get sadly wrung, and deep ulcers will be produced, resembling fistulous withers in the horse. These ulcers are very troublesome to deal with. 'The secret, however, of properly treating them, is to pass a seton through the very bottom of the ulcer, in order that the matter may flow freely out: then. in the majority of cases, the wound will readily heal, or if it should nut, the diabolical scalding mixtures of the farrier are never wanted. Ii I allowed any scalding mixture it would be boiling tar, because tar buils at a very low degree of temperature. The surface of the wound would be sufficiently stimulated, and the life of the part would not be destroyed; 
but he who pours in his boiling oil, or his corrosive sublimate, deserves never more to possess, or to be permitted medically to treat, a beast. In obstinate cases diluted nitric acid (one part of nitric acid, and two of water) may be applied over the surface of the ulcer, with a pencil or sponge.

When a tumour is forming on the shoulder from the pressure of the collar, every attempt should be made to disperse it. A saturated solution of common salt will often be useful, or sal anmoniac dissolved in eight times its weight of water; but the best discutient application is the following :-

\section{RECIPE (No. 50.)}

Discutient Lotion.-Take, bay salt, four ounces ; vinegar, one pint ; water, a quart ; oil of origanum, a drachm. Add the oil to the salt first, rub them well down with a little water, then gradually add the rest of the water and the vinegar.

The part should not only be wetted with this embrocation, but gently, yet well rubbed with it.

Should the swelling still increase, and, on feeling it, matter should evidently be formed, the sooner the tumour is opened the better, and the best way to open it is to pass a seton from the top through the lowest part of it.

Oxen are very apt to be wounded in the feet. If this is soon discovered, all that will be necessary is to apply a pledget of tow wetted with tincture of aloes, confining it between the claws with a bandage, or to touch the part lightly with the butyr of antimony. When the application of the caustic is necessary, there is no need to apply it with the severity used by some, so as to corrode the parts to the very bone.

If the wound is extensive, and accompanied by much swelling, heat, and pain, and especially if the beast should begin to lose its appetite, and to heave at the flanks, it will be prudent both to physic and to bleed.

If much contusion or bruise attends the wound, and which is very likely to happen when cattle are gadding about and breaking out of their pastures in summer, and especially when strange beasts are intermixed, the previous fomentation will be more than usually necessary, in order to prevent inflammation, and to disperse or favour the escape of the effused blood. The fomentations should be continued during half an hour at each time, and repeated three or four times in the day. The flannels should be applied dripping wet, and as hot as the hand can bear them.

If the wound penetrates the cavity of the chest, as it sometimes will when one beast gores another, it will be necessary to bring the parts more accurately together, and to confine them by closer stitches; a piece of adhesive plaister should then be placed over the wound, and secured by the application of proper rollers or bandages. If the air is suffered to pass in and out of the wound for any considerable time, the edges of it will be indisposed to unite together and to heal, 
and the pleura or lining of the chest will probably become inflamed by the unnatural presence of air in the cavity of the chest.

Should the belly be wounded, and a portion of the bowels protrude, it will be necessary to calculate the probability of being able to return them into their proper situation, and healing the wound : for in many of these cases the best thing the farmer can do is to send the animal at once to the butcher. If a cure is attempted, all dirt and clotted blood should be carefully removed from the protruded intestine with a sponge and warm water. It must then be cautiously returned into the belly, and the edges of the wound brought together and secured by very close stitches. After that, rollers or bandages must be passed round the belly, and which, being removed only while the wound is dressed, must remain until a cure is completed, and for a few days afterwards.

In all these cases a veterinary surgeon should be consulted. He alcne is able to give an accurate opinion as to the probability of a cure, and to guard against a thousand accidents and annoyances that are likely to occur in the treatment of such a case.

Many persons are frightened when they see the profuse bleeding , which sometimes takes place from deep or lacurated wounds. Except some large arterial trunk is divided, there is little or no danger of the animal bleeding to death. When a certain quantity of blood is lost the stream will flow slowly, and a coagulum, or clot of blood. will be formed in the vessel, and plug it up, and afford a mechanica. obstruction to the hæmorrhage. Sufficient blood, however, mav be lost, to interfere very materially with the condition of the beast, and to leave considerable and lasting weakness behind. We are therefore anxious to stop the bleeding as soon as we can.

Where the situation will admit of it, a dossil of lint, placed upon or in the wound, and secured by a firm bandage, will often be effectual. If the vessel is but partly closed by the pressure of the lint, yet that may be sufficient to produce a coagulation of the blood, and the consequent stoppage of the stream.

The next preferable way of proceeding is to endeavour to pass a ligature round the bleeding vessel. This is often practicable by means of a tenaculum or any hooked instrument, by which it may be drawn a little from its situation, and some waxed silk or twine passed ronnd it. Sometimes it may be laid hold of with a pair of forceps or small pincers, and so serured; or, should neither of these methods be practicable, a crooked or glover's needle, armed with waxed silk, may be plunged into the flesh or cellular membrane in two or three places armund the wound, and when the silk is tightened the vein or artery w. ill probably be compressed and closed. The hot iron is sometimes applied, but usually a great deal too hot, so as to destroy the life of the part, instend of simply searing it. and thus causing renewed hamorrhage when the dead part is thrown off. As for styptic powders or lotions, they appear to thave little or no effect in stopring profuse bleeding in cattle. 
The bleeding is gencrally arrested with most difficulty when the horn is broken of in some of the fights among the cattle. The bone of the horn is full of blood-vessels, and it is only by plaister after plaister of tar that a compress is made all round the horn, and through which the blood cannot penetrate. These plaisters should not be removed for many days, otherwise the bleeding from such a vascular part will return.

Of all the wounds. however, to which cattle are occasionally exposed, the most dangerous are those about the joints, and especially when the joint itself is penetrated. The ox is not so subject to this as the horse; but the fetlock and the knee are occasionally deeply wounded, and the joint laid open, either by falling, or by being brutally wounded by a fork.

Here, as in all other wounds, the first thing to be done is carefully to wash away all dirt and gravel. 'The probe must then be irtroduced; and the depth to which it will penetrate, and, more particularly, the grating sound which will be heard when it comes into contact with the bone, will generally determine whether the joint has been injured. If any doubt remains about this, a poultice should be applied. This will not only abate or prevent inflammation, but if the joint has been penetrated, the synovia, or joint oil, will escape, and appear upon the poultice in the form of a glairy, yellowish fluid. Then there is no doubt as to the course to be pursued. The flow of this must be stopped, and that immediately. It was placed there to be interposed between the ends of the bones, and thus to prevent them rubbing against each other, and becoming irritated or inflamed. The membrane with which the heads of the hones are covered is 'in the highest degree sensitive, and with the slightest injury produces inflammation, attended by the extremest torture. There is no agony equal to that caused by an opened joint. We must then confine the interposed joint oil, and prevent this dreadful friction between the membranes.

'There are two ways of accomplishing this. That which seems to be the most humane is to place a small compress on the part, exactly covering the wound; to bind it down tight, and not to remove it for many days. Yet it has often happened that when the compress has at length been taken off, the joint oil has flowed as quickly as before: therefore, I believe, we must go back to the old method, and apply the hot iron to the wound. The iron, being of a dull red heat, should be run lightly across the surface of the wound in various directions, the consequence of which will be that so much inflammation and swelling will usually be produced, as fairly to block up the orifice with that which soon becornes organized, or converted into the same substance as that in contact with which it is placed, and thus the opening into the joint is securely and for ever stopped; or, should the joint oil in a very few cases afterwards flow a little again, a re-application of the iron will put an end to the business : the sore may then be treated as a common wound.

In many cases a lotion composed of corrosive sublimate dissolved 
in spirits of wine, applied several times a day to the surface of the wound, only until the joint oil disappears, will answer the purpose better than the hot iron. In very severe cases, where the carease of the animal is of trifling value, and it is therefore desirable to attempt a cure at all risks, the application of a paste made with flour, and firmly bound round the part by a number of linen bandages, will, by preventing the flow of joint oil, succeed in closing the joint in many cases: the bandages, however, should not be removed for several weeks, and if necessary the animal may be slung.

Should, however, the wound be very large, and the opening into the joint large too, it will usually be prudent to destroy the animal at once, especially if it is in tolerable condition. A dead horse is worth comparatively little, but a dead ox, fairly slaughtered, will produce its full value. Therefore, the possibility of a cure not being effected, or of the animal materially losing condition while the cure is attempted to be performed, should always be taken into account; and in cases $w$ here the meat is not injured it should be inquired whether the expense and trouble, and the sufferings of the animal, should not be at once terminated by the buteher.

These are the only means that should be used. When the farrier or the cow-leach wants to inject his corrosive sublimate, or his oil of vitriol, let no consideration tempt the farmer to comply. It is cruel work, and it does not succeed in one case out of ten.

These cautions are repeated again and again, for it begins now to be generally felt and acknowledged, that we have no right to torture and abuse our quadruped servants.

In every joint case it will be prudent to bleed, and administer a dose of physic, and use all proper means to prevent or abate fever.

\section{CHAPTER XXX.}

\section{STRAINS AND BRUISES.}

THE ox is not so subject as the horse to strains, for his work is slower and usually less laborious. The horse is seldom strained at slow and steady work, and that only is generally exacted from the ox. The principal cause of strain in these animals arises from their contests with, or their riding or ramping each other.

In recent strains, attended with lameness and heat, the following is one of the best embrocations that can be used :-

RECIPE (No. 51).

Enobrocution for Strains.-Take bay salt, four ounces; oil of origanum, one drachm : rub them well trgether, until the salt is reduced to a powder, then add vinegar, half a pint; spirits of wine, two ounces; water, a quart. 
Bathe the part frequently with this embrocation. There cannot be a better application for strains or bruises in the horse or cattle, or even in the human being, when the skin is not broken. When the heat and tenderness have somewhat subsided, and only weakness of the part remains, the Rheumatic Embrocation (Recipe No. 9, p. 52) will be serviceable.

Frequent fomentations with warm water should precede the use of these embrocations. In bad cases it may be prudent to give a dose of physic, or even to bleed.

For very deeply-seated strains a more powerful application may be necessary. Then use the following:-

\section{RECIPE (No. 52).}

Strongest Embrocation for Strains.-Take spirit of turpentine, half a pint; oil of origanum, half an ounce; olive oil, a pint and a half; cantharides, one ounce. Mix them together, shake them often, and keep them in a bottle for use.

This shonld be well rubbed in morning and night. It is not intended absolutely to blister the animal; and should the embrocation cause much redness or tenderness, it may be lowered with an equal quantity of olive oil.

After all, a considerable degree of weakness and lameness will occasionally remain, and especially about the hips and loins. A strengthening plaster will be very useful here. It is best applied in the form of a charge.

\section{RECIPE (No. 53).}

Charge for old Strains or Lameness.-Take Burgundy pitch, four ounces; common pitch, four cunces; yellow wax, two ounces; Barbadoes tar, six ounces. Melt thein together in a ladle, and apply the mixture to the parts when thoroughly warm and liquid.

A little short tow is then placed over this, before it gets cool, and which, adhering to it, forms a thick coat over it. The charge acts as a support to the part, and as a permanent bandage. It can never do harm; and many an old strain, or lameness, or rheumatic affection, has been effectually removed by it. It should remain on the part two or three months, in order to ensure its full success; and after the application of the charge, the beast should be turned out.

Although not exposed so much as the horse to strains generally, yet there is one joint - the fetlock - in the ox, which often suffers. The division of the lower part of the leg into two bones materially weakens this joint: therefore it is not unusual to see enlarged fetlocks, and a considerable accumulation of bone about them. The mild and the strong embrocation must in turns be diligently applied, and these failing of success, recourse must be speedily had to the blister, or the firing iron; but, if these should not be successful, and the lameness is so considerable as to injure the condition of the animal, relief can be obtained by dividing the nerve which supplies the foot above the fetlock, thereby removing pain and lameness by destroying sensation. 
Fractures of the leg sometimes occur; they have been successfully treated by bandaging the parts, and keeping the animal quiet.

The leg too has even been ampulated with success, a wooden leg being afterwards substituted.

\section{CHAPTER XXXI.}

\section{CANCEROUS ULCERS.}

There seems to be a natural disposition in cattle to the formation of tumours on various parts of the body. They are mostly found in the neighbourhood of joints, and generally either hanging loose, or slightly adhering to the parts beneath. They sometimes grow to an excessive size. In some cases they are evidently constitutional, for many of them appear on different parts. They do not seem to give much pain to the animal, and occasionally they continue month after month without being of any serious inconvenience: they then suddenly break, and a malignant ulcer ensues, which speedily degenerates into a cancerous one.

The tumours are sometimes smaller, and fixed to the parts beneath by a broad base, and which are chiefly found about the face, on the cheeks, or under the eyelids, or in the channel between the jaws. These are more likely to break than the others, and when they break are far less manageable. The fluid that is discharged from them is thin and excoriating, and the wounds are covered with proud flesh, springing again as quickly as it is removed. If they are attacked before they break they will generally be got rid of.

As an external application nothing is superior to the Iodine Ointment, (No. 25, p. 69).

At the same time a drachm of the tincture of iodine may be given in a little gruel morning and night, at or soon after the time of feeding; or the Hydriodate of Potash, beginning with four grains morning and night, and gradually increasing the dose to twelve grains. This preparation of iodine is preferable to the tincture; but the internal and the external use of the iodine must be continued at least three or four weeks, before any decisive benefit will be obtained. The tumours will frequently disappear altogether; but the oirtment and tincture must be used for at least a month before any decisive good can be expected.

If the tumours at the end of that time should not be evidently. diminishing, the veterinary surgeon should begin to think about removing them with the knife. They are seldom fed by any very considerable vessel, and may usually be taken away without the slightest danger. It will however be prudent to give the tincture of iodine for three weeks or a month after the operation, in order to remove the constitutional tendency to a return of the tumours. 
It will in the majority of cases be useless to attempt to heal these tumours when they have once broken. Strong ointments, and caustics of all kinds, have been tried, but the ulcer has daily spread and gone deeper and deeper, until it became necessary to destroy the animal. If anything is attempted in the way of healing the ulcers, the wound should be washed before every dressing with the tincture of iodine, lowered with four times its weight of water, and the Healing Cleansing Ointment (Recipe 10, p. 53) be daily applied.

These tumours are often very troublesome to treat, and the preferable way will generally be to remove them as soon as possible with the knife, except more should be found on any other part of the beast, in which case the removal of the principal tumour would only hasten the growth of the rest. Mercurial ointment will have no effect on these tumours, except to irritate them, and eause them to grow faster, and sometimes it will salivate and seriously injure the beast.

\section{CHAPTER XXXII.}

\section{A N G LE BERRIES.}

These are little warty tumours growing on various parts of the skin. They are unpleasant to the eye, and they sometimes become very sore.

They are a sad nuisance about the teats, and often render the cow very difficult to milk; and, on the eyelids, they are a source of perpetual torment to the animal. The easiest and surest way to remove them is to tie a piece of waxed silk firmly round the base of each, and to tighten it every day: by means of this the tumour will drop off, and rarely grow again; there will be no bleeding, and the neighbouring parts will not be inoculated.

If they are so numerous and large that it is necessary to have recourse to the cautery, the heated iron should be immediately applied to the angle berry. The bleeding will thus be readily stopped, and the tumour will not sprout anew.

If they are early attended to, and before they have reached any considerable size, they will gradually disappear when they are daily touched with the nitrate of silver, either in substance, or in the form of a strong solution. The strong nitrous acid will answer the same purpose. When there is an inveterate disposition to the growth of these berries, the iodine may be given, as already directed, with every prospect of success. 


\section{CHAPTER XXXIII.}

\section{THE FOUL IN THE FOOT.}

Tuis is also a troublesome and obstinate disease. It consists of nlcers of the foot, usually about the coronet, running under the horn, and causing more or less separation of it, with intense pain and lameness. It is produced by cattle being pastured too long on wet and poachy land, or their being driven too far over a hard and flinty road. It generally first appears between the claws in the form of a crack, extending from the coronet down the foot, with considerable inflammation, and the discharge of a stinking matter or pus. At other times a little swelling appears on the coronet between the hair and hoof, which breaks, and likewise discharges much stinking matter; and on being examined with a probe, a sinus or pipe will be discovered descending from the coronet down the foot and under the horn. The pain is often so great that the animal altogether refuses his food, and becomes as thin as a skeleton. The being pricked in shoeing is not an unfrequent cause of foul in the foot, especially if the ox be hardly worked afterwards, or turned on damp and boggy grounds. It very much resembles quittor in the horse, and must be treated in the same way.

'The first thing to be done is to examine the wound carefully, and see how far it extends under the horn. If there is little or no under running, the case may be easily and successfully treated. The country practice is to clean the part carefully, and then take a small cart-rope, or a pair of cow-hopples, and chafe them backward and forward between the claws for four or five minutes, and afterwards to dress the sore with a little butyr of antimony, and turn the beast into a dry pasture.

I should object to this, that it seems to be a very rough and cruel way of going to work. All that is necessary is, after cleaning the part well, to cut away all loose or separated horn, and all proud flesh, and then lightly apply the butyr to the sore. There will not be much difficulty in effecting a cure if the case is taken in time, and the sore rept dry while under treatment.

should, however, the pasterns swell, and be hot and tender, as they will do if the case has been neglected, or any gravel has insinuated itself between the horn and the foot, the wound must be more carefully examined, every sinus must be laid open to the very bottom, and cleansed, and touched with the caustic. A poultice of ?inseed meal should then be applied, and changed morning and night until the swelling and inflammation have subsided, when the caustir, may be again employed, but not more severely than the ease seenıs to require. It is the frequent light application of the butyr, and not 
the cruel burning to the very bone, that will soonest and most perfectly effect a cure.

In a few cases the foul in the foot cannot be traced to any external injury, but seems to be the result of natural foulness of the habit. It then resembles grease in the horse, and must be similarly treated. A brisk dose of physic should be given, and when that has ceased to operate, the Diuretic Drink (No. 26, p. 69) every morning. The sores, if foul and hot, should be cleaned and cooled by poulticing for a few days, and then the feet should be washed morning and night. with a tolerably strong solution of alum in water. A moderate bleeding will be serviceable in such a ease. It should not be forgotten that foul in the foot is a highly infectious disease, and that the lame beast should be speedily removed from his comparions.

Foul in the foot is a most serions disease when it breaks out in a dairy. It preys upon the health of the animal, and thus, to a degree almost incredible, lessens the quantity of milk which the animal yields. The grazier likewise severely suffers when it retards the fattening of his store-cattle. Much suffering speedily and most injuriously preys upon these animals. They were not designed to endure it, or to be exposed to the usual exciting causes of it. Lameness in cattle should, therefore, never be for a moment neglected.

\section{CHAPTER XXXIV.}

\section{TO DRY A COW OF HER MILK.}

IT is often necessary to dry up the milk when cows are wanted speedily to fatten, and this is now and then found to be a difficult matter, especially with large and gross beasts. If the flow of milk is suffered to continue, it may overload the udder, and produce inflammation of it, or garget, or general fever, or inflammation of the lungs, or foul in the foot.

The best time to dry the cows is very early in the spring, when they are eating dry meat. A good dose of physic, followed by mild astringent drinks, will usually settle the business, especially if she is moderately bled before the physic is given. Alum in the form of whey (No.19, p.64), or dissolved in water, will be the most effectual, as well as the safest astringent. Six drachms will be the medium dose. The cow may be milked clean when the astringent is given, and then turned on some dry upland pasture.

Two days afterwards she should be examined, and if the udder is not overloaded, nor hard nor hot, the milking may be discontinued; but if the udder is hard and full, and especially if it is hot, she should be fetched home, cleanly milked, and another astringent drink given. The third drink, if it is necessary to give one, stonild be an aperient 
one, and after that the Diuretic Drink (No. 26, p. 69) every second day.

The milking should only be resorted to if the state of the udder absolutely requires it, for every act of milking is but encouraging the secretion of unilk.

\section{CHAPTER XXXV.}

THE MA NGE.

THis is a troublesome and a disgraceful disease. It argues bad management in some way or other. An occasional cause is overfeeding, especially with hot, stimulating food. A more frequent one is starvation in the winter, by which the animal is so much debilitated that he cannot support the change of diet when the flush of grass comes on, and nature, overloaded, relieves herself by this eruption on the skin. A third cause is filth, and in the cow-houses of many little farmers it is not an unfrequent one. The last cause that I shall mention is contagion: mange is highly contagious, and if it gets into a dairy will often run through all the cows.

When there is not much eruption, the disease is recognised by the hide-bound appearance of the animal; the dryness and harshness of the hair; its readily coming off; the beast continually rubbing himself; and a white scurfiness, but not often much scabbiness, being seen on various parts.

Medicine alone will be of no avail here. The beast must be dressed. There is no occasion to use anything poisonous for this purpose, as cow-leeches are too much in the habit of doing. The corrosive sublimate and hellebore and tobacco should rarely be suffered in the dairy. They have destroyed hundreds of cattle.

The most effectual application is an ointment of which sulphur is the principal ingredient. Some mercurial ointment, however, must be added, but in no great quantity, for cattle will lick themselves, and salivation may ensue. There is nothing so injurious to the milk, or to the fattening of the beast, as salivation, even in a slight degree.

RECIPE (No. 54).

Mange Dintment.-Take fower of sulphur, a pound; strong mercurial ointment, twe runces; common turpestine, half a prond ; lard, a pound and a half. Melt the turpentine ant the lard tugether, well stir in the sulphur when these begin to enol; arof afterwards rub down the mercurial cintment on a marble slab, with the other jugredients.

This should be well rubbed in with the hand daily, wherever there is mange, the hair being carefully separated where the affected part is covered by it. Nin possible danger can happen from the prolonged. use of this ointment if the animal is not exposed to severe cold. 
Alterative medicine will materially assist the cure. The following may be given without injury to the milk, and without any precaution being needed :-

\section{RECIPE (No. 55).}

Alterative Drink - Take fiower of sulphur, two ounces; black sulphuret of anti. mony, one nunce; Athiop's mineral, half an ounce; nitre, two ounces. Mix, and divide into four powders; give one every second morning in a little thick gruel. Turning into a salt marsh will be an excellent auxiliary.

Connected with mange, generally accompanying it, and often producing it, are lice. The presence of these vermin argues extreme negligence, and is an absolute disgrace to the farmer. They rapidly spread from cow to cow; the slightest touch transfers some of them from one beast to another; they are crawling continually in the stable or on the pasture; and although they are never originally bred in the skin of a diseased animal, yet in one that has been half starved or mangy, and whose coat clings to the skin, and will not come off when nature usually sheds it, these vermin find too favourable a shelter. They are both the consequence and the cause of mange, and other affections of the skin. Myriads of them are sometimes found on the poor beast, teazing it almost to death.

The mange ointment above recommended will often be effectual in destroying them, or should it not be sufficiently powerful, a weaker kind of mercurial ointment may be applied.

\section{RECIPE (No. 56).}

Mercurial Ointment for Vermin.-Take strong mercurial ointment, one ounce; lard, seven ounces.' Mix them well together, and rub the ointment well on wherever the lice appear.

Some prefer a lotion: the best is-

RECIPE (No. 57).

Lotion for Vermin.-Take corrosive sublimate, two drachms; rub it down in two ounces of spirit of ivine, and add a pint of water.

This is strong enough to kill the vermin, but cannot possibly injure the beast. An ointment, however, is best, for it can be more thoroughly rubbed among the hair, and into every lurking-place which the vermin may occupy. A portion of the lizuid is often lost in the act of applying it. The ointment or the lotion should be used daily, and three or four dressings will generally remove the nuisance.

Scotch snuff has been dusted on the beast with partial good effect: the animalculæ have been thinned, but not extirpated. The snuff cannot possibly reach half of them.

While the lice are attacked, the condition of the animal should, if possible, be improved. Poverty and bad condition are sad encouragers of these pests. The alterative drink just recommended may be advantageously combined with tonics.

[The Boston Cultivator says:-"Many of our patrons inform us that their own experience confirms our doctrine, as to the facility of destroying lice on cattle by means of sand or any fine dust sifted into their hair. Mr. Hardy, of Waltham, Massachusetts, one of our observing and successful farmere, says cattle that lie in 
the dirt will never be lousy." Mr. C. Bullare, of Farıningham, who keeps the best of cattle, says that "dirt or any fine powder sifted into the hair, will destroy ver. min."

Instinct teaches partridges and other game to wallow in dusty places to keep off vermin; and for the same purpose, every poultry yard should be provided with heapa of fine dust and ashes. - $\mathbf{S}$.]

\section{RECIPE (No. 58).}

Altcrative Tonic Povoders.-Take flower of sulphur, four ounces; black sulphuret of antimnny, one ounce; Athiop's mineral, half an ounce; nitre, two nunces; pow. dered gentian. two ounces; powdered ginger, one ounce. Mix, and divide into six powders, and give one daily.

Warbles may here be not improperly considered. The breeze or gad-fly, or ox-fly, appears about the end of summer, and is a sad annoyance to the ox. At the very hum of the insect the cattle will gallop distractedly over the field, and sometimes do themselves serious injury. When the fly has the opportunity of alighting on the beast, he chooses the back or the loins, and piercing the skin, deposits an egg under it. Some venom is also distilled into the wound, for a tumour is shortly afterwards formed, varying from the size of an hazel-nut to that of an egg. It is a kind of abscess, for it speedily bursts, and leaves a little hole on the top of it for the grub, which is now hatched, to breathe, and where he lives on the fatty matter that he finds in this curious abode.

These warbles are often a sad nuisance to the animal. He licks them when he can get at them, and rubs himself violently on anything within his reach.

Country people sometimes get rid of them by compressing them between the finger and thumb, and forcing the maggot out. Others, with more certain effect, either pull off the scab around the mouth of the tumour, or open it with a lancet or penknife, and then pour in a few drops of spirit of turpentine, or introduce a heated needle.

The farmer is scarcely aware how much injury this fly does to the hide; for, although the holes may apparently close up, that part will always be weak.

\section{CHAPTER XXXVI.}

TO PRODUCE BULLING iN THE COW, AND TREATMENT OF BULL-BURNT.

Ir sometimes happens that the cow will not stand to the bull at the time that the farmer wished, so that either the calf is dropped a month or two after the most convenient and profitable time, or the most valuable season for making butter and cheese is lost. Some cows are thus backward because they have been previously starved; a week or fortnight's better keeping will usually effect the desired purpose. Indeed, if the animal has been well kept, and is in goou 
health, there will be little trouble from her unwillingness to associate with the bull, but occasionally some of a contrary nature.

Many recipes have been given by various authors to hasten the period of the cow being in season. A very common thing with the farmer is to give the cow that is wanted to take the bull a quart of milk immediately after it has been drawn from a cow that is in season. Two or three good cordial drinks, such as that recommended in Recipe 31, (p. 79), will be more serviceable. A few malt mashes, oats, carrots, \&c., may likewise be given. I would earnestly advise the farmer never to have recourse to cantharides. It is a dangerously stimulating medicine: some cows have had suppression of urine quickly following the exhibition of it, and others have died from inflammation of the sexual parts.

On the other hand, cows should not be too fat at this time, because they will frequently then not stand the bulling. A fat cow should have a dose or two of physic and be bled; a lean cow requires better keeping.

The sheath and penis of the bull occasionally becomes swollen and tender, and full of little ulcers, with fetid ichorous discharge. The animal can seldom be managed unless he is thrown, when the yard should be drawn out, and all the sore places bathed with the following lotion :-

\section{RECIPE (No. 59).}

Lotion for Bull-burnt.-Take Goulard's extract, one ounce; spirit of wine, two ounces; watcr, half a pint. Mix.

A few applications of this will give speedy relief, and heal the sores.

The shape of the cow will sometimes inflame and swell, accompanied with considerable pain at the time of staling, and also a thin ichorous discharge. The part should be washed with this lotion, or a - little of it ejected up the shape with a syringe.

\section{CHAPTER XXXVII.}

\section{THE COW - POX 。}

This disease used to be generally confounded with sore teats, until the immortal Jenner discovered its preservative power against smallpox. Other scientific men have since proved that it is identical with small-pox,-that it is, in fact, the small-pox of the cow.

It appears under the form of pustules or vesicles on the teats, which are easily broken in milking, and which, left alone, break of themselves, and discharge a thin, unhealthy fluid. The pustules are surrounded by a broad circle of inflammation, and if neglected, or roughly handled, occasionally run into ulcers, very foul, and difficult to heal. 
At the time of, or a little before, the appearance of the pustules, the animal droops, refuses to feed, ceases to ruminate, and labours under considerable fever. The eyes are heavy and dull; the cow moans and wanders about by herself, and her milk materially lessens, and at length is almost suspended.

It will rarely be prudent to bleed, but the bowels should be fairly opened, and the fever drink, (No. 1, p. 46), given once or twice in the day, according to the apparent degree of fever. The teats should be frequently washed with warm water, and the following lotion applied morning and night:-

RECIPE (No. 60).

Lotion for Cow-pox.-Take sal ammoniac, a quarter of an ounce; white wine vinegar, half a piut; camphorated spirit of wine, two ounces; Goulard's extract, an ounce. Mix, and keep them in a bottle for use.

If the ulcers become very foul, and difficult to heal, they must be treated in the way recommended for garget.

It is well known that these eruptions give a similar disease to the milker. Pustules appear about the joints of the hand, and the ends of the fingers; and there is sometimes considerable fever, pain in the head and limbs and loins, shivering, vomiting, and a quickened pulse. The pustules burst in three or four days, and sometimes become troublesome sores difficult to heal; and if unfortunately the patient should have rubbed his cheek or his lips with the diseased hand, the ulcers will appear there also.

It was the observation that persons who had had this disease of the cow were usually exempt from small-pox, which led to the most important discovery in medicine that has been made in modern times.

There is another eruption on the teat of the cow that bears no inconsiderable resemblance to the true cow-pox, and that has been confounded with it. The pustules are smaller: they are not so round, nor so deep; nor have they the blue colour of the others, and they contain pus or matter from the very first. They will readily yield to the ointment for sore teats recommended in Recipe 29 (p. 75).

Even without any application to them, the scabs usually peel off in a few days, and the skin underneath is quite sound. If, however, these are carelessly rubhed off in the act of milking, troublesome ulcers are apt to ensue.

It is of much importance to the farmer to be able to distinguish between these two eruptions. The first is contagious, snd may be communicated to the milk-maid, and, by her, to other cows. It is the true cow-pox. The second is not contagious, and is readiv got rid of. 


\section{CHAPTER XXXVIII.}

\section{CLUE-BOUND.-FARDEL-BOUND.}

These are different terms for costiveness, to which cattle are often subject, and especially in the beginning of almost all inflammatory complaints. The dung gets inore tenacious and harder, and is forced away in very small quantities. There is considerable dryness of the muzzle, heat of the mouth, quickness of the pulse, anxiety of the countenance, and every indication of fever. Sometimes the disease is evidently in the bowels principally or entirely; at other times it is only the symptom or accompaniment of other diseases. It always requires immediate attention, and may be considered as highly dangerous. Bleeding will be very useful, not only as lowering the fever, but disposing the purgative medicine to act more speedily. After bleeding, the bowels should be attacked in good earnest. The physic drinks already recommended should be given, -at first, the mild one (No.2, p. 47). If that, repeated after an interval of six hours, is not successful, the stronger dose (No.47, p. 111) should be tried: and if that also fails, a pound of common salt should be administered, and repeated four hours afterwards. This will seldom deceive, in extreme cases, although, from its irritating the bowels a little too much, it is not a purgative to be recommended in ordinary cases.

The action of the purgatives will be hastened, and generally secured, by the use of injections; and here also Read's patent pump will be advantageousiy employed. Half a pailful of warm water, in which Epsom salt or common salt has been dissolved, may be thrown up every two or three hours.

After the obstruction has been once overcome, the continued exhibition of mild purgatives will be prudent, for the costiveness is too apt to return. The Sulphur Purging Drink (No. 7, p. 52) will be the vest medicine for this purpose. The food should be mashes principally, or young succulent grass.

\section{CHAPTER XXXIX.}

\section{RABIES.-HYDROPHOBIA.}

THis dreadful disease is produced by the bite of a rabid or mad dog. The time that may elapse between the bite and the appearance of the malady varies from three weeks to three or four months. 
The symptoms of its approach are dulness; loss of appetite; the eyes are anxious, protruding, and red; the animal frequently and pitifully lows, and is continually voiding its dung or its urine. Saliva drivels plentifully from the mouth, but after a day or two the discharge dries up, and is succeeded by thirst almost insatiable: there is no hydrophobia, or dread of water, at any time. Presently weakness of the loins and staggering appear: these are succeeded by palsy of the hind limbs, and the animal lingers six or seven days, and dies.

In some cases the beast is dreadfully ferocious: he runs furiously at every object, stands across the path bellowing and tearing up the ground, and violently attacks and gores his companions.

There is no cure; the most prudent thing is to destroy the animal as soon as the disease is sufficiently plain. Care should be taken that the saliva of the rabid ox is not received on a wound or abraded part, for it has produced the disease in other animals. Any wound on which it has fallen should immediately have the lunar caustic applied to it.

When a mad dog has been known to bite an ox, or a cow, there is a possibility of their escape, for the hide is thick, and the hair is thick too, and the skin may not be penetrated, or the tooth may have been cleaned in passing through the hair. They should be most carefully examined, and especially ábout the part on which they were seized hy the dog, and if the minutest scratch can be found, the hair must be cut off round it, and the lunar caustic applied. That being done effectually, and every bite being discovered and operateo on, the animal is safe; but it is possible, or rather it is too probable, that every bite will not be discovered, considering how thickly the skin is covered by hair. It is, therefore, the safest course, if the beast is in tolerable condition, to sell it at once to the butcher, for it will not be fit for the shambles after rabies has once appeared. Medicine would be perfectly thrown away in these cases. The stories which are prevalent in every village, of the wonderful power of certain drinks, are all founded either on ignorance or fraud. There is no cure; and no prevention but the destruction of the part.

\section{CHAPTER XL.}

\section{THE DISEASES INCIDENT TO YOUNG CALVES.}

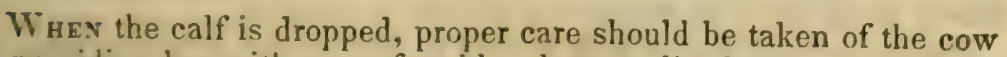
by providing her with a comfortable place to lie down: she should also be suffered freely to lick her calf, for this will not only make her fond of it, but the young animal will be thoroughly cleansed, and raised much sooner than it otherwise would; and the mother, in eat- 
ing the cleansing, will obtain that medicine which nature designed for her.

It is usual to take away a quart of the first milk, called the beastings, before the calf is allowed to suck. After this the young animal may be allowed access to the cow, but regulated by the plan of suckling or bringing up on which the grazier may determine. The calf should remain with the mother during a few days at least, or until the milk is proper for the purposes of the dairy

The mother's first milk is of an aperient quality, and sufficiently so to cleanse the bowels of the calf from the black sticky substance which they contain when first dropped. If this should not be effected, a little opening medicine will be necessary.

RECIPE (No. 61),

Aperient Drink for Calves.-Take epsom salts, from one to two ounces, according to the size and age of the calf, and dissolve in half a pint of gruel; then add ginger, a scruple; essence of pepperinint, three drops.

The Epsom salts are as efficacious as any kind of oil for purging young cattle, as well as far less expensive than most oils. Custom, however, has sanctioned the almost general use of castor oil in these cases, and there is no objection to it.

After the first or second day it will be prudent to tie the calf in a corner of the hovel, that it may not be always sucking the mother, for it might overgorge itself with milk, which would coagulate in the fourth stomach, and choke it up, and produce disease, and even death. If it is evident that the cow would yield more milk than the calf should have, it is the custom, and very properly, to take away a portion of it from her two or three times in the day, before the young one is unfastened.

The time that the calf, after this, remains with the mother is chiefly regulated by the system which the breeder usually pursues, but reference should always be had to the state of the cow's udder. If it is perfectly free from knobs, or kernels, or hardness, the calf may be removed at a comparatively early period; but if any induration of the teats appears, the yourig animal should be permitted to suck a while longer. The frequent sucking will prevent the milk from curdling in the udder; and also the friction and shaking of the bag, by the jolting of the calf's head in the act of sucking, will contribute not a little to the dispersion of the tumours. I have already spoken of garget, and shown that a very prevalent cause of it is the weaning of the calf too soon.

Few things are more injurious than the exposure of the young calf to wet and cold. It lays a foundation for rheumatism and hoose, which no medical treatment can afterwards remove.

For every information with regard to the rearing of calves from the pail, the reader is referred to the newest edition of "The Complete Grazier ;" or the treatise on "Cattle," published by the Useful Knowledge Society, both of which should find a place in the library of every agriculturist. 
Bleeding from the navel string is not an uncommon complaint among calves, and it is a very troublesome one. 'The first thing to be done is to pass another ligature round the string nearer to the body; for if the bleeding is not stopped the life of the young animal will sometimes be endangered. It may happen, however, that the first ligature may have been nearer to the belly than it ought to have been, so near, indeed, that another cannot be passed within it. A pledget of lint that has been dipped in a decoction of galls (half-a-dozen galls bruised, and boiled in half-a-pint of water), shonld be placed over the part, and confined with a proper bandage. This will be far preferable to the blue vitriol, and oil of vitriol, which some cow-leeches are so fond of applying. It will stop the blood, but not eat into and destroy the part.

From the application of the caustic, or even of the second ligature, a great deal of swelling will sometimes take place. 'This should be well fornented until inflammation is pretty nearly subdued. The after-treatment will depend on circumstances. If there is a solid tumour, the fomentation, or a poultice, must be continued until the swelling breaks, or points so decidedly that it may be opened with a lancet. Poultices must then be applied until the matter has fairly run out, after which a little Friar's Balsam will usually complete the cure.

In consequence of the bleeding and discharge of matter, the calf will sometimes be exceedingly reduced; some tonic medicine will then be necessary. The Recipe No. 13 (p. 54), given in half-doses, will be serviceable, and at the same time the calf should be forced with good oatmeal or peameal gruel.

\section{I A R R CE A.}

One of the most frequent and fatal diseases to which young calves are subject is diarrhœa, or violent purging. It occurs most frequently when the young animal is from a fortnight to six weeks old; and is in the majority of cases the consequence of neglect. The calf has been too early exposed to cold and wet, or has been half starved, and then one full and hearty meal often disarranges the whole alimentary canal. It is bad policy to stint the calf too much in its quantity of milk. The loss of two or three calves in the course of a year will more than swallow up the supposed saving resulting from a system of starvation.

At the time of weaning, or when the food is changed from milk to gruel or porridge, diarrhœa and dysentery are very apt to occur, and are subdued with great difficulty. The weaning and change of food should be effected slowly, and with a great deal of caution. The new milk should be mixed with the skim milk or gruel which is afterwards to be substituted, and the quantity of the one gradually diminished, while the other is as cautiously increased.

'The symptoms of diarrhcea in calves are, continual purging; the matter discharged is covered with more than its natural quantity of 
mucus; sometimes it is bloody, and often fetid; the animal loathes its food, staggers as it walks, and becomes rapidly thin. Towards the last stage of the disease the dung is more and more fetid and bloody, a greater portion of mucus mixes with it, and at length the discharge seems to be composed of mucus and blood, with scarcely any mixture of natural fecal matter. When this occurs there is little or no hope of cure.

The principal thing is to treat these diseases in time, before the mucous coat of the intestines becomes so inflamed that a bloody discharge ensues which soon wears the animal down.

Much acidity in the stomach and bowels attends all these complaints; therefore, it is necessary to get rid of it, first of all, by the administration of a mild purgative, and afterwards by the exhibition of chalk, or some other medicine with which the acid will really combine. Two ounces of castor oil, or four of Epsom salts, may be given.

Opium in some form or other must always be united with the chalk. It is of no use to get rid of one complaint when others are lurking and ready to appear. It will not be sufficient to neutralize the acidity of the stomach; the mouths of the vessels that are pouring out all this mucus and blood must be stopped; and we have not a more powerful or useful medicine than this in our whole catalogue of drugs. It acts by removing the irritation about the orifices of the exhalent vessels, and when this is effected they will cease to pour out so much fluid. Other astringents may be added, and a carminative mingled with the whole to recall the appetite, and rouse the bowels to healthy action. The following medicine will present the best combination of all these things :-

RECIPE (No. 62).

Take prepared chalk, two drachms; powdered opium, ten grains; powdered catechu, half a drachin; ginger, half a drachm; essence of peppermint, five drops. Mix, and give twice every day in half a pint of gruel.

This will be the proper dose for a calf from a fortnight to two months old. If the animal is older the dose may be increased onehalf. The common Dalby's Carminative is not a bad medicine, although a dear one, and may be given in doses of half a bottle at a time, when it happens to be at hand, and the case is urgent, and the drugs which compose Recipe No. 62 cannot be immediately procured.

When these preparations have been given some time, and have failed to stop the purging, I have known the following given with very good effect :-

\section{RECIPE (No. 63).}

Take Dover's powder, two scruples; starch, or arrow-root, in powder, one ounce ; compound cinnamon powder, one drachm; powdered kino, half a drachm. Boil the starch or arrow-root in a pint of water until it becomes well thickened, and then gradually stir in the other ingredients.

This may be given morning and night. 
When constant and violent straining accompanies the expulsion of the dung, an injection of a pint of thick gruel, with which half a drachm of powdered opium has been mixed, will be very useful.

Diarrhœa will often in the early stage be accompanied not only by inflammation of the howels, but much general fever. This will be known by much panting, heat of the mouth, and uneasiness, the animal Jying down and getting up again, rolling, or kicking at its belly. It will then be prudent to bleed. A pint will be the proper quantity to be taken from a calf under a month; after that an additional ounce may be taken for every month. When, however, the diarrhœa has been long established, and the calf is getting weak and rapidly losing flesh, it would be madness to bleed; the strength of the animal would be more speedily exhausted, and its death hastened. Chalk, or starch, astringents, and carminatives will then afford the only rational hope of success. After the cure has been completed, much care should be taken respecting the diet of the animal; and it will sometimes be useful to give him a lump of chalk and ancther of salt in his feeding place, to lick them when he likes.

[The following recipe was originally published in the New England Farmer, sanc. lioned with the name of Lovett Peters, of Westbornugh, Massachusctts, who pro. nounces it an infallible care for diarrhoa, or scouring in calves:- "I call it," says he, "infallible, because in thirty years" use of it I have never known it to fail in effecting a cure, by once giving it, except in one instrnce, and then a second dose proved effectual. Put into a suitable bottle about half a pint of good cider, (not gweet nor bottled cider). Then open a vein in the neck of the calf, and lct into the bottle about the same quantity of blood. Shake it well together quickly, and before it has time to coagulate, put it down the calf's throat, which is easily done with the bottle. $-\mathbf{S . ]}$

\section{COSTIVENESS.}

This occasionally attacks young calves a few days after they are born. It is then caused by coagulation of milk in the fourth stomach, which is completely distended by the solid curd, and the passage through it obstructed. There is not often any remedy for this. The most likely method to succeed is to pour in plenty of warm water in which Epsom salts have been dissolved, by means of the stomachpump so often recommended. The first dose may consist of two ounces of the salts dissolved in two or three quarts of water; after which ounce-doses may be given every six hours, likewise in the same quantity of water, until the bowels are opened.

The costiveness of calves is generally produced by bad management. Fither the calf is suffered to suck too plentifully, or put to a enw whose milk is too old, or fed with new milk from the dairy promiscuously. All these things are injurious, and thousands of young animals have been destroyed by them.

When costiveness nccurs in calves of two or three months old, it is usually when they have been too suddenly changed from fluid food, as gruel or porridge, to that of a dryer and more stimulating kind, 
and consisting principally of hay. This is a dangerous complaint; for there is not only obstruction usually in the manyplies, or third stomach, which is employed in rubbing down the hard fibrous food, and now becomes overloaded and clogged, but the paunch itself is generally filled with undigested food, and rumination has ceased.

Here again everything depends on diluting the hardened mass, and opening the bowels. The first dose of medicine should consist of a quarter of a pound of Epsom salts, dissolved in a gallon of warm water. It will not be forgotten that by introducing the pipe a little way, or far down the gullet, the medicine may be thrown at once into the third and fourth stomachs, or into the first. If it is introdated only a little way, and the pump worked gently, the fluid will pass on through the canal at the base of the gullet, which was described in the early part of the work, and enter the third stomach. Flowing through this in considerable quantities, it will perhaps dissolve, and wash out the hardened mass contained between the leaves of the manyplies, while the salts will open the bowels, and by emptying them solicit the food forward from the gorged stomachs.

If, after the bowels have been well opened, rumination should not return, it will be prudent to have recourse again to the stomachpump, the tube of which should now be pushed farther down the gullet until it enters the paunch. Plenty of warm water being now pumped in, and with some force, it will stir up the contents of the paunch, and cause them to be disgorged into the canal leading to the true stomach ; or vomiting will be excited, and the greater part of it thus brought away. The stomach will probably act upon the little that remains, rumination will again be established, and the animal will speedily recover.

There are few things so dangerous to young cattle as being thus sapped or costive. It is the foundation of fever, and of many a serious complaint. As soon as the dung is observed to be hard, a mild dose of physic should be given to every ealf. A little attention to this would keep the breeding stock in good order; and their preservation, and health, and rapid thriving would abundantly repay the little additional trouble and expense. Farmers in general, however, are shamefully careless here; and no notice is taken of half the diseases under which their stock of every kind plainly and evidently labour, until they are past all cure. It is also matter of general ob. servation, that a calf that has a considerable tendency to costiveness is slow in getting fat and preparing for the market.

All eattle are subject to oceasional costiveness, and which should be removed as early as in the ealf, as being the frequent root of much evil. It is either one of the symptoms of the beast labouring under inflammatory fever, or it lays the foundation for inflammatory fever. A purge of Epsom salts, or even of common salt, if the other should not be at hand, will not cost much, and would save the life of many a beast: let not the farmer, however, follow up the farrier's practice of giving a cordial drink two or three days after the physic, under 
the notion of removing flatulence, and promoting digestion, and invigorating the system. The fever, of which this costiveness is either the forerunner or the cause, would only be hastened and aggravated loy this absurd system of stimulation.

\section{TII H OOSE IN CALVES.}

This disease in the adult animal has already been considered: in the calf it assumes different and more aggravated symptoms, and is more speedily connected with consumption and death. The moment a calf is observed to cough violently, he should be removed from the pasture, and put under tolerably warm shelter and taken care of. A bleeding and a dose of physic, and a fever powder, will then usually restore the animal to perfect health.

At times the hoose is epidemic among cattle, and hundreds of them die. Proper treatment at first will, in the majority of cases, remedy the evil; but should the animal get rapidly worse, and his cough be peculiarly violent and distressing, care should be taken to examine the first that happens to die, on the farmer's own estate, or that of his neighbour, and if the windpipe and the air-tubes below should be found filled with the worms which have already been described, recourse should be had to the spirit of turpentine, which will often succeed in destroying them. The principle on which the turpentine acts has been already explained. The following will be found a good formula for its administration to calves from six to twelve months old :-

RECIPE (No. 64).

Take oil of turpentine, one ounce; linseed oil, three or four ounces; ginger, pow. dered, one drachm. Mix. To be repeated at the interval of a week, as often as may be required.

A cure has also been obtained by the exhibition of half a pint of lime-water every morning and a table-spoonful of salt the same afternoon. The origin of these worms has not yet been satisfactorily developed; but it is supposed that the eggs are taken with the water absorbed by the blood-vessels, and thus enter the windpipe, where they are hatched: but one thing is certain, that in nine cases out of ten the farmer may attribute all the losses he sustains to neglect of the calf, or premature exposure of him to cold and wet.

\section{CANKER IN THE MOUTH.}

The teeth of the young calf follow each other in rapid succession, and, as is the case with the human infant, the cutting of the teeth is attended by soreness of the mouth, and disinclination to eat. Numerous pimples also appear about the gums and membrane of the mouth, and these often run together, considerable ulceration follows, and the animal pines ay through lack of nutriment. The gums and tongue are sometimes considerably swollen, and no small degree of fever is excited. The first business is to evacuate the bowels. Epsom salts will here also constitute the preferable medicine, given in doses of one or two ounces, and repeated daily until the proper effect is pro.
$12 *$ 
duced. As a local application, equal parts of tincture of myrrh and water may be advantageously applied to the mouth, or a solution of common alum in water in the proportion of half an ounce of alum to a pint of water. Should any considerable degree of fever accompany the soreness of the mouth, the fever drink already recommended may be given in half doses, with a scruple of magnesia added to each.

\section{POSTSCRIPT}

\section{THE DISEASES OF CATTLE.}

ONe of the most fatal and extraordinary diseases with which any country has been infected is that which, in Ohio and other western States, is called the TrEM BLEs. Professor Drake, of the Transylvania University, and more recently Doctor J. J. McIlhenny, of Springfield, Ohio, have both published their views on the subject ; and if they have not succeeded in prescribing any effectual remedy, it has not been for want of diligence of research and an obvious benevolence of motive which do them honour. As resulting from the use of the meat and milk of cattle infected with the trembles, is believed to occur one of the most terrible diseases to which the human family is liable, called the Míк Siскness, alias Stck Sтомасн, "there is, says Dr. McIhenny, "no disorier that fills the minds of persons residing within the infected districts with more horror, with more dread, with more forebuding of death, than does this disease." He considers the trembles in cattle to he clearly of vegetable origin, that is produced by animals eating the vegetable, and through them commu. nicated to the person or animal that partakes either of the meat, butter, or milk.

Dr. T. B. Johnston, whose residence is in Southern Indiana, says that he never knew the trembles to prevail where there was not a free growth of weeds. "I well know that it is circumscribed, that a small section will produce the diseast, then an exemption for some distance, when it will again recur. So of some farms; a portion will produce it, and the other will not. In fact, there is not a county from Floyd to the mouth of the Wabash, and as far north as White River, that is exempt from milk sickness; and it often occurs in both Southern Illinois and Kentucky. I have never beard of it above the 41 st degree of north latitude, and it seldom reaches that line. As to the carse of the trembles, Dr. McIlhenny, who has devoted much and anxious attention to the subject, says that he differs with Professor Drake as to the true cause-" Our difference, however, consists merely in a name, in distinguishing between a different species of plants of the same genus. He appears to be prefty well satisfied that the Rhus Toxicodendron (Poison Oak) or Rhus Radicans (Poison Vine) is the plant that produces the disease.

My firm convictions are that the disease termed sick stomach is produced by the Rhus Toxicodendron, or Poison Oak, and that it is a separate and distinct species from the Radicans, or Poison Vine. It is further stated that the Poison Oak never vines that it is never seen to take hold on trees, and that it grows from one to three feet in height; that it has threc, while the Radicans or Poison Vine has five leaves. 
Dr. McIlhenny thus sums up the reasons which lead him to consider the trembles as the effect of the Rhus Toxicodendron, or poison ouk.

"To sum up our conclusions on the cause of milk-sickness, we must be allowed th express our decided conviction, that it is produced by the Rhus T'oxicodendron, or Poison Oak, for the following reasons:-

1. Sick stomach does not prevail where there is no rhus-that in every section of country where none of the small rhus can be found, there can be none of the trembles found.

2. It does universally exist where there is an abundance of the smaller rhus.

3. It never occurs until vegetation comes forth in the spring.

4. Where it prevails most, the rhus is in its greatest luxuriance.

5. After the heavy frosts kill all vegetation, the disease subsides.

6. It is a well-known fact, that cultivation kills the Poison Oak - entirely de. stroys it.

7. It is equally as well established, that animals kept within a well-cultivated enclosure, are perfectly exempt from the disease.

8. Almost every observant and intelligent individual who has been raised amidst the disease, has come to the conclusion, that the Rhus Toxicorlendron is the cause of milk sickness.

9. That it is distinguished from the Radicans, or common Poison Vine, by its different number of leaves - also, by its acridness of character.

10. A certain locality produces the disease, find it where yo may, such as flat, heavy timber-land, interspersed with hazle and other undert.ush, which is quite productive of the rhus.

11. The seldom appearance of the disease on hilly, dry ground, is in consequence of such a place not being congenial to the production of that plisnt, so that what little dnes exist, is not so apt to produce the disease, in consequence of its unhealthy growth."

The PATHozory of the disease is thus described by the same author:-

"As to the pathology of this disease I know but little. I have treated quite a number of cases, but have never been favoured with a post mortem examination; consequently, I have had no other means of ascertaining morbid appearances than shat of judging from symptoms: the mere external developments of the internal condition. We are told, however, that in animals which die of this disease, the many folds, or mesentery, is in a hard, dry condition, and, in many cases, perfectly black ; and that all the folds which lie enclosed in the bowels, and are in close contact with them, are frequently in such a brittle condition, that they can be readily broken, particularly those that envelope the stomach; and that traces of inflammatory ac. tion can be frequently discovered the whole length of the intestinal caual; but the griater anount, those that have left the deepest marks, are to be seen in and arcund the stomach and duodenum.

"If this should be a true condition of the morbid apnearances of the animal, which we are satisfied it is, we may reasonably expect that the same results are to be seen in the human subject. Sn far, however, as my opinion goes, I believe that the poison, when taken into the stomach, produces inflammation of that organ, particularly confined to the mucous coat; that inflammation continuing, thickens the mucous lining to such an extent, that it closes, in proportion to its severity, the passage from the stomach to the howels. I am satisfied that there is inflammation down to the upper part of the bowtls, but, generally, in a slight degree. I do not believe that there is any general inflammatory condition of any of the chylopœtic viscera, but that the entire.force of the disease is spent upon the stomach, and, perhaps, duo. denum.

"Froin what observation I have been able to make upon the subject, I am inclined to the opiuion that the lower portions of the bowels remain, measurably, if not en. [irely, exempt from inflammation; that it is entirely a disease of the stomach; that in priportion to the severity with which that organ is attacked, in that proportion will the chylopetic viscera become deranged.

Another proof that the disease is inflammatory, is the constipated condition of the bowels. There could not be such a dry and hardened condition of the fecal matter profluced by any other derangement, excepting that of inflammatory action.

"I have been led to make these remarks, in consequence of an opinion that is prevalent with some of our practitioners, that the disease is nervous; that the great gastric irritability is, or might he, attributed to nervous excitement. This, to me, appears immseible; for, if the nerves of the stomach were in such a morbid condi. 
tion, acting under such a powerful excitement as to produce such distressing symptoms, would not the brain become sympathetically affected? Would we not have an apparent case of Phrenitis? Whereas, the mind, generally, remains quiet. We sometimes see mental depression, but rarely ever mental aberration."

Professor Drake enumerates the animals liable to this disease, as the cow, horse, sheep, hog, dog, goat (doubtful), and the mule and huzzard. "The characteristic symptoms," says he, " are so much alike in all, that an account of them in one of the species will serve for the whole," and he selects THe cow.

"In the earliest stages of this malady, in the cow, it may not display its exist. ence, if the attack be not violent and the animal left to itself; for in the beginning, as in all stages of the disorder, the appetite seems to be unimpaired, and the thirst not increased. Even this early stage, not less than the more advanced, appears, however, to be attended with constipation of the bowels. The animal at length vegins to mope and droop, to walk slower than its fellows, and to falter in its gait. $\boldsymbol{f}$, under these circumstances, it should be driven, and attempt to run, the dehility and stiffness of its muscles are immediately apparent. It fails rapidly, trembles, pants, and sometimes seems blind, as it runs ayainst obstacles, but this may arise from vertigo; at length it falls down, lies on its side quivering, and is not, perhaps, able to rise for severa! hours, sometimes never. Now and then, the quivering amounts to a slight convulsion. When the disease is not viofent, the animal, after a longer $\boldsymbol{\partial r}$ shorter period, is again on its feet; but its capacity for muscular effort is greally impaired, and, if hurried in the slightest degree, it is seized with trembling and stiffness, and may even fall again. Of the state of the circulation, when it lies seriously :11, but little is known, as the pulse has not been inspected. One observer perceived shat the nose of a heifer was hot, but others. have found that part and the skin generally cool. Perhaps their observations were made in different stages of the dis. aase. While lying unable to walk, the animal will still eat fieely, and also take drink, but does not seem to have excessive thirst. Its costiveness continues to the last when the malady goes on to a fatal termination. Of the symptoms which pre. cede dissolution we could not obtain a satisfactory account. Our witnesses generally declared, however, that the abdomen dues not swell in any stage of the disease. When it assumes a chronic form, the animal is liable, for weeks and even months, to muscular infirmity unler exercise, looks gaunt and thin, its hair assumes a dead appearance, and sometimes falls off in consicterable quantities, especially from the neck."

Finally, as to the remedy for this dreadful disorder in cattle, we quote Professor Drake-Dr. McIlhenny's observations applying to the treatment of milk-sickness in the human subject - and then append the article on mad-itch and black-foot from Governor Vance with the following introductory remarks :-

"Treatment of the Trembles.-We met with no medical gentleman who had sub. jected animals labouring under this disease to a systematic, or even varied empirical treatment. All the penple of the district have one and the same indication to fulfil, that of opening the bowels. When this can be effected, the animal, they say, scarcely ever dies-when it cannot, death occurs. For the fulfilment of this indication, epsom salts has been administered in very large quantities, even to pounds, but without effect. Drenches of lard and various mixtures have also been given, with no satisfactory result. Judge Harold, near South Charleston, has exhibited calomel followed by lard-no essential benefit. Dr. Toland has administered the oil of turpentine, in doses of eight, twelve, and sixteen ounces, without advantage. An opinion is pre. valent that drenching animals injures them by causing them to struggle. On the whole, we found among the people of the district a total want of confidence in all kinds of cathartic medicines; and an exclusive reliance on Indian corn. Some pre. ferred old corn, some new, and others that which had been frost-bitten. This is fed to all those species of a nimals that are accustomed to eat it, and is snid never to be refused. The more the animal will eat, the greater is the hope of the owner. It is said to produce purging, when every other meaus have failed, and then, it is affirmed, recovery is almost certain. On these points we found but one opinion in the district. Several of its physicians, after trying other things, had, with the people, settled down on this.

"We found blood-letting not in favour. Dr. Toland supposes it has, generally, been employed at ton late a perind. Many non-professional persons spoke of having recorted to it without advantage, and sme thought it had dont harm. 
"Throughout the disease, rest is considered a sine qua non to the favourable effect of any measure, and of itself, in mild cases, sufficient; that is, if they be not aggravated by exercise, the disease will wear itself out, or spontaneously subside."

Other dispases of cattle which prevail in Ohio and the West have heen thus de. scrihed to us by Governor Vance of Ohio, a gentleman alike distinguished for the study and the practice of what is useful and amiable, rather than the ornamentalhence his great and deserved popularity.

\section{From Governor Vance, of Ohio.}

[M.D ITcr.-The effect of cattle following hogs that are fed on green corn, cut up and thrown to them when in the roasting-ear state, is very fatal. The hogs will chew the corn-stalk, and extract all the sap, and then throw it out. These fibres thus thrown out, with all the sap extracted, will be eaten voraciously by the cattle. It contains no nutriment to give fermentation to enable the animal to ruminate; and it thus lays dormant and inactive in the many folds, or stomach; becomes per. fectly compact and undigestahle; creates fever, and in the end destroys the animal.

Cattle destroyed by cating these fibres of the corn-stalk will first. show the symptom by a wild stare of the eye, and in its first stages will frequently hecome cross, and even atrack their keepers. They will then begin to rub the nose and head against the fence until the skin and flesh are torn and lacerated in a most frightful manner, and in the end die in great misery. I have lost many fine cattle in this way, and have never been able to save one thus afficted. The entire symptoms are similar to what is ealled the mad $\mathrm{ttch}$, which $I$ have no doubt is created by the same cause, by taking into many folds indigestible matter incapable of fermentation and rumina. tinn.

Brack Foot.-There is a late complaint amongst our cattle in the west, called the black foot. It is fatal to stock, destroying thein in a few hours. The at:ack is gene. rally in the fore leg or foot; the animal becomes stiff, and moves with great difficulty, the fiesh turning black from the foot to the body, causing mortification and immediate death. This disease has never been in my stock, and I only speak of it from information; but it is saif to be very fatal, and as far as I have heard we are witl. out a cure or preventive to arrest its progress.] 



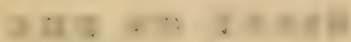

\section{E S S A Y}

ON T H E

\section{ADVANTAGES TO BE DERIVED FROM A MORE EXTENDED}

\section{USE 0 F $0 X \mathrm{X} N$}

\author{
IN THE
}

\section{HUSBANDRY OF THE UNITED STATES.}

\author{
BY J. S. SKINNER, Esq.
}

So de:p is the conviction of the great saving which would be accomplished by individuals, adding immensely, in the aggregate, to our national wealth, by a more extended use of OXEN in lieu of HORSEs in the general labours of husbandry, that the occasion is here embraced to present the views by which that conviction has been established, and the editor feels persuaded that he might venture to introduce these views, on the score of their intrinsic importance, even though the subject to which they relate were not so naturally associated, as it seems to be, with a work on the diseases of cattle.

That "a farming district may be judged of by its working oxen, as safely as by its barns or its corn-fields," has been laid down as an axiom by a Committee of Farmers, - working men in the true sense of the word, - of Massachusetts, at an exhibition where no premium was offered for horses, expressly on the ground that "it was believed that the interest of the farmer is promoted by substituting the ox for the horse, for most purposes, as he is fed with less expense, is more patient of labour, and is more valuable when his service is ended." This declaration in favour of the ox for "most purposes" is at once explicit and broad, and might seem to settle the question; but there are considerations arising out of difference of soil and climate, which obviously demand a comparison of circumstances to see how far that system admits of general application, which is here proclaiined on the best authority to be expedient th England : and this brings us at once to the most formidable objections to the use of oxen - their alleged incapacily to withstand, when labouring, the heat of more southern latitudes, and their slowness of motion.

As to New England, in addition to the evidence already quoted, we may give here the answer of the venerable Josiah Quincy, now President of the time-honoured Harvard University, to a letter once 
addressed to him by the writer of this_-" Oxen," said he, "are used almost wholly for plough and team work in this quarter of the country. A single horse is usually kept by our farmers to go to mill and to church, and for the convenience of the family. This is so universal as to be almost without exception among mere farmers. They certainly answer all purposes except perhaps speed, and in this, on a long journey, they are considered as quile equal to horses. Our farmers are so satisfied with their utility and economy, that no arguntent would induce them to change."

Hence it is seen that no reasoning is necessary to recommend the ox to general use in all that portion of America, and this evidence has been adduced to prevail upon sonthern readers to reflect on the subject, by showing, what many of them do not know, that already, in many of our States where the folks are nice judges of economical and labour-saving machines, animate and inanimate, oxen are actually substituted, and horses altogether banished for all farming purposes, and that their speed on long journeys is quite equal to that of horses. On the point of speed we shall speak again and conclusively, when we shall have dismissed the one in hand, to wit:-capacity to bear heat!

It was for a long time believed that the ox was a native of Europe, and that in the Aurock, running wild in the forests of Poland, his original type was to be found; but Cuvier's researches in comparative anatomy have established the belief that the cow is a native of Southern Asia, and thence may be deduced an argument that there is nothing in the natural constitution of the ox which forbids his manifesting his entire capabilities in southern climates. If there were, how is it that in South America he reaches his highest developements of size and power? As one of the Commissioners to South America, Chancellor Bland, in a report which Mr. Adams pronounced to be one of the ablest papers ever presented to the government, thus describes the ox-carts employed, and the wonderful powers of endurance of this patient animal in crossing the pampas of Buenos Ayres. It speaks conclusively to both the objections - want of speed and of power to bear heat.

"The Tucuman and Mendoza carts, at a little distance, looked like thatched cabins slowly moving over the plain - the whole machine is destitute of a nail or a bit of iron; its great coarse wheels are not less than eight feet in diameter; six oxen, in general nohle strong animals, move it; the two front pair have a great length of cord by which they draw; and the load of the cart, which, on an average, is not less than four thousand weight, is pretty nearly balanced on the ixletree; the body of the cart is either covered with raw hide or thatch, made of reeds or straw ; and with a collection of brushwood, as fuel, tied on the top, and brought from the westivard of the pampas, these carts are seen crossing the plains in carasans of from thirty to forty together. On the journey the oxen are unyoked occasionally through the day and night, and permitted to seek their food round about. Thus without any other provision than what is 
necessary for himself, the carrier pursues his way over a waste of thirty days or six weeks passage. From Buenos Ayres to Mendoza the distance is nine hundred miles, and the journey is periormed in about thirty days."

In some parts of England they formerly had ox races, and it is said triat some years ago an ox ran four miles, over the course at Lewis, for one hundred guineas, at the rate of fifteen miles the hour.

We are told that in India bullocks are used for the saddle and coach, and that there travelling oxen are curried, clothed and attended, with as much solicitude, and much greater lindness, than we bestow on our best horses. The Indian cattle are extremely docile, and quick of perception, patient and kind; like the horses, their chief travelling pace is the trot; and they are reported by those who have ridden them often, to perform journeys of sixty successive days at the rate of thirty to forty-five miles a day.

'lo come back to our own country on this point, it is worthy of bring here added that in an address delivered before the Barnwell A rrricultural society of South Carolina in 1821 , Dr. J. S. Pellinger remarked, that "in the lower districts of our State they appear fully to appreciate the value of their labour in heavy drafts. With those of us who have attempted the use of thein, oxen appear fully calculated tn answer the many purposes upon our farms to which we almost exclusively apply the inore expensive, though nobler animal, the horse."

'Time was when the horse was not considered "the nobler" of the two; else why the many cautions in Scripture in favour and in honour of the ox-thou shalt not muzzle the $0 x$ - thy ox shall not labour nn the Sabbath day - t'iou shalt not covet thy neighbour's wife nor his maid - nor his $o x$ !

The late Jimes V. Garnett, of Virginia, honoured be his name by ail friends of American agriculture, stated in one of his addresses "A gentleman of my acquaintance had a mixed team of horses, mules, and oxen - in each season his horses failed first, the mules next, alihough hoth were fed upon grain and hay; and the oxen, fed exclusively on hay and grass, finished the crop. But to come down to the present time and nearer home, in Maryland, at the hottest season of the year and the most busy one with the planter, the same teams of oxen are worked, during the whole day, hauling very heavy loads of preen tobaces for weeks togrether, and do well without any food but the grass of common pasturage on being turned out at night whereas horses, working steadily in the same way, on the national roal in watrons, consume twenty-five pourds of hay, and grain at the $r$ te of four bushels of oats per day for the five horses, or four-fifths of a bushel for earh horse - or, what is considered equivalent, four bushels of corn in the ear - making of oats at the rate of two hundred and thirty-two bushels for each horse for a year!

As th hurse power on the national road, the following is the answer from Major Thruston:- 
"Cumberland, Maryland, Nov. 17, 1843 :-The general result, (for they differ widely in their opinions), obtained by conversation with the oldest teamsters on the national road, is this - A five-horse team with a load of sixty cwt. (the average) will make daily, throughout the year, fifteen miles per day; the weight of the empty wagon between one and a half and two tons. At this work horses will not last as long as at farm-work by one-third, certainly. They a verage one set of shoes monthly, each horse; cost of shoes, one dollar each per month; feed, four bushels of oats per day, or four-fifths of a bushel per day to each horse; the same of corn in the ear; hay, twenty-five pounds. On this subject they are uniform in their statements. This amount of food is enough, and not more than will be consumed."

But the comparison in point of expense will be extended in another part of this essay.

In answer to the argument against oxen now under consideration, and the one which has had most influence in restricting the use of them, we now offer the views urged by the illustrious Madison, whose pen simplified and enlightened every subject it touched, as could not but happen with a mind so pure and so bright.

The objections generally made to the ox are-1st, that he is less tractable than the horse; $2 \mathrm{~d}$, that he does not bear heat as well; $3 \mathrm{~d}$, that he does not answer for the single plough used in our corn-fields; 4 th, that he is slower in his movements; 5 th, that he is less fit for carrying the produce of the farm to market.

'The first objection is certainly founded in mistake. Of the two animals the ox is the most docile. In all countries where the ox is the ordinary draught animal, his docility is proverbial. His intractability, where it exists, has arisen from an occasional use of fim only, with long and irregular intervals; during which, the habit of discipline being broken, a new one is to be formed.

The second objection has as little foundation. The constitution of the $\mathrm{ox}$ accommodates itself as readily as that of the horse to different climates. Not only in ancient Greece and Italy, but throughout Asia, as presented to us in ancient history, the ox and the plough are associated. At this day, in the warm parts of India and China, the ox, not the horse, is in the draught service. In every part of India the ox always appears, even in the train of her armies. And in the hottest parts of the West Indies, the ox is employed in hauling the weighty produce to the seaports. The mistake here, as in the former case, has arisen from the effect of an occasional employment only, with no other than green food. The fermentation of this in the animal, heated by the weather, and fretted by the discipline, will readily account for his sinking under his exertions; when green food even, much less dry, with a sober habit of labour, would have no such tendency.

'The third objection also is not a solid one. 'The ox can, by a proper harness, be used singly, as well as the horse, between the rows of Iridian corn; and equally so used for other purposes. Experience may be safely appealed to on this point. 
In the fourth place, it is alleged that he is slower in his movements. This is true, but in a loss degree than is often taken for granted. Oxen that are wcll chosen for their form are not worked after the age of about eight years, (the age at which they are best fitted for beef), are not worked too many together, and are suitahly matched, may be kept at nearly as quick a step as that of the horse, might I not say quicker than that of many of the horses we see at work, who, on account of their age, or the leanness occasioned by the costliness of the food they require, lose the advantage where they might have once had it ?

The last objection has most weight. The ox is not as well adapted as the horse to the road service, especially for long trips. In common roads, which are often soft, and sometimes suddenly become so, the form of his foot and the shortness of his leg are disadvantages; and, on roads frozen or turnpiked, the roughness of the surface in the former case, and its hardness in both cases, are inconvenient to his cloven foot. But where the distance to market is not grea:, where the varying state of the roads and of the weather can be consulted, and where the road service is less in proportion to the farm service, the objection is almost deprived of its weight.

In cases where it most applies, its weight is diminished hy the consideration that a much greater proportion of service on the farm may be done by oxen than is now commonly done; and that the expense of shoeing them is little different from that of keeping hcrses shod. It is observable that when oxen are worked on the farm over rough frozen ground, they suffer so much from the want of shoes, however well fed they may be, that it is a proper subject for calculation whether true economy does not require for them that accommodation, even on the farm, as well as for the horses.

A more important calculation is, whether, in many situations, the general saving by substituting the ox for the horse would not balance the expense of hiring a conveyance of the produce to market. In the same scale with the hire is to be put the value of the grass and hay consumed by the oxen; and in the other scale, the value of the corn, amounting to one-half of the crop, and of the grass and hay consumed by the horses. Where the market is not distant, the value of the corn saved would certainly pay for the carriage of the market portion of the crop, and balance, moreover, any difference between the value of the grass and hay consumed by oxen, and the value of the oxen when slaughtered for beef. In all these calculations, it is doubtless proper not to lose sight of the rule, that farmers ought to avoid paying others for doing what they can do for themselves. But the rule has its exceptions, and the error, if it be committed, will not lie in departing from the rule, but in not selecting aright the cases which call for the departure. It may be remarked that the rule ought to be more or less general, as there may or may not he at hand a market by which every produce of labour is convertible into money. In the 
old countries, this is much more the case than in new; and in new, inuch more the case near towns than at a distance from them. In this, as in most other parts of our country, a change of circumstances 's taking place which renders everything raised on a farm more convertible into money than formerly; and as the change proceeds, it will be more and more a point for consideration how far the labour in doing what might be bonght, could earn more in another way than the amount of the purchase. Still, it will always be prudent, for reasons which every experienced farmer will understand, to lean to the side of doing rather than hiring or buying what may be wanted."

The next most serious charge against the ox is constitutional slowness of motion, which, as many suppose, no course of education can overcome, but which may be set off in comparison with the greater speed of the horse, as Esop illustrated the difference in the long run between the pace of the 'turtoise and the hare!'-"'The greater haste the less speed," is a proverb suited to this case as to that. It has already been seen that ox-teams travel over the ever-verdant pampas of Buenos Ayres, at the rate of thirty miles a day, for a month together. Twenty years ago, the writer of this held correspondence with Commodore Jacob Jones, himself a practical farmer, and an habitually close and judicious observer, and then commanding our squadron in the Mediterranean, on the subject of Andalusian horses, cattle, and other animals, with a view to the importation, under authority from the Albemarle Agricultural Society, of such as might be deemed essentially superior to animals of the same species in America; and we now quote from his letter as applicable to the questions both of speed and susceptibility to heat:- "The cattle that I have seen in Spain appear to be nothing superior to ours, nor have I seen anywhere on the coasts of the Mediterranean any that appear better than those in America, except a race of white cattle at Naples used for the draft. I was informed by a gentleman who, in supplying the government with timber, had used thirty yoke of them for two years, that during that time they had constantly travelled from twenty to twentyfive iniles a day. They are generally fifteen hands high; their bodies long, thin, and deep; legs long; sinall light head; sharp muzzle resembling deer; colour entirely white, except black nose, ears, and tuft of the tail. They are most frequently worked in the thills of the cart, and are as spirited and walk as quick as a horse, and appeared not to suffer from heat more than a horse."

To show, however, that we are not dependent on any foreign stock, it may be stated that the small, pale-red old field ox about Salishury in Maryland will travel twenty-five miles in a day, with heavy loads of lumber going, and returning empty, over the sandy roads of that region; while it may be affirmed, after particular inquiry, that the distance made by the heavy-bodied, grain-devouring, Conestoga horses on the national road between Cumberland and Wheeling averages not over sixteen miles, six horses with loads of from six to eight thousand pounds. 
To the letter from Major Thruston already given may be added the following, which goes somewhat more into detail, from Mr. Agrew, Postmaster at Wheeling, Virginia :-

J. S. Skinner, Esq.

Wheeling, Nov. 23d, 1843.

Dear Sir, - Your favour requesting me to obtain information respecting horses, wagons, \&c., was received in due course of mail; but as I was just leaving for Pittsburgh, I was compelled to defer answering until my return. I conferred with several wagoners, and give below the result of their united opinions.

\section{Respectfully, your ob't. servant, \\ David Agnew.}

1. The usual average daily travel of load- Sixteen miles. ed wagons?

2. How many horses, and their average cost or value?

3. The average time that horses so $\mathrm{em}$. ployed will last?

4. At what age is it considered safe to put them to such labour?

5. What the average cost of shoeing each horse per annum?

6. What is the usual feed of kind and quantity, and to how many oats is it equivalent where oats are not used?

7. As to hay - is it in regular use on the road, or does cut straw, or what, take the place of it ?

8. What is the usual weight of their load exclusive of their wagons, and what the weight of the wagons?

9. What is the first cost of wagon-harness per horse, and how long will a get of hamess last?

10. What is the cost of a wagon in proportion to what it will carry - and about how long will a wagon last with ordinary care?

Six horses, average cost of each sixty-five dollars.

Seven years.

Five years. Many are used at three and four years.

Fifteen dollars.

Oats is the only feed in use. Four and a half bushels is allowed per day for six horses.

Cut straw is not used. Hay is in regular use.

The weight of loads varies from sixty to eighty hundred pounds; seventy hundred pounds is the usual weight ; wagon's weight about $3,500 \mathrm{lbs}$.

A wagon of the largest size used on the national road costs $\$ 250$; harness per horse, $\$ 20$; and will last six years.

A wagon thit will carry 3,000 lbs. costs $\$ 150 ; 4,000$ lbs. $\$ 160 ; 5,000$ lbs. $\$ 175$; 6,000 lbs. $\$ 200 ; 7,000$ lbs. and up. wards, $\$ 250$; and with ordinary care will last four years.

In support of the adaptation of the ox to the road for heavy draft and long journeys, the last authority which it is deemed necessary to produce is one of unquestionable validity; being no other than the festimony of the late Timothy Pickering. Being called on for his knowledge of the employment of ox-teams for the transportation of military stores during the revolution, when he acted as Quarter-Master-General under General Washington, the following is extracted from an interesting reply, in which other views are embraced, connreted with wher aspects of the subject, to be presently considered:

"When in August, 1781, disappointed in the expected co-operation of a French flect against the cnemy in New York, the commanderill-rhicf decided on the expedition against the British army under Lord Cornwallis in Virginia, I received his orders to provide for $13 *$ 
moving the troops destined for that service. The $1 x$-teams effectually performed the transportation of baggage and stores to the points where they were relieved by water conveyances. From the head of Elk in Maryland (sixteen miles eastward of the Susquehanna) to James' River in Virginia, near three hundred miles, the ox-teams (without loads) travelled expeditiously. The heavy artillery, shot, shells, \&c., brought from the head of Elk by water, were landed on the shore of James' River, I think at or near Jamestown, whence they were transported by the ox-teams to our camp before Yorktown, a distance, I believe, of about fourteen miles. In the performance of this service, those teams were of essential importance.

"The late Colonel Jeremiah Wadsworth of Connecticut (one of the most judicious and efficient men in business that I ever knew) was then the contractor for supplying the French army with provisions, teams, carriages, -in a word, with everything necessary for it, in the quarter-master's and commissary's departments. I introduce his name, because he had provided a great number of ox-teams and wagons for the use of the French army during the same carnpaign, and these also travelled to Virginia.

"I always understood that the great transportation of provision and stores from Massachusetts and Connecticut to the troops on Hudson's River, was almost wholly performed by ox-teams during the war.

"Just at the close of the war, in the summer of 1783 , I recollect being at the house of an agricultural gentleman of Princeton, in New Jersey, where Congress was then sitting, and that Charles Thomson, the Secretary, was present. One of Arthur Young's Agricultural Tours in Fngland lay on the table, and gave rise to a conversation on the use of oxen for the draft, particularly when geared with collars, hames, and traces, like liorses; and Mr. Thomson related the following fact, now, for substance, perfectly in my recollection. Travelling in that part of Chester county in Pennsylvania which lay between Lancaster in that State and Newport on Christiana creek, Mr. Thornson fell in with a team of a novel character in that country, being, composed of one pair of horses and one pair of oxen: and the latter were accoutred wilh hamess litie hirses, only with the collars turned upside down. His curiosity being excited, he stopped and made some inquiries, and received from the driver an account as follows: that he and a neighbour, each having a horse-team and wagon, had entered into) a contract to transport a quantity of flour (I think in a given time) to Newport; that in the midst of the work one or two of his horses failed, (fell sick or died), and he was not in circumstances conveniently to procure others; but he had a pair of oxen, and he concluded to try whether they would supply the place of his horses; that he made the experiment and succeeded. He told Mr. Thomson that the oxen were more uséful to him than horses; for after some fall-rains, when the roads had become miry, he continued to carry his full complenent of barrels of flour, while his neighbour's horke- 
team, frequently gettin-r stalled, (the familiar term in Pennsylvania when a team gets sel fast in a slough), compelled him to lessen his luads. But he added, that in returning from Newport with their wagons emply, his neighbour had the advantage in speed, although. none in the actual performance of the contract."

Thus it appears that as Rome is said to have been saved by the cackling of geese, the labour of oxen contributed on a critical occasion to the establishment of the American Republic. So much in answer may we not say in refutation, of the objection made to these animals in comparison with horses for heavy draft even on the road.

\section{OX-SHOES AND MACHINE FOR SHOEING OXEN.}

A great impediment to the use of oxen on our public rords in the winter season, is the liability of their feet to get sore for want of shoes - a great scandal on the intelligence and humanity of all southern farmers - for nothing can be easier or more simple than the manner of doing it in New England, where cattle driven on the roads in winter are as regularly shod as horses. In the hope of introducing a practice recominended equally by interest and humarity, a view is here given of the fraine used for that purpose, and the smith who does not provide himsclf with one ought not to receive the patronage of any enlightened neighbourhood.

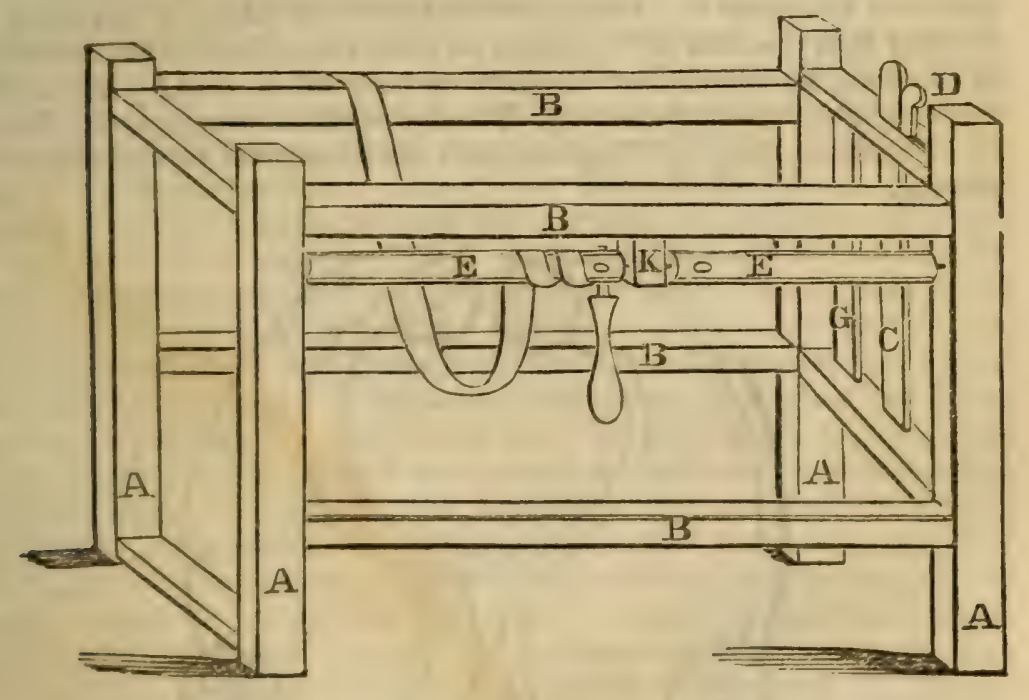

The frame, as here exhibited, should be seven and a half feet long by shree and a half wide, and five and a half high, consisting of four upright posts A A A A, and two horizontal bars on each side B B B B, 
joined by mortices. In the bars of one end, at the distance of ten inches from each other, are two perpendicular stanchions, the one fixed, the other moveable, and fastened by a key D, which are let into the bars and form a head stall. The lower bars of the sides are eighteen inches from the ground. Immediately under the upper bar on the right side is a windlass $\mathbf{E} \mathbf{E}$, separated in the centre, working in the posts, and a block $\mathrm{K}$ let fall from the bar-with one end passing over, and moving upon the opposite beam, is a broad leather strap six feet long, attached by an iron ring at the other end to the staples in the windlass. To give sufficient stability, the posts may either be let into the ground, or framed into sills, with end braces.

The ox to be shod is led into the frame, and his head confined in the head stall. The strap is brought under the lower part of the belly and fastened to the windlass, by turning which his hind feet are raised six or eight inches from the ground. The foot is then lashed by a cord to the upper surface of the lower bar. In this situation the shoes are easily set. By moving the strap till it comes near the fore-legs the other part of the body is raised, and the shoes set on the fore-feet in like manner.

The shoe is the arc of a circle, of the thickness of a common horseshoe, from half to three-quarters of an inch wide, flattened to double that width at the hind part. The flat or hind part covers the frog, the tenderest part of the foot. The heel and toe are either corked or raised to make a level with the heads of the nails. Five or six nails are sufficient to secure it. Particular care must be taken by the smith in shoeing that the toes of the shoes do not extend quite to the extremity of the hoof, in which they impinge on each other, and by the motion of the feet are easily thrust off. These directions are given by Benjamin Coleman, Esq. of Virginia, and are illustrated by the following sketch:

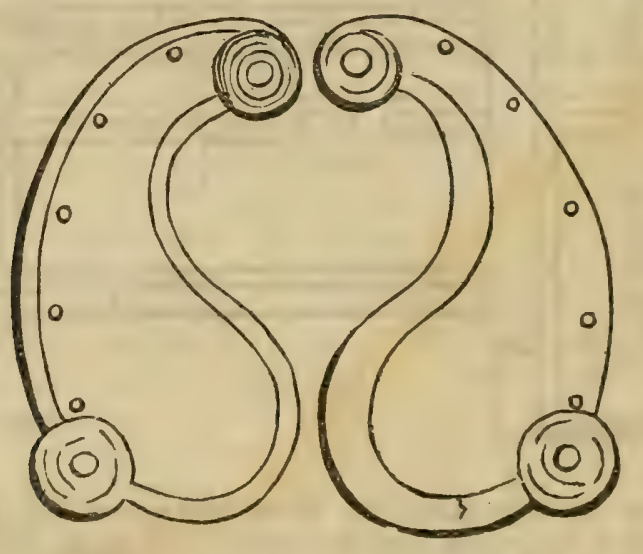


For the speed of an ox-team in the plough we might rely on the numerous certificates of committees for the last twenty years, in which our agricultural annals abound, from Boston in the north to Baltimore at least going south. These testify in innumerable cases to their ploughing five or six inches deep, an eighth of an acre thoroughly well, at the rate of an acre in four hours. Making the most liberal allowance, however, for the favourable circumstances under which the work has been done at this rate. and it may still be safely assumed that a yoke of oxen, well trained, will turn over more than an acre of strong land in eight hours.

All that we have contended for is more than confirmed by the following testimony taken from a very interesting letter from Governor Hill, dated 7 th December; 1843 , on the use of oxen in the lumbering business in Maine. He says - "My own experience in this matter is quite recent, and of course limited. I have at this time cattle of my own raising, which, having been taught to step quick, and having worked in the same team with horses, will side by side travel as fast and plough as much in a day as the same number of horses. A pair of these oxen will turn over with a plough that carries twelve inches of the last year's corn or potatoe ground, or easy stubble land, from one and a half to two acres in a day, working eight hours, four in the forenoon and four in the afternoon. Oxen well fed with hay and a portion of Indian corn or meal, will in the heat of summer stand it to work daily from eight to ten hours."

At the Exhibition of the Maryland Agricultural Society in 182.3, (quorum pars fui), in the view of hundreds of spectators, an ox-team started in competition with five horse-teams, and was the second in completing an equal quantity of ground, and would have been the first if the horse-team had cleared out the middle furrow; but supposing that when ready to start the horse has a little the advantage of foot, it is to be considered that for small jobs and short bouts his competitor can be more quickly hitched up, and the work despatched by the time the horse would be geared:- such cases as we have stated abound in all the accounts of the proceedings of agricultural societies. A writer in the Memoirs of the Massachusetts A gricultural Society, speaking to a community who neither could nor would be deceived on a matter so well understood by, and so deeply interesting to them, says - "The principal argument of the advocates for the cultivation by horses in Maryland seems to be the superior speed of the horse. Now this must proceed from an imperfect training of the cottle. With us our cattle will plough an acre of ground much beller, and in as short a time, as a pair of horses would do it, unless they can trot their horses in the plough; so they will get in a ton of hay in as short a time." Here we are well persuaded the sagacious writer hits the nail on the head, when he sucrests that the objection on the score of speed must arise from an "imperfect truining "if the calle." He must possess an imperforct knowledge of the difference between the habits of the New England ard the Southern pluughman 
who is not prepared to admit that in nothing is that difference greater than in their treatment of all their cattle, and more especially their oxen. In this very difference, in fact, is to be found the solution of the question, and this brings us to the point for making the suggestions we propose on the breed, gearing, training, and general treatment of the ox.

As to the breed, there can be no doubt that if regard were had alone to the working qualities of cattle, a skilful breeder might in a series of years, not very long, manufacture out of our own country cattle a race which would be as distinguished for quickness of motion and endurance as, by like care and attention and skill, the improved short horns have been made, and established for early maturity, symmetry and disposition to lay on flesh and fat on the most valuable parts. There is, however, in the two cases, this obvious difference in the system of breeding the horse and ox, which is a matter of necessity militating against the ox and detracting from him on the score of action, leaving it even a subject of surprise that he should be as quick as he is. While the horse, for instance, is bred and cultivated with a view to the possession and display of a single quality, either highbred for light harness or the saddle, or cold-blooded, with weight to be thrown into the collar, for the plough or heavy loads, for the cart or the wagon, true economy compels the husbandman as to his cattle, to keep in view and to combine, as far as he can, several objects in some degree incompatible with each other, and with the highest attainable degree of excellence in any particular one of them. Few, for in: stance, could afford to breed cattle with exclusive reference to the pail, the yoke, or the shambles! For either of these objects a different breed w) ild be taken, while, under all circumstances, for all these purposes combined, we should pronounce in favour of the Nurth Devon. It is from this stock that the famous New England oxen are descended. Being of moderate size, and active and thrifty, they are adapted to a wider range of country; and being in itself an unmixed distinct natural breed, if we may say so, it transmits and preserves its peculiar quali= ties with remarkable uniformity as to shape, size, colour, temper and action; and without demanding, in order to keep them up to the mark, that practised skill and extraordinary care in the selection of the breeding stock which has been for many years exercised in the formation of some other artificial breeds, choosing for that purpose individuals in every case most free from the defects, and possessing the greatest number of the points which it may be the object of the breeder to establish.

In a correspondence between Dr. Mease of Philadelphia and some English stock-breeders of celebrity, one of them, Mr. Chandler, who had repeatedly gained prizes at Smithfield for the cattle he had raised or exhibited, says in his answer to certain inquiries- ${ }^{6}$ Not being an advocate for very large animals or for feeding to an excess, I have endeavoured from experience to make use of that description of animals which pay best for the fond they eat, and are the readiest sale 
when fit for inarket. I have in consequence used the North Devons. They are the best breed that I am acquainted with for the united purposes of labour and feeding, being very active, fast walkers, quick feeders, of a very good quality when slaughtered, and of a size now very generally preferred in our markets to the very large beasts, being from one hundred to one hundred and fifty stone of eight pounds. They are worked in yokes from four to six to a plough, and plough upwards of an acre per day; indeed they work harder than any other oxen in this country, for Devonshire is a very hilly country. The Devonshire cows are not of a large size, but very handsome forms, quick feeders, and give milk of a very rich quality. I should suppose that a yearling bull would not be procured in either Devon or Hereford, from the first breeds, for less than one hundred guineas."

It is stated in the communications to the Board of Agriculture in Fngland, vol. iv., that ten North Devon cows of Mr. Congon produced on an average five dozen pounds of butter per week in summer, and two dozen in the winter; or, in other words, two hundred and sirty-eight pounds per cow. His thirty cows averaged an annual profit of $\mathfrak{L} 13,14 s .8 d$., or $\$ 60.52$ per head.

Another fact which weighs heavily in favour of the ox is, that his size is not diminished by labour; a consideration dwelt upon with emphasis by the late John I owell of Massachusetts, eminent alike for his knowledge and for his public-spirited use of it. In a report in 1825, he remarks - "There was another very interesting fact disclosed on this examination. There were three fine five year old steers of Joseph Eastlurooks, two of which had been worked hard from the age of three, and the third had never had a yoke around his neck. The judgres, and better judges there could scarcely be than my associates, could perceive no sensible difference in the value of the worked and unworked rattle of the same age, owned by the same man; and with the same treatment and food, the unworked oxen often were in no degree superior to those which had been submitted to labour. G:eat Britain might learn a lesson from this example if her farmers could have been present."

Were it admitted, as perhaps it should be, that an ox will consume more hay or long provender than a horse, it must also be conceded that the horse refuses much that will well sustain the ox - and the oljjection can at any rate only apply in all its force where the owner is near enough to narket to send his hay for sale. Now as the graincrop is inore condensed in proportion to value, and admits of much filsier transportation to market, the horse being the consumer, accordine to .Mr. Stabler's calculation, of nincty bushels more of grain, is in that view and in that proportion the more expensive animal of the (w). In a national point of view it is worthy of remark that he consumes too the very staple which goes nost efficiently to increase and sustain the population and strength of a country; very few, perhaps, liave reflected on the number of perple who may be kept on the food of une hurse. For example, the usual allowance for a slave is a peck 
of corn-meal and three and a half pounds of meat for a week, besides salt fish and vegetables; not enough, supposing the meat to be converted into hay, to keep the horse he drives for a single day.

Another view which must not be overlooked is, that the ox makes much more and beller manure than the horse. He is, in fact, a much better machine for grinding down by his ruminating process into manure, all the provender which cannot be taken for sale from the farn. It is in few cases economical, often not even with hogs, to consume the grain on the farm; and of all things that eat it, not excepting poultry and pigeons, the horse is the most expensive, as he gives it back in no way but by his labour, and therefore is the last animal that should be kept when it can be avoided.

We proceed to the practical suggestions which it is believed will be useful to those who may feel persuaded to adopt our recommendations.

BrEAKING. - The sooner this is commenced, the more complete will be the command of the teamster. It would be well, if convenient, to have them named and haltered, and taught to stand and to start, to " gree" and to "haw," when not more than a year old, and slightly worked in the summer and autumn after they are two. Gree and hxw are the terms used in most parts of the country. The first indicates that the yoke is to incline off to the right, or from the near side on which the driver should al ways take his stand. The yoke, however, should not be put on their necks until they are to be worked, as they might acquire a habit of running off in it, which it will be found very difficult to correct.

The directions which follow are taken principally from practical observations by T. P. Stabler, of Montgomery county, who has performed in Maryland all the requisite labour on a farm of one hundred and sixty acres, with but one horse in addition to his oxen, and of Mr. Gilinan, then of Alexandria. "The proper time," says Mr. Stabler, "for putting them to work, is at three years old; and such as have not been handled, as above recommended, while growing, should be driven round the field for a day or two, before being yoked, so as to tire them." The propriety of this is proved by the greater ease with which they are broken, when taken and yoked directly out of a drove, before they have time to recruit from the fatigue of traveliinu. Instead, then, of being yoked two together, they should be tis:l by the horns (with a rope slipped over and resting on the top of the liead) to the side of a honse, taking care that there be no place for the horns to become entangled, and stand tied in this manner till thoy cease to pull by the cord, which will in most cases be in a day or two. They may then be led very readily, and taught to turn, stop, or start. singly, just as a colt may be, instead of coupling two toge-ther at first, which any man in the care of horses would condemn, as being most likely to end in the destruetion of one or both, which has not unfrequently happened with young steers when forcibly yoked together in the first instance. 
"When two young cattle," says Mr. Stabler, "are yoked and turned loose with their tails tied together to run and plunge about, they are almost certain to acquire a habit of running away ; and even should this not be the case, one, and sometimes both, lose a part of their tail in these violent exertions. When they are sufficiently broken to the halter, they may be placed side by side, for the purpose of receiving the yoke, having reference to their relative size, strength, and mastership; because, if one is stronger and more free than the other, he should be placed on the off-side that the team may rather incline to, than from the driver."

If one should be larger than the other, he will be likely to be stronger and more free; and, should they be put to the plough, the furrow ox being the larger, the yoke will be kept nearer a level than in the other case. It requires but little observation to see that they are easier to be turned to the right, or made to "gee," than to the left, or to "haw," or "come hither;" therefore, if the master-ox be on the off-side, he will assist in controlling the near or left one in "coming round;" but when reversed, and the master-ox on the near side, and he not altogether willing to "come here," the team is some timie stationary; for let the then off-ox be ever so willing to obey the voice of the driver, the horn of the near one speaks a contrary language, equally intelligible. After the yoke is put on securely, their tails should be well tied together, and they suffered to stand tied as before until a strong pen is built round them, not more than sixteen or eighteen feet in diameter, taking care that the ends of the rails do not extend inwardly. The ropes should then be loosed, if possible, in such a way that they will not be sensible of it. Here they will soon learn to turn themselves about, without one violent exertion, or the least fright. They should be tied up as before, at night, their tails untied, and the yole removed, to be replaced in the morning as before; and the day following they may be led or driven in a larger space. By this time the cause will be gained in a manner calculated to insure a prime pair of cattle. They may now be attached to something light, and led about for a few hours, daily and gradually increasing the draft, and greasing their necks occasionally, to prevent galling. When put to the curt or harrow with others already broken, contrary to the usual practice, they should be placed before instead of behind them; by which arrangement it will be found that if frightened the old cattle will not let them run; but, if otherwise, they. by running against the older ones, may frighten them also.

In Kentucky they practise another mode of breaking steers, which is thus described:- Where the establishment is a large one, and ticere are some to be broken in, every year, the fixture and practice here recommended would seem to be eligible and judicious-"Get a strong post eight feet long by two thick; plant it three and a half feet in the ground, well rammed; round or level the top of the post, and leave a pin to it, or make a mortice and insert a strong two-incit pin of tough wood in it, perpendicularly at the top, six or eight inches 
long. Then get a tough sapling, twenty-five feet long; measure off at the small end of it the usual length of a yoke, and bore the holes for your bows. Then bore three holes, or more if you choose, four, eight, and twelve feet from the other end of the sapling, of the size of the pin in the top of the post, giving the shortest lever first, draw your steers up, let them be young or old, gentle or wild, it makes no difference; yoke them to the end of the pole; but instead of tying their tails together, if you wish to avoid bob-tailed oxen, tie their loins together with a good rope, wrap up their head halters, clear the front, and let them go; round and round they will go with a rush; drunk - drunker still they grow, until groaning, down they drop. For a while they lie panting and looking wild; at length they leap as if suddenly frightened, rush round and round again, grow drunk and drop again. Leave them, they will repeat the experiment, until reeling, they will stop or stand. In a few hours you may lead them around by their halters. Uncouple them from the pole, or yoke them to your eart, and drive them where you please with safety. 'The preceding method is recommended with confidence from personal knowledge by Mr. William P. Hart, of Kentucky.

There is no point in the comparison between oxen and horses which more strongly illustrates the economy of ox-power than the difference in the expense of gearing.

For each horse employed on public roads, where it is in constant use, the harness costs, according to the best information, as has been seen, twenty dollars; being one hundred and twenty dollars for a team of six, leaving the swingle or whiffle-trees, as they constitute a part of the wagon, out of the question; and this harness is not expected to last more than six years; while for six oxen, the whole gearing, consisting of three yokes and two chains, would not cost more than twenty dollars, and would probably last twenty years.

A singular method of accustoming young animals to draw is practised in France; and, although it must be admitted that few nations have been more the slaves of routine and of old habits, or slower in the progress of improvement in agricultural implements, yet the system they pursue in this instance, as here illustrated, looks and reads so plausibly as to appear worthy of trial, and to bespeak confidence in its efficacy. It is well known that nothing is more humbling to the wildest and most indomitable animal than the sufferings of extreme hunger; and among the French, in the very act of satisfying its cravings, they habituate young animals to the yoke and harness. For this purpose they attach them to the manger by means of a cord which runs through a ring, at the extremity of which a weight is attached, as represented at $\mathbf{A}$, in the annexed Plate, so that the animal may, at pleasure, approach or recede from the manger. A collar is put on the animal with two cords fixed to a bar or swingle-tree, to which another cord is attacherl at $B$, which passes throught the pulley $\mathrm{a}_{\iota} \mathrm{C}$, and to which is suspended a weight as at $\mathrm{D}$, to be increased or diminished at pleasure. Things being thus arranged, fodder is put 
USE OF OXEN .

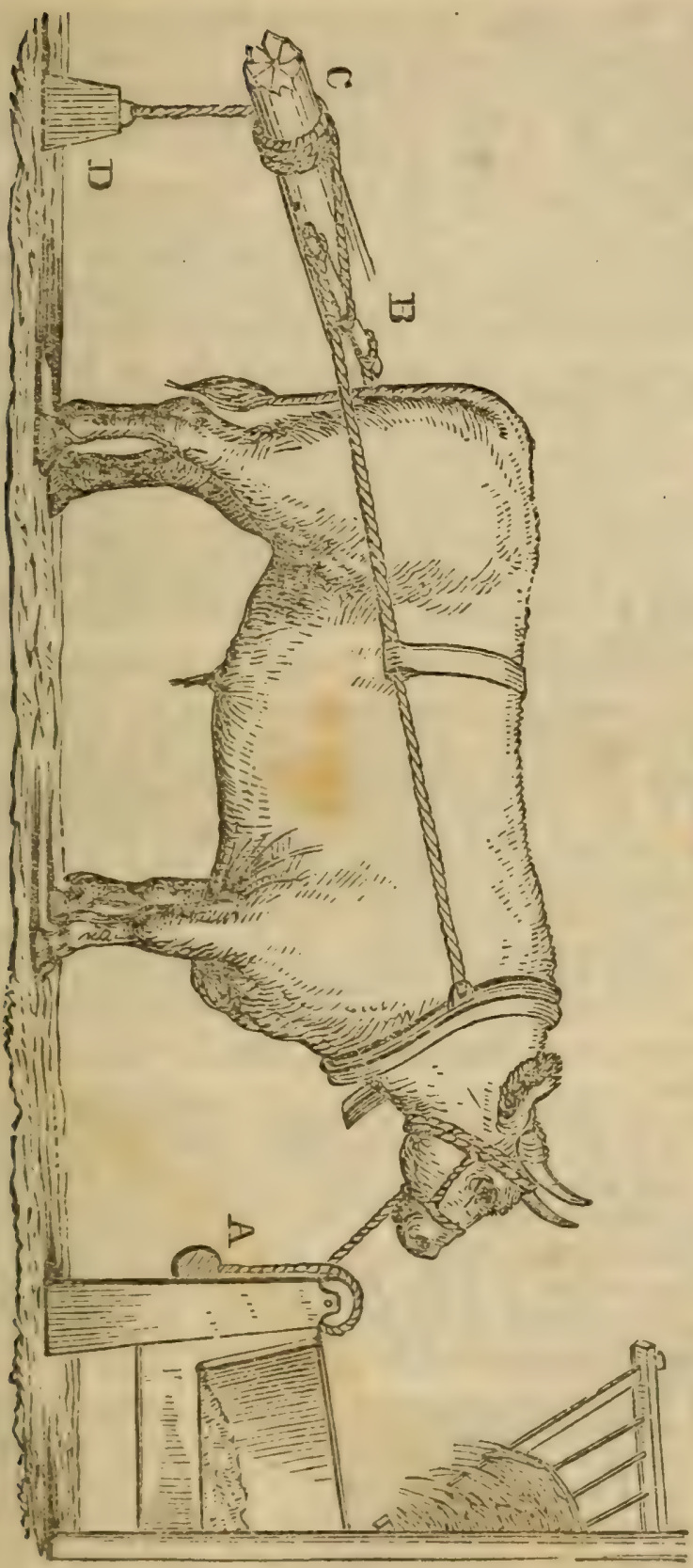


in the rack. The animal, when pressed with hunger, approaches his food, in doing which he raises the weight, and keeps it suspended as long as he continues to eat, and thus contracts the habit of drawing in a few days. He is free to relax his exertions, for whenever he recedes, the weight reposes on the ground.

"In many respects," says Mr. Gilman, "proud man must look up to the beast as his superior: mar's reason is replete with error; but instinct, or the inference drawn by a brute, from certain sounds and motions, after having once learned their purport, is infullible. I have seen the best drilled soldier mistake, for the instant, advance arms for recover arms, but never saw a well-trained ox mistake gee for haw, or huw for gee: hence, system is indispensable in the management of working cattle. He who would work them with ease and facility, should maintain a strict uniformity in his conduct towards them. 'T'hey must have names; therefore, calves intended to be raised for working should be named while young, to which they become familiar by the time they are ready for the yoke. Anything appropriate to their colour, shape, \&ce., is proper; such as bright, broad, line, spark, back, star, turk, golden, \&c."

"The buffaloe breed of cattle, or those without horns, will not answer well for working, as horns are necessary in backing a cart, and in carrying it down hill. This may be obviated by having a plain harness with breeching fastened to the yoke of the oxen to the tongue, as is the practice in Pennsylvania. Oxen should never be changed in the yoke after having been broke; the near and off-ox should always remain as such; by changing them, they become confused, and all the benefit of their tuition is lost."

"A temporary change, however, can be made in one instance to advantage; this is when they hang off from each other, as they are apt to do in bad travelling, when they get fretted; they then cut each other's feet with their shoes; shifting them puts this out of their head for that time."

"There are, however, several ways in which oxen may be geared for work; they are willing to earn their bread any way; they have been tried and found to pull by a yoke on the reck, by a shaft lashed across the forehead, and traces to its ends; by traces fastened to the horns; hy harness like horses; and they will pull by the tail. From these various modes, it is the husbandman's duty first to study the nature and convenience of the ox: secondly, economy and his own convenience, and then select that which embraces most of these desirable objects."

"There are but two of these modes mentioned that can be adopted with any degree of satisfaction or success; these are the yoke and the harness. From the former being in general, not to say universal use, the inference is a natural one, that some inconvenience must attend the latter. The form of the ox is one objection to harness; his belly is so much wider than his shoulders, it is embraced so hard by the iron traces as to impede his wind, as well as to be injured by 
galling. The yoke, on the other hand, being of hard wood, appears to be an instrument that would gall, but I never knew any injury done by it. 'The neck of the bullock seems by nature fitted for the yoke; the skin, naturally thick, soon becomes so callous as not to be hurt by friction; it is there his strength lies, even to a proverb.

In point of economy, there is a wide disparity between the harness and yoke; the expense of the former that of the latter, for eight years' wear, would be as ten to one, and the time of gearing and ungearing is as three to one; in other words, a yoke will cost only five dollars, which will average eight years' wear, and can be put to oxen in two minutes.

A yoke which is properly made for oxen of equal size and strength will have no particular end for the near or off-ox; but the bows being sometimes untrue, will fit to the neck better one particular way. This the nice teamster will observe, and always put them sa An ox can feel as sensibly as a man the pains of tight or unfitting accoutrements; but not being so fluertly gifted, and heing too noble and patient to shrink on that account from his task, it particularly behooves every driver (who cannot all day wear a key or penknife in the foot of his boot) to be vigilant that the tackle sits easy and free on his team.

When oxen are unequally matched as to strength, the strongest is apt to carry his end of the yoke several inches before the other; this makes the yoke uneasy to them, and is soon remedied by putting the stiple of the yoke nearest to the end of the strong ox. It does not, however, always follow that the stronger ox carries the fore end of the yoke. It often occurs that an inequality of strength begets such ambition in the weaker $\mathrm{x}$ as will ruin him by his overstraining himself for an even yoke. The driver should be attentive to this circumstance (if it ever occurs with him), and remedy it, as has been just pointed out.

It is unnecessary, in yoking well-tutored oxen, to lug the yoke round the yard after them, as they are easily called to that. I have often called the ox I wanied from a drove of all sorts of cattle. Stand the yoke on one end; take out the off-ox's bow; steady the yoke with the left hand, and with the right hold up the bow towards the ox, and beckoning with it, call him by name to you; slip the bow under his neck; turn the yoke down upon it; enter it in the bowholes, and put in the bow-pin; then take out the other bow, and lifting up the near end of the yoke with the left hand, with the bow in the right call the near-ox also by name, who will come and "bow his neck to the yoke," and is harnessed the same as his companion.

An ox-goad to drive with is made of hickory, or any tough wood, three and a half to four and a half feet long, as may suit the whim of the driver, about the size of a man's finger, with a prick or sharp point of iron in the end, projecting not more than a quarter of an inch. This is more cheap and simple, and has been found to answer much better than a whip, or a long green withe. The ludicrous $14 *$ 
practice of using the latter, and of having a driver on both sides of the team to keep them straight, or of fastening a rope to the horn of the near-ox for the same purpose, cannot be too soon exploded. Riding on oxen is a shameful lazy practice, that should also be done away with. Oxen may, and ought to be so taught, that by speaking to them and making a kind of beckoning motion with the goad, they will come to; or, in other wds, turn to the left without the trouble of an assistant on the off-side, or a rope to pull them round.

I would have one thing remembered in driving oxen, (which also applies to every species of servants), I mean the impolitic habit of a uniform harsh deportment, and of keeping the goad constantly going over them; it is a needless tax upon the lungs and sinews; the oxen will not do so much work for it; and, what is worse, they become so callous from this perpetual rough discipline, that they cannot easily be brought to any extra exertion when it is indeed necessary.

The benefit of a calm management has been very apparent to me when I have been driving in company with these peevish geniuses; and coming to a steep hill, I would then speak sharp and determined to my team, and ply the goad pretty freely, if necessary. This treatment, so novel, would be fully appreciated; every one of them would pull as for his life, and the hill would be quickly surmounted; while the driver who has always been speaking harshly, and always been plying his goad, could not here make use of any new argument to stimulate his cattle to the exigence of the moment. The consequence was, he would often have to receive assistance from a team no stronger than his own. Drivers should acquaint themselves with the burthen of their oxen, and never load them beyond it; it discourages and hurts them.

Because they are very strong, many unthinking taskmasters appear to believe them omnipotent. When they are properly taken care of, they are not apt to be sparing of their strength; they are sometimes profuse with it.

I have often been beset with difficulties when at work alone in the woods with a yoke or two of oxen, and have then thought I could perceive traits of reason in them; for, in proportion to my anxiety and exertions to extricate myself, have I seen their's spontaneously to increase.

That all cattle should be sheltered in cold and wet weather, is obvious to every person; but to those that work, it is indispensable; their health and strength depend upon it.

From the severity and duration of our winters at the northward, our barns are generally spacious, and calculated to hold as much as possible of our grain and hay. No doubt, however, but this is good economy in every climate in the United States; as the farmer loses as muck in quantity and quality of his produce in a short time, by stacking out, as would build a barn.

Our old-fashioned barns, I believe, are not susceptible of much improvement. Those which cattle are wintered in are built a small 
distance from the house on a rising ground, with a yard opened to, and descending a little towards the south, if such a spot be near; it being thereby warmer, kept cleaner, and the wash enriches the adjacent ground. The barn has two large doors opposite each other for the convenience of driving loads of grain and hay; on one or both sides of this thoroughfare is a stall for cattle, say ten feet wide and six and a half high, and running the whole width of the barn; so that if a barn were forty feet long, the stalls would take up ten feet on each end, and twenty would of course be the width of the thoroughfare; which latter being also used as the threshing-floor, is floored with two-inch plank, well joined.

The partition between this and the stalls is only three feet high, for the convenience of feeding cattle, whose crib joins the partition, and is thus made :-A piece of timber, the length of the stall, about four inches thick by eight wide, is laid down on edge, parallel with the partition, and two and a half feet from it; this makes a crib on the floor, being the most natural one that cattle can have to feed at. It is perfectly clean, as the stall-floors have a gradual descent of about three inches. Immediately over this timber is another smaller one of the same length, fixed to the joist above; in both of these timbers from end to end holes are bored at three feet distance, and smooth round stations or studs, three inches in diameter, are fixed therein; round each of these stations is bent a small hickory hank or hook, sufficiently loose to play up and down thereon; a wooden bow passing through this hoop, embraces the neck of the ox, who is thereby kept at his post, yet still has every rational liberty. He has room to eat his fond, lay down, or stand at his pleasure. (See drawings on page 161.) These stalls have small windows, four feet from the floor, and a convenient distance from each other, through which to throw the manure. Satisfactory experience of the safety and economy of this mode of housing cattle has made it universal in that quarter.

On tying up cattle for the night, respect should be had to mastery among them; the strongest should be put in first, and at the further end from the door, and so on, according as they hold dominion over each other, leaving the cows, yearlings, \&c., next the door, in case of civil war among them.

It is interesting when " the curfew tolls the knell of parting day," and the farmer's boy opens his stall-door and gives a nod of invitation to his "leading characters," to see them forming a line of march, entering the door, and taking their places precisely according to rank, without martial music, word of command, or confusion.

The thorough-bred teamster never suffers himself to partake of his repast before his oxen have begun theirs. They require little else in winter but good wholesome hay and water; but when sufficient time cannot well be allowed them to dine on hay, then corn in the ear is the best thing that can be given them. Pumpkins are also very grateful to them, and being remarkably prolific, may be raised with little trouble. In winter, cattle are tied up and fed at about sunset; fed 


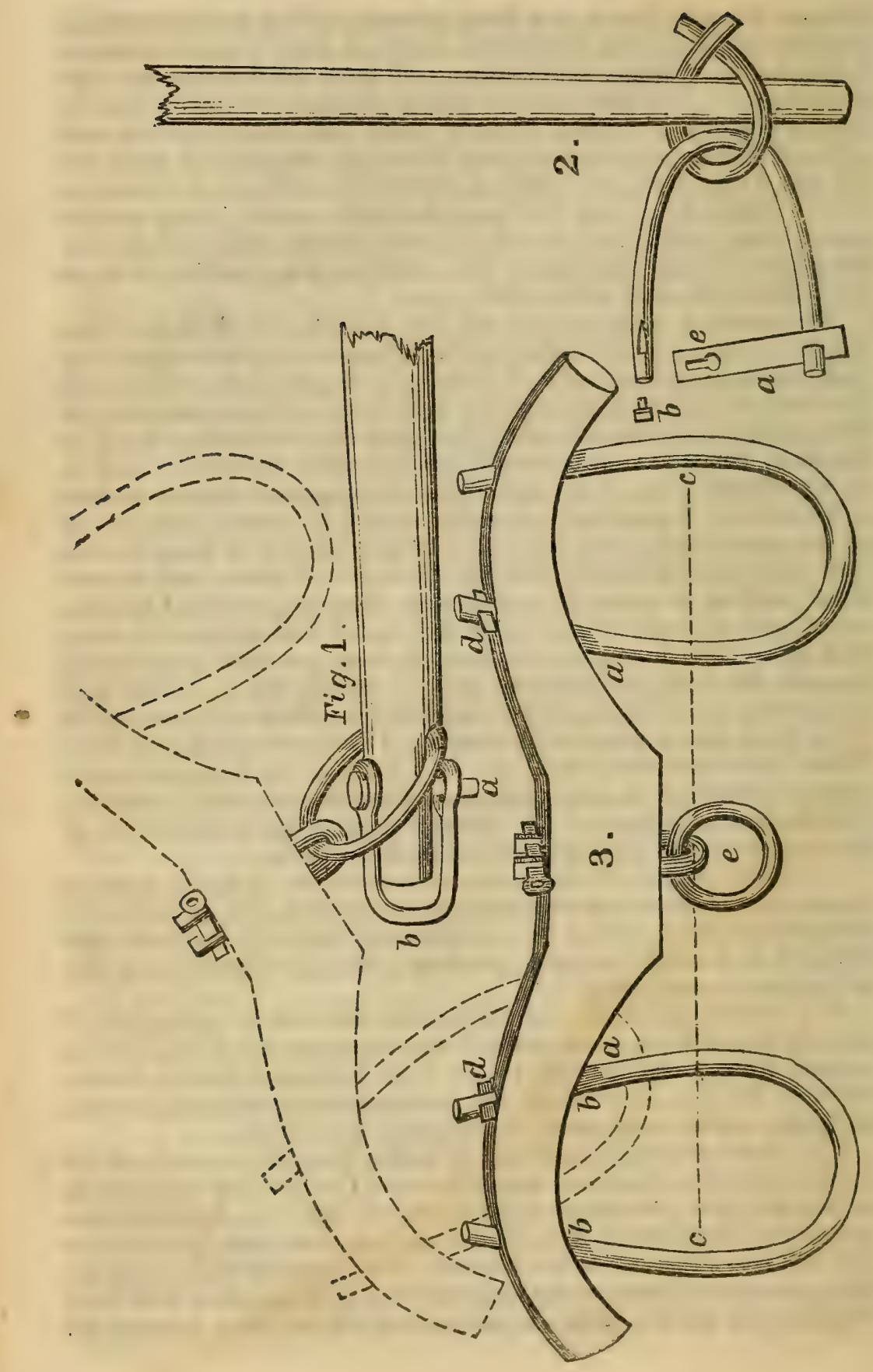


again at eight o'clock; again at daylight; then at sunrise they are ready for the labours of the day. This mode of feeding is considered preferable, being fresher in small quantities, eaten more freely, and less liable to get under their feet, and be wasted.

Carts being cheaper than wagons, and handier about the ordinary business of a farm, are therefore to be desired. Different kinds of bodies inay be attached occasionally to one pair of wheels; an open one for hav, sheaves, \&c., and a close one for fruit and vegetables. 'The naked wheels are handy to haul spars, poles, and all kinds of long timber on. In hitching a cart to the oxen, the tongue or spire thereof passes into the ring of the ox-yoke, as far as the shoulder in the tongue will permit; an iron instrument called a copes pin, resembling the capital letter $\mathrm{U}$, is put on the end of the tongue, embracing it above and below, and the copes pin is inserted through the end of the tongue and through the copes. This copes is for the purpose of hitchin's the second yoke of oxen to, when necessary. (See drawing on page 164.)

Wherever oxen and yokes are used, chains become indispensable; four of these, each ten feet long, with a hook in each end, or part of them with a ring in one end and a hook at the other, are enough for two or three yokes of oxen.

The drawings opposite are necessary for a better understanding of what has been said.

Fiu. 1 represents a cart-tongue hitched to a yoke, as in the act of drawing; $a$ is the copes pin, which goes through the tongue, and by which the yoke draws; $b$ is the copes by which the second pair is hitched, when necessary.

Fig. 2, a stanchion and bows, by which cattle are secured at their crib; $a$, the cap lies flat on top of their neck; the end of the bow at $b$ is sometimes like a buttor, and is put in the hole at $c$, and springs into its place.

At Fig. 3 is the model of a yoke for a middling sized pair of oxen. Whole length, three and a half feet; distance of bow-holes, $a$ to $a$, twenty inches; from $b$ to $b$, in the clear, six and a half inches. The bows being something of an oval form, and $c$ to $c$ being the greatest swell, and where the ox's shoulders come, the staple $e$ should be in a direct line between, so that the strain will come right, in drawing: $d d$ may be flat leys or round pins of wood; one in each bow is sufficirnt. The stuff of which the bows are made must be at least one and a half inches in diameter.

'There is no good reason why the ox should not be worked singly; so might cows when not at the pail very well do the single ploughing, aid liaul light loads in carts; and it would he yet more economical and expedient to spay and work heifers under certain circumstances. In Spain and France it is a common practice. Every judicious farmer will endravour to get all possible remuneration for the certain expense attendant upon the keeping of everything thut cunsurues the produce of his land. Even the dog that eats what would keep a pig, besides guard- 
ing his house, protecting his fields, and finding his game, is made by the calculating New England man to churn his butler.

It is observed that less food is necessary for spayed heifers to keep and fatten them than is required for the ox; and Mr. Marshall, in his rural economy of Yorkshire, remarks, that it is a fact well established in the practice of that district, that they work better, and have better wind than oxen.

It is a common thing to see a single ox in a cart at Norfolk in Virginia, among a people as little as any other observant of improvements going on in agricultural machinery. That whole States, even where oxen are used, should forego the use of single oxen, serves to show how proverbially slow is the change of habits among ayriculturists. Large bulls of immense strength are often kept and fed through the entire year, for the sole purpose of their services for eight or ten cows, when they might haul immense quantities of wood and manure in vehicles adapted to the purpose.

For an ox working singly, some recommend a single harness with the collar reversed; but for the reasons he gives, and which are obvious, the single yoke recommended by Mr. Stabler, and here exhibited, is greatly to be preferred. When the collar is used, and the draught heavy, the pressure of the traces on the sides is obviated by the yoke. The length for a single yoke must be proportioned to the thickness of the animal, so that the traces will be as far apart when fastened to a small hook on the under side of each end as is required to prevent his sides from being chafed. 'The following will show the proper shape of the single yoke :-

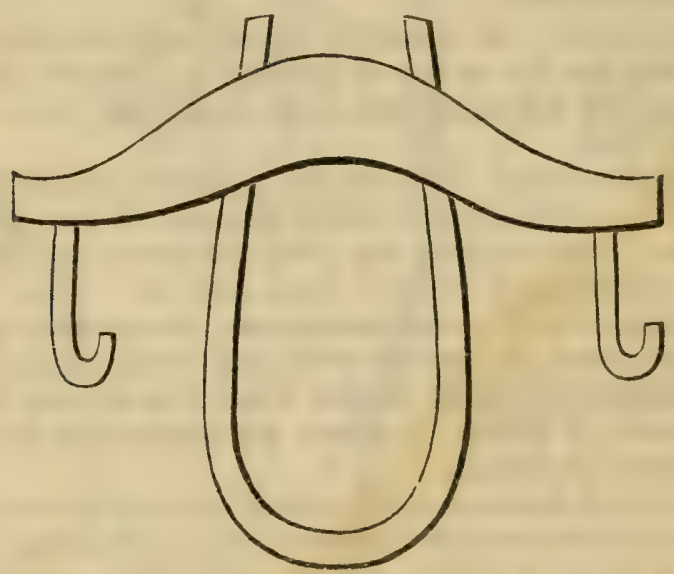

It will be observed that by placing the hooks perpendicularly through the ends of the yoke, the draught is applied precisely as in the double yoke, and the bow consequently keeps its proper place.

Mr. Stabler, a nice observer and a practical man, residing in a middle State, sets it down that a horse when at work must have at 
least three gallons of grain a day, and for six months in the year one hundred and twenty-five pounds of hay per week. Supposing him to be at work only two-thirds of his time, and during the remainder to be kept on hay or pasture alone, he must consume upwards of ninety bushels of grain, and two thousand eight hundred and seventy-five pounds of hay in a year, which latter is amply sufficient, with such pasture as the horse must have, (and some additional coarse food in the winter), to keep the ox in prime order for work without the use of any grain. Thus it appears, that for every ox substituted for a horse, there are ninety bushels of grain saved in the year.

From data given, Mr. Stabler shows a saving on four oxen instead of four horses in twelve years, of two thousand four hundred and fifty dollars - and concludes his observations on the subject with this wholesome advice :-

"It cannot be too strongly urged upon those who are about embarking in agricultural pursuits as a means of securing a livelihood, (and who may be free from many of the prejudices entertained against oxen), to make the experiment at least, and give the thing a fair trial, before they encumber themselves with that moth, a stock of farm-horses; in doing which, it will easily be seen they hazard nothing; for should any wish to abandon the plan after a sufficient trial, ore summer's grass will enable them to obtain, in cash, an advance on the first cost of their cattle, if young and thrifty; and such are always to be had."

J. S. S. 


\section{SHEEP HUSBANDRY.}

\section{DISEASE 0 F SHEEP.}

"Be thou diligent to knowo the state of thy flock."

THE subject of sheep husbandry, as adapted to the United States, involves so many considerations, that no system can be recommended for universal adoption, so much do the objects to be kept in view depend on the circumstances of the farmer - the food at his command and the markets within his reach. The most that can be done with promise of usefulness is to describe the characteristics of the several races of sheep which are known to be in the country, and, laying down some general principles as applicable to sheep husbandry, under all views of the subject, leave the farmer to determine how far it may be expedient to appropriate a portion of his capital and care to the business of sheep raising, and what breed promises to yield the best return. While one farmer convenient to a large market will naturally look to the butcher as his best customer, another will find his interest in the adoption of a breed that will best meet the demands of the manufacturer. The one chooses a kind of sheep that will in the shortest time give him the best return in meat; the other bestows his care on the one whose fleece will bring him the most money, the carcase being regarded only as subsidiary to that end. And again, where lamb and mutton are the principal objects, the choice of the breed may depend on the quality of the soil and the abundance of the pasture: where these are rich and luxuriant, a breed which ripens soonest, and is most inclined to fat, as the Bakewell, or a yet much larger sheep - a variety of the Lincolnshire - called the Cotswold breed, will be preferred more especially, and as long as the butcher has to consult the prevalent and vulgar taste for fatness, above all other qualities of meat.

On the other hand, for the far greater portion of the United States, where pastures are more scanty, and the animal is exposed without regular feeding or care to all the vicissitudes of climate, a more hardy race, as the improved Soulh-down, is to be preferred. Here it may be added that the present race of South-downs, such as have been im(168) 
porter to the United States, as will hereatter be seen, are as much meliorated and improved in form and early maturity over the little old animal of that name, of times gone by, as is the improved shorthorned breed of cattle on the original stock upon which they were built.

This improvement of the South-down has been accomplished, not by crossing and dovetailing with other breeds, but by a much safer process, one which guarantees a continuation of its established excellence under ordinarily good management; by crossing to be sure, but by crossing with and upon their own blood; the best South-down ram upon the best South-down ewe; thus perfecting the shape and disposition of the breed until a British writer entitled to great weight has expressed the opinion in respect of it which we anticipate will prevail and be acted upon before a great many years throughout the greater portion of the United States, to wit:-that, "taking all their qualities fairly into account, the South-down excels for general purposes any breed in Great Britain." The intelligent reader will, however, be the better enabled to judge for himself, when the peculiar qualities of the several breeds shall have been, as we propose, impartially and more particularly described.

Fluctuation of price has heretofore restricted, and will continue to linit, investments in fine-woolled sheep; and this uncertainty of price is the consequence of two causes which but too strongly forbid the hope of long-continued uniformity in that particular, to wit: - the fluctuating tariff policy of the country, rising or sinking in the scale as one party or another gains or loses the ascendant; and then again liable to be depressed by the ready facility with which in a short time the supply may be brought up to and above the level of the demand; making it so uncertain whether the remunerating price of one year may not be followed by a ruinous depression the next. Under all circumstances, the grazier of sheep that yield a wool of moderately good quality, can probably make his calculations with more certainty; for, should the prospect justify it, he has but to withhold his flock another year from the butcher, to avail himself of a rise in the wool-market. In New England, the calculation is, that if the fleece be carefully shorn when ripe, and the pelt carefully stripped from the carcass when the sheep dies, his death can be attrnded with no positive loss at any rate, let it die when or how it may. Taking all the chances of reasonable profit, in the existing condition of the country, there can be no doubt that the sheep hushandry of the United States, in all the States, south and west of Penusylvania especially, might be sooner extended, with less outlay, and a surer prospect of remunerating results, than could almost any wher branch of industry, if sheep-masters could be brought to bestow upon it a degree of care and of regular management approaching to that which this interesting business commands in older countries. Jave we not in the ice-bound regions of the north envincing proof that in the vast expanse of the middle and southern States, the rear- 
ing of sheep for the butcher, and of wool for the manufacturer, ought to be a leading object of attention? Yet look at the table hereafter to be presented, of the number of sheep to the acre in the States of Maryland and Virginia, and the Carolinas, with their fine possessions of cheap mountain land, compared with the number in Vermont and New York! It would really seem as if these old southern States were animated by that antipathy to this emblem of meekness and innocence which the great cynic "of Roanoke" once avowed on the floor of congress would prompt him to go "out of his way at any time to kick a sheep!" New York, one sheep for every two and a half acres; Maryland and Virginia, one for every thirty-three; South Carolina, only one for every hundred; and Arkansas, one for every thousand acres!

Were it allowable in this mere introduction to a work on the diseases of sheep, the whole subject of sheep husbandry is one which might be profitably, if it were well discussed, opening as it does so wide a field for observation and lecture. All that we can take space to do will be to call attention to the unemployed capacities of the country for doubling its flocks from Pennsylvania to the southern and western limits of the Union; and he who runs may read the addition which may thus so easily, and with so little cost, be made to the aggregate wealth of the country.

How different the calculation and the practice in the north, where, incredible as it may appear, it is truly a common thing for farmers to go round as winter approaches and buy up large numbers of old sheep at a price little, if any more, than the worth of their skins, the profit of the speculation consisting in part in the value of the carcass as food for their hogs. The pelt being first taken off, the carcass is boiled, or tryed, as they term it, for the tallow it will yield; the residuum is given to their hogs, meal being mixed therewith, not long before they are slaughtered.

It has been somewhere said that our enlightened minister in England was thought to be "boiling the ewe" with John Bull, when he alluded to this practice in New England; hence we may suppose that sheep have been brought to no such base uses in Great Britain; but it has been many years since the writer was assured at Brighton, Massachusetts, that flocks of sheep were sometimes sent with droves of hogs from Vermont to that market, to constitute, in part, their cheapest provision on the way; and very recently Mr. Hyde, a respectable and extensive mail contractor from Vermont, sustained in his statement by Mr. Russel, formerly a member of congress from New York, declared the system of buying up and appropriating old sheep, as before stated, to be a matter of common occurrence. The facts are here mentioned to show to the owners of millions of acres of unappropriated hilly and mountain lands from the western branch of the Susquehanna to the State of Alabaina, that very nice calculators of profit and loss find their account in raising sheep, even. 
where land is from twenty to one hundred dollars an acre, and without stipulating for high prices for mutton ard for wool.

In viewing this branch of industry as it is pursued in other countries, it must be conceded that in none of them is the sheep to be found in such variety as in England, nor are the principles of sheep managrement anywhere better understood. T'en years since, the number in England was estimated at thirty-two millions, and the value of wool at seven millions pounds sterling; while in the United States, one of which is larger than England, there were not exceeding twenty millions of sheep in 1840 .

But here again, as in other industrial pursuits, the superiority of British husbandry is referable, not to more advanced knowledge, but to lower wages for labour, and to their greater humidity of climate, which enables them to provide succulent rye and other grass pastures in early spring, but more especially in the productiveness of their turnip husbandry. Each contributes to sustain and extend the other, and both to supporting and increasing population. But the vast crops of turnips on which English sheep are folded, are produced with an outlay of labour in quantity that nothing but the cheapness of it would warrant, and at an expense after all which shows how as necessary capital is to the best system of tillage as it is to the prosecution of mercantile or any other business. How great again must be the profits of the turnip crop, direct and indirect, to authorise a tenant on land loaded with taxes to go to an expense of nearly fifty dollars per acre in putting in his root crop, as may be seen in the article Appraisement, in that inestimable work for the American agriculturist, Governeur Emerson's edition of the American Encyclopedia, published by Carey \& Hart of Philadelphia. The details as there given of expenditures in pulting in only seventeen acres of Swedish turnips, are estimated at nearly nine hundred dollars, a sum actually paid for the crop in the ground, in a case stated by the in-coming tenant. Owing to the mildness of their winter, the turnip crop is left on the land, and sheep are hurdled on small lots at a time. The land is thus wonderfully sustained and improved for the production of barley and wheat, yielding of the latter in many cases forty, fifty, and sixty bushels, and that in light land. How admirably adapted too would be these two products thus auxiliary to each other, turnips and sheep, to the sandy lands in some of the counties along our southern seaboard! In England, both Old and New, instead of leaving, as is done in some of the southern States, large numbers of sheep to die off, of poverty and old age, breeding from the worst, and to the last, and thus producing a diseased and rickety stock, they are systematically sorted out, fattened at a given age, and handed over to the butcher.

The best sheep-masters in England fatten and sell off their ewes, at four or at most five years old. It was the opinion of the celebrated Mr. Ellinan, a Dritish farmer of high and liberal character, that though an old ewe would bring a large lamb, yet such a lamb will 
not generally make a large or fine sheep; nor will it, as he thought, batten so well as a lamb from a younger ewe. He made the same observations on cows, sows, mares, and even bitches.

There is an almost universal readiness to believe that by sagaciously crossing different breeds, the best qualities of all may be obtained in one, and the worst of any one bred out. But experiments have not verified these speculative attempts, either with sheep or cattle; and even if admitted to be practicable, it would require rare skill, the fruit of great sagacity and experience, to carry it out successfully. The prudent farmer, therefore, will do better, having first made himself distinctly acquainted with the inherent peculiarities of the different races within his reach, to make his choice of some particular one, which, under all circumstances, promises to pay best for his outlay of attention and capital. Having done that, if a man of pride and diligence, he will go on breeding systematically, until in a few years he may be proud to exhibit his flock to the best judges. Entering upon sheep husbandry with that feeling, he will be extremely careful in the first instance in the selection of his breeding ram. Mr. Ellman, the distinguished English farmer and sheepmaster before referred to, recommends one ram for a flock of eighty or one hundred ewes, unless a lamb ram be used, in which case he advises only forty ewes. Great care should be taken that some bad point in the form, or old stain in the blood of the ram chosen, does not counterbalance the good points which it is desired he should communicate to his progeny. He will reserve from his whole flock the very best ewe lambs to the number necessary to keep up his regular stock of breeding ewes; he will have his ram let to his ewes on a given day, to ensure the yeaning of his lambs at the very season which his best judgment tells him will be most advantageous; and he will take care that his flock comes into the feeding yard in good season and in good condition, well knowing that according to the maxim of the shepherd, sheep well summered ure already half wintered. He will be careful to sort out and get rid of all unthrifty and unsightly individuals, and to ensure a flock of uniform healthiness of condition and comeliness in the eye of the practised and sagacious observer; he will regularly sell off all after a given age. It may be as confidently remarked of sheep as it may of every production of the animal and vegetable world, that to attain a high degree of excellence, it should be, not forced, but well kept, and never stinted in infancy or during that period which nature has assigned to its growth. Without careful attention to this, it is impossible to establish for any flock of sheep the character of excellence. No after-management or nourishment can eradicate the effects of neglect or short feed at this period. It not only diminishes the frame, but impairs the constitunon. Hence, in regard to sheep, it is obviously necessary so to have lambs yeaned at a season when the ewe may be well sustained with what may be requisite to ensure a good supply of milk, and that snould consisi of good sound clean hay, or well-cured corn-blades, 
with some vegetables in winter, as being necessary alike in a medicinal point of view, and as tending to increase the quantity of milk. Ur if vegetables, either turnips, potatoes, or sugar-bects, have not, or cannot be provided, then the season of yeaning, a matter always uncer the control of the sheep-master, should be postponed until the rye lots, sowed with express reference to this subject, may afford the best pasture, or at all events, in the absence of that provision, until the grass has "taken a start." And herein Great Britain may well boast her eminent advantage over us; one that with a view to sheep yet more than to cattle husbandry, more than counterbalances the great boon of Providence to these United States, Indian corn. If the political economist were called upon to indicate the broadest basis and most fruitful source of English wealth and population, he might probably designate the introduction of turnip culture.

Lord Townshend, in the reign of George III., having accompanied that monarch to Hanover, there saw turnips cultivated in open fields, as fodder for cattle, brought home the seed, and in spite of the ridicule which was cast upon the undertaking, he succeeded in persuading some of his tenants to plant them, and thus it happened that the heaths and wastes of Norfolk, that might have to this day remained in the ir original barrenness, were converted into magnificent vegetable and grain fields. Fed off to sheep that are folded to consume the turnip on the ground, the land is at once cleared of weeds, and highly manured, so that the original value of the turnip as fodder, great as that is, does not equal the resulting benefits in the preparation of the soil for heavy crops of grain. 'Thus the old system of fallowing has been superseded, and, as has been eloquently said by an English writer, "Mighty nature renews her strength, not by indolent repose, but in alterations of energy."

Considering how lately, and, as it were, accidentally this vegetable was introduced into England, it is marvellous to witness its progress and effrets. From being cultivated only in gardens for cattle, as late as the beginning of the eighteenth century, Colquhoun, in his statistical researches, estimates their value at fourteen millions of pounds sterling; and two years since, a respectable writer puts it down as being equal to the interest of the national debt. It was in view of such facts that our enlightened and eminent fellow citizen, Nicholas Bidille, so well qualified by liberal education, various attainments, and philosophic turn of mind, to speak with wisdom and furce on all useful subjects, was prompted to remark in one of his luminous discourses on agriculture - "It is strange how things so lowly acquire mational importance; the best farming is that which will give the greatest mass of sustenance to animals, since the less land required for animals, the more can be given to the maintenance of human beings. That fine farming region of England had reached the limit of supporting animals; it has more than doubled or quadrupled its puwer in that respect; and now, odd as the mingling of such dissiwilar norions may seem, it is scarcely an exaggeration to say, that $15 *$ 
England's power is based upon its iron, its coal, and its turnips!" Thus we find that sheep, since the introduction of turnip culture in England, have increased from sixteen to upwards of thirty-two millions.

Embracing with pleasure every opportunity to do honour to the names of those real benefactors of agriculture like Lord 'Townshend, who contribute unostentatiously to multiply the comforts of life, in the same connection it may be well for the special benefit of those who affect to ridicule book farming and learned farmers, to remark, en passant, that the greatest agricultural improvements in all countries have been introduced by Gentlemen Farmers; to them the best informed annalists of English agriculture acknowledge that country to be indebted for the turnip, for clover, for sanfoin, for lucerne, potatoes, cabbages, \&c. While it is admitted that this vegetable has supplied in England the great desideratum, winter food for sheep and cattle, and given to the supplies of both prodigious extension, it cannot be denied that she enjoys for suceess in turnip husbandry two great means which, for bettor and for worse, are denied to, or are not possessed by us. It is better for us in the long run, that labour is too dear to bestow on the culture of this vegetable, in the present condition of the country, that immense outlay in preparing and nınuring the land which attends it in England. It is worse for us if we could command the labour, that our climate is generally too arid for its growth, in anything like the abundance yielded by the turnip crops in England; and sisch is the severity of our frosts and its action on the earth, that it would not be practicable to feed them off to folded sheep as in England, where they are confined by hurdles to small portions of the field at a time, and moved to fresh lots every morning. Against this English crop, however, valued as before stated, we have (though not, it must be admitted, altogether available as a substitute for turnips in sheep husbandry) our three hundred and seventy-seven inillions, five hundred and thirty-one thousand, eight hundred and seventy-five bushels of Indian corn! which she reckons not at all among her cereal grains. Yet it does not by any means follow, that because the turnip is not so well suited to our climate, therefore we cannot profitably raise them, especially the rntabaga variety, and if not them, other vegetables access:ary, if not indispensable, in northern climates, to the increase of our flocks of sheep.

In looking for the reason why sheep should be a source of a large proportion of the income and wealth of the farmer, in the snow-clad regions of Vermont, where his sheep go into the fold-yard in $\mathrm{No}$ vember, to be fed until May, one of the most obvious would seem to be that the climate is better adapted to hay and to potatoes. Look at the statistics in these respects, of Virginia, for example, with her forty-four millions eight hundred thousand of acres, and Vermont, containing but two millions one hundred and seventy-five thousand, we find that the former produces of hay hut three hundred and sixtyfour thousand seven hundred and eight tons, and of potatoes only two 
millions nine hundred and forty-four thousand six hundred and sixty bushels, while Vermont produces of hay eight hundred and thirtysix thousand seven hundred and thirty-nine tons, and eight millions eight hundred and sixy-nine thousand seven hundred and fifty-one bushels of potatoes; and somewhat in correspondence with these crops, and to indicate the connection of sheep-rearing in some measure with them, Virginia, where the sun shines and the grass grows on the face of the earth almost every day in the year, carries, as will hereafier be seen, but one sheep to every thirly-three acres within her borders, while her frost-bitten, snow-clad sister in the north, carries one for every two or three acres, and feeds them during five months in winter, being content to drive them from one to two hundred miles to market, or to get for the wool an average price for the last twentytwo years varying from forty-fonr up to eighty cents per pound, except this year, when it is put down at thirty cents.

It may as well be noted here in reference to the general management of sheep - indeed of all domestic animals - that in nothing is there more gross neglect than in omitting to salt them regularly and abundantly. In Spain, where fine wool has been for ages one of their chief staples, one hundred and twelve pounds of salt is given in five months to one thousand sheep. The late celebrated English farmer and writer on agriculture allowed his sheep daily each from two to four ounces of salt when on dry pasture, and when fed on turnips they were not stinted at all in the use of salt. It is asserted as a fact in the Cyclopedia before referred to, that in all cases they should have access to common salt; and many are the authorities to prove that a free use of salt is a preventive of rot and other diseases.

We proceed now in fulfilment of an intimation, and for the reason already given, to submit a brief sketch of the characteristics of the few race's from which the farmer, having recourse to those now accessible to him in our country, must make his selection, repeating the warning that by no skill, in combination, or any artificial mixture of blords, need he expect to get united the fine fleece of the Saxony merinn, the carly maturity and obesity of the new Leicester, the weight of the Lincolnshire, or yet larger Cottswold, and the hardness and fine mutton that give eminence to the South-down. There may yet he room to improve any particular breed of eattle or sheep by that still in the choice of breeding stock and perfection in management, which care and experience only can beget, but we much douth whether any new breed can be firmly established that shall represent the excellencies without the defects of different natural races, and one that will, at the same time, endure! All such made-up breeds, upon the least relaxation of attention, or the least mistake in snrting with a view to breeding stock, will fly to pieces and exhibit he deferts with which nature is sure to reward the impertinent attempts of ignorance and presumption to interfere with her fundamenta] laws and purposes. A wayward dame is she, to be consulted, not thwarted; she will accept and repay all efforts of art to carry out her 
designs, and to improve her works according to her laws, and even leaves room for and invites the exercise of skill and diligence, but will not be crossed in her path or permit things which she has ordained to be distinct, each with its nature adapted to peculiar circumstances and ends, to be mingled up with any hope of forming a new organization better in all respects than she had designed.

In England, the South-down sheep is infinitely improved in all that can give it value, except the grain and flavour of the inutton, which tine immemorial has been esteemed superior, but that has been accounplished, not by mingling with it the blood of any other family, but by selection and care in breeding and feeding. The description of the different breeds of sheep will be confined to those which it is known have been imported into the United States in such numbers as to give latitude of choice to those who may propose to look to the rearing of sheep as an object more worthy of attention than it has been hitherto generally regarded-and first of the SPANISII Merino. This is the head spring of all the known flocks of finewoolled sheep. While their name would indicate that they were imported into Spain from beyond sea, their exportation from that country was strictly prohibited for ages, until as late as 1765 , by special license from the King, two hundred were sent to the Flector of Saxony, where, according to the best authority, Mr. Jarvis of Vermont, they were made an object of government attention. A board of scientific agriculturists was appointed to draw up rules and directions for their management, and to disseminate the breed throughout the electoral dominions. Woollen manufactures were likewise encouraged, and the good effects of this wise policy, says Mr. Jarvis, soon became apparent, in the increased wealth of the country, and the amelioration of the condition of all classes of society. He adds, when the merino was first introduced into Saxony, that State, and all the rest of Germany, were dependent upon England and France for a supply of a considerable part of their woollen goods; but at this time Saxony, as well as several other States of Germany, manufacture all the woollen goods that are necessary for their consumption; in addition to which Saxony now exports a considerable amount of woollen goods annually, and the rest of Germany an immense amount of wool. Mr. Jarvis is of opinion that while, owing to the different systems of management that prevail, the Saxony descendant of the Spanish sheep has become more and more tender and infirm of constitution, its fleece has been certainly somewhat improved in this country; and in reference to the suitableness of our own country to the growth of the finest wool, he says, - "About six years ago I cumpared my merino wool with fifteen or twenty samples of the Paular flock that had been sent me from Spain where I purchased, and eight of the ten judges who examined the two, gave a decided preference to that taken from the backs of my shecp." "He goes on to say, - "Mr. James Shepherd, who carried on the factory at Northampton, and who purchased my merino wool for several years, told 
me, that the superfine broadcloths made from my wool handled softer than did those from the best imported Spanish wool he could purchase; where," adds he, and there need be no better judge, "the merino has been bred with attention and care, the wool has not deteriorated in any other country except England, and the deterioration there has undoubtedly been owing to the uncommon humidity of the climate." Here, then, is evidence sufficient to satisfy the mest slieptical on the point of adaptation of climate and food to the production of the finest wool, where circumstances invite the farmer to chonse his breed with an eye to the manufacturer as his customer; and the testimony of $\mathbf{M r}$. Jarvis goes further to prove that if England owes the superiority of her turnip crop for coarse-woolled sheep to the moisture of her climate, for the same reason she can never supply her own manufacturers with fine wool.

It is not deemed necessary to give the history of the introduction of the merino into the United States, further than to state that the first, a buck and two ewes from the Rambouellet flock in France, were sent into New York by Chancellor Livingston, then Minister to France. The Hon. David Humphreys, who had been minister to France afterwards, got in two hundred more through Portugal into Connecticut. These importations remained unnoticed and almost unknown, until the embargo of 1807 and the non-intercourse cut off our supply of woollen goods from England; attention was drawn to the necessity of making ourselves independent of a foreign supply of an article as it were a necessary of life, and in 1809 and 1810 several thousand merinoes were sent from Spain to the United States by Mr. Jarvis of Vermont, and Mr. Grove of New York, and distributed chiefly in the northern States, but in smaller numbers as far south as Norfolk and Richmond. Subsequently, to wit, in 1826, there arrived in New York, Boston, and other ports, two thousand five hundred Saxony merinos. Such is the basis of the flocks now kept, of pure and of mixed blood, in our northern States, where, according to some interesting statistical accounts on the subject of sheep and wool, compiled in 1836, by Messrs. Benton and Barry, the average price of wool was per pound, in
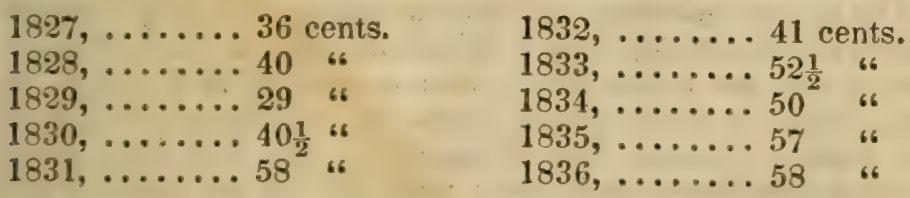

Since then, the price has been, according to the best accounts we can get, in

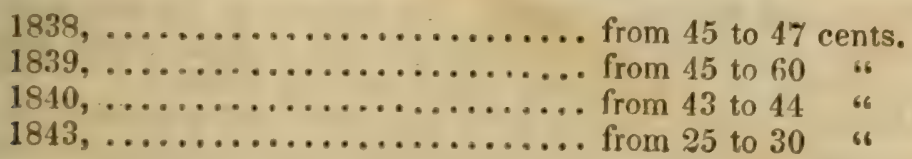


Here may be aptly inserted the following articles from the February number of the Albany "Cultivator," to assist the judgment of those who would decide on the best information as to the prospects for a remunerating price for the coarser kinds of long wool. It will be seen that under the influence of the present tariff, and the probability of its remaining for some time undisturbed, a large amount of capital is finding its way to employment in woollen manufactures by the establishment of branches of it, hitherto unattempted in this country.

"We have great pleasure in laying before our readers the following letter from Samuel Lawrence, Esq., of Lowell, in answer to one we addressed him, enclosing samples of wool from some Leicester sheep, owned by Mr. Howard, associate editor of the Cultivator. It will be seen from this letter that rapid advances are making in this country in the manufacture of such goods as require long wool, such as is produced by the breeds of sheep known as Cotswolds, Leicesters, Lincolnshires, \&c. ; and that the increasing demand for this kind of wool affords encouragement to the breeders of these sheep, which they have not heretofore enjoyed. It will be seen, also, that Mr. S. expresses great confidence in the belief that the prospects of the wool grower are fully equal to those of any other branch of husbandry."

\section{"Editors of the Cultivator,}

"Lowell, January 10, 1844.

"My numerous engagements at the opening of the year have prevented an earlier reply to your respected favour of the 28th ult.

"I have examined the two samples of wool, and am of opinion that they are admirably adapted to combing purposes for the manufacture of Mouslin de Laines. The staple is long, strong, and lustrous, qualities not desirable for felting purposes, especially the two latter. 1 judge these samples to be from Cotswold sheep, a breed which it is very desirable to propagate in this country, as the worsted business is just coming into existence. The secret of England's advance of all the world in the manufacture of worsted goods, lays in the fact of her possessing better breeds of sheep for the production of combing wools, and not from her superior skill in working them.

"The worsted business, in its various shapes, is to be of immense importance in this country; and it affords me sincere pleasure to be able to say to you that it has already been commenced in this State upon a liberal scale, by parties whose means and intelligence are a guaranty of its success. A great deal of talent and skill have been brought to bear upon this branch of industry; and if I am not greatly deceived, the time is near when old England herself will be astonished at our success. A number of hundred looms on mouslines are already in operation, and more in progress. In addition to the works already projested, a company is now being formed in Boston, with a capital of a million of dollars, fir works on mouslin de laines, \&c.

"In reply to your inquiry about the kinds and quantities of wool used in the Middlesex mills, I have to say that we use about a million 
of prands yearly, of such kinds as are considered in this country the chuicest produced; say full-blood Saxony, and Saxony inixed with Murino. We are very fastidious in the selection of our wools, both as regards the blood and condition; and, in consequence, we are in the habit of paying prices which many manufacturers think absurd.

"I am clearly of the opinion that no branch of agriculture promises better than the culture of wool, and I sincerely hope more attention will be given to it than has been paid for the last few years.

$$
\text { "Your's, }
$$

Samuel Lawrence."

According to the following table it will be seen that the aggregate amount of capital in 1810 , in woollen manufactures, was under sixteen millions; here is to be an addition, according to Mr. Lawrence, of one million in a single new branch of it.

\begin{tabular}{|c|c|c|c|c|c|}
\hline \multirow[b]{2}{*}{ NAME Sf STATE, \&c. } & \multicolumn{5}{|c|}{ WOOL. } \\
\hline & $\begin{array}{l}\text { No. of } \\
\text { fulling } \\
\text { mills. }\end{array}$ & $\begin{array}{c}\text { No. of } \\
\text { woollen } \\
\text { manufac- } \\
\text { tories. }\end{array}$ & $\begin{array}{c}\text { Value of } \\
\text { inanufac- } \\
\text { tured } \\
\text { goods. }\end{array}$ & $\begin{array}{c}\text { No. of } \\
\text { persons } \\
\text { emplow. }\end{array}$ & Capital in \\
\hline 1. Maine,.....$\cdots$ & 151 & 24 & क\$ 412,366 & 532 & $\$ 3] 6,105$ \\
\hline 2. New Hampshire,... & 152 & 66 & 795,784 & 893 & 740,345 \\
\hline $\begin{array}{l}\text { 3. Massacliusetts, .... } \\
\text { 4. Rhode Island, .... }\end{array}$ & 207 & 144 & $7,082,898$ & 5,076 & $4,179,850$ \\
\hline $\begin{array}{l}\text { 4. Rhode Island, ..... } \\
\text { 5. Connecticut, ..... }\end{array}$ & 45 & 41 & 842,172 & 961 & 685,350 \\
\hline $\begin{array}{l}\text { 5. Connecticut, } \ldots \ldots \\
\text { 6. Vermont, ......... }\end{array}$ & 157 & 119 & $2,494,313$ & 2,356 & $1,931,335$ \\
\hline 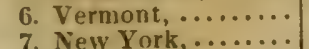 & 239 & 95 & $1,331,953$ & 1,450 & $1,406,950$ \\
\hline 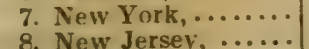 & 890 & 323 & $3,537,337$ & 4,636 & $3,469,349$ \\
\hline 8. New Jersey, ....... & 49 & 31 & 440,710 & 427 & 314,650 \\
\hline 9. Pennsylvania, $\ldots$. & 346 & 235 & $2,319,061$ & 2,930 & $1.510,546$ \\
\hline 10. Delaware, $\ldots \ldots \ldots$. & 3 & 2 & 104,700 & 83 & 107,000 \\
\hline 11. Maryland, $\ldots \ldots \ldots$. & $\begin{array}{l}39 \\
47\end{array}$ & 29 & 235,900 & 388 & 117,630 \\
\hline $\begin{array}{l}\text { 12. Virginia, } \ldots \ldots . . . \\
\text { 13. North Caroliua, ... }\end{array}$ & 47 & 41 & 147,792 & 222 & $\begin{array}{r}112,350 \\
9 \succ 00\end{array}$ \\
\hline $\begin{array}{l}\text { 13. North Caroliua, ... } \\
\text { 14. South Carolina, ... }\end{array}$ & 1 & $\mathbf{3}$ & 3,900 & $\begin{array}{l}4 \\
6\end{array}$ & $\begin{array}{l}9, \varepsilon 00 \\
4,300\end{array}$ \\
\hline $\begin{array}{l}\text { 14. South Carolina, ... } \\
\text { 15. Georgia, ......... }\end{array}$ & $\cdots \cdots$ & $\begin{array}{l}3 \\
1\end{array}$ & $\begin{array}{l}1,000 \\
3,000\end{array}$ & 10 & $\begin{array}{l}4,300 \\
2,000\end{array}$ \\
\hline $\begin{array}{l}\text { 15. Georyia, } . \ldots \ldots \ldots \\
\text { 16. Alabama, } \ldots \ldots \ldots \ldots\end{array}$ & $\ldots \cdots$ & 1 & & $\ldots \ldots$ & $\ldots \ldots$ \\
\hline & & $\ldots \ldots$ & $\ldots \ldots$. & ..... & ........ \\
\hline $\begin{array}{l}\text { 17. Mississipp1, ........ } \\
\text { 18. Louisiana, ...... }\end{array}$ & $\cdots \cdots$ & $\ldots \ldots$ & *....... & $\cdots \cdots$ & ........ \\
\hline 19. Tennessee, ........ & 4 & 26 & 14,290 & 45 & 25,600 \\
\hline 20. Kentucky, $\ldots \ldots \ldots$ & 5 & 40 & 151,246 & 200 & $13 \div, 1000$ \\
\hline 21. Olino, $\ldots \ldots \ldots \ldots$. & 206 & 130 & 685,757 & 935 & $5: 37,985$ \\
\hline 22. Indiana, ......... & 24 & 37 & 58,867 & 103 & 77,954 \\
\hline 23. Illinois, $\cdots \ldots \ldots$. & 4 & 16 & 9,540 & 34 & 26,205 \\
\hline 24. Missouri, ........ & ..... & 9 & 13,750 & 13. & 5,100 \\
\hline 25. Arkansas, $\ldots \ldots$. & $\cdots \cdots$ & 1 & 129 & 1 & 12,600 \\
\hline 26. Michigan, $: \cdots \cdots \cdots$ & 16 & 4 & 9,734 & 37 & 34,120 \\
\hline 27. Florida, $\ldots \ldots \ldots$ & $\cdots \cdots$ & $\cdots \cdots$ & $\cdots \cdots$ & $\cdots \cdots$ & $\because \ldots \ldots$ \\
\hline 28. Wisconsin, ....... & $\cdots \cdots$ & $\cdots \cdots$ & $\cdots \cdots$ & $\cdots \cdots$ & ....... \\
\hline 24. Iowa,,$\ldots . . . . .$. & $\ldots$ & $\ldots \ldots$ & $\begin{array}{r}800 \\
\ldots\end{array}$ & $\cdots \cdots$ & $\ldots \ldots$ \\
\hline 30. Dist, of Columbir & $\because \cdots$ & $\because+0$ & $\because \cdots \cdots$ & $\cdots \cdots$ & ……… \\
\hline Total, ......... & 2,585 & 1,420 & $20,696,999$ & 21,342 & $15,765,124$ \\
\hline
\end{tabular}

South-Down. - Let those who would properly appreciate this excellent race, banish from their thonghts the diminutive mottled original South-down stock of the olden time, with the idea of which the name is apt to be associated in the mind, and contemplate the portrait hero 
presented of the Buck imported in 1838 , by E. Prentice, of Mount Hope, near Albany.

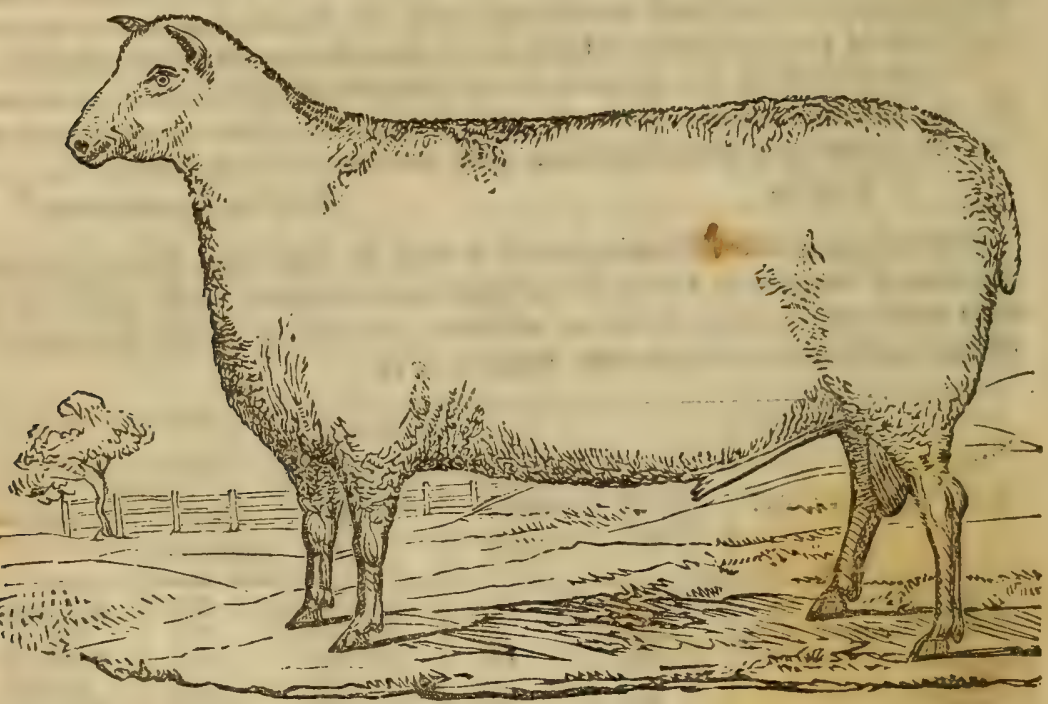

The Sheep on the Green Grass.

Mr. Prentice says they are " in size between the Cotswold and ous native sheep, and will weigh in ordinary flesh from one hundred and sixty to two hundred pounds; the one of which this is an engraving, weighs one hundred and eighty pounds. They are of round, full and beautiful form, and of great weight for their apparent dimensions, possessed of extraordinary vigour and constitution, fitting them for great endurance of keep and exposure. In one flock of about fifty, I have never known an invalid for an hour, or one low in flesh, though their pasture has often been as short as I have ever known one, on which sheep have been sustained."

Of the improved South-down, as they are at this day in great perfection in England, no further description need be added than the fillowing sketch by $\mathbf{M}$. Allen, editor of the American Agrieulturist, in an interesting account of his visit to Mr. Webb, an English farmer, in company with the Hon. Andrew Stevenson, then our minister to England, whose judgment as an agriculturist was well displayed, and whose least service to his country was important, if it consisted in selecting and bringing home some of the finest specimens of Southdown to be found in Great Britain.

"To give an idea of the weight of Mr. Webb's animal, the Southdown buck selected by Mr. Rotch, though only six months old, weighed one hundred and fifty-two pounds on the scales; bishop Mead's, eighteen months old, two hundred and forty-eight pounds; and Mr. Stevenson's, of the same age, two hundred and fifty-four 
pounds, whice 1 wether, exhibited at Cambridge on Christmas day, 1840, weighed dressed, with the head on, two hundred pounds, aside from yielding twenty-eight pounds rough tallow. The average weight of his wethers, however, at eighteen or twenty months old, is but about thirty to thirty-five pounds per quarter. The bucks shear from nine to eleven pounds; and the average shearing of the whole flock is six pounds fifteen ounces, and of a quality of wool that we thought better than the generality of South-downs. The fleece is close and compact, and, we should think, would resist rain, sleet, and snow, nearly as well as the best Merino." Mr. Allen adds, respecting Mr. Webb's sheep, - "They are very hardy, and are never housed in winter, but lie in the open fields, and are fed upon hay, with cut turnips, sugar-beets, or mangel wurtzel. In the summer they are taken to a poor pasture by day, at a distant part of the farm, for change and exercise; and towards night are brought near home, and folded on vetches, clover, or rape. The lambs, after weaning, are turned into fair pasture; and fed about a pint each per day, of beans, oil-cake, or some kind of grain. Mr. Webb says he is an advocate for good feeding, and that a good animal always pays for it. This is our doctrine, and if people want South-downs to starve, they had better take up with the smallest of the old unimproved race."

The editor of the Cultivator adds_- "Messrs Bement and McIntyre, in the vicinity of this city, have beautiful flocks of South-downs; and the flock of Mr. Rotch, of Butternuts, in this State, is one of the best in the Union, embracing, as it does, the blood of the Duke of Richmond's, and Messrs Ellman's and Grantham's flocks, and now that of Mr. Webb's."

"Mr. Rotıh's sheep have proved perfectly hardy, wintering finely on nothing but hay; and we have little doubt that where fine qualities of wool are not the great object in sheep-growing, the South-downs will prove to be one of the best breeds for the farmer."

To ascertain the number and the whereabouts of the importers and breeders of this admirable race of sheep, unequalled for mutton, unless it be $t o$ gratify the coarse taste for fat meat, the reader has but to consult the pages of the Cultivator, the American Agriculturist, and other journals, for the names of Prentice, Rotch, Bement, McIntire, $\mathrm{Bagg}$, and others. The prices, we believe, are from twelve to twenty dollars for thorough breeds.

The Dishley or Batiewell, or new Leicester sheep. - With this breed all persons at all conversant with sheep-breeding must be acquainted; so much so, that it is deemed only necessary to say that according to our observation, which has been not very limited, being among the earliest importers of some of the best of them from one of the best flocks in England, they have been thus accurately characterised :"Heads clean, straight, and broad; bodies round and barrel-shaped; eyes fine and lively ; bones fine and small ;" carried, as we think, by $\mathrm{Mr}$. Bakewell in this last point to an extreme. An English writer of high character, Mr. Ellman, describes the wool of the Bakewell 16 
as being "long, fine, and well calculated for combing, and fleeces weighing about eighty-five pounds at two years old. They fatten kindly and early, and are the most popular sheep for the market, but are not very sure breeders nor good nurses." Mr. James Bagg, of Montgomery, New York, a very large importer of cattle, sheep, and hogs, presents a comparison and an estimate of the value of the only breeds to which we deem it necessary to call the attention of American farmers. The reader will draw his own conclusions. "A Saxon lamb, six months old, weighing $18 \mathrm{lbs}$. at 8 cents, $\$ 1.44$
Merino lamb,

Bakewell,

Cotswold,

South-down, ".

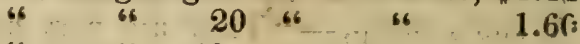

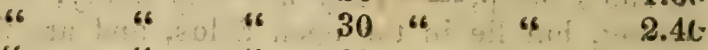

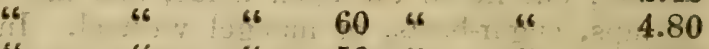

In the second, their wool.

Saxon fleece, weighing $3 \mathrm{lbs}$. at 50 cents, ........... \$1.50

Merino " " 3 " 440 " $4 \ldots \ldots \ldots \ldots \ldots \ldots 1.20$

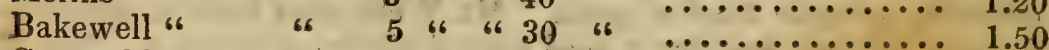

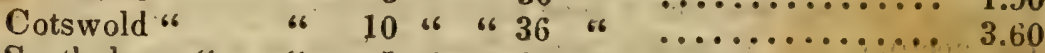

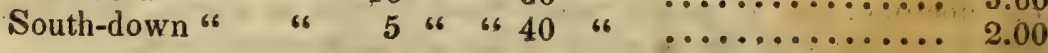

"The above, I think, will show the difference in value of the lambs and fleeces, but no one is to suppose that eight cents per pound is the value of the Cotswold or South-down lamb. They are now worth about twenty to twenty-five dollars each. I would not sell at a less price.

"In the third place, the sheep when full grown.

Saxon sheep, weighing $50 \mathrm{lbs}$. at 6 cents, ............. \$3.00

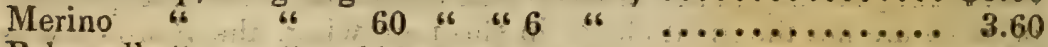

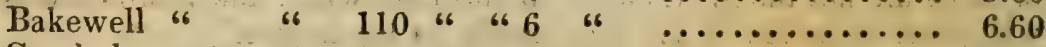

South-down " $" \quad 120$ " 46 " $6 \quad \ldots \ldots \ldots \ldots \ldots \ldots, 7.20$

Cotswold " " 240 " 6 " 6 " $6 . \ldots \ldots \ldots \ldots$ 14.40

"The Bakewell I consider a sheep not at all adapted to this climate, being of a tender constitution, hard to keep, wool coarse, small fleeee; another objection is, when the wool is a few inches long, it parts and leaves the back of the sheep naked; and when exposed to cold storms, the animal is much injured, and many of them die. The Saxon and Merino I find much alike, both of a weak constitution, and require great attention to keep them alive, through the winter; they are also very bad nurses; a great difficulty in rearing their lambs. I have conversed with many gentlemen who keep large flocks of Merino and Saxon sheep, and they all agree what I have stated respecting them to be correct, but they say we must have fine wool.

"I must say that the South-down and Cotswold sheep have exceeded my expectation. I have seen some of the South-down wool manufactured into cloth fine enough for any man; and if people get the pure-blooded South-down sheep, they have an animal in every 
respect that is wanted; their mutton superior to any in the world; of a hardy constitution; the wool good; and no sheep will live on shorter pasture. The South-down has a brown face and legs, or dark grey.

"I consider the Cotswold sheep a hardy animal well adapted for this country; but they want better keep than the South-down; they make great weight, and their fleeces are heavy. I had last year eighteen Cotswold ewes whose fleeces averaged ten and a half pounds, and one buck whose fleece weighed eighteen and a yuarter pounds. I sold a lamb to Mr. Haviland of Long Island, who had it shorn at one year old; the fleece weighed twelve and a half pounds clean wool. I saw some of this breed of sheep slanghtered in Gloucester, England, which weighed seventy-five pounds per quarter. A noted breeder there informed me that they often exceeded that weight.

"Some may say that the South-down and Cotswold lambs cannot weigh one hundred pounds at the age stated. If any doubt it, if they will call on Barg and Watt, of Montgomery, New York, they can see lambs of five months old much heavier.

"Montgomery, N. Y., July 21, 1810."

Those who have rich pastures and abundant food, and whose object is to supply the butcher, would probably best adopt the Cotswold, already spoken of by Mr. Bagg, of which we find, among other inducements, great size and aptitude to fat, with more hardiness and better constitution than the Bakewell. The following item in the seventh volume of the Cultivator may prove interesting on some of these points :-

"I cannot leave this place without giving you some description of six Cotswold wether sheep, bred and fed by Mr. Dunn, with reference to the whole inhabitants of Albany. Mr. Kirkpatrick, who purchased them, says the heaviest sheep weighed two hundred and ten pounds, and the fat on the ribs measured five and a quarter inches. I saw the smallest; the thickness of fat from my own measurement was four and a quarter inches; the price twenty-two dollars each; and the meat sold in the market readily for twelve and a half cents per pound. The fleeces from these sheep averaged about ten pounds each; these are facts from the breeder and the butcher without dimi-

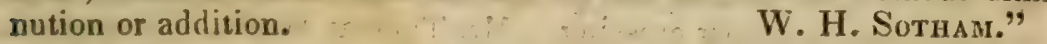

"P.S. Perhaps it will be as well to observe that these lambs were not thought sufficiently good to reserve for breeders, and were the culls of his males:"

An Finglish paper stated that a fleere weighing twenty-three pounds was taken from a Cotswold ram in 1840, owned by J. Gould of Potmore.

Albnny, Fcb. 27, 1840.

Later still, in 1813, a sheep of the Cotswold breed was slaughtered in Albany; live wright, two hundred and sixty pounds; carcass, dressed with head on, two hundred and ten pounds; showing a differ- 
ence of less than one-fifth between the live and death weight. It is added that the only feed of this sheep during the past summer was clover pasture, hurdled with others from 15 th of October to 15 th of November. From that time to his being slaughtered and exhibited, $22 \mathrm{~d}$ of February, he was fed, with three South-down bucks, under cover, with turnips, buckwheat, and clover; one bushel of turnips and three quarts of buckwheat, togrether with two pounds of hay, were fed to the four daily. It is enough to ensure confidence in the accuracy of this statement that it appears to be from the editor of the Cultivator himself.

The Lincolnshire Sireep are described by Mr. Ellman as being "faces white; bones larre; legs white, thick, and rough; carcass long, thin, and weak; wool fine and long, from ten to eighteen inches, weighing per fleece, when killed at three years old, an average of about eleven pounds; flesh coarse grained; slow feeders, calculated only for the richest pastures ; constitutions tender."

Mr. L. D. Cleft, of Somers, New York, had a large flock of this breed in 1810, and states in the Cultivator of that year that he had "raised in 1839 from sixty-four ewes, (chiefly ewes two and three years old), ninety-two lambs, and had not lost a single lamb by reason of exposure." That when his ewes were older, "more than half had twins." Mr. C. says further, in 1811 - "The present winter my primest wethers went to market about the first of December, twentyfour in number; six of these sheep were three years old, and gave a total dead wei ght of eight hundred and seventy-nine pounds, or one hundred and forty-six and a half pounds per carcass, equal to thirtysix and a half pounds per quarter; and I am informed that one of these sheep gave thirty-six pounds of caul or rough fat." 'This breed is sometimes mistaken, or passed off for the Dishley or Leicester breed, which is more perfectly formed, of perhaps somewhat earlier maturity, but not so large by eight or ten pounds to the quarter.

The Cotswoud. - The same English writer, in whom we have already expressed our respectful confidence, treats of the Cotswold sheep as one of the "varieties" of the Lincolnshire, the "Treswater" being another, and describes the Cotswold as "in most resperts resembling the parent breed, but superior; wool not so long as that of the original s rt; mutton fine grained and full sized, capable of great improvement by proper crossing. Mr. Thomas Wells, of Hampnett, has favoured us with the following particulars on the improved condition of this excellent breed:- "The Cotswold sheep, previously to being crossed with the Leicester, were of large size, well woolled, and good sucklers, but high on the shoulders, with a hollow behind, inclined to a thin fore-flank and eoarseness in b sne. In their improved state, they are rendered not only much fincr in bone, but fit for market in half the period they were formerly, as they were not fatted until three or four years old; but now they are seldom offered to a butcher at more than two years. Their size is not quite so large as before the cross, but when fat, average about the same weight, which by com- 
mon feeding is about fourteen or sixteen stone, and will by extraordinary feeding arrive at about twenty-five or twenty-six stone. As yearlings they possess the striking qualification of averaging under good management ten or eleven stone, which is found to answer much better than keeping them longer. These merits, in addition to the great weight of combing wool they produce, has greatly increased their value. It is highly requisite to guard against breeding them too fine. If they are well bred they are equally as hardy as they were formerly, but if bred too fine they lose in constitution, are unable to support their young, produce meat of a bad quality, and not having a proportionate quantity of lean, their wool becomes short and too fine in quality, and they frequently become naked bellied, which occasions grcat loss in the weight of their fleece." It is this "breeding too fine," in other words too closely, that has impaired the constitution of the Bakewells or Dishleys, made them bad nurses, and diminished too much the proportion of lean meat. The true problem for the sheep farmer is what breed will give him one year with another the greatest profit to the acre. If pasturage be short, it is clear that a greater number of sheep of smaller size will gather more in a given time than a smaller number of heavier sheep; and we believe that keeping in view the resources for maintaining sheep through the year, the safer plan is to take a breed of hardy constitution and of a size not so large, such as the South-down, and thus hit the happy medium; and, in the general way, we have no hesitation in hazarding the opinion for what it is worth, that the same principle - moderate size and thriftiness of habit and hardiness of constitution - is the one on which it is most expedient for American husbandmen to act, in the great majority of cases, in regard not only to sheep, but to cattle, hogs, horses, and even poultry.

At a meeting of the Pennith Agricultural Society in England, in 1839 , the awards of the judges were in favour of the middling sizer sheep. At the dinner, on the health of the judges heing proposed, Mr. Gray, the chairman, speaking on the comparative profits to the grazier of large and small sized sheep, made the following among other remarks :-

"I dare say that the opinion of the judges with respect to sheep has been much censured, although I declare I have not heard any observations to that effect. My reasons for supposing so is this that people who have not great experience in the qualities and niceties connected with every description of stock, are apt to look principally at that which fills the eye, and to form a favourable opinion of animals upon a large scale; and this is particularly the case with respect to r:the Leicester sheep. I have had considerable experience with sheep of this description, having in former times kept a flock of between nine hundred and one thousand Leicester ewes, and therefore I have some title to speak upon the subject. I say, then, that the largest sheep are the least profitable. If it can be ascertained, as I believe it has been, that you can feed on an acre of land a greater nuxaber or 16 * 
pounds of mutton in carcases of from eighteen to twenty pounds per quarter than in carcases of from twenty-eight to thirty pounds, then every one must agree that the advantages are on the side of the smaller carcases. The reason of this is obvious. In times of drought and scarcity, a small animal can collect as much food as a larger one, and having a smaller carcass, it derives much more advantage from it. While, therefore, the larger animal is losing in condition, the smaller one, if not improving, remains stationary; and when the period arrives at which abundance of food can be obtained, it almost immediately reassumes its position, and is fit to go to the market sooner than the larger animal. I do not presume to offer anything like dictation to this meeting, but I am confident that those gentlemen present, who have had experience on this subject, will bear me out in saying that there are advantages in breeding the description of stock to which I have been referring, which do not attach to animals of better appear. ance and larger size."

Nevertheless, we should say, that if the farmer have at command a superabundance of grass and corn, which it would be his interest to convert into meat, that its value may be more condensed and portable, then the most economical machine or animal is that one which above all will, as a machine, soonest convert that superabundance of food into meat of a kind that will bring the best return in the market.

In all ages, among nations in any degree removed from the lowest stage of barbarism, a census in some form has been deemed necessary to an understanding of their condition, resources, and means of defence; and the fullness and accuracy of these periodical returns may be said in some sort to mark the progress of political science and civil polity. As yet the census of the United States is altogether defective in many particulars connected with important questions of political economy, and there is too much reason to believe that the actual returns have been made with a degree of carelessness and want of uniformity sufficient to create distrust in the results as they have been published. Yet such as it is, it forms the most reliable means of calculation on questions like the one in hand. We have, it seems, no return, for instance, (as we happen to have had occasion to observe) either of the number of mules or of the turnip crop in the United States. In the following table we have embraced the returns of hay and of potatoes, as these in the northern States constitute the chief food of sheep, as before said, for four or five months in the year. We have added to the table, as nearly as could well be ascertained, the number of acres to a sheep in the several States and territories; and the reader will be struck with the fact, that while fine wonl may be transported at such a trifling expense in proportion to its value, they should be in such a very large proportion located very near to the wool market, and on land which bears the highest price, while the natural distribution would appear to be to rear the fine wool on the cheap table-lands of the mountains, and the limitless prairies of the west. It has been ascertained that wool may be sent from the prairies of Illinois to 
Lowell, Massachusetts, inland, for only two dollars twelve and a half cents per hundred pounds, or forty-two dollars and fifty cents per ton.

Distribution of sheep and wool, hay and potatoes, in the United States, according to the census of 1840 , with a calculation of the number of sheep to the acre, in each of the States and 'Territories :-

\begin{tabular}{|c|c|c|c|c|c|}
\hline Namis of State, \&ec. & Sheep. & $\begin{array}{l}\text { Pounds of } \\
\text { wool. }\end{array}$ & $\begin{array}{l}\text { Tons of } \\
\text { hay. }\end{array}$ & $\begin{array}{l}\text { Bushels of } \\
\text { potatoes. }\end{array}$ & $\begin{array}{l}\text { No. of } \\
\text { acres to } \\
\text { a sheep. }\end{array}$ \\
\hline 1. Maine, . & 649,264 & $1,465,551$ & 691,358 & $10,312,280$ & 50 \\
\hline 2. New Hainpshire, & 617,390 & $1,260,517$ & 496,107 & $6,206,606$ & 10 \\
\hline 3. Massachusetts,.. & 378,226 & 941,906 & 569,395 & $5,385,652$ & 12 \\
\hline 4. Rhode Island, ... & 90,146 & 183,830 & 63,449 & 911,973 & 10 \\
\hline 5. Connecticut, .... & 403,462 & $88 !, 870$ & 426,704 & $3,414,238$ & 10 \\
\hline 6. Vermont,....... & $1,681,819$ & $3,699,235$ & 836.739 & $8,869,751$ & $3 \frac{1}{3}$ \\
\hline 7. New York, ..... & $5,118,777$ & $9,845,295$ & $3,127,047$ & $30,123,614$ & 2 \\
\hline 8. New Jersey, ..... & 219,285 & 397,207 & 334,861 & $2,072,069$ & 24 \\
\hline 9. Penusytrania, . & $1,767,620$ & $3,048,564$ & $1,311,643$ & $9,535,663$ & 24 \\
\hline 10. Delaware, ...... & 39,247 & 64,404 & 22,483 & 200,712 & $33 \frac{1}{2}$ \\
\hline 11. Maryland, ...... & 257,922 & 488,201 & $106,687 \frac{1}{2}$ & $1,036,433$ & $33 \frac{2}{3}$ \\
\hline 12. Virginia, ... & $1,243,772$ & $2,538,374$ & $364,708 \frac{1}{3}$ & $2,944,660$ & $33 \frac{1}{2}$ \\
\hline 13. North Carolina, . & $5: 38,279$ & 625,044 & 101,369 & $2,609,239$ & 50 \\
\hline 14. South Carolina, & $2: 32,981$ & 299,170 & 24,618 & $2,698,313$ & 100 \\
\hline 15. Grorgia, ......... & $2 i 7,107$ & $3 \% 1,303$ & $.16,969 \frac{3}{4}$ & $1,291,366$ & 143 \\
\hline 16. Alabana, ....... & If 3,243 & 220,353 & 12,718 & $1,708,356$ & 240 \\
\hline 17. Mississippi, .... & $12-, 367$ & 175,196 & 171 & $1,630,190$ & $25 n$ \\
\hline 18. Lnuisiana, ...... & 98,072 & 49,283 & $24,(i 51$ & 834,341 & 50 \\
\hline 19. Temnesste, ..... & 741.593 & $1,010,232$ & 31,233 & $1,904,370$ & 50 \\
\hline 20. Kentucky, ..... & $1.008,240$ & $1,786,847$ & 88,306 & $1,055.085$ & 25 \\
\hline 21. Ohio, ........... & $2,028,401$ & $3,6,5,315$ & $1,022,037$ & $5,805,021$ & 10 \\
\hline 22. Indiana, ....... & 675,982 & $1,237,919$ & 178,029 & $1,525,794$ & $33 \frac{3}{3}$ \\
\hline 23. Illinois,...... & 395,672 & 650,007 & $\mathbf{1 6 4 , 9 3 2}$ & $2,025,520$ & 100 \\
\hline 24. Missouri, ....... & 348,018 & 562,265 & 49,083 & 783,768 & 125 \\
\hline 25. Arkansas, ...... & 42,151 & $64.94: 3$ & 586 & 293,608 & $1,0(1) 0$ \\
\hline 26. Michigau, ..... & 99,618 & 153,375 & 130,805 & $2,109,205$ & 250 \\
\hline 27. Florida, ....... & 7,198 & 7,285 & 1,197 & 264,617 & 5,000 \\
\hline 28. Wisconsin, ..... & 3,462 & 6,777 & 30,938 & 419,608 & 14,285 \\
\hline 29. Іоwu, $\ldots \ldots .$. & 15,354 & 23,039 & 17,953 & 234,063 & 2.500 \\
\hline 31. Dist of Columbia & 706 & 707 & 1,331 & 12,035 & 100 \\
\hline Total. . & $19,311.374$ & $35,802,114$ & $10,248,108 \frac{3}{4}$ & $108,298,060$ & \\
\hline
\end{tabular}

Since writing thus far, an opportunity has been embraced to obtain some information as to the resources of Western Virginia and the Carolinas. We were informed hy a member of congress from Pittsylvania county that his flock of two hundred go through the winter one year with another at a cost for food of not exceeding ten dollars for the whole flock. It was only yesterday, 1st of February, that, in conversation with Mr. J. Wadsworth, of Geneseo, President of the New York State Agricultural Society, eminent for his intelligence and enterprise, as an American farmer of great opulence and influence, we learned that coarse wool, under influences of recent existence, is getting into greater demand. He observed that there were practical farmers in New York, though he was not prepared to say it could be realised, who contended that they could pursue sheep husbandry profitably on land costing thirty dollars the acre. 
How different are the circumstances of sheep husbandry in the North, may be estimated by the following account of his treatment of his flock, by Mr. Leonard Jarvis, of Claremont, New Hampshire, a sheep breeder of great intelligence and experience, owner of four distinct families of fine-woolled sheep. He says, in a letter to the Rev. Mr. Coleman, "I annually commence with dry fodder by the middle of November, and discontinue by the 5th of May, (nearly six months); generally, however, for the first and last fifteen days, giving no hay, unless the grcund should be covered, but feeding ahout half a gill of Indian corn to each sheep twice a day. As far as my experience extends, a ton of good hay will suffice for ten sheep with the above quantity of grain; they are fed from racks in the yard, and have sheds to retire to at will; I have fed under cover, but believe that it has a tendency to diminish the appetite and weaken the constitution. 'They are kept in separate yards, in number from fifty to one hundred, taking care to keep those of about the same degree of strength to themselves, and have running water through; when the ground is covered with snow, I think they do well without it. I allow about four bushels of sell to the hundred sheep, the greater part of which is consumed when the sheep are at grass. My bucks run with the ewes from the 1st to the 10 th of December, allowing three to one hundred. The number of lambs reared depends much upon the season. Sixty lambs to the hundred ewes may be the average from flocks of quality like mine; from coarser flocks the return is greater. The ewes are not permitted to receive the buck until after they are two years old; and I prefer bucks from two years old to four."

We must here close this introduction to the work on the "diseases of sheep" with the following correspondence, opened on the part of the editor, in the hope of obtaining some reliable information as to the advantages held out for the growth of sheep and the manufacture of woollen goods in the distriots of country which have been strangely overlooked since facilities were created and the rage inspired for emigrating to the far west! leaving behind immense tracts of cheap land, abounding in water-power, and adapted to the growth of everything conducive to successful sheep husbandry; in truth, wanting nothing but capital and industry. In presenting Mr. Clingman's letter, we may express the hope that its interesting character, and the freshness of the country it opens to our view, will atone to the reader for the length and dryness of the route by which he has been led to it.

How. T. L. Cuneman,

Washington, 30th January, 1844.

Dear Sir, - I have lately had occasion, as a leisure hour has offered, to bestow some consideration on the sheep husbandry of the United States; in the course of which it has occurred to me that the people of Virginia and North Carotina, Kentucky and Tennessee, have not availed themselves to the extent that they might probably do of that source of reward for labour and capital. It seems to me that the uniddle or 
hilly, and the mountainous portions of those States and of Maryland, must be pecu. liarly adapted to the constitution of au aniunal which appears to have a natural appetency for rolling and elevated pastures. Or is it that the mountains in Yancey county fur instance, are almost exclusively covered with rocks aid timber or wood, affurding wo scupe either for the plough or for grazing? Its elevation of some thou. sand teet above the sea secures it, without doubt, against the autumnal diserses of the tide-water country. Is it that the price of the land there forlids investment in it with a view to such employment of capital? Or why is it that the swarms of hardy yeomanry that annually migrate from the North sbould not settle down in districts described by the latest and ablest geographical authority, $\mathbf{D}_{\mathbf{A}} \mathbf{R B Y}$, as being " highiy salubrious and well watered," instead of wending their weary way to regions less blessed with health, and so remote frum the comforts of denser populations?

If time will allow you, Sir, to auswer according to your knowledge and observation how far my impressions are correct, as to the resources of Norih Carolina in the particulars to which I have adverted, you will much oblige me; and the earlier you can favour the with an answer, the more will the kindness be esteened, by

Yours, with great respect,

J. S. SKINNER.

Housc of Representatives, Feb. 3, 1844 .

Dear Sir,-Your favour of the 30th ultimo was received a day or two since, and I now avail myself of the very first opportunity to answer it. I do so most cheerfully, because, in the first place, I am happy to have it in my power to gratify in any manner one who has done so much as yourself to diffuse correct information on subjects most important to the agriculture of the country; and, secondly, Lecause I feel a deep interest in the subject to which your inquiries are directed.

You state that you have directed some attention to the sheep husbandry of the United States, in the course of which it has occurred to you that the people of the mountain regions of North Carolina, and some of the other southern States, have not availed themselves sufficiently of their natural advantages for the production of sheep. Being myself well acquainted with the western section of North Carolina, I may perhaps be able to give you most of the information you desire. As you have directed several of your inquiries to the county of $Y$ ancey, (I presume from the fact, well known to you, that it contains the highest mountains in any of the United Statpg!, I will, in the first place, turn my attention to that county. First, as to its elevation. Dr. Mitchell, of our University, ascertained that the bed of Tow river, the largest stream in the county, and at a ford near itscentre, was about twenty-two bundred feet above the level of the ocean. Burnsville, the seat of the court-house, he found to be between two thousand eight hundred and two thousand nine hundred feet above it. The general level of the country is, of course, much above this eleva. tion. In fact, a number of the mountain summits rise above the height of six thousand feet. The climate is delightfully cool during the summer; in fact there are very few places in the county where the thermometer rises ahove eighty degrees on the hottest day. An intelligent gentleman who pussed a summer in the northern part of the county (rather the more elevated portion of it) informed me that the thermomeler did not rise on the hottest days above seventy-six degrees.

You ask, in the next place, if the surface of the ground is so much covered with rocks as to render it unfit for pasture? The reverse is the fact; no portion ot the county that I have passed over is too rocky for cultivation; and in many gections of the county one may travel miles without seeing a single stone. It is only about 
the tops of the higher mountains that rocky precipices are to be found. A large pnrtion of the surfuce of the county is a sort of elevated table-land, undulating, but seldom too broken for cultivation. Even as one ascends the higher mountains, he will find occasionally on their sides flats of level land containing several hundred acres in a body. The top of the Roan (the highest mountaiu in the county except the Black) is covered by a prairie for ten miles, which affords a rich pasture during the greater part of the year. The ascent to it is so gradual that prirsons ride to the top on horseback from almost any direction. The same may be said of many of the other mountains. The soll of the county generally is uncommonly fertile, producing with tolerable cultivation abuudant crops. What seems extraordinary to a stranger is the fact that the soil becomes richer as he ascends the nountains. The sides of the Roan, the Black, the Bald, and others, at an elevation even of five or six thousand feet ahove the sea, are covered with a deep rich vegetable mould, so soft that a horse in dry weather often sinks to the fetlock. The fact that the soil is frequently more fertile as one ascends is, I presume, attribitable to the circumstance that the higher portions are more commonly covered with clouds; and th: vegetable matter being thus kept in a cool moist state while decaying, is incorporated to a greater degree with the surface of the earth, just as it is usually found that the north side of a hill is richer than the portion most exposed to the action of the sun's rays. The sides of the mountains, the timber being generally large, with little undergrowth and brushwood, are peculiarly fitted for pasture grounds, and the vegetation is in many places as luxuriant as $j$ is in the rich savanna of the low country.

The soil of every part of the county is not only favourable to the production of grain, but is peculiarly fitted for grasses. Timothy is supposed to make the largest yield, two tons of hay being easily produced on an acre, but herds-grass, or red-top, and clover succeed equally well; blue grass has not been much tried, but is said to do remarkably well. A friend showed me several spears which he informed me were produced in the northern part of the county, and which by measurement were found to exceed seventy inches in length. Oats, rye, potatoes, turnips, \&cc., are produced in the greatest abundance.

With respect to the prices of land, I can assure you that large bodies of uncleared rich land, most of which might be cultivated, have been sold at prices varying from twenty-five cents to fifty cents per acre. Any quantity of land favourable for sheepwalks might be procured in any section of the county at prices varying from one to ten dollars per acre.

The few sheep that exist in the county thrive remarkably well, and are sometimes permitted to run at large during the winter without being fed and without suffering. As the number kept by any individual is not large enough to justify the emplnyment of a shepherd to take care of them, they are not unfrequently destroyed by vicious dogs, and more rarely by wolves, which have not yet been entirely exterminated.

I have been somewhat prolix in my observations on this county, because some of your inquiries were directed particularly to it, and because most of what I have said of Yancey is true of the other counties west of the Blue Ridge. Haywond has about the same elevation and climate as Yancy. The mountains are rather more steep, and the valleys somewhat broader; the soil generaliy not quite so deep, but very productive, especially in grasses. In some sections of the county, however, the soil is equal to the best. I have seer.

Buncombe and Henderson are rather less elevated; Ashville and IItndersonville, the county towns, being each about two thousand two hundred teet above the sea. 
The climate is much the same, but a very little warmer. The more broken portions of these counties resemble much the mountainous parts of Yancey and Haywood, but they contain much more level land. Indeed the greater portion of Henderson is quite level. It contains much swamp land, which, when cleared, with very little if any drainage, produces very fine crops of herds-grass. Portions of Macon and Cherokee counties are quite as favourable, both as to climate and soil, as those above described. I would advert particularly to the Valley of the Nantahalah, in Macon, and of Cheoh, in Cherokee. In either, for a comparatively trifling price, some ten or fineen miles square could be procured, all of which would be rich, and the major. part sufficiently level for cultivation, and especially fitted, as their natural meadows. indicate, for the production of grass.

In conclusion, 1 may say, that as far as my limited knowledge of such matters authorizes me to speak, I am satisfied that there is no region that is more favourable to the production of sheep than much of the country I have described. It is everywhere healthy and well watered. I may add, ton, that there is water-power enough in the different counties composing my congressional district to move more machinery than human labnur can ever place there-enough perhaps to move all nuw existing in the Union. It is also a rich mineral region. The gold mines are worked now to a considerable extent. The best ores of iron are found in great abundance in many places; copper, lead, and other valuable minerals exist. That must one day become the great manufacturing region of the South. I doubt if capital could bo used more advantageously in any part of the Union than in that section.

For a number of years past the value of the live stock (as ascertained from books of the Turnpike Company) that is driven through Buncombe county, is from two to three millions of dollars. Most of this stock comes from Kentucky and Ohio, and when it has reached Asheville it has travelled half its journey to the more distant parts of the Southern market, viz., Charleston and Savannah. The citizens of my district, therefore, can get their live stock into the planting States south of us at onehalf the expense which those of Kentucky and Ohio are obliged to incur. Not only sheep, but hogs, horses, mules, and horned cattle can be produced in many portiong of my district as cheaply as in those two States. This must ere long become the great manufacturing region of the South, \&c.

I have thus, sir, hastily endeavoured to comply with your request, because you state that you would like to have the information at once. Should you find my sketch of the region a very unsatisfactory and imperfect one, I hope you will do me the favour to remember that the desk of a member during a debate is not the most favour. able position for writing an essay.

With very great respect, yours,

\section{J. వ. STINMER, ESQ.}

\section{T. L. CLINGMAN.}

As to the usual weight of the carcass of the South-down and of the fleece, as well as of the value of the Cotswold compared with that of the Merino, it may be useful to state that, according to the most recent information to be fully relied on, Mr. Bement's ewes, (near Albany, New York), about seventy-five in number, averaged last year three and a half pounds washed wool per head-Mr. McIntire's about the same. The South-down wool sold at Albany last year at twentyeight to thirty cents per pound, where at the same time Merino wool sold for thirty-four to thirty-six. 
The carcass of the improved South-down, fatted, may be put down at eighteen to twenty-five pounds the quarter. Mr. McIntire killed, as before stated, a cross-breed Cotswold and South-down wether last year, that weighed, dressed, with the head on, two hundred and ten pounds. He sold one very recently that weighed about one hundred and seventy-five pounds. Mr. Bement's price for fourteen - all he has for sale - South-down ewes, a year old this spring, which have not been tupped, is twelve dollars a head; and a buck to accompany them at the same price. Mr. McIntire's price for ten ewes that will have lambs in April, is seventeen dollars a head, and will put in a good buck at same price. This statement is made for the benefit of readers not residing in the neighbourhood of flocks of sheep of this kind. The demand for all kinds of improved sheep is increasing, and will increase in the south-west.

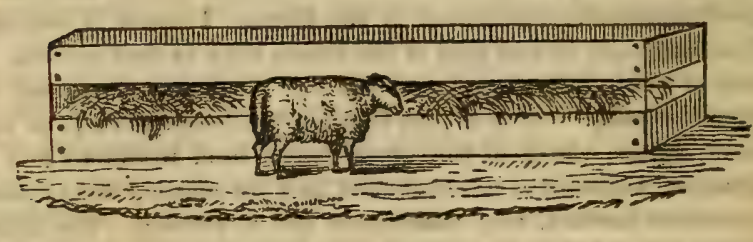




\section{DISEASES OF SHEEP.}

THis has heen a sadly neglected branch of veterinary inquiry and practice. The nature and treatment of the diseases of sheep form little or no part of the instruction given in some of our veterinary schools, and seldom come under the cognizance of the surgeon afterwards. The shepherd undertakes the treatment of foot-rot, and scab, and hoove; and with regard to the other maladies to which this animal is subject, they are either suffered to take their course, or, if a veterinary practitioner is ever employed, it is when the disease is firmly established, or the whole flock infected, and medical aid is fruitless. This is much to be lamented, and very absurd ; for although an individual sheep may not be worth much, yet a numerous flock forms no inconsiderable portion of the farmer's wealth, and the frequent mortality among these animals is a very serious loss to him.

The internal structure of the sheep so nearly resembles that of the ox, that I will content myself with referring to the anatomy of the ox, as described in the early part of this work. The diseases of both have a very great resemblance in their nature and cause, and progress, and medical treatment. 'The same drugs are administered to both. There cannot be a better purgative for sheep than Epsom salts : there is no better fever medicine than the digitalis, emetic tartar, and nitre. The principal difference is in the quantity to be administered; a sixth or eighth part of the usual dose for cattle will be sufficient for the sheep. The quantity of blood taken will depend on the size of the animal and the nature of the disease. Four ounces would be a fair average bleeding from a lamb, and a pint from a full-grown sheep. Shepherds are apt to bleed from the eye-vein; but the blood generally flows slowly, and, after all, the proper quantity will not always be obtained. The best place for bleeding is from the jugular, as in cattle. A ligature should be tied round the neck, and then the vein will rise so evidently that it cannot possibly be mistaken. The vein should be opened with the lancet commonly used for the human being: the orifice should be large, and the blood obtained as quickly as possible. 


\section{SECTION I.}

\section{THE LAMBING SEASON .}

The ewe goes with lamb five months. The general time of yeaning is about the end of March, but in some of the western counties, and particularly in Dorsetshire, by which the metropolis and many of the towns in the west are principally supplied with house-lamb, it is so contrived that the lambs shall be dropped in the middle or even the beginning of February. With the best care a great deal of danger attends this early lambing, and even at a later period a few cold nights are fatal to many of the lambs. There is nothing that requires more reformation than the treatment both of the ewe and the lamb at the ime of yeaning.

During the time of gestation more attention is required than is generally paid. To enable the ewe to produce her lamb with comparative safety, she should not be too well fed. One of the most prevalent causes of puerperal fever, or dropping after calving, in the cow, is her too high condition. It is more particularly so with the ewe; and there are few things that the farmer should be more careful about than that the fair, but not unusual of forced, condition of the animal is preserved. A week or two before the time, a little better keep may be useful in order to give them sufficient strength for the lambing. It is a kind of middle course which the farmer has to pursue, and the path is not very difficult to trace: too high condition will dispose to fever; on the other hand, with too poor keep the ewe will not have sufficient strength to go through the process safely, nor will she have milk enough for the lambs. If the dam has not sufficient support previously, the lamb will be weakly when it is dropped, and will not thrive well afterwards.

When the time of yeaning approaches, a little care may prevent a very great loss to the farmer. The ewes should be brought as nearly home as possible. They should be sheltered from the wind, if it be only by a high and thick hedge; but a kind of shel, however rudely constructed, would abundantly pay the expense of building it. At night, particularly, they should be folded in some sheltered place.

At the period of lambing the shepherd should be far more attentive than he is frequently found to be, and especially than he is if the pelt of the dead lamb is absurdly made his perquisite. If the master's loss is the servant's gain, it will not be surprising if casualties occur. A reward, increasing in proportion to the number of ewes and lambs saved, would do more than any other thing to save both the dam and her offspring. The care of the farmer or lamber will vary a great deal according to the period of the year and the state of the weather. In the early lambing the greatest losses are at the beginning: they arise principally from cold. In Narch or April the latter part of the 
lambing season is most dangerous, for there is more abundant keep, and more tendency to inflammation.

The clatting of the ewes is a very useful practice now. They are thrown, and a portion of the wool is removed from their tails and udders. The sticking together of the wool from the purging to which the ewe is often subject in the early part of the spring, when the grass is fresh, has lost many a lamb. When the udders are thus cleaned, the lamber will more easily perceive the stain on the part, which, and which alone, will sometimes tell him whether the ewe has yeaned: for it is no uncommon thing for a young ewe to desert her lamb, and be found grazing with the rest of the flock as unconcernedly as if nothing had happened.

An experienced lamber will almost always tell when the ewe is $a b r$ t to yean. If he finds her soon afterwards taken with labour pains, and they continue to succeed each other regularly, and she remains lying down, he will talie great care not to disturb her; but if a couple of hours pass, and the lamb is not produced, he carefully examines her. If the nose and the tips of the toes have presented themselves, and the lamb seems to be in a proper position, but the head is large, or the passage is narrow, he leaves her again for another hour; but if there is evidently a false presentation, he introduces one or two fingers, or his hand, well guarded with oil, puts the young one in the proper position, and nature speedily effects the rest.

The principal art of the lamber is to know when he should interfere. In every case of false presentation his help should be ready and immediate; but otherwise he should very rarely meddle with the ewe, except the mother is nearly exhausted, or the life of the young one appears to be in danger. One moment's observation will discover the state of the mother; and the degree of protrusion of the tongue of the young one, and its colour, will not often deceive with regard to him. When the tongue hangs far from the month, and is getting livid or black, it is high time for the lamber to interfere.

The lamber should use as little violence as possible; but then he should recollect that the ewe will often bear a great deal of force being applied withont the slightest injury to her, and sometimes with no great danger to the little one. 'The exhausted state of the one or the other will regulate the degree of force. When there is much exhaustion, no time is to be lost, and some strength should be applied in the extrication of the lamb.

The state of the weather, too, will somewhat regulate this. In cold weather more time may be allowed. The process of parturition is then slower. In warm weather there is more tendency to fever, and the ewe should not be suffered to exhaust herself too much.

Unnatural presentations are often very awkward things to have to do with. The ewe should be driven into the pound, and after having rested a few minutes, some of the fingers, or the hand, if it is small, should be introduced into the vagina. If only one leg presents, and the shoulder thus forms an obstruction, the other leg will generally 
be easily laid hold of and brought down. If the neck is bent, and the crown of the head presents itself, it may be pushed back, and the two fore-paws brought into the passage, and then the muzzle will naturally follow. If the foetus lies sideways, the cord and the position of the legs will enable the shepherd to distinguish between the spine and the belly. The turning is sometimes a difficult thing; but practice will often give the lamber a great deal of cleverness in this operation.

In extreme cases, and when the lamb is evidently dead, it may be necessary to introduce a blunt-pointed knife into the uterus, and cut the little animal to pieces. The greatest care must be taken that the mother is not wounded, for that would produce inevitable death. When the lamb has been thus taken away piecemeal, a little physican ounce of Epsom salts, with a few grains of ginger - should be given to the mother, who should then be left undisturbed for several hours.

The ewe, and especially if she was in high condition, is occasionally subject to after-pains. Some of the country-people call it heaving. It continues many hours, and sometimes exhausts and destroys the animal. It is particularly dangerous if she has been too well kept, and much force has been used in extracting the lamb. Twenty drops of laudanum should be given in a little gruel, and repeated every second hour until the pains abate. It will always be prudent to bleed the ewe if she is not better soon after the second dose of the landanum.

The womb is sometimes forced ont of the orifice when great force has been used in extracting the lamb. It must, if necessary, be cleaned with warm water, and carefully returned by a person with a small hand. Gentle and continued pressure will effect this much sooner and safer than the application of the greatest force. It will, however, again protrude if a couple of stitches with tolerably strong twine are not passed through the lips of the orifice. If the womb is thus returned before it has been much bruised or inflamed by hanging out, there will be little danger to the mother, and she may suckle her Jamb as usual. When she has accomplished that, she should be fattened, for the same accident would almost certainly happen at her next parturition.

Attention should now be paid to the lamb, and it requires it even more than the mother. It is want of care that causes the loss of mose than fonr-fifths of the dead lambs. The principal evil is exposure to cold. If the weather is severe, great numbers of lambs are often lost in a single night. A few hurdles with straw, or a warm quick hedge, or a shed for them to go into, would save the greater part of them. The farmer needs but to use a little observation in order to be convinced how eagerly the ewes and the lambs seek that shelter, and how safe they are compared with others that are exposed. Some breeds are more hardy than others, but the hardiest of them will not endure absurd and cruel neglect and exposure. Let the farmer think 
of the sudden change from the warmth of the mother's womb to the driving sleet, and the cold wet ground: he will not wonder that so many of his lambs are palsied and starved to death.

The lambs are not quite out of danger when a day or two has passed after they have dropped. They live for the first week or fortnight on the mother's milk, and then begin to imitate their parent and graze a little; indeed they have not their teeth up to enable them to graze at first. 'I'hey should not be put on too good pasture at this early period, for the change of food is often dangerous. A lamb of a fortnight old will often sicken suddenly, refuse the teat, cease to ruminate, swell, heave, and die, in less than twenty-four hours. On being examined, the stomach will sometimes be found enormously distended, at other times there will be little food in it, but there al ways is a great deal of bile in the upper intestines, with inflammation there, the evident cause of death, and produced by the change of food. Those who die at this early period are often called gall-lambs, from the great quantity of bile found in their intestines. When, at three or four months old, the lamb is perfectly weaned, he is subject to a similar complaint, and from a sinilar cause. The lamb should certainly have better pasture when he is deprived of his mother's milk, but the change should not be sudden and violent.

Physic will evidently be required here, such as Epsom salts in doses of half an ounce every second or third day; and if there is much swelling, the stomach-puinp will be used with advantage, both in extricating the gas, and in injecting warm water into the stomach with an intention either to cause vomiting or to wash out the contents of the stomach.

The operation of castration is a very simple one in the sheep, and yet is often attended with danger, sometimes resulting from the unskilfulness of the operator, and at other times from some unfriendly state of the atmosphere. I have known on the same farm, and the saine gelder being employed, that in one year not a lamb has been lost, and in the following year several scores. Generally speaking, however, the fatal result is to be attributed to bad management. The younger the lambs are the better, provided they are not very weak. From ten days to a fortnight seems to be the most proper time, or, I may say, as soon as the testicles can be laid hold of. I would advise the fariner never to set apart a day when the whole or the greater part of his male lambs are to undergo the operation, for many of them will then be too old, and he will assuredly lose some of them. He should take thein as soon as they are ready, although there may be only a few at a time.

'The lamb being well secured, the scrotum or bag is to be grasped in one hand high up, and the testicles pushed down as low as possible: two incisions are then to be made across the bag at the bottom of it, and the testicles forced nut. The gelder now often takes the stones between his teeth, and bites the cord asunder. This is a nasty and a crus? way of proceeding. The better way is to draw the testi17 * 
cles down an inch or more from the scrotum, and then to cut through the cord close to the scrotum with a knife that is not very sharp. Scarcely a drop of blood follows when the cord is thus separated; the end of the cord retracts into the bag, and there is not half the danger of inflammation which there is when the cord is gnawed and torn by the teeth.

Except the lambs are very weakly, and the ewes much exhausted and emaciated, it will not be requisite to give any medicine after yeaning. In the great majority of cases the animals will do a great deal better without it. Should, however, tonic medicine be necessary, $I$ know nothing better than the following:-

$$
\text { RECIPE (No. 1). }
$$

Take gentian root, powilered, one drachm; caraway powder, half a drachm; tinc. ture of caraway, ten drops. Give in a quarter of a pint of thick gruel.

If the ewes will not feed well at all, they should be forced with good gruel, and the best is made of equal parts of oat and linseed meal.

\section{SECTION II.}

THE DISEASES OF YOUNG LAMBS.

These are numerous, and many of them dangerous; some belonging exclusively to the period which $I$ have been describing, and others often occurring when the animals get a little older.

\section{COAGULATION OF THE MILK.}

I have spoken of this when treating of the diseases of calves. The lamb is, if possible, more subject to this curdling of the milk than the calf is, and it carries off the finest and best of the flock. The farmer likes to see his lambs growing fast; but it is possible to make more haste than good speed. The lamb may have excess of nutriment, and particularly of its mother's milk. When a lamb thrives at an extraordinary rate, the bag of the mother should be examined, and if it is too large and full, it will be prudent to milk away daily a little of its contents; otherwise the yet weak stomach of the young animal may have more coagulated milk in it than it can digest. All the milk that is swallowed by the young lamb coagulates in the stomach, and if it accumulates too fast, the stomach will become perfectly choked with it, and the lamb will be destroyed. Two pounds of curdled milk have been found in the stomach of a lamb. When a thriving lamb, with a healthy mother having a full bag, begins all at once to be dull, and stands panting and distressed, and can scarcely be induced to nove, and is considerably swelled, it is probably from this cause.

In this disease there is often apparent purging of a light colour, 
which is in fact the whey passing off whilst the curd accumulates and produces obstinate constipation.

'The first thing to be done is to administer an alkali, to aissolve the mass, such as magnesia, in doses of half an ounce twice a day; after which two to four drachms of Epsom salts, with a little ginger, dissolved in warm water, and the warm water often repeated, if necessary, by means of the stomach-pump. The farmer with a valuable flock of sheep will find the stomach-pump as useful for them as for cattle. When the bowels have thus been opened, and the curdled milk has in some measure passed off, the stomach may be strengthened by occasional doses of the Tonic Drink for Cattle (No. 32, p. 81). The ewe and lamb should then be turned into scantier pasture.

\section{DIARRHCEA.}

There is not a more destructive disease among young lambs than this. It frequently attacks them when they are not more than a day old, and carries them off in the course of another day. Oftener it does not appear until they are nearly a week old, and the lambs have not then a much better chance: but if they are two or three $m$ onths old, and have gained a little strength, they may, perhaps, weather the disease. The canses are various, but not always difficult to discover: they are generally referrible to the neglect and mismanagement of the farmer. It may be the consequence of absurd and cruel exposure to cold. For sheep generally, and more particularly for lambs, I once more repeat it, and $I$ would impress it on the mind of the farmer and the practitioner, shelter and comfort are the first and grand things to be considered. I do not mean confinement in a close and ill-ventilated place, but that defence from the wind and snow which it would cost the farmer little to raise, and for which he would be amply paid in one season. If it probably arises from cold, the remedy is plain better shelter, and, for a few days, housing.

It is sometimes attributable to want of proper support: the ewe, if it is her first lamb, may have deserted it, or she may have little milk to give it; and the combined influence of starvation and cold produces diarrhœa sooner than anything else.* Warmth and new cow's milk are the best remedies.

Not unfrequently the mother's milk seems to disagree with the lamb. It is naturally aperient. It may occasionally be too much so. If her teats are full, and she evidently has plenty of milk, this will probably be the case. She should be fed on dry meat for a day or two, or should be turned out only during the day, and housed at night,

* [.Mr. S. W. Jewett, of Weybridge, Vermont, says - "It is generally caused by eating raw or early cut hay. The best method to cure or prevent is to give them daily a few messes of wheat in the sheaf; a regular quantity of salt at all times. If it occurs in the winter, steep, in brine, ripe hay in the seed; wheat chaff is good, as is a small quantity of oats, and a few pine or hemlock-tops. Keep them a few days on ripe hay, or corn fodder. - S.] 
when she should be allowed a little hay. While the food is altered the bowels should be well cleansed. There may be something amiss about the ewe, which causes the milk to be thus purgative and unwholesome. The best purgative for sheep is the following :-

RECIPE (No. 2).

Purging Drink for Sheep.-Take Epsom salts, two ounces; powdered caraways, a quarter of an nunce; warm thin gruel sufficient to dissolve the salts.

This being given to the mother will likewise be of service to the lamb, by helping to carry off any acidities or crudities from the stcmach or bowels.

In a disease so fatal, and which runs its course so rapidly, no time is to be lost, and therefore astringent medicine should be administered to the lamb as speedily as possible.

\section{RECIPE (No. 3).}

Astringent Drink for Lambs.-Take conpound chalk powder with opium, a drachm; gentian, a scruple; essence of peppermint, three drops. Mix with a little thin starch, and give morning and night.

If the animal should still linger on, and the purging should not be much abated, it is probable that the milk of the mother is most in fault. The lamb should then be taken from her, and fed with cow's milk boiled, to every pint of which a scruple of prepared chalk has been added, the astringent drink being continued as before.

If the purging abates, the medicine should be immediately suspended, or not given so frequently, lest costiveness should follow, a disease which I shall presently describe, and which is also very fatal.

The lamb with diarrhœa should be docked on the first appearance of the disease, if the operation had not been previously performed, and the hair should be carefully cut away under the tail, otherwise it is liable to become clotted. It will adhere together, and form an obstruction about the anus, so that the fæces cannot be discharged. The least ill consequence of this will be very great soreness about the part; but in many cases the animal will die in consequence of the obstruction, before the existence of it is suspected.

The colour of the discharge will considerably influence the mode of treatment. If it is of an olive-green colour, the drink should be persevered in; and on every third day half a table-spoonful of castor oil should be administered. If it is of a white colour, it may probably proceed from coagulation of the milk, and should be treated as advised in a previous page.

If the lamb is two or three months old, the medicine should be correspondingly increased, and he has a better chance: if he is five or six months old, he will only be lost through the negligence of the farmer or attendant. The same means must be pursued; but another thing must be added, and that of the greatest importance, - a change of pasture from a succulent to a bare and dry one. The removal to a stubble-field is a frequent and very successful practice. 
COSTIVENES.

When no evacuation appears to be effected, but the animal is continually straining, two circumstances must be carefully examined into, - first, whether there is the obstruction of which I have just spoken, utterly preventing the discharge of the dung, and a speedy remedy being at hand, namely, the removal of the clotted wool; or whether, after the straining, some drops of liquid fæeces may not be perceived: this, although often mistaken for costiveness, clearly indicates a very different state of the bowels; they are actually relaxed, - too much so, and the straining results from irritation about the anus.

Actual costiveness, however, is not an unfrequent complaint, and must be speedily attacked; for it is either the accompaniment of fever, or it will very speedily lead on to fever. The existence of fever should be carefully iriquired into: heaving of the flanks, restlessness, and heat of the mouth, will be sufficient indications of it. Bleeding in proportion to the degree of fever, and the age and strength of the lamb, should then be had recourse to. Next, the bowels must be opened; one-fourth of the Purging Drink (No.2, p. 200) will be the best thing that can be given, and it should be repeated every sixth hour until the desired effect is produced. The lamb should be turned into greener and more succulent pasture, and especially where there is any fresh flush of grass; and if, after a while, he should altogether refuse to eat, he may be drenched with gruel, in which a little Fipsom salts should always be dissolved. While this affords nutriment, it will cool the animal, and open the bowels.

\section{ST A G G E R S.}

Many lambs are lost from this disease, and the farmer most certainly has here no one to blame but himself. It attacks the most thriving lambs, and especially when they are about three or four months old; and it arises from the farmer making a great deal more haste than usual in fattening them for the market. It resembles the blond in cattle, and is usually produced by the same causes.

The lamb will appear to be in perfect health. All at once he will stand still, heaving violently at the flanks, and with the head protruded; or he will wander about with great uncertainty in his walk and manner: he will then all at once fall down and lie strugggling upon his back until he is helped up, or dies. Sometines he is very much convulsed.

Bleeding must be resorted to immediately, and afterwarls the bowels well opened hy means of the Purging Drink. To this some cooling febrifuge medicine should succeed.

\section{RECIPE (No. 4).}

Cooling Fecer Drink. - Take powdered digitalis, one scruple; enntic tartar, ten grains; nitre, two drachms. Mix with thick gruel, and let it be given twice every day. 
On examination after death, the head will be found to be the prin cipal part diseased : the vessels of the brain will be distended with blood, and there will sometimes be water in the ventricles.

I have seen half a dozen lambs in staggers in the same field at the same time. 'They had all bcen exposed to the same cause; and when the disease had begun in one or two, it spread among the rest by the strange, and often too powerful, influence of sympathy.

\section{SECTION III.}

\section{R E D - W A T E R.}

THE disease recognised under this name is very different from that described in the cow, for here it consists in an accumulation of reddish-coloured fluid (whence its name is derived) in the cavity of the abdomen, and frequently in the chest and heart-bag likewise. This water accumulates in consequence of inflammation of the serous membrane which lines these cavities. In many places the disease is termed water-braxy. It is most prevalent at the latter end of autumn or the beginning of winter, and is generally observed among sheep that are in the most thriving condition, and especially if they have been turned into new and rich pasture, and by the side of a copse or wood. Sometimes it is very sudden in its attack, and speedily fatal. In some fine flocks I have seen it destroy the animal in twenty-four hours. In other cases it is less violent, and also slow in its progress. The sheep is first observed to be off its feed, dull, disinclined to move: it loiters behind, and pants, and is restless. The flanks are tucked up, and there is often costiveness, though sometimes purging. This disease is still more common in lambs than in sheep, and in them often appears in the spring of the year, when they are first put on turnips with the ewes. In farms where pasturage is scarce, this disease is a very frequent visitor, and may be considered to be produced by the application of cold, either externally or internally, or probably both.

In the treatment of this disease it is very important to remove the animal to a dry and comfortable situation. Bleeding should then be freely employed and a laxative administered.

\section{RECIPE (No. 5).}

Take Epsom salts, one ounce; ginger, one scruple; gentian, one drachm; warm water, two nunces; linseed nil, one ounce. The above may be given, either alone or with gruel, to a full-grown shecp, and from one-fourth to one-half to a lamb, according to its age.

In addition to this the abdomen should be well fomented with hot water-a lamh, indeed, may be placed altogether in a warm bath.

Every shepherd should have a little horn, made of that of a sheep, and which will hold about the usual quantity of medicine given as a 
drink; or at least the quantity which the horn will hold should be carefully ascertained, and then a large bottle of the mixture may be taken into the field, and the proper dose given to as many of the sheep as may seem to require it, without the trouble of measuring it every time.

If the animal recover, a change of food must be afforded, and a short sweet pasture should be preferred.

\section{SECTION IV.}

\section{THE BLOOD.}

This is a disease too well known by farmers, and occasionally prevalent in every part of the kingdom where the pasture is luxuriant, and the system of close feeding is practised. I have known more than a hundred sheep die on one farm in the course of a fortnight, and entirely because the farmer would not take warning by the loss of the first, and put them on poorer ground, but obstinately pursued his plan of fattening them as fast as he could. In spring, particuJarly, when the young grasses shoot and are full of juice, and especially after a few warm days, the blood appears in the flock, and the sheep die away by scores. The rich pastures of Romney Marsh in Kent, and the Sedgemoors in Somersetshire, are particularly productive of this malady.

It is not always that warning is given of the attack, but generally the affected sheep will separate himself from the rest of his flock, appear dull, hang his head, his eyes will be heavy, and, if examined, bloodshot. He will heave considerably at the flanks, stretch out his fore-legs to ease himself, with great difficulty be induced to move, or will stagger about, threatening to fall every moment. If neglected, six hours will occasionally close the affair; and the animal will very rarely live eight-and-forty. On being examined after death, air and an effusion of yellow or reddish fluid will be found in the whole of the cellular membrane; the veins will everywhere be turgid with blood, the muscles livid or black, and the whole contents of the belly and chest dark-coloured, hastening to decay, and offensive almost as sonn as the animal is dead. If it is a ewe near her lambing that is attacked, the lamb will always be found dead and putrid.

Bleeding is the grand thing; on it alone can much dependence be placed; and if the animal is bled at the commencement of the disease, and plenty of blood is taken away, he will usually be saved, aithough nothing else were done. The jugular is the vein that should be opened here, because most blond can be procured from it, and most rapidly procured-cireumstances both of immense importance in such a case. 'The sherep should be bled until it stagrers and falls. 'Then comes, as in other similar cases, physic, and this should be liberally 
given. Two ounces of Epsom salts, and no ginger with them here, should be administered every second hour until the sheep is well purged, and the purging should be kept up by occasional doses of the medicine for several days.

'The bowels having been well opened, the Fever Drink Recipe (No. 4, p. 201) should be given morning and night, and the animal turned on shorter pasture, and a partial system of starvation for a while adopted, and strictly pursued.

It sometimes happens, as we stated when a similar disease in cattle was treated on, that the stage of inflammatory fever rapidly passes, and one of a typhoid character, and with a tendency to decomposition and putridity, succeeds. There is little chance of saving the ox in this state; there is scarcely any of saving the sheep; for when he is once down, and foams at the mouth, and looks anxiously at his sides, it is generally all over with him. If, however, anything is attempted, the following tonic mixture is as good as any :-

\section{RECIPE (No. 6).}

Tonic Drink for Sheep.-Take gentian root, powdered, a drachm ; ginger, a scruple ; spirit of ujtrous ether, a drachm; tincture of cardamoms, a drachin. Mix, and give iil a little gruel.

It is a good practice, when the disease once appears in a flock, to bleed every sheep, and give each a dose of physic and change the pasture.

\section{SECTION $\mathrm{V}$.}

STURDY, GIDDINESS, OR WATER IN THE HEAD.

THis is a very singular, and also a very fatal disease. It commonly attacks yearlings; a two or three-shear sheep is generally exempt from it. The animal becomes dull; separates himself from the rest of the flock; is frightened at the most trifling circumstance, and at the least noise; he runs round and round, but always in one direction; holds his head on one side: if there is a brook in the field, he stands upon its banks, poring over the running stream, and nodding and staggering, until he frequently tumbles in; or he breaks from his fit of musing, and gallops wildly over the field, but with no certain course, and with no determinate object. Soon his appetite fails, or he evidently feels so much inconvenience when he stoops to graze, that he gives up eating altogether; and then he wastes rapidly away; he seems to be half stupid, and at length dies a mere skeleton.

'The disease generally altacks the weakest of the flock. It is in some measure connected with a peculiar state of the atmosphere. It is most prevalent after a moist winter, and cold, and ungenial spring. It usually begins in the spring, continues through the summer, and disappears as the winter approaclies. It is dependent partly on the 
season, but more on the health and strength of the animal. It may be prevented by good and upland pasture; and is most common in low and marshy ground. It is not contagious, nor does it seem to be hereditary. Having once attacked the animal, and gradual loss of flesh having commenced, the case is hopeless.

All medicine will be thrown away in such a case. It is the consequence of pressure on the brain by a strange, bladder-like-formed animal; and it would be more for the advantage of the owner to destroy the sheep, however out of condition it may be, than to commence any desperate and fruitless course of medicine.

Various methods have been tried in order to break this bladder, such as hunting the sheep with dogs, and frightening him half to death, throwing him into a gravel-pit, and various other absurd as well as brutal methods. They who pursued this course much oftener succeeded in breaking the animal's neck than rupturing the bladder. $\Lambda t$ length some persons bethought them of getting at, and puncturing or removing, this bladder by soine operation. They. thrust iron wires or skewers up the nostril, and into the brain, and sometimes succeeded in effecting their purpose. If they hit upon the nuisance, and pierced its envelope or skin, they were made aware of it by a greater or smaller quantity of water flowing from the nostril, and they could always tell on which side the hydatid lay, by the sheep inclining his head that way. They could also sometimes tell the precise situation of the bladder; for after being a long time inclosed between the skull and the brain, and pressed upon by both, and pressing upon both of them in turn, not only in consequence of that pressure was a portion of the brain below destroyed and absorbed, but even the bone above was softened, nothing but a yielding membrane sometimes remaining over a particular spot. Some surgeons suggested that this membrane should be punctured, and it was done so with the lancet, or, oftener, by a heated sharp-pointed wire, and thus the creature beneath was wounded and destroyed. Others improved upon this method of operating. A surgeon's trephine was used, and a circular piece of the skull taken nut at the place where it was softened, and thus the hydatid was bodily removed; and when this was carefully done, and the bladder was not broken, the hydatid, by slight but sufficiently distinct motion, when put into warm water, showed that it was alive.

Both these operations occasionally succeeded, but the instances of failure were so numerous, that the farmer's interest still required that he should kill every sheep, unless a favourite, or very valuable one, as soon as he was evidently sturdied, and before he had wasted and become unfit for the market.

There may, however, be some prevention, although no cure; and that prevention consists in good, and sufficient, and upland pasture: yet in some untoward seasons even this will not avail with unhealthy and weakly animals. Habitual shelter from the sleet and snow of winter is another and very important means of prevention. The unfeeling abandonment of the sheep to all the inclemency of the coldest 18 
weather is the fruitful source of the majority of the diseases, and of the most fatal ones, to which these animals are subject.

This malady is sometimes accompanied by palsy. Every continued pressure on the brain is apt to produce loss of power over some of the limbs; but in this case the palsy is variable: it shifts from limb to limb, and from side to side, and, unlike simple palsy, is generally attended by partial blindness, and by the greatest degree of stupidity.

I repeat it again, that no medicine can be of the least avail in destroying the blob, as it is called in some parts of the country: but if either of the operations is tried, one of the purging drinks may be useful in abating inflammation; and whether the skull is punctured or trephined, a pitch plaster over the wound will preserve the sheep from being tortured by the flies.

\section{SECTION VI. \\ INFLAM M T ION OF TIIE BRAIN .}

This, although a frequent disease of the sheep, and of the same part, and almost as fatal as that which has been just described, is accompanied by such different symptoms, that it is scarcely possible to confound them. Inflammation of the brain generally attacks the healthiest sheep, and of all ages, and more in hot weather than in the early part of spring. There is no character of stupidity about this affection, no disinclination to move, no moving round and round without any determinate object: but the eyes are protruding, bloodshot, and bright; and there is an eager and ferocious, not a depressed and anxious countenance. The animal is in constant motion: he gallops about attacking his fellows, attacking the shepherd, and sometimes quarrelling with a post or tree; he is labouring under wild delirium, and this continues until he is absolutely exhausted. He then stands still, or lies down for a while panting dreadfully, when he starts afresh, as delirious and as ungovernable as before.

The first and the grand remedy is bleeding; and that from the jugular, and copiously, and to be obtained as quickly as possible. The guide as to the quantity will be the dropping of the animal. To bleeding, physicking will of course succeed, and the sheep should be removed into a less luxuriant pasture. This also is one of the diseases that should be attacked at its very commencement. Violent inflammation of the brain and its membranes will very soon be followed by serious disorganization; and if water once begins to be formed under the membranes, or effused in the ventricles, the case is hopeless. Here also the attention of the farmer should be directed to preventives. One case of goggles may be accidental; but if two or three are seized with inflammation of the brain, the farner may be. 
assured that there is something wrong in his system of mangement, and that which, in the majority of cases, is the root of the evil, is too rich pasture, probably succeeding to spare feed. A dose of salts should, therefore, be given to each sheep, and the pasture of the whole should be clianged.

\section{SECTION VII.}

\section{COID, AND DISCHARgE From THE NOSE, \&c.}

Hene again, from the cruel and impolitic abandonment of the sheep, hundreds of thein are lost during the winter. When they are drenched to the skin by continual rains, or half smothered with snow, and have not even a hedge a yard high to break the biting blast, can it be wondered that cold and cough should be frequent in the flock; and that it should be severe and unmanageable, and even occasionally run on to inflammation of the lungs, and consumption and death? I am not an advorate for close housing, or too much nursing. I am aware that we may thus render the sheep unnaturally tender, and more exposed to catarrh and all its consequences; but I would tell the farmer, that the fleece of the sheep, however thick, is an insufficient protection in cold and wet weather, and an open and bleak situation.

'The symptoms of catarrh are heaviness, watcry eyes, running from the nose. 'The discharge is thick, and clings about the nostril, an I obstructs it, and the sheep is compelled to suspend its grazing almost every minute, and with violent efforts blow away the obstruction. Cough frequently accompanies this discharge; and if there is much fever, it will be shown by loss of appetite and rapid weakness.

There is a discharge from the nostrils which sometimes attacks the whole flock, and if it is not attended by wasting in flesh or loss of appetite, the farmer does not regard it; for he knows from experience, that, in spite of all he can do, it will probably last through the winter, and disappear as the spring advances. When, however, he perceives this nasal gleet, he should keep a sharp look-out over his flock, and if there is one that stays behind, or will not ent, he should catch him, and remove him to a wariner situation, and bleed him, and give him the laxative and fover drinks, and nurse him with mashes and hay. If a second or a third sireep should fail in the same manner, he must indeed look about him; there is dancer to all, for the inflammation has spread itself from the thrnat down the windpipe to the air-passagres of the lungs, and a very dangerous disease, called bronchitis, is produced. He must move the whole flock to a more sheltered situation. He must incve them to a pisture of somewhat different character. He must take thrin from their turnips or their hay, and give them what other fond his firm will afford. He should, if he will take the trouble to do sn (and he would he amply repaid for that trouble), bleed them all round, and physic them all. This is strange doctrine to the farmer, 
who is accustomed to look on and let things take their course. It is, however, good advice, and he will find it so, if he will but follow it. Yet let him not, in his determination to rouse himself and do something, listen too much to the suggestions of the shepherd or the farrier. Let him not give any of those abominable cordial drinks, which have destroyed thousands of sheep. Warmth, housing at night, littering with clean straw, and warm gruel if the animal will not eat or drink, are not only allowable, but useful : nay, I would allow a litlle ginger or a little ale with the medicine; but not those compounds of all manner of hot and injurious spices, which would kindle a fire in the veins of the animal, if it were not blazing there before.

[Experienced sheep-breeders recommend a dose of tar, to be repeated for foul noses ; but lest that be neglected, it is recommended as a good precaution, under all circum. stances, to have some saplings or small trees hored with a large auger at proper dis. tances, and the holes to be kcpt supplied with common salt. Let the edges of these hotes be smeared with tar, and thus the sheep in the act of getting the salt will tar his own nose. There can be no doubt that this would be a good and wholesome practice as an item of general management. Few farmers attend as they ought to do, to having their stock regularly and plentifully salted, and there is known to he something in tar and in resinous plants, as pine and cedar, particularly healthy for sheep. - S.]

\section{INFLAMMATION OF THE LUNGS}

Is not unfrequently the result of a common cold, not attended to, the disease extending itself to the lungs: it more commonly appears in the spring of the year; its symptoms are dulness, hanging of the ears, quick breathing, cough, and discharge from the nostrils. The animal should be bled freely from the neck - a pint in general will not be too much for a full-grown animal to lose. After this a dose of salts should be given, and should be followed by the Fever Drink (No. 4, p. 201) once a day.

\section{N F L U E Z A.}

Sometimes a catarrh assumes an epidemic form, and appears as the influenza. 'This disease may be distinguished from a cold, or from bronchitis, by the discharge from the nostrils being more profuse and the eyes nearly closed, great uneasiness of the head, and a sudden prostration of strength. Sometimes the animal will run round in a circle, and a rattling will be heard in the windpipe: these symptoms will be soon followed by death.

Bleeding should in general be abstained from in this disease, but half an ounce of Epsom salts, with one drachm of gentian, should be given dissolved in gruel; but if the sheep purged before, instead of the above the following should be given, and be assisted by good nursing and care :-

\section{RECIPE (No. 7).}

Take prepared chaik, one ounce ; catechu, half a drachm ; opium, twenty grains ; apirit of nitrous ether, two drachms; gentian, one drachm. To be dissolved in gruel, and given twice a day till the purging ceases; after which the two last ingredients, with a drachm of nitie and ten grains of tartarised antimony, should be given in gruel once a day. 


\section{SECTION VIII.}

\section{BLOWN, OR BLAST .}

Turs is of as frequent occurrence among sheep as oxen, and $i t$, $s$ as fatal. The cause is the same, the removal of the animals from poor keep to rich and succulent food. When sheep are first turned on clover, or even on any pasture more nutritious than that to which they have been accustomed, if they are not watched and kept moving during the day, and folded elsewhere at night, they are too apt to overload the paunch, so that it can no longer contract upon and expel its contents: fermentation then ensues, and the extrication of gas: the paunch is distended to the utmost, and the animal is often suffocated. The remedy of the farmer is the same here as with the oxpaunching, or thrusting a sharp pen-knife into the paunch, between the hip-bone and the last rib on the left side, when the gas with which the stomach is distended will escape. The objection to this practice is likewise the same as in oxen-that when a portion of the gas has escaped, the stomach will no longer be firmly pressed against the side, and the wounds in the side and the paunch will no longer exactly correspond; a portion of the gas, and of the contents of the stomach too, will then pass into the cavity of the abdomen; and (although the animal may seem for a while to recover) will be an unsuspected source of inflammation, and even of death.

The common elastic tube, so strongly recommended by Dr. Duncan, is preferable to the knife: the gas will escape as completely, and without any possibility of danger. It is passed down the gullet into the paunch. The stomach-pump, however, is here likewise a far preferable instrument, for, as was remarked when treating of the hoove in oxen, the acid fluid which is probably in the stomach may be pumped out, or sufficient warm water pumped in to excite vomiting, and thus free the stomach of its oppressive load. If neither the pump nor the tube is at hand, a stick with a knob at the end of it should be passed by the shepherd into the paunch, which, separating the muscular pillars that constitute the roof of this stomach, is far preferable to the knife.

When a sheep is first seized with the blown or blast, he will often be relieved by being driven gently about for an hour or two, and put into a bare pasture. In the act of moving, these pillars will be occasionally separated a little from each other, and the gas will escape; but the animal must not be gallopped or driven by dogs, lest the stomach should be ruptured.

The animal having been relieved, or the contents of the stomach evacuated, a purgative should always be administered, and that cor.bined with some aromatic. The following will be useful:- 
RECIPE (No. 8).

Physic for Blozn.-Take Glauber's salts, one ounce, and dissolve in peppermint water, four ounces; to this add, tincture of ginger, a drachm; tincture of gentian, a drachm; boiling water, an ounce. This should he given every six hours, until the bowels are opened, and half the quantity on each of the four next mornings.

The same treatment recommended for cattle for this disease is likewise equally desirable for sheep, the dose being about one-sixth or one-eighth less in quantity.

\section{SECTION IX.}

THE YELLOWS, OR JAUNDICE.

SHEEP are subject to several sad affections of the liver, among which ranks that destructive disease the rot. Jaundice is a less formidable malady, but often sufficiently destructive. It consists of a superabundant discharge of bile, or an obstruction of the biliary tubes; and in either case a considerable quantity of bile enters into the circulation, penetrates into the capillary vessels, and thus tinges the skin. A superabundant discharge of the bile is the most frequent cause.

The liver seems to be a very tender organ in fatted and pampered sheep, aud easily inflamed or put out of order. In the half-starved, half-wild varieties of the sheep, inflammation of the liver and jaundice seldom occurs; but too high living exhibits its injurious consequences in this organ first of all. It is often seen, after sheep have been moved into fair but not too luxurious pasture, that if they have. escaped the blown, a yellowness has soon begun to steal over the eyes and the mouth, and the skin generally; and the animal has been dull, and has disliked to move, and has sometimes been purged, but more frequently costive, and the urine has been of a dark yellowbrown colour. The liver could not maintain its healthy state under this injudicious increase of nutriment. When the farmer and the shepherd have either neglected to observe this, or to adopt the proper treatment, many of the sheep have died in a few days. On examination after death, marks of intense inflammation have appeared everywhere, but more particularly in the liver, which has been of a redbrown colour, and double its natural size, and is broken to pieces with the slightest force.

If it is taken in time, this is not a disease very difficult to treat. On the first decided yellowness being observed, the animal should be removed to a bare field, and should have the Purging Drink (No. 2, p. 200): half doses of it should also be repeated for several successive mornings, so that the bowels may be kept in a relaxed state. Mercury will not be wanted. Calomel is rarely a safe medicine, and it is a very uncertain one for sheep. A little starvation, and plenty 
of purgative medicine, will be all that is required. Should the ani mal appear to be considerably weakened, this drink will be useful :RECIPE (No. 9).

General Tonic Drank.-Take, gentian, two drachms; colombo, one drachm ; ginger, half a drachm: give in four ounces of warm gruel.

\section{SECTION $\mathrm{X}$.}

\section{* THE ROT.}

THIs disease is the very pest of the sheep, and destroys more of them than all the other maladies put together. There are $\mathrm{f} \in \mathrm{w}$ winters in which it may not be safely said that many hundred thousands perish by it. The cause seems to be better understood than it used to be, and on many a pasture that had formerly obtained a fatal cel:brity for rotting sheep, they may now feed securely; yet almost as many sheep die of the rot as there ever did. I shall, perhaps, be able to show the principal reason of this, and arouse my readers and agriculturists generally to the adoption of more effectual preventive measures.

The symptoms of the rot in the early stage are exceedingly obscure. There is little to indicate the existence of the disease even to the most accurate observer. This is one cause of the mischief that is done; for it prevents the malady from being attacked when only it could be conquered. The earliest symptom is one that is common to a great many other diseases, and from which no certain conclusion can be drawn, except that the animal is ill, and labours under fever. The sheep is dull, he lags behind in his journey to and from the fold, and he does not feed quite so well; but these are as much early symptoms of the staggers as of the rot.

This, however, goes on some time, and then a palish yellow hue steals over the skin, easy enough to be seen when the wool is parted, and most evident in the eyelids, and that which is generally called the white of the eyes. The lips and mouth are soon tinged, but not to so great a degree. The sheep does not otherwise appear to be ill. If he does not eat much, he does not lose flesh; on the contrary, he seems to gain condition, and that for several weeks. Graziers were taught this by Mr. Bakewell. He found that he could save a fortnight or more in the fattening of his sheep for the market by giving them the rot; and he used to keep a piece of wet ground expressly for this purpose, and on which he regularly turned the sheep that he destined for the butcher. This may be a useful hint for those farmers who have too much of this disease every winter. It may be hard to be compelled to part with some of the best of their flock, but if they are watchful they may sell the greater part of them without any very 
serious loss. The farmer, however, is not always sufficiently watchful about this, and too frequently will not believe that his sheep have the rot until the conviction is forced upon him by the loss of some of his flock, and the wasting condition of many more.

This thriving period soon passes over, and the sheep begin to waste much more rapidly than they had acquired condition. First, there is a perceptible alteration in the countenance, - a depressed, unhealthy appearance, accompanied by increased yellowness. 'Ihe tongue especially becomes pale and livid. The animal is feverish; the heat of the mouth, and the panting, and heaving of the flanks, and general dulness, sufficiently indicate this. Some degree of cough comes on; some discharge from the nose; or the breath begins to be exceedingly oflensive. The sheep is sometimes costive; at other times it purges with a violence which nothing can arrest, and the matter discharged is unusually offensive, and often streaked with blood. And now the soft mellow feel of the sheep in condition is no longer found, but there is an unhealthy flabbiness; even where there is but little left between the skin and the bone, there is a flabby - a kind of pitty feeling; the parts give way, but they have lost their elasticity, and they do not plump up again: there is also a crackling sound when the loins or back are pressed upon. The farmer knows what this is, and what he is to expect, both in the sheep and the ox: very few of them recover after this crackling has once been heard.

At an uncertain period of the disease the sheep usually become what the graziers call chnckered, that is, a considerable swelling appears under the chin. If this is punctured, sometimes a watery fluid escapes, and sometimes matter; and occasionally the swelling bursts, and an ulcer, very difficult to heal, follows.

The bowels, which are variable at first, become at length very relaxed. A fetid purging comes on of all colours, and which pursues its course in defiance of every astringent.

The wool begins to fall off in patches: it is loose all over the animal, and easily pulled off, and there is a white scurfiness adhering to its roots. The disease now still more rapidly proceeds; and while the sheep loses flesh every day, and every rib and every bone of the back can be plainly felt, his belly increases-he gets dropsical. 'The end is not then far off.

The progress of the disease is more or less rapid, according to the violence of the attack, or the strength or weakness of the sheep, or the care that is bestowed on him, or the utter neglect to which he is abandoned. The animal occasionally dies in two months after the first evident symptom of rot, but usually four or five or six months elapse before the animal is perfectly exhausted.

The farmer is not much accustomed to examine his sheep after death. It would be better for him if he paid more attention to this, for he would discover the nature, and probably the cause, of many a complaint that is committing sad ravages in his flock. The appearances exhibited in the sheep that has died of the rot are very singular. 
There appears to be dropsy, not only in the belly, but all over the animal. Wherever the knife is used, a yellow watery fluid runs out; and the consequence of the existence of this fluid every where is, that the muscles, and that which should be firm, honest fat, are yielding, and flabby, and unwholesome. When the belly and chest are opened, the heart is pale, and soft, and flabby, and often to such a degree that we wonder how it could have continued to discharge its duty. The lungs are more or less gorged with blood; and there are a great many hard knotty points, of various sizes (tubercles), in them and on them, some of which have probably broken, and the lungs are full of uleers; or when this is not the case, the lungs are studded with innumerable little knotty points of a dark colour.

The principal disease, however, is in the liver, which is much enlarged, often of double its natural size, broken down by the slightest touch, sometimes black from inflammation and congested blood, and at other times of an unhealthy lividness : but that which is most remarkable, which is characteristic of the disease, is, that its vessels are filled with flukes, curiously-shaped things like little soles, which are swimming about in the bile in every duct, and burrowing into every part of the liver. Several hundreds of them are sometimes contained in one liver. A few of them may occasionally be found in the upper part of the intestines, but there only.

The upper part of the liver is frequently speckled like the body of a toad; indeed this has been so often remarked, that the examiner, if he does not find flukes, and sometimes when he does, looks out for the toad's liver. The liver is so diseased and corrupted, that if an attempt is made to boil it, instead of becoming hardened, it falls all to pieces, or is in a manner dissolved. Abscesses are oftener found in the liver than in the lungs, and to an extent sufficient to destroy the sheep without any other cause. Sometimes there are knots in the liver as well as in the lungs - small, round, hardened lumps and in a few cases they are so numerous, that it is almost impossible to find a sound part.

If the farmer would accustom himself to observe these things, and carefully examine every sheep that dies in the autumn, he would sometimes detect the existence of this disease in his flock before he would otherwise have been aware of it. Nay, he should not confine his examination to this, but should observe the appearance of the inside of every sheep which he may kill for the use of his family ahout that time. It should be a practice never omitted, and however swemingly healthy the animal may die, whatever quantity of suet may cover the kidneys, if the liver is dappled with white spots, or if the vessels of the liver are thickened, and if there are flukes, however s.nall, floating about in the bile, that sheep was certainly rotted; and if nne sheep is rotted, the greater part of the remainder will probably follow. Aware of this, and at this early period of the disease, the grazier may, either hy hastening the fattening process, or shifting the pasture, or adopting medical treatment, put many scores of pounds into his pocket, which would otherwise be irrecoverably lost. 
This examination of the sheep will lead us to the principal and primary seat of the disease, namely, the liver. What is the cause of this affection of the liver is another question, and a very important one. There is a dispute which no one has yet scttled, whether this fluke-worm is the cause or the consequence of the discase. I am very murh inclined to think that it is the consequence, although it may and does much aggravate the disease. These parasitical animals, both in the animal and vegetable kingdoms, fasten upon a part that is diseased, or the vitality of which is weakened.

Another disputed point is the source of these flukes. Are the eggrs taken up in the herbage? Does some insect or fly, that is a fluke in one part of its existence, lay its eggs on plants growing in wet pastures, or by the side of stagnant water? We have no proof of this, and we never saw the fluke in any other form. "Therefore, it is useless to dispute about that which cannot be resolved. The most probable thing, however, is, that the eggs, whence the fluke is produced, are, like the eggs of many animalcula, floating in the air, so small and pellucid as to be invisible to us; that they are inhaled with the breath, or received with the food, but only find a proper nest, a proper place to be hatched into life, in the liver of the sheep labouring under the rot.

These flukes are occasionally found in the livers of almost every domestic quadruped, and so far as it has hitherto appeared, they are in all of them connected with disease.

Well, then, what is the cause of this affection of the liver? It is evidently connected with moisture, although it may be difficult to trace the connexion between this moisture and a diseased liver.

It is, however, proper to observe, that the eggs of flukes have been found in countless numbers in the biliary ducts on examining the liver of a cothed or rotten sheep in the months of April, May, or June; and it is considered by respectable authority, that these eggs are passed into the bowels, evacuated with the dung, and, their vitality being preserved by the sun and moisture, they are swallowed with the grass by sound animals, who thus hecome infected. Whereas if the eggs had fallen on dry land, their vitality would be destroyed. Although it appears reasonable enough that the infection is produced through the medium of the stomach, yet it would be expected, if the above theory were entirely correct, that by keeping sheep from rotting land for several years, such land would cease to produce the disease, from the absence of the eggs; which, however, is not found u be the case. It is therefore probable that there are other sources from which the eggs of flukes are derived, besides the dung of shecp.

The history of the rot is plain enough here. It prevails, or rather it is found only, in boggy. poachy ground. On upland pasture, with a light sandy soil, it is never seen; and in good sound pasture, in a lower situation, it is only seen when, from an unusually wet season, that pasture has become bogry and poachy. It is also prover to demonstration, that land that has been notoriously rotting ground, has 
been rendered perfectly sound and healthy by being well underdrained, that is, by being made dry. There are hundreds of thousands of acres, on which a sheep, forty years ago, conld not pasture for a day without becoming rotten, that are now as healthy as any in the kingdom.

We can also tell the kind of wet ground which will give the rot. Wherever the water will soon run off, there is no danger; but where it lies upon the surface of the ground, and slowly evaporates, the rot is certain. One part of a common shall be enelosed; or if it has not been drained, at least the hollows in which the water used to stand are filled up, and the surface is levelled: no rot is caught there. On the other side of the hedge there are these marshy places, these little stagnant ponds, where evaporation is always going forward, and the ground is never dry - a sheep cannot put his foot there without being rotted. These are plain, palpable facts, and they are sufficient for the farmer's purpose, without his puzzling his brains about the manner in which wet ground produces diseased liver.

He may be assured that it has nothing to do with the animal's feeding on stimulating or poisonous herbs. It has nothing whatever to do with the food. It depends on the wetness or dryness of the pasture.

How is it, then, that when so great a part of the country is underdrained, the rot should continue to be almost as prevalent as ever? Why is it not so prevalent where the ground has been properly underdrained? There are fields in every well-managed farm in which the rot is never known; there are others in which it still continues to depopulate the flock.

The draining may not he equally effectual in both. It might have been carelessly, superficially performed in the one case; or the soil of the two pastures may be very different. 'The one may be light and porous, and a little draining may effect the purpose: the soil of the other may be heavy and tenacious, and drains not more than a yard asunder would scarcely keep it dry. What is more to the purpose, but less thought of, there may be little nooks and corners in the field that have not been underdrained. A few minutes' trampling upon them will be fatal to the sheep, and one or two of them upon the whole farm will render all the labour bestowed on every other part absolutely nugatory.

It is surprising how soon the animal is infected. The merely going once to drink from a notedly dangerous pond has been sufficient. The passing over one suspicious common in the way to or from the fair, and the lingering only for a few minutes in a deep and poachy lane. Then it can easily be conceived what mischief one or two of these neglected corners, in which there may be little swamps perhaps only a yard or two across, may do in a farm in other respects well managed, and perfectly free from infection.

The disease of the liver terminating in or constituting the rot, is, then, dependent on moisture, and that retained for a certain time on 
the surface of the ground, so that the process of evaporation may have commenced: it is also probable that the decomposition of vegetable matter growing on the surface has much to do in producing the complaint.

If sheep-breeders would get more into the habit of having oxen to turn upon the aftermath of their low and dangerous pastures, instead of venturing so frequently to send their sheep there, because they cannot afford to lose that portion of the crop, they would not suffer the grievous losses which sometimes almost break them down.

The preventive, then, seems plain enough. On good sound ground the sheep need not fear the rot; and other stock should be kept on the farm to pasture on the suspicious or dangerous places. The draining should be effective where it is attempted, and no nook or corner should escape.

Can anything be done by way of cure? Probably there may, and a great deal more than the farmer imagines. All, however, depends upon the stage of the disease. The liver may be diseased, but it must not be disorganised; it must not be tuberculated or ulcerated; and the flukes must not have burrowed too deeply into it. The farmer, from habitual observation of his flock, must have discovered it at the very commencement of its attack, or he must have been made aware of it by the examination of some sheep that died, or that had been slaughtered for the use of his family. Then he may do good. Good is often done without his help. A succession of dry weather will often stop, or at least retard, the ravages of the rot. If moisture be the cause of it, he must remove that cause. He must change the pasture, and drive his flock to the driest ground his farm contains; and besides this, he must give a little dry meat - a little hay. Some have advised to feed the suspected sheep altogether on hay. This is carrying the matter a little too far: for in the prime of the season the sheep will pine for the grass, and rapidly lose condition for want of it. A change to a thoroughly dry pasture will sometimes do wonders. At all events, it is worth trying. The animals must, however, be carefully watched, and if it is not evident from their more cheerful countenance and manner, and the diminution or disappearance of the yellowness, that the disease is giving way, advantage must be taken of their present condition, and they must be turned over to the butcher. Let the farmer at least do something : let him either sell them at once, reckoning, and generally rightly, that the first loss is the least; or let him set to work and endeavour to combat the disease: but do not let him stand with folded arms, and suffer the best of his flock to dwindle away one after another.

As for the medical treatment of the rot in sheep, there are a great many nostrums, but few, if any, have stood the test of extensive experience. This has partly arisen from a cause which has already been hinted at-the disease not being recognised and attacked before it has made much inroad on the constitution, and when, or perhaps when only, it will yield to medicine. But I believe that with regard 
to the fairest cases every medicine has occasionally failed, or failed almost as often as it has succeeded. We must in no case despair : the disease has sometimes been suspended, and the sheep has recovered. Let not, however, the practitioner be deluded into the use of calomel, or blue-pill, or any preparation of mercury, because the rot is an affection of the liver. Mercury rarely seems to agree with the herbivorous animals in any form. I have seen it do much harm in some affections of the liver, and I have known many animals destroyed by the use of it.

'There is, however, a drug, or, rather, a very common and useful condiment, which I believe has entered into the composition of every medicine by which this complaint has been successfully treated; I mean common sall. The virtues of this substance are not sufficiently estimated, either as mingled with the usual food, or as an occasional medicine. All herbivorous animals are fond of it. It increases both the appetite and the digestion. Cattle will greedily eat bad forage that has been sprinkled with it, in preference to the best fodder without salt; and it seems now to be a well-ascertained fact, that domesticated animals of all kinds thrive under its use, and are better able to discharge the duties required from them.

The consideration of this induced the use of salt in various complaints, and especially in the rot, which is an affection of one of the most important of the digestive organs; and it has not deceived the expectations that were raised as to its sanative power.

As, however, the rot is a disease accompanied by so much debility, and wasting of flesh as well as of strength, tonics and aromatics are usually mingled with the salt; but first of all the bowels are evacuated by some of the usual purgatives, and the Epsom salts are the best. The following prescription should then be tried :-

RECIPE (No. 10).

Mixture for the Rot.-Take, common salt, eight ounces; powdered gentian, two ounces; ginger, one ounce; tincture of coinmho, four ounces: put the whole into a quart bottle, and add water so as to fill the bottle.

A table-spoonful of this mixture should be given morning and night for a week, and then the following mixture may be given at night, while the former is continued in the morning, and by which the flukes will be destroyed, as the worms in the bronchial tubes sometimes are in the hoose of young cattle.

RECIPE (No. 11).

Second Mixture for the Rot.-Take, of recipe No. 10 (above), a quart; spirit of tur. pentine, three nunces: shake them well together when first mixed, and whenever the medicine is given. Two table-spoonfuls are the usual dose.

The morning dose should be given on an empty stomach, and the evening dose before the night's feed is given, if the animal is housed.

All the hay should be salted, and some have recommended that even the pasture should be impregnated with salt. This is easily managed. A little plot of ground may be selected, or a portion of a 
field hurdled off, and salt scattered over it as equally as possible, and in the proportion of ten bushels to an acre. Three weeks afterwards the sheep may be turned on it to graze, stocking the ground after the rate of ten sheep to an acre; in the meantime the field from which they are taken may be brined in the same manner. When they have eaten the grass quite close, they may be changed back to the other plot, and so on as often as may he necessary, strewing at each change five bushels of salt per acre on the pasture. The sheep will fatten at a rapid rate if the disease is not too much advanced, and the disease will sometimes be arrested even in the worst cases.

It must, however, be confessed, that although sheep are often saved from the rot by the use of salt, they have rarely been perfectly restored to their former health. The taint is left; they are more disposed to receive the infection from a slight cause; and, six or twelve months afterwards, they frequently die of hoose or inflamed bowels : therefore, it will be the interest of the farmer to fatten them as soon as possible, and sell them to the butcher. The butcher will always tell by the appearance of the liver whether the sheep had at any former time been rotted. In some few cases lambs have been procured from ewes thus cured, but they have seldom lasted longer than one or two seasons.

\section{$\longrightarrow$ \\ SECTION XI.}

THE FOOT-ROT.

Although this disease resembles the last in name, it is altogether different in character. It is not so fatal as the liver rot, but it is sadly annoying: it is of very frequent occurrence, and it seems to be increasing.

It is, like the rot, peculiar to certain pastures; but there is more variety in this than is found with regard to the rot. There we must have stagnant water, and the process of evaporation going forward. For the production of the foot rot we must have soft ground, and it does not seem much to matter how that softness comes about. In the poachy and marshy meadow, in the rich and deep pasture of the lawn, and in the yielding sand of the lightest soil, it cannot, perhaps, be said that it is almost equally prevalent, but it is frequently found. Soft and marshy ground is its peculiar abode. The native mountain sheep knows nothing about it: it is when the horn has been softened by being too long in contact with some rich and moist land, that the animal begins to halt. This softness is connected with unnatural growth of horn, and with unequal pressure; and the consequence is, that some part of the foot becomes irritated and inflamed by this undue pressure, or the weakened parts of the horn, too rapidly and unevenly growing, are broken off, and corroding ulcers are produced. 
Although there would not appear to be any great wear and tear of the f ot in this soft land, yet the horn becomes so exceedingly unsound and spongy, that small particles of sand or gravel make their way through the softened mass, and penetrate to the quick. It not unfrequently $h$ :ppens that injuries of this sort are produced unconnected with and independent of the foot-rot, and they may be cured much easier, but by very similar means. 'The hardness or the sponginess of the horn depends altogether on the dryness or moisture of the soil in which the animal has fed. Large, heavy sheep, having comparatively thinner hoofs than lighter ones, are more subject to the disease.

'True foot-rut more frequently begins from above than below. 'The horn is rendered sufter, weaker, and more luxuriant by exposure to wet: the foot, from being kept wet and cold, is exposed to re-action with any change of weather, and inflammation is thus excited within the font, which often ends in suppuration, and this occasions those troublesome ulcers that are sometimes witiessed.

'The first symptom of the disease is the lameness of the sheep. On the font being examined, this morbid growth is almost invariably found. The foot is hot, and the animal shrinks if it is firmly pressed. It is particularly hot and painful in the cleft between the two hoofs; and there is generally some enlargement about the coronet. There is always an increased secretion, usually fetid. and often there is a wound about the coronet discharging a thin, stinking fluid: sometimes there is a separation of the horn from the parts beneath, and that too frequently preceding the dropping off of the hoof. In comparatively a few cases the hoofs seem to be worn to the quick at or near the toe. 'The lameness rapidly increases, and often to such a degree indeed, that the sheep is unable to stand, but moves about the field on its knees. The soft portions of the foot, and sometimes the very bones of it, slough away, and hrop off.

All this is necessarily attended by a great deal of pain, and the animal shows how much it preys upon him by his moaning, and refusing to eat, and ceasing to ruminate, and most rapidly wasting. Irritating fever comes on, and after the poor creature has crept about the field on his knees for a few weeks, he dies from irritation and starvation.

Of one thing the farmer may be assured - that the foot-rot is exceedingly infectious. If it once gets into a flock, it spreads through the whole. Some valuable writers have denied this; but there is scarcely a farmer who has not had woful experience of the truth of it. Even on the dryest soil the greater part of the flock have become lame in a very few weeks after a diseased sheep has come among them. There are, however, some instances in which a sheep with the footrot has grazed among others during several months, and no disease has ensued; and so:ne curious experiments would make it appear that under particular circuinstances it is difficult to produce foot-rot by inoculation. But these are exceptions to the general rule; and he who trusts to the non-contagiousness of foot-rot will suffer as assuredly as 
the man who, deluded by some of the mischievous theories of the day, believes that he may keep a glandered horse in his stable with impunity.

The treatment of foot-rot is simple enough, and, in the early stage of the complaint, usually successful. The foot must be carefully examined, and every portion of horn that has separated from the parts beneath thoroughly removed, and the sore lightly touched with the butyr (chloride) of antimony, applied by means of a small quanticy of tow rolled round a flat bit of stick, and then dipped irto the caustic. A stronger, and oftentimes a better, application is made by dissolving corrosive sublimate in spilits of wine. Hydrochloric acid is also a very useful caustic for foot-rot. If a fungus is sprouting at the place where the horn separates from the font, it must be first cut away with the knife, and then the root of it touched also with the caustic; or, what is still better, it may be removed by means of a hot iron. It is necessary, indeed, to be rather sparing with the use of the linife throughout the disease. There will seldom, except in very bad cases, be necessity for binding the foot up; indeed, the animal will generally do better without this. It will be seen by the altered colour of the part whether the caustic has been applied with sufficient severity, and the dry surface which will be formed over the sore will protect it from all common injury better than any covering.

To these must be added that reasonable and successful practice of removing the sheep to higher ground. Sheep among whom the footrot is beginning to appear are sometimes completely cured by being driven to higher and dryer ground. Some farmers, and with a great deal of advantage, have their flocks driven four or five times daily along a hard road. They thus accomplish two purposes - they wear away the irregularly formed horn, the unequal pressure of which has irritated and inflamed the foot, and the remaining horn is hardened, and enabled better to resist the influence of the moist or soft ground. Where the ulceration is extensive, means must be adopted similar to those recommended for the treatment of foul in the foot in cattle; but in most cases it will be more profitable to the farmer to destroy the sheep that has bad foot-rot, if it is in tolerable condition, rather than rely on a cure that is uncertain, and durirg the progress of which the animal very rapidly loses flesh and fat.

If, however, he is determined to attempt a cure, let him wash the foot well from all grit and dirt, and then cut off every loose and detached piece of horn, and every excrescence and fungus, and cover the wound with the following powder:-

\section{RECIPE (No. 12).}

Caustic Astringent Ponoder for Foot-Rot.-Take verdigris; bole armenian; and sugar of Jead, equal parts. Rub them well ingether, until they are reduced to a fine powder.

This should be sprinkled over the sore, and a littie dry tow placed upon it, and bound neatly and firmly down with tape. The animal should afterwards stand in a dry fold-yard for four-and-twenty hours. 
On the next day the tape should be removed, and if the surface is tolerably regular, it may be touched, as already directed, with the butyr of antimony; but if any fungus remains, the powder must be applied another day. The fungus no longer continuing to grow, a light dressing with the butyr should be continued every second day until the animal is well. Some prefer a liniment or paste to the powder, and it is made by mixing the powder with a sufficient quantity of horey. The farmer may use which he pleases; but a firm and equable pressure being produced by the tape is the principal thing to be depended upon.

The sheep-master should as carefully avoid the ground producing foot-rot, as that which causes the fatal affection of the liver; and he should attempt the sarne method of altering the character of the low and moist ground by good underdraining. The effect of this, however, is far from being so certain and beneficial as with regard to the rot. The water which would stagnate on the surface may be drained away with tolerable ease, but the soil cannot be rendered hard and dry, or, if it could, that would not be an advantageous change. 'The sheep might not have the foot-rot, but the ground would be comparatively unproductive.

If the farmer intends to drive his sheep a considerable distance to the market or fair, he will prepare them for the journey by a few days' removal to harder and firmer ground, or, perhaps, by driving them a short distance, daily, on the still harder public road.

The farmer should not only take his sheep from light sandy soil in long-continued dry weather, because they would starve there, but because then alone that soil would give them the foot-rot: its yielding nature will not sufficiently keep down the growth of horn, and many a particle of sand will insinuate itself into the soft and spongy horn, and produce inflammation. For the same reason he should avoid dry old pasture at the season when the dews are heaviest, because then moisture would most abound there.

In grounds that are disposed to give the foot-rot, the farmer would find it advantageous to have the hooves of his sheep rasped or pared once every fortnight or three weeks. 'This is not often done, but it appears reasonable, and would not be very expensive. In uninclosed or mountainous countries, where the sheep have particular tracts, gravel might be scattered in sufficient quantity to wear and harden the horn.

[This disease is among the greatest scourges to which sheep are liable in America, but writers generally regard it as not difficult to be cured. J. R. Speed, of Caroline, Tompkins county, New York, found a valuable merino buck much afflicted with it, and not having at hand the ingredients recommended in the Complete Grazier and other books, he "took down that cure-all among farmers, my bottle of spirits of tur. pentine, and with a feather applied it to the parts affected quite plentifully twice or three times in the space of three days, (keeping him on a dry floor), when I found a perfect cure had been effected." 
Mr. Jewet, of Vermont, speaking on ample experience, says-" The foot rot is an infectious disorder which locates between the hoofs, and unless immediate attention is rendered, it operates under the horns of the hoof. It is more easily cured in the winter, or where the infection freezes. If thoroughly seated, it cannot be entirely eradicated from the flock in warm wearher, unless they are permitted to run in a fresh pasture where there is no exposure after the treatment, which is this-first, the foot must be pared if infected, and all the ulcerous matter removed; then apply with a swab, zig, or water strongly saturated with pulverised blue vitriol. When tho. roughly done, the rot will he removed, and the foot will be healed in four or five days. It is very important that the diseased animals should he separated from the flock. Fine-woolled sheep, and those that have long hoofs, are much more subject to the rot, and more troublesome to cure. It spreads by inoculation only, and rages worse in low wet grounds. It is inportant that they should be examined every week until cured, which will require three or four thorough examinations, where the uicer. ation is confirmed.

By using a trough, the description of which you have in the cut helow, the foot can be examined with ease; and where there is a large flock, there is a great saving in time and labour.

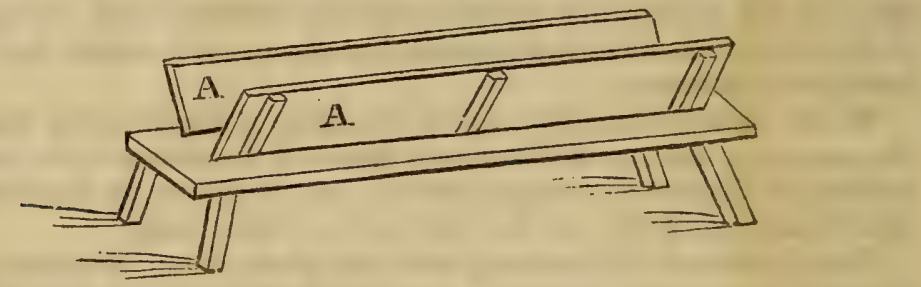

The figure represents a trough which will conveniently hold two sheep, with their feet uppermost. The frame simply consists of a plank about six feet in length, in which four legs are fastened eighteen inches long. Six arms are extended from the upper side of the frame, which supports the side-boards $\mathbf{A} \mathbf{A}$, six feet long and thirteen inches wide, and forms a trough about one foot in width at the top and four inches at the bottom. This trough should stand near the door of another dry yard, where the sheep must remain an hour or so after the application of the vitriol, which should be applied between the toes of every foot. By the assistance of this apparatus, three men can go over from three to four hundred sheep in a day.

Another very simple remedy is recommended hy $T$. Baynes, of Wilmingtnn, Dela. ware. "Take a few bushels of lime, and put it near some place where the sheep have to pass, say the bars, and as it is natural for sheep to jump, take notice where they alight, and place the lime there about three inches deep. This did effectually cure my flock in about a week. The lime should be fresh and slacked, and not less than three inches deep; if deeper it might take the hair off the leg above the honf."Cultivator. The lime might be more conveniently and perfectly applied by means of the trough, of which a drawing is given, for the examination of sheep. - S.] 


\section{SECTION XII.}

THE S C A B .

Tnis is a most troublesome and infectious disease, and generally to be attributed to bad management. Sheep that have been too much exposed to the inclemency of the weather, or that have been halfstarved, and thus debilitated, are most subject to it. 'The forest sheep are particularly liable to the scab. It is first discovered by the animal eagerly rubbing himself against every post, or gate, or bank, or, if the itching is very great, tearing off his fleece by mouthfuls. He looks thin and ragged; and if he is caught, there will appear on various parts, and particularly along the back, either little red pustules, or a harsh dry scurf. The pustules speedily break, and the scurf succeeds. The roots of the wool are matted together by it, and portions of the fleece come off with almost the slightest touch.

No one ever doubted the infectiousness of this disease, or suffered a scabber sheep to enter his flock without dearly rueing it. Fvery post, or stone, or tree, against which it has rubbed itself, seems to be empoisoned. Every sheep that comes in contact with it is infeeted.

The itching of the eruption preys upon the sheep almost as rapidly as the foot-rot. A scabbed sheep is a poor hungry-looking, halfstarved creature; his fleece is spoiled, and he is useless for the butcher.

Sheep proprietors used to be fond of various lotions for the cure of scab. Some applied a strong solution of tobacco, others a solution of sal ammoniac, and others one of corrosive sublimate. If these are ever used, they should not be made too strong, for many an animal has been destroyed by them all. Not more than a quarter of a pound of tobacco should be boiled or infused in a gallon of water, nor more than an ounce of corrosive sublimate, and which should be previously dissolved either in muriatic acid or spirit of wine. The sal ammoniac rarely did much harin, but on the other hand it more rarely did good, and when used with the corrosive sublimate seemed to impair its powers. There are those who have preferred a solution of arsenic to either of the others. It is as efficacious as any of them, but it is by far the most dangerous.

A great tub or vat used to be procured, and half filled with either of these solutions, and the sheep put into it one by one, and well rubbed and washed until the fluid had evidently penetrated the fleece, and come into contact with every part of the skin; but even where these lotions succeeded, they gave a peculiar coarseness and harshness to the wool, which very much decreased its value. The scurfiness likewise did not soon come off; or when it did, patches of the fleece separated with it, and left the skin bene.th it red, and chapped, and ulcerated. 
An ointment is far preferable, for it softens the scurf, and detaches it from the wool, and saves the fleece, and heals the chaps and ulcers of the skin, and promotes the future growth of the wool.

The mercurial or blue ointment in a greater or less degree of strength is commonly used; and if used with caution, the real strength of it being previously ascertained, it has generally a good effect; but when bought from too many druggists, the quantity of mercury is so variable, and so many tricks are played with it, that the shepherd scarcely knows how to use it, and too often salivates, and even destroys, some of his sheep.

If the mercurial ointment is to be used, it will be of advantage to the farmer, especially if he has many scabbed sheep, to make it himself, and that he may very easily do if he has a wooden pestle and a large mortar or iron pot.

\section{RECIPE (No. 13).}

Mercurial Dintment for Scab.-Take crude quicksilver, one pound; Venice turpen. tine, half a pound; spirit of turpentine, two ounces.

These should be rubbed well together for five or six hours, until they are perfectly united; and that will be known by a little being taken and rubbed with the finger on a piece of glass. If not the slightest globule can be detected, the killing of the mercury is complete; but if the smallest shining particle can be seen, the substances are not sufficiently mixed. When this is completed, four pounds and a half of lard should be added, and the more rancid it is the better: for it more readily combines with the mercury, and gives it additional power. This lard may be well rubbed with the mixture of mercury and turpentine on a square slab of marble; or it may be melted, and, when about the temperature of new milk, added to the other ingredients, and the whole stirred together until the ointment becomes stiff.

If the ointment is made during the summer, it will perhaps be too fluid to be thoroughly rubbed into the sheep. It may penetrate among the neighbouring wool, or run off and be lost. When this is the case, one pound of the lard should be omitted, and a pound of black resin substituted.

A great deal depends on the manner in which the ointment is applied. It should extend to every part that is in the slightest degree affected, and it should be gently but well rubbed in. The wool should be carefully parted on the middle of the back, from the poll to the tail, and a little of the ointment rubbed in all along the channel thus exposed. If the disease is slight, another furrow may be made on either side, at the distance of two or three inches, and more rubbed in; but if it appears to be inveterate, the divisions should be made at two inches distance from each other, and over every part that is affected. A second dressing may be applied four days afterwards, if the sheep continues to rub itself, but it would not be safe to proceed farther. If the sheep should yet rub, a milder ointment should be resorted to, which may be repeated every second day with pcrfect safety until the animal is cured. Indeed I should be very much disposed to use the 
mililer ointment from the beginning, because I could go on to the very end, without any fear of unpleasant consequences; and although the cure is effected more slowly, the process is safer and surer.

RECIPE (No. 14).

Mild Ointment for Scab.-Take flowers of sulphur, a pound; Venice turnentine, four ontuces; rancid lard, two pounds; strong inercurial ointment, fuur ounces. $R \backsim b$ them well together.

Flowers of sulphur must be used, and not the common black sulphur: that is the reiuse of the sulphur, and is almost inert, except it derives any power froin the arsenic which is generally in combination with it, and that would be a dangerous power. There are several instances of aninals being destroyed by the use of the black sulphur in ointment, which had been empoisoned with arsenic.

This ointment may be used at any time of the year; but the mercurial ointment is not safe in cold or wet weather.

In tery bad cases the following powerful ointment may be employed :-

\section{RECIPE (No. 15).}

Take white hellehore, three ounces; bichloride of mercury, two nunces; fish-oil, twelve pounds; resin, six ounces; tallow, eight nunces. The two first ingredients to be mixed with a part of the oil, and the other ingredients to be melted and added.

Prevention is here again better than cure, and the practice of smearing, and especially in cold and exposed situations, is very commendable. It is not a certain preventive, but it renders the animal less likely to take the infection, and it is very comfortable and useful to the sheep in protecting him from the cold, and hindering the wet from penetrating to his skin.

\section{RECIPE (No. 16).}

Smearing Mixture.-Take a gallon of common tar and twelve pounds of any sweet grease. Melt them together, stirring them well while they are cooling.

Here, as in dressing for the scab, the wool should be parted in rows from the head to the tail, three or four inches asunder, and the mixture rubbed carefully with the finger at the bottom of each row. The smeared fleece will not fetch so much per pound, but the increase of weight, generally in the proportion of five to four, will more than compensate for the diminution in price. The usual time for smearing is in October, and the sheep are hardier and warmer, free from vermin, and gencrally free from scab; and this being the case, they evidently thrive better, are sooner fit for the market, and weigh heavier.

It will be evident enough that every precaution ought to be taken to prevent the re-appearance of this disease. Every rubbing-place of every kind should be thoroughly washed with chloride of lime, and every sheep that begins again to ferret immediately separated from the flock.

The scab appears under an exceedingly virulent form in some mountainous parts of the country, and particularly in Scotland $\mathrm{Mr}$. Stevenson, in his communications to the Highland Society, thus de- 
scribes two varicties of it. The first he curiously calls red-water, an improper term, and more especially as the same name is given to another disease to which sheep are subject. He says, "This disease commonly makes its appearance about the beginning or end of winter, and first appears about the breast and belly, althongh at times it spreads itself over other parts of the body. It consists in an inflammation of the skin that raises it into blisters, which contain a thin, reddish, and watery fluid: these continue for a short time, break, and discharge their matter, and are followed by a blackish scab.

"When the sheep are exposed to cold or wetness, the skin being fretted, makes the blisters rise; or they often arise from cold affecting the animal internally, thus producing a slight fever, which throws out these vesicles on the body."

The diseased sheep should be put into a fold by himself. A little blood should be taken, and the blisters slit up, and a few drops of the infusion of tobacco put into them; a quarter of an ounce of sulphur should also be given on six successive mornings. A dose of physic should follow. The parts affected should also be daily washed with lime-water.

A more violent eruption is called the wildfire, probably from the rapidity with which it spreads. It is more infectious than the scab, or, probably, it is one of the worst species of scab. The nitre and sulphur should here also be given internally, and the lime-water applied externally.

[The frequency of this loathsome and highly contagious disease induces us to add the following from the Cultivator:-

Among sheep, there is no disease so common, or productive of so much injury, certainly not in the United States, as the scab, or as it is called by some, the itch. A sheep affected by this disease is restless, rubbing itself violently against posts, fences, or whatever is in its way; biting and tearing out the wonl with its teeth, and exhibiting every sign of intense irritation. On examining the sheep, the skin will be found red and rough, with usually an extensive cutaneous eruption, or an accumulation of small pimples or pustules, some of which have broken, and the matter discharged has formed patches of crust or scab, from which the common name of the disease is derived. The fleece on a sheep diseased with the scab will be irregular in its growth, and the quality inferior; and if the complaint is severe, or long-continued, the health is impaired, and the animal pines away rapidly, till released by death. The rot may be more immediately fatal, and produce greater losses in Europe, but here the scah is more injurious, perhaps, than all other diseases put together. The scab is one of the most infectious of diseases, and if introduced into a flock, unless the diseased aninals are immediately removed, the farmer may depend on the whole flock being infected, and both sheep and wool greatly lessened in value. The shoulders and back are the places first usually affected; but unless check. ed, it will spread until the whole surface is diseased, or the animal perishes; or such is the usual course of the disease. The infection seems to spread in two ways; by actual contact with diseased animals, or by means of the places where infected sheep have rubbed themselves or lain. As pay for sheep infected with scab and sold for gound cannot be collected in Europe, or may be recovered. much attention is paid to 
the time that elapses aner the infection, before the disease appears. About tho twelfth day, it is stated by Youatt, the pustules begin to appear, and the rubbing of the animals shows the irritation has commenced. In four days more the pustules. break, and the matter escaping forms the crust.

Aner it was found that the itch in the human race was caused by an insect, a. species of acarus, it was supposed that similar cutaneous diseases might arise from the same source. M. Waltz, a German, was the first to establish this point and fully investigate its character; and numerous subsequent examinations have proven the correctness of his opinion. He found that the scab, like the itch, mange, \&c., is caused by animalculæ; that the irritation caused by his burrowing in the skin forms the pustule, and that when this breaks, the acarus leaves his habitation, and travels to another part of the skin, and thus extends the disease, or it may he left on the rubbing post, or the wool of an animal coming in contact. When one of these acari is placed on the wool of a sound animal, they quickly travel to its roots, where the place of burying themselves is shown by a minute red point. About the sixteenth day the pimple or pustule breaks, and if the acari is a female, it appears with a multitude of young. These immediately set to work on the skin, bury themselves, and propagate, until the poor animal is irritated to death, or becomes encrusted with scab. M. Waltz satisfactorily traced the parasite through all its changes, and by experiments discovered all its modes of action and method of infection. He found that when the male acari was placed on a sheep, it burrowed, the pustule was formed, but the itching and scab soon disappeared without the employment of amy remedy. Such was not the case where the female acari was placed on the sound skin; as with the breaking of the pustule, from eight to fifteen little ones made their appearance. M. Waltz found that the young acari kept in a dry place dried and crumbled to dust, but when old, that it would retain its life through the whole winter, thus proving the necessity of not relying on the season for their destruction, but on preparations of active medicine when the disease shows itself. Of the origin of these insects we of course can know nothing ; it is enough that we are certain when they make their appearance, they can be met and destroyed.

Various remedies have been recommended for the cure of the scab; but although the sheep acarus is very different in form, size, and colours from the human acarus, the application that will destroy one will prove fatal to the other. The remedy is the destruction of the acarus.

A strong decoction of tobacco, of hellebore, or a solution of arsenic, will cure; but the difficulty with washes is, that the burrowed insect sometimes goes untouched, and unless the washing is repeated, some are apt to escape, and the disease is continued. Owing to this, it has generally been deemed a safe and more expeditious mode to use the mercurial ointment. When used too strong it will salivate lambs or ewes. Where the cases are very bad, the ointment may consist of one part of mercurial nintment or unguentum, with three parts lard; but for ordinary cases of scab, one part of the mercurial ointment to five of lard will be sufficiently powerful. The wool should be separated, a small quantity placed on the skin, and carefully rubbed in. The extent of the application and the quantity used will depend on the spread of the disease, from half an ounce to two ounces being demanded. A decoc. tion of tobacco or hellebore will cure, but as before remarked it may be necessary to repeat the washing. Arsenical applications are effectual, but dangerous, unless great care is used. Where an animal has been waslied, or ointment applied, infertion is generally prevented; but whenever the scab appears, and is supposed to he cured, examinations at the end of every few days should take place, particularly if any 
symptoms of itching or irritation appear. The sheep-grower should pay strict atten tion to the heaith of his animals, and such care and attention will be abundantly repaid.

Below we give the figures of the acari, that produce the scab as delineated by $\mathbf{M}$. Waltz:-

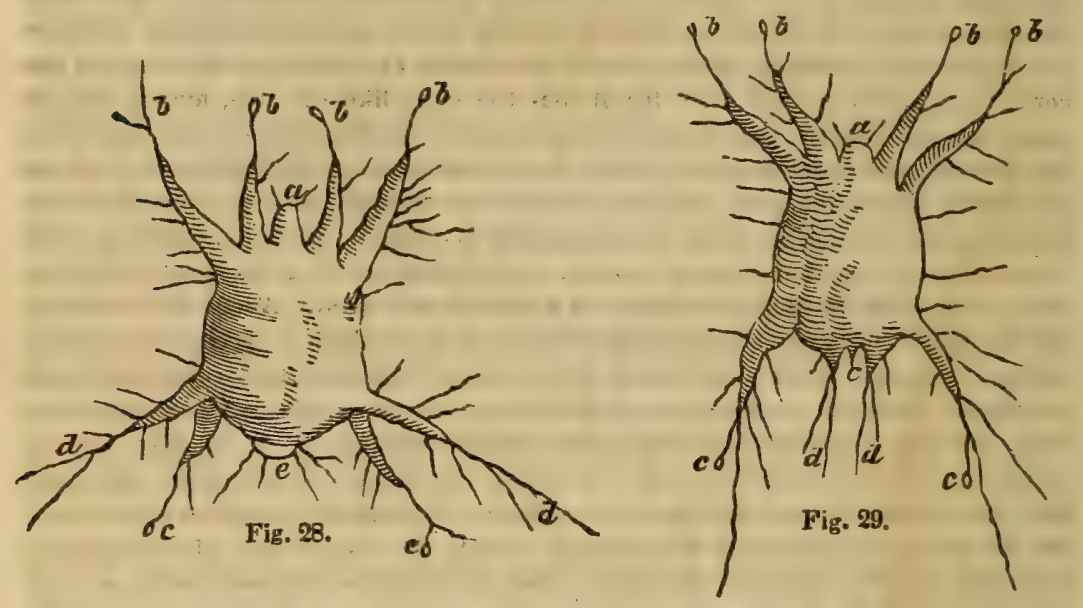

(Fig. 28), the female of 366 times the natural size, larger than the male, of an oval form, and provided with eight feet, four before and four behind; $a$ the sucker; $b \quad b \quad b$ the four anterior feet, with their trumpet-like appendices; $c c$ the two interior hind feet; $d d$ the two outward feet, the extremities of which are provided with some long hairs, and on other parts of the legs are shorter hairs. To these hairs the young ones adhere when they first escape from the pustule- $c$, the tail, containing the anus and vulva, garnished by some small hairs. (Fig. 29). The male on its back, and seen by the same magnifying power; $a$ the sucker; $b b b b$ the fore-legs, with their trumpet like appendices, as seen in the female $c c$, the two hind legs, with the same appendices and hairs; $d$ the rudiments of the abdominal feet; $e$ the tail. $-\$$.

\section{SECTION XIII.}

\section{I CE, TICKS, A N D FLIES.}

Sheep, and especially if they are neglected and poor, are often sadly annoyed by these vermin. They frequently precede the scab: the dreadful itching which they occasionally cause, prepares for or produces the scab, or they multiply most rapidly when the skin is fouled by the scab. The sheep-louse is too well known to every shepherd : it is of a brownish or reddish colour, with a flat body, and three legs on either side: the tick has a large round body, and small 
chest and head, which he buries deep into the skin, and by means of which he holds so fast as to be with difficulty torn off. The lice are propagated by means of eggs or nits : the origin of the tick is not so well understood.

They are both injurious to the wool, and also to the health of the animal, from the constant irritation which they produce. 'The louse is more injurious than the tick. The tick only buries his head in the skin; the lice burrow, ana form their nest in or under it. They collect together, and a seab soon rises, whence a glutinous matter proceeds. The scab continues to increase until it is of the size of a sixpence, and undermines and destroys the roots of the wool, and the fleece comes off in patches. The itching then becomes intolerable, and the sheep rub themselves eagerly against every thing within their reach, and tear off the wool by mouthfuls. The lice are thickest about the throat and under part of the neck, and when this is the case, it has sometimes happened that the sheep has been seriously injured, or even destroyed in a very curious way. He bends his head down as closely as he can to get at the vermin, and then some of the wool entangling itself about the teeth, the head becomes fixed, and the animal is said to be bridled. If he is not observed and relieved, the head will be held until the muscles are seriously injured, so that he ran no longer comfortably bend his neck to graze, or until he is absolutely destroyed.

Many washes have been invented to destroy these insects, but few of them have perfectly succeeded. That which seems to have the best effect is thus composed :-

\section{RECIPE ( No. 17).}

Arsenical Wash for Sheep Lice.-Take arsenjc, two pounds; soft soap, four pounds: dissolve in thirty gallons of water.

The infected sheep should be immersed in this, the head only being kept out; and while he is in the liquid, the fleece should be well rubbed and moulded, so that the wash shall penetrate fairly to the stin. When taken out of the tub, the fluid should be pressed as thoroughly as possible out of the fleece, which will then do for another of the flock; and the sheep should be kept from cold and wet for afew days.

Other persons prefer the following lotion:-

$$
\text { RECIPE (No. 18). }
$$

Mercurial Wash for Sheep Lice.-Take corrosive sublimate, one ounce; spirits of wine, two ounces; rub the corrosive sublimate in the spirit until it is dissolved, and then acli-cream of tartar, one vunce; bay salt, four nunces: dissolve the whole in (wo quarts of water, and apply a little of it with a small piece of sponge wherever the lice appear.

These washes, however, are not always safe, and they are very troublesome in their application. The ointment which I have recornmended for the scab is more easily applied, and more effectual. It may be rendered more fluid, and consequently more easily rubbed in, by being raixed with an equal weight of neat's-foot oil; and it 20 
should be as carefully applied over every part as it would be in the act of smearing, for the vermin will speedily collect and burrow in any spot which the ointment may not have reached.

'The tick is many times as large as the louse, but not so frequently found. When not gorged with blood it is flat, but when bloated it is round, and brown or black, and varies in size from a pin's head to a small bean. When one of them fastens itself upon the sheep, it seems to retain precisely the same situation for some weeks, or even months, and yet the young ticks are found round the old ones, resem bling numerous red points, but becoming brown as they increase in size. They, too, select the sheep that is debilitated by want of proper nourishment or by disease.

The tick is more frequent on some grounds than on others. On some farms, even although badly managed, it is seldom found; on others it is scarcely to be got rid of, even although the sheep should be healthy. It would seem as though it were bred in the ground, and that one part only of its existence is sperit on the sheep. Some shepherds set diligently to work, and pick them off. This, however, is an almost endless task. Others dress the sheep with turpentine, which usually destroys them; but the seab ointment is the surest remedy, as well as preventive.

The sheep is tormented by two species of flies. The one endeavours to lay its eggs on the muzzle, and thence, speedily hatched by the moisture and warmth of the breath, the animalcule, or larva, creeps up the nostril, and finds its way into the frontal sinuses, or some of the cells above the nose, and there fastens itself, and lives and grows, until it becomes a large worm: it then creeps again down the nostril, assumes the form of a grub, burrows in the earth, and in due time appears in the form of a fly. It is only during the time of the depositing of the egg that the sheep are disturbed or injured, and then they may be seen huddling together on the barest part of the pasture, with their noses close to the ground, and by continual shaking of the head and stamping, endeavouring to prevent the depositing of the egg. When the little worm has reached its destined situation, it seems no longer to trouble the animal; and these bots are found in the heads of some of the largest and fattest sheep. This is the destined place of this worm, and nature would not make it destructive, or even much annoying, to the animal by which it is to be supported.

Another species of fly, or perhaps several other species, are far more troublesome and injurious. At some uncertain time after shearing, and seemingly oftener occurring to those that were early than to those that were later sheared, the sheep will be struck with the fly. This will be discovered by the uneasiness of the animal. It is not the itching of scab, for it is before the usual appearance of that disease, and when the sheep was shorn there was not the least appearance of it. The sheep will hang down their heads, stand for awhile as if listering, then bow up their backs, violently shake their tails, stamp furiously with their feet, gallop away for a short distance, and 
then turn round and try to bite the affected part. The tail is evidently the part oftenest attacked.

On being caught, there will probably he found little lumps or bladders on various parts, but particularly about the tail; and if these are pierced, they will be found to contain numerous little maggots. If there are any sores about the animal made in the shearing, they will become full of maggots in different stages of maturity, and these vermin will crawl through the wool, over almost every part of the body.

In warm weather they are peculiarly annoying and destruetive. I have seen them spreading from the root of the tail to the head of the sheep, deepening every sore, eating even through the sound skin in various places, and penetrating to the very entrails.

A sheep struck by the fly should not be neglected a single day, for the maggots will sometimes do irreparable mischief in a very short spare of time. The wool should be cut off round the places where the maggots seem principally to prevail, and they should be carefully picked out : but this will not effectually destroy them; for many will crawl far away out of the reach of the looker. Some ointment or powder must be applied, which will at the same time heal the sores and destroy the maggot. An application of this kind may be obtained in some of the preparations of lead. 'The following will be very useful :-

RECIPE (No. 19).

Fly Poucder for Sheep.-Take white lead, two pounds; red lead, one pound; and mix them together.

While one man holds the sheep by the head, let another have a dredger or prpper-box containing some of the powder in his right hand, and a stick in his left : let him introduce the stick near the tail of the animal, and draw it gently along the back as far as the head, raising the wool, and scattering in the powder as he proceeds. Then let him dip his hand in some of the coarsest whale oil, and smooth down the wool again, smearing the whole of the fleece with the oil. This will not only destroy the maggots, but prevent the future attack of the fly. There are few flies that will approach anything that smells strongly of this oil: it would, therefore, be a good practice to smear the sheep with a little of it after shearing. No injury could possibly be done to the wool, but, on the contrary, its growth wours, be promoted.

If, however, the flies have made any deep wounds or ulcers, some of the powder should be mixed up with tar, and the ointment gently rubbed on the sores.

[Judge Postwick, of Delaware county, N. Y., dips his lambs in a decoction of to. bacen, just strong ennugh to kill the ticks in a minute or two. One man takes the lamb by the furelegs and heatl. and dips him in the vessel so as just to leave the head out. It is then raised and helt over the kettle while another presses the liquor out of the fleece back into the kettle.

Magmots originatiug from fly-blows on wounds, may be prevented by dressing the wound with tar, and may be destrnyed by an application of honey, when spirits of turpentine would prove ineffoctual. $-\mathbf{S}$. 


\section{SECTION XIV.}

\section{SORE HE A DS.}

THIS disease is connected with, or often produced by, the striling of the fly, and especially in woody countries. Next to the tail, the nead is the part most frequently and seriously attacked, and in defending themselves from their tormentors, the sheep are continually striking their heads with their hind feet, until at length a considerable sore or ulcer is formed. No sooner is this done, than the fly persecutes the poor animal with tenfold fury, anxious to lay its eggs on or near the wound; and the ulcer will of ten spread so far and so rapidly, as to be very difficult to heal, and occasionally it will destroy the sheep.

The first thing to be done is to procure a cap or covering for the head, made of soft leather, or of brown paper, if leather cannot be procured. This should be cut so as to protect the whole of the head, and yet not to come too close to the eyes. Then the following ointment must be prepared :-

\section{RECIPE (No. 20),}

Ointment for Sore Heads - Take black pitch, two pounds; tar, one pound; finwers of sulphur, one pound. Melt them in an iron pot over a very slow fire, stirring to. gether the ingredients as they begin to melt, but carefully watching the compound, and removing the prit from the fire the moment the ingredients are well mixed, and before they begin in boil, for they would then rapidly swell to an extraordinaryextent, and the whole mass would run over into the fire.

While this ointment is warm and soft, it should be thickly spread upon the leather, and the cap fitted to the head. If this be done in the evening, when the fly begins to cease to torment the sheep, the animal $\mathrm{w}$ ill be quiet, and the ointment will gradually cool, ard stick close to the head.

Some spread the ointment over the head without the cap, making a kind of charge, a few flocks of wool being scattered over the top. of it; and if it should be somewhat too liquid for this purpose, it is stiffened by the addition of a little yellow resin. It is difficult, however, to confine the ointment to the sore when it is thus applied, and it is very apt to run over the eyelid and the face, to the great annoyance of the animal.

In some parts of Scotland there is another disease of the head that is speedily fatal. If the sheep are suffered to rest for the night near the summit of the Grampians, or the hills of Galloway, the head will become enormously swelled, and ulcers will break out, as if the animal had been bitten by a venomous reptile. $\Lambda$ great portion of the scalp often comes off, and the animal generally dies. The shepherds there call it the head-ill, and the malady is kept from spreading only by removing the flock from these elevated and dangerous spots. The cause of this disease is uncertain : probably it is produced by the eating of somn poisonous plant. 


\section{SECTION XV.}

DIARRHOEA, OR PURGING.

THE full-grown sheep is almost as subject to purging as is the lamb, but it is not so difficult to be cured, nor is it so fatal. A sheep can scarcely be turned into fresh pasture in the spring without beginning to scour, and especially when warm weather is succeeding to cold, and the grass shoots rapidly; but this in most cases is beneficial rather than injurious. It rouses the digestive organs to full and healthy action, and the sheep that scours a little when first turned into the meadow or on the marsh, is sure to thrive more quickly afterwards. The purging, however, must not be too violent, nor continue too long.

The looseness caused by feeding on young succulent grass, seldom lasts more than a few days; but if it should continue longer, the sheep must be removed to inferior pasture, and a little hay allowed them if they can be induced to eat it: some dry sound old seeds should also be put before them, and the following powder administered:-

\section{RECIPE (No. 21).}

Astringent. Powder for Sheep.-Take prepared chalk, a quarter of an ounce; ginger, half a drachim; catechu, powdered, half a drachm; powdered opium, two grains. Give this in a little gruel once or twice daily until the purging abates.

A favourite remedy with some farmers, and succeeding in slight cases, but inefficacious in severe ones, is suet boiled in milk. Others give a very curious medicine : it consists of the lime dug out of an old wall, and mixed with tar. What grod purpose the tar can answer, I cannot conceive, and the lime would be superseded by the prepared chalk recommended in the last recipe.

When the disease abates, the sheep must not be turned out again on their former pasture, but on the best old grass land which the farm will yield; and even then, a little good hay and corn should be daily allowed them.

The fariner should be careful that he does not confound the consequence of the diarrhoa with costiveness. When there is much mucous discharge, it is very sticky, and adheres to the wool under the tail, and glues it to the rump, thus forming a mechanical obstruction to the passage of the dung. 'The sheep straining very hard, careless observers have supposed that he was costive, and have given him a strong dose of physic, and thus added fuel to the fire.

'There is but one form of the disease under which all hope is precluded, and that is when it is connected with chronic cough or confirmed hoose. 'That animal may be patched up for a little while, but he will most assuredly perish.

It is necessary to make a distinction between diarrhoe and dysentery, the latter being attended with considerable fever ind the evacua20 * 
tions are often slimy and bloody, and the disease sometimes tcrminates fatally in a few days. It sometimes follows diarrhœa, hut is generally produced by change. of food or pasture and exposure to bad weather. Lambs are rather more liable to the disease than sheep, and it has been found to attack them very frequently on coming from low lands to high. The treatment should consist in giving mild laxatives, such as-

\section{RECIPE (No. 22).}

Take linseed-oil, two ounces; powdered opium, two grains; to be mixed with linseed tea. Linseed and ontmeal gruel should be given several times a day, and the second day the medicine No. 21 should be administered.

\section{SECTION XVI.}

\section{INDIGESTIONAND DEBILITY.}

BAD management, and that alone, causes the appearance of these complaints in a flock. When sheep have been over-driven, and excessively wearied; or ewes have had twins, and have afterwards been kept with their lambs on scanty pasture, where there was not enough even for the mother; or have yeaned very early, before there was any flush of grass; or, during the winter, have not yet been supplied with a proper quantity of hay or corn -in all these cases, the sheep are apt to pine away. They do not seem to relish their food, but wander over the field picking a little here and tinere, the belly being tucked up and the back bowed.

The remedy for this is simple enough if the sheep have not been neglected too long. It is plain that the powers of digestion are weakened or suspended, and the object to be accomplished is to rouse them once more to their proper tone and action. A mild purgative should lay the foundation for this. Half the Purging Drink (No. 2, p. 200) should be given, and this followed up by tonics or stomachics. Some farmers content themselves with giving a little good caudle for two or three successive days, and with general good effect, except that its sweetness is objectionable. The following mixture will be preferable :-

RECIPE (No. 23).

Tonic Drink for Debility.-Take gentian and powdered caraway-seede, of each an ounce; Colombo and ginger, of each half an ounce. Pour a quart of boiling water upon them, and let the infusion stand three days, well stirring it every day. Then pour off the clear liquid, and bottle it for use. Give a table-spoonful daily, in a little gruel, mixed with an equal quantity of good ale.

Repeat the half-dose of physic a week afterwards, and put the sheep on fresh and good pasture. 


\section{SECTION XVII.}

\section{B L I N D N E S .}

SHEEP are more subject to diseases of the eye that lead on to blindness than many persons who are most accustomed to them imagine. It is a singular circumstance, and not so well known as it ought to be, that if the eyes of a flock of sheep are carefully examined, half of them will exhibit either disease then present, or indications of that which existed at no very distant date.

Inflammation of the eye, which constitutes the commencement of the disease, may arise from various causes. Sheep driven fast to a distant market have suddenly become blind; those who have been chased about by dogs, have at no great distance of time lost their sight, and especially if, in both cases, they were afterwards exposed in a damp and bleak situation. The violent driving, while it produced fever, determined an undue quantity of blood to the head: it pressed, or perhaps was effused upon the origins of the nerves of the eye; and the after neglect confirmed the fever, and aggravated the mischief.

At other times, this seems to be an epidemic complaint. The greater part of the flock is suddenly afflicted with sore and inflamed eyes, and particularly at the latter end of the year, and when the weather has been variable, yet cold and moist. Some have thought that this complaint is infectious, but it is at least epidemic. A white film gradually spreads over the eyes, which the animal generally keeps closed, while at first a watery fluid, and afterwards a thicker mucous matter, is discharged from them. The film increases until the whole of the eye is of a pearly whiteness. If proper means are adopted, and often if nothing is done, inflammation abates, and the eye begins to clear, usually commencing at the upper part of the eye, and gradually proceeding downward until the whole of the organ is once more transparent, with the exception, perhaps, of a diminutive spot or two, or a discoloration of part of the iris. Many of the sheep, however, do not perfectly recover the sight of both eyes, and some remain totally blind, either from the continuance of the opacity, or that, while the eye becomes clear, the optic nerve is palsied, the pupil does not dilate, and there is gutta serena.

The first thing to be done is to bleed from the vein at the corner of the eye. There will be the double advantage of bleeding generally, and of drawing blood from the inflamed part. The shepherd should take the sheep between his knees, and then, placing the animal with his rump against the wall, he will have full command of him. If he now presses upon the vein with his left hand, about two inches from the angle of the jaw, and opposite to the third grinder, he will see it rise as it descends from the corner of the eye, and runs along the cheek. He should puncture it about an inch or rather less from the eye. Some shepherds recommend that the blood should be suffered 
to run into the eye, but this is a ridiculous notion. It must do harm rather than good.

Next give the Purgative Drink (No.2, p. 200), and repeat if necessary, in three or four days. No other medicine will be required.

No stimulating application should be made to the eye. It is too often the practice anong shepherds to apply sugar or salt, or white vitriol: but this worse than uselessly tortures the poor animal; it increases the inflammation, and causes blindness where it would not otherwise have occurred. A drop or two of the vinous tincture of opium may be introduced into the eye, two or three times daily; or a tea-spoonful of laudanum may be added to a half pint of water, and the eyes frequently washed with it.

It will be quite time enough to think of stimularits if the eye should remain cloudy after the inflammation has subsided, and then the following is the strongest that can be permitted.

RECIPE (No. 22).

Lotion for Cloudiness on the Eye. - Take corrosive sublimate, four grains; rub it down with spirit of wine, half an ounce; and add water, a piut.

Although, perhaps, it would be prudent to send the sheep decidedly and confirmedly blind to the butcher, lest they should perchance be drowned in a ditch, or some serious accident should occur to them, yet it is pleasing to observe how well they shift for themselves, and what little harm comes to them. For the first few days they are awkward and confused, but, after that, they keep to their own walk, and take with the others, or even by themselves, the accustomed way home; and, some one of the flock takes the blind sheep under his protection, and is always at his side in danger, and tells him the way that he is to go by many a varied and intelligible bleat.

[Grub in the head of sheep, is a troublesome disease in some parts of the United States.

The editor of the Cultivator, Vol. X., says:-The Grub in the head of a sheep, is the larva or maggot of a fly, which deposites its egg in the nose, generally in the month of August. The egg soon hatches, and the young maggot soon makes its way. up into the cavities called the frontal sinuses, where it attains its growth, causing constant irritation and disease, and not unfrequently death. Arrived at its growth, it falls to the earth, enters it, and in a short time emerges a perfect insect or fly, ready to commence the career of re-production and destruction. We formerly Jost many sheep from the grub, and could find no cure for them, or but very partial ones, after it became evident they were diseased. Our course was preventative. About the time the fly made its appearance, which is easily known by their exhibiting great alarm, running from one part of the field to another, with thcir noses close to the ground, \&c., we caught one sheep, and with a woolen spatula, or flat stick, rubbed the nose with tar. We then placed tar at the bottom of our salting troughs, over which the salt was sprinkled, and this brought their noses frequently in contact with the tar. This course we found a great preventative. Sheep, during the period they are exposed to the attacks of the fly, should have access to a ploughed field, or if such is not convenient, a few furrows should occasionally be opened in their pastures for thoir benefit. Inhaling the dust, or rubbing their noses in it, renders the mucus dis- 
agreeable to the fly, or enables the sheep to expel the larva when depositer. With these preventatives, we have rarely lost a sheep from the grub, and think, that in most cases, they will be effectual. $-\mathbf{S}:]$

\section{SECTION XVIII.}

\section{FRACTURES, WOUNDS, AND BITES.}

IT is not often that the sheep gets a broken bone by any fault of his own, but the shepherd is sometimes a brutal fellow. If he is a youngster, he is too frequently designedly mischievous; and in the struggle between a sheep and the dog a leg has now and then been broken. 'The treatment of fracture below the elbow or the hock is easy enough. The broken limb must not be roughly stretched or handled, but the divided edges of the bone must be brought gently and as perfectly opposite, and close, and fitting again to each other as possible, and kept together by some strips of adhesive plaister or pitch spread upon leather wound round the part. Over this splints should be placed, reaching a little beyond the joint, above and below, and these confined with more plaister, or with waxed thread. A little lint or linen rag should have been previously placed under the end of the splints, to prevent them from excoriating or injuring the part beneath. This being done, the leg should not be meddled with until the bandage becomes loose, which will be in about ten days. The splints must be replaced once, and at the expiration of another ten days the edges of the bone will generally be found to have united: the animal, however, should be kept for a little while longer as quiet as possible, and if the bone is not quite firm, the strips, without the splints, should be once more bound round it.

Sometimes considerable swelling will take place after the splints have been employed. 'They may have been put on a little too tight, or they do not press equally. They should not, however, be taken off at once, for the bones beginning to unite may again be separated during the removal of the bandages; but, with a sharp and strong pair of scissors, two or three notches should be cut through the edge of the bandacre above and below. This will generally afford sufficient room for the re-establishment of the circulation, and the swelling will subside, without the fracture having been disturbed.

If it should be a compound fracture, that is, if a portion of the bone should protrude through the skin, either the setting of the bones must be deferred until the wound is healed, or the bandages must be so applied, that the wound can be readily got at for the purpose of dressing. 'This, however, is so difficult a matter, that it will be prudent to destroy the animal that has a bad compound fracture. 
$\therefore$ Sheep are far oftener subject to wounds than they ought to be, from the ferocity of the shepherd's dog, encouraged by his brutal master needlessly to worry the flock. They are too frequently seriously lamed, and the ears almost torn from their heads. 'The proprietor of sheep should never forgive wanton cruelty of this nature.

The treatment of wounds in sheep is very simple, and consists mostly in avoiding the burning irons and caustics, of which the farrier, and sometimes the shepherd, are too fond.

The first thing is to clean the wound thoroughly with a sponge and warm water, and to remove those parts which are much lacerated, or in a manner torn off. If it is a simple cut wound and the edges are not far separated, all that will be necessary to be done will be to apply daily a little tincture of alo: s, and to cover the part that the flies may not deposit their eggs on the sore. If it is a wide and gaping wound, the edges of it must be brought as nearly and accurately together as possible, and confined by one or two or more stitches passed through them with a crooked needle and waxed thread, and which the shepherd should always carry with him. The only dressing wanted here will be the tincture of aloes, with occasional fomentations if there is much inflammation; but the wcund should be more carefully covered from the flies, either by a bandage or pitch plaister, or for a small wound, a little tar will answer.

No dependence is to be placed on the accounts which are given by some authors of the udders of the ewes being sucked by snakes. The reptile has never been seen thus employed; but sheep are sometimes bitten by the viper, and a few have been destroyed by the swelling having been neglected, and inflammation widely spreading. It is difficult at all times to discover the accident. Whenever a sheep is lamed, the affected limb should be well examined; and at other times, if he is evidently ill, and the illness accompanied by local or general swelling, careful search should be made into the nature of the mischief. The wound inflicted by a viper will be very small, but there will be swelling and heat about it, and a great deal of tenderness.

The best application is oil of turpentine, which should be well rubbed over and around the part; while a quarter of an ounce of hartshorn, and four ounces of sweet oil, may be given to the animal, and repeated in half an hour if the part should continue to swell, or the sheep appear to be seriously ill. Some shepherds, when they suspect an accident of this kind, rub the part well with an onion, and doubtless with considerable effect: the turpentine, however, is more effectual, and should be obtained as speedily as possible. 


\section{SECTION XIX.}

\section{GENERAL CAUTIONS.}

I wiL.L conclude this account of the diseases and treatment of sheep with a few general observations, which may be useful to the farmer as well as the veterinary surgeon.

It is an old maxim, and a most excellent one, that prevention is in every case far better than the cure; and there cannot be the least doubt that by a little attention, and the exercise of common humanity towards these useful and neglected animals, there need not be half the diseases, and scarcely a fourth part of the deaths that occur.

In the first place the farmer should look more than he does to the actual state, and health, and comfort of his flock. Instead of riding or walking in among them every day, and, in a manner, making every animal pass muster before him, he frequently contents himself with looking at them from a distance, or perhaps he does not look at them at all for many a day.

He deserves to be unfortunate who, in the lambing season, is not early and late among his ewes. Many a ewe is lost by rough handling; many more by not receiving the requisite assistance in difficult parturition: many a lamb is deserted by its mother ; many a one palsied by lying on the cold wet ground, and many more through want of being frequently and carefully suckled.

The owner will be induced by a regard to his own interest to take into due consideration many a circumstance connected with the season and state of his flock, that would never enter into the mind of the looker-on, but on which the eomfort, and thriving, and perhaps the very life of the sheep depend. Many a lamb dies for want of a little shelter in an inclement season; but many more die when the winter is mild, and the spring is early. In the one case they are lost from cold and starvation: in the other from being in too high condition, and having too much milk. The shepherd will often go on in the same regular way whatever be the state of the season: it is the proprietor alone who will have sufficient consideration to allow additional food and shelter in the one case, and in the other to stock as hardly as may be, before and during the lambing. The proprietor alone will consider as much as he ought when he should suckle, and feed, and shelter the weakly; and keep back and prevent the suckling, and milk the dain, and stock hard, the lambs being thriving and the weather kindly. These are affairs about which the generality of lookers. on scarcely concern themselves, and into which the best of them will not enter so anxiously as the master.

The most important circumstance to be attended to at all times, and particularly at the lambing season, is shelter,-not confinement, but shelter from the searching north and east wind. There should not be a lambing-field without a shed in it, or at least without some place 
surrounded with brushwood faggots on the north and east sides at least, if not all round; and into which the weakly lambs and ewes may be driven, and in stormy weather the whole flock may take refuge with manifest advantage.

Next in importance to shelter stands food. The animal may be stinted in his growth, and prepared for scab by starvation; or he may be inevitably destroyed by over-feeding, or by sudden change of food. The unhealthy seasons for sheep, putting the rot for a moment out of the question, are not the winter, when no grass grows, nor the summer, when it is all burned up, but the spring and the autumn, when there is plenty, and too much to eat. They contrive to live, if not to fatten in the two former seasons, but they perish from excess or change of food during the latter two.

There is one disease, however, which is caught, or the foundation for which is laid in the summer, and that is the rot; but from what has been stated with regard to this disease, a proper system of husbandry, and attention to little unsuspected, but most dangerous, nooks and corners, would materially limit the ravages of the rot.

The grand fault in the management of sheep, and of all domestic animals, is, that the farmer pays so little personal attention to them, and pursues one undeviating course, the same that he learned from his father, whatever be the state of his flock, and whatever the state of the season. To this must be added - the most absurd, and the most injurious of all - a spirit of fatalism; a submission, not without repining, but without an effort to avert them, to many and serious losses, which a little care and personal trouble might have prevented.

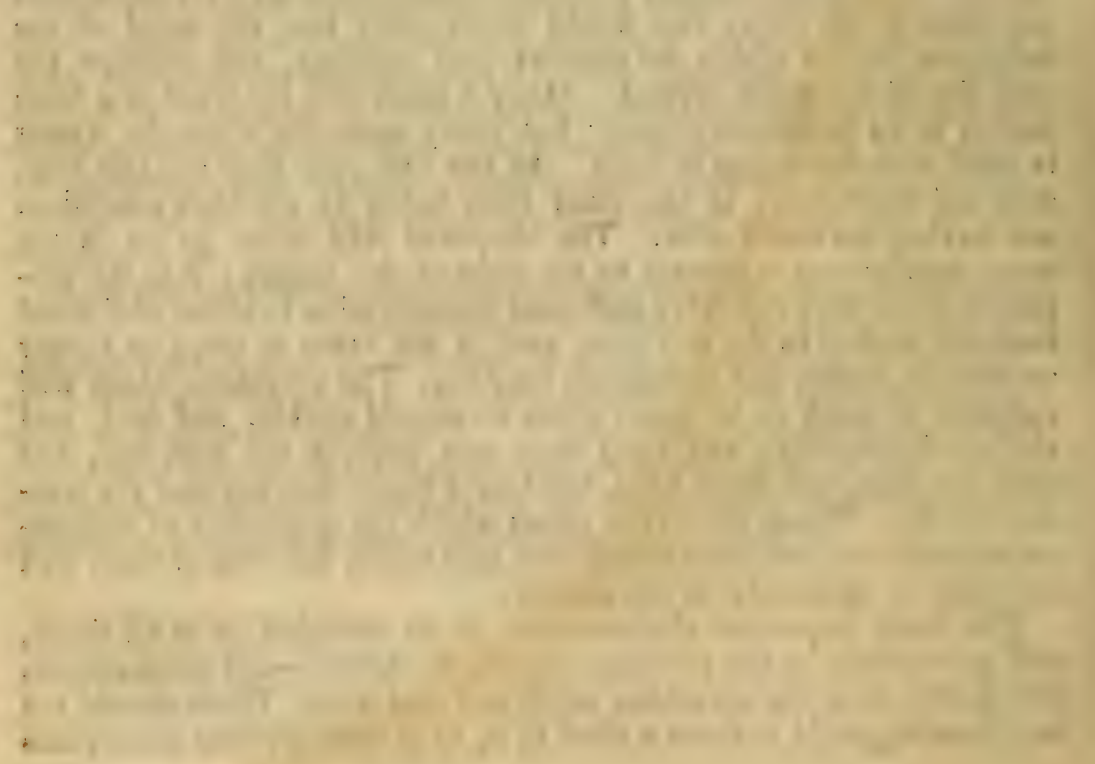




\section{DISEASES OF SWINE.}

Ir is only very lately that any persons have condescended to take into consideration the maladies of swine, and they are little understood. The diseases that have been recognised are not numerous, but they are exceedingly fatal; and that fatality is increased by the difficulty of managing these unruly animals.

'The most frequent disease, and as fatal as any, i: -

\section{INFLAMMATION OF THE LENGS.}

This complaint is known among the breeder 3 and fatteners of swine by the term of rising of the lights. There seems to be a peculiar tendency in every malady of this animal to take on a highly inflammatory character. It is the consequence of the forcing system that is. adopted in the fattening of the hog. It resembles the blood or inflammatory fever of oxen and sheep,-a general and high degree of fever, produced on a system already strongly disposed to take on intense inflammatory action from the slightest causes. Every little cold is apt to degenerate into inflammation of the lungs in the fatted or fattening hog; and so many cases of this sometimes occur in the same establishment, or the same neighbourhood-in fact among those who are exposed to the same exeiting cause, that the disease is mistaken for an epidemic. There is no doubt that when this heaving of the lights begins to appear in a herd of swine, a great many of them are sooner or later affected by it, and die. It is the cough or cold that is epidemic, but it is the plethora and inflammatory state of the animals that cause it to be so general as well as fatal.

The early symptom is cough. A cough in a hog is always a suspicious circumstance, and should be early and promptly attended to. The disease is rapid in its progress. The animal heaves dreadfully at the flanks; he has a most distressing cough, which sometimes alinost suffocates him, and he refuses to eat. The principal guiding symptom will be the cough getting worse and worse, and becoming evidently connected with a great deal of fever.

In many cases congestion takes place in the lungs, and the anımal dies in three or four days: in others he appears for a while to be getting better; but there is a sudden relapse, a frequent dry husky cough comes on, there is little appetite, rapid wasting, and the log dies in a few weeks, evidently consumptive. 
The first thing that is to be done is to bleed, and the most convenient place to bleed the hog is from the palate. If an imaginary line is drawn from between the first and second front middle teeth, and extending backward an inch.along the palate, and the palate is there cut deeply, with a lancet or fleam, plenty of blood will be obtained. A larger quantity of blood, however, can be abstracted from the vein on the inside of the fore-arm, about an inch above the knee. 'The application of cold water with a sponge will generally stop the bleed ing without difficulty, or at least so far arrest it, that no harm will be done, if it should continue a little while longer. An assistant may easily open the mouth sufficiently for all this by means of a halter or stout stick, but beyond this the swine is an awkward patient to manage. He will struggle obstinately against every attempt to drench nim, and the inflammation may be aggravated by the contest. It will, therefore, be necessary in the majority of cases to endeavour to cheat him by mixing his medicine with his food.

Here we must recollect the nature of his stomach : it is not of that insensible character and difficult to be acted upon or nauseated as in the cow and the sheep, but it approaches as nearly as possible to the structure of that of the human being; and we must adapt our medicine accordingly. The emetic tartar must be omitted from our Fever Medicine, or it would sadly vomit the patient. 'The following may be given :-

RECIPE (No. 1).

Fever Medicine for Swine.-Take digitalis, three grains; antimonial powder, six grains; nitre, half a drachm. Mix, and give in a little warm swill, or milk, or mash.

In the greater number of cases the animal will readily take this: but if he is so ill that nutriment of every kind is refused, he must be drenched.

This should be repeated morning, noon, and night, until the inflammation is abated. A purgative should quickly follow, and we have those for the hog which are mild as well as effectual, and from which no danger can result. The Epsom salts may be given in doses of from one to three ounces, and they will communicate a not unpleasant or unusual flavour to his broth or swill.

If this inflammation of the lungs in the hog rivals in the speed with which it runs its course, and in its intensity and fatality, the bliod, or inflammatory fever of oxen and sheep, no time should be lost in adopting the proper measures, and the hleeding should be copions, and the medicine given in doses sufficiently powerful. When the disease lingers on, and the dry husky cough remains, and the animal is evidently wasting, medicine will be in a manner useless, and warmth and cleanliness, and food that has no heating quality, affurd the only chance of cure.

APOPLEXY AND INFLAMMATION OF THE BRAIN

In distilleries, and where many hogs are kept, and too well kent 
this is a very destructive, and not unfrequent malady. If the swine had been cirefully observed, it would have been seen that they were making a more than usually rapid progress, but there was at the same time a laziness, or heaviness, or stupidity, about them. A dose or two of physic would have removed this, and not have interfered with the fattening; indeed they would have thriven the better after it. If this, however, has been neglected, the apoplexy will probably be established. The swine, in the act of feeding, or when moving across the sty, will fall suddenly, as if struck with lightning. He will be motionless for a little while, and then convulsions will come on, strong and dreadful : the eyes will seen protruded, the head ard neck will swell, and the veins of the neck will be brought into sight, notwithstanding the mass of fat with which they may be covered. In the midst of his struggles the animal will be perfectly linconscious. He will often die in a few minutes, or should he recover, he wilt be strangely exhausted, and some internal injury will be evidently done, so that he will afterwards be very subject to refurns of these attacks either of apoplexy or of fits.

The course here is plain enough. He should be bled, and bled copiously. Indeed the blood should be suffered to flow as long as it will. Two or three ounces of Epsom salts should then be given; the quantity and the heating character of the food should be diminished, and a couple of drachms of sulphur given daily in the first meal.

When apoplexy or fits have once appeared in a sty, they spread like wild-fire. There is nothing contagious in them, but there is the power of sympathy acting upon animals become too disposed to inflammation and fever. The most forward of them should be disposed of as soon as possible.

The habit of fits once established cannot easily be broken, and the only way to prevent the continuance of much annoyance is, to separate those that are oftenest affected from the rest, and to fatten them as soon as possible.

\section{MEASLES.}

This is an inflammatory disease, not always indeed discovered during the life of the animal, but plain enough after death, and very considerably diminishing the value of the carcass. The red and pimpled appearance of the skin, or of the cellular substance between the flesh and the skin, sufficiently marks the disease. It shows that there has been general inflammation, either resulting from the fattening process being carried too far, or, much oftener, from the animal having ton suddenly been taken from poor keep, and suffered to have as much as it will eat of highly nutritions and stimulating food. The measles are very seldom $n$ r never fatal, but the disease may generally be recounized by the pink blush of the skin, or of some parts of it, and by the hog rubbing himself more than usual, while the skin is free from pimples and scurf. The remedy would be a less quantity 
of food, or of not so stimulating a character, and occasional doses of Epsom salts or sulphur.

MA N G E .

Few domesticated animals are so subject to this loathsome disease as the hog if he is neglected and filthily kept; but in a well cleaned and well managed piggery it is rarely or never seen, unless some, whose blood from generation to generation has been tainted with it, should be incautiously admitted. A mangy hog cannot possibly thrive well. His foul and scurfy hide will never loosen so as to suffer the accumulation of flesh and fat under it.

Except it is hereditary, it may, although with some trouble, be perfectly eradicated. The first thing to be done is to clean the hog well; without this all external applications and internal medicines will be thrown away. The animal must be scrubbed all over with a good strong soap-lather, and when he is well dried with wisps of straw he will be ready for the ointment, and no better one can be used than the Mild Ointment for Scab in Sheep (Recipe No. 14, p. 225). A little of this should be well rubbed all over him every second or third day; but at the same time internal medicine should not be omitted. There is no animal in which it is more necessary to attack this and similar diseases constitutionally.

RECIPE (No. 2).

Altcratine Ponder for Sinine.-Take flowers of sulphur, a quarter of an ounce ; Athiop's mineral, three grains; nitre, and cream of turtar, half a drachm. Mix, and give daily in a little thickened gruel or wash.

This, like the scab in sheep, is a very infectious disease, and care should be taken to scour the sty well with soap, and afterwards to wash it with a solution of chloride of lime, as recommended at page 225. The rubbing-post, that useful, but too often neglected article of furniture in every sty, should particularly be attended to.

\section{SORE EARS .}

There are very often troublesome cracks and sores at the back of the large lop-ears of some breeds. If there is any disposition to mange, it is most evident about the ears of these animals, and the mischief is sadly aggravated when brutes in human shape set every ferocious dog at the stray pig, the favourite hold of which is the ear. The Healing Cleansing Ointment for Cattle (Recipe No. 10, p. 53) will most readily heal the sores.

\section{P 1 G G IN G .}

The sow usually goes with pig four months, but there is more irregularity in her time than in that of any other of our domesticated quadrupeds. A week or ten days before her pigging she should be separated from the rest, otherwise the young ones would probahly be devoured as soon as they are dropped; and if she shows any dispo. sition to destroy them, or if she has ever done so, she should be care 
fully watched, a muzzle should be put upon her, and her little ones should be smeared with train oil and aloes as soon as possible.

The teats of the sow will sometimes swell, and hard knots may be felt in them as in the garget of cattle. The treatment should be nearly the same except that bleeding is scarcely requisite. A dose of physic, however, is indispensable. The Garget Ointment for Cattle (Recipe No. 24, p. 69) may be rubbed with advantage into the teats, which should be carefully wiped or washed before the young ones are permitted to suck again; indeed they will not suck while any unusual smell remains about the teats. 'The milk should also be gently but well pressed out of the diseased teats.

When it is wished to spay a breeding sow, in order that she may be put up for fattening, it may be done while she is suckling. The young pigs may be cut at three or four weeks old : they should never be suffered to suck longer than two months; and they may be rung as soon as convenient after weaning. No hog should escape ringing, even if he is destined to live in the sty. It is the only way to keep him quiet, and will contribute materially to his thriving.

\section{QU I N S Y .}

This disease in the hog is compounded of sore throat and enlargement of the glands of the throat, and is something like strangles in the horse - inflammation and enlargement of the cellular substance between the skin and muscles under the lower jaw. The progress of the malady is rapid, and the swelling is sometimes so great as to prevent the breathing, and consequently to suffocate the animal. To a skin so thick as that of the hog it is useless to make any external application. The patient should be bled; two ounces of salts should be given, and half-ounce doses repeated every six hours, until the bowels are well opened; while warm weak wash, or milk and water. should be occasionally poured into the trough. It is not often a dangerous disease if remedies are early adopted.

[Governor Vance, of Ohin, now in Congress, has been very observant of the dis. eases to which domestic animals are subject in that State and the west. These sheets having heen submitted to his inspection, he answered :-

\section{Washington, January 22d, 1844.}

I have lonked over the sheets enclosed relative to the diseases of hogs, and am convinced that what is termed "quinsy" in these sheets is the same disease we were conversing about the other evening at Mr. Seaton's. By careful attention to the early stages of this disease, if it is the same that afflicts our swine in the west, it will be found that they will become stiff in all their limbs, and will move with as much difficulty as a foundered horse, and with almost the precise symptoms.

When this is the case, we know of no cure but a thorough cleansing and opening of the ducts or hroles in the inside of the fore-legs, which will give free respiration : this, with ashes and sulphur mixed with salt, or incorporated with the food, will generally effect a cure. 
KIDNEY-WORM.-There is a fatal disease amongst our swine in the west, called the Kidney-Worm, which causes a weakness in the back, and finally a falling of the hind quarters, which they will drag around for months, until they becnme the most loathsome objerts that you can conceive of. Arsenic in small portinns, mixed with their food, will generally prove effectual, if given in the first stages of the disease; and the best preventive medicine is ashes and sulphur mixed with their salt; for hogs require as regular salting to keep thein healthy and in good condition as do cattle or horses. - S.]

\section{COSTIVENESS.}

This is not an uncommon complaint of the confined and fattening hog, and is easily removed by the Epsom salts, or by five grains of calomel being given in a little of the animal's favourite food. It will be dangerous, however, to push the calomel beyond the second or third dose, for the hog is very easily salivated. 'The bowels having been well opened, a dose of the Alterative Powder (Recipe No. 2, p. 244 ) given every fourth day will be very beneficial, and will hasten the fattening of the styed hog that exhibits any disposition to costiveness.

Sometimes, however, this costiveness is produced by -

\section{INFLAMMATION OF TIE BOWELS,}

which is attended by considerable pain, heat and tenderness of the abdomen, with a quick pulse, and other symptoms of fever, and sometimes by fits and insensibility. The treatment should consist of copious bleeding, oily laxatives, clysters, warm fomentations to the abdomen, and, if the animal is not too large, warm baths. 


\title{
I NDEX.
}

\author{
manuman
}

Page

Abortion, the cause and remedy, 72

Absorbents, account of the,.. 31, 33

After-pains, the treatment of,. . 196

Age of cattle, how known by the horns,$\ldots \ldots \ldots \ldots \ldots 21$

Aloes, seldom used for cattlo and sheep, ............... 44

Alum whey, prescription for, . 64

Angle-berries, account of, .... 122

A poplcxy in swine, ........ 242

Arteries, account of the, ..... 26

Astringent drink, .... 61, 64, 200

Belly, wounds in, treatment of, 117

Bile, account of the ....... 32

- obstruction of the $\ldots \ldots .55$

Black-foot, description of the, . 141

$-\mathrm{leg}$, the nature and treatment of, ........... quarter, ditto,.........

Buter, the treatment of, . 66

Blidder, inflammation of the, in cattle, ............. 94 neck of, ......... ib. stone in the, ....... 96

Blain, nature and treatment of. 80

Blast, nature and treatment of, in cattle, .............. 101

-

Blceding, when necessary, .... 42 manner of performing, 43

—— freep, ......... 193

from wounds, treat. ment of, ....... 117

Blindness in shcep, ........ 235

Blister ointment, a recipe for,.. 57

Bloud, account of the, ..... 33, 82

- the nature and treatment

of, in cattle,....... 82

- sheep,....... 203

Blown, nature and treatment of, in cattle,............. 101

- sheep,........209

Bones, the structure and use of, 19

Bowels, inflammation of the, in cattle,... ........... 59

Brain, account of the ,..... 24

inflammation of the $\ldots .56$

- in sheep, ......206

-

Bruises, treatment of, ....... 119

Bull-burnt, treatment of, ..... 127

Bulling, how to produce,..... ib.

Bullock, age of the, ........21

Calf, description of its natural

growth in the womb,..... 36

- early treatment of the, .. 132

- bed, protrusion of the, ... 74

Calves, the diseases of, ....... 131

cordial, an excellent one, 134

Calving, treatment of the cow, before, during, and after, ... 71

— symptoms of its a pproach, 73 difficult treatment of, .. ib.

Cancer of the eye, ........ 99

Cancerous ulcers, treatment of, 121

Canker in the mouth, in calves, 137

Capillaries, account of the, ... 26

Cartilage, the structure and use of, ...................20

Castration of lambs, directions for, ............... 197

Catarrh, in cattle, on ...... 47

- sheep,.......... 207

Cattle, different names applied to, 21 diseases of, . ........ 138 zoological description of, 19

Cautions, general, respecting sheep, ................ 239

Caul, account of the ....... 35

Cellular membrane, account of the $\ldots \ldots \ldots \ldots \ldots \ldots$. 
Chest, description of the,.... 21

- wounds in, treatment of, 116

Choking, ..............108

- Mr. Simmond's instrument for, ........ 109

Chyle, account of the, ...... 31

Chyme, account of the, ...... ib.

Circulation, account of the,... 25

Clatting of the ewes, recommended, .............. 195

Cleansing after calving, nature of 76

Clue-bound, nature and treatment of, ............130

Coagulation of the milk in Iambs, 198

Cold, in cattle, ...........44 46 - sheep, ............207

peculiarly dangerous to young lambs,.........

Condition, high, danger of, ....

Consumption, from the hoose,..

Cordials, drink for cattle, .....

- cautions with regard

to them,.........

Corrosive sublimate employed in too great quantities, is poisonous, ................ 125

Costiveness in calves, treatment

of, ................. 135

cattle, on,.....

lambs, treatment of, ....135, 201

swine, treatment of, .......2 241

Cough drink for cattle, $a, \ldots .46$

in calves, nature and treatment of,...... 137 - cattle, nature and treatment of,.... importance of immediate attention to,......... in sheep, nature and trcatment of, ......207 in swine, nature and treatment of, .......241

Cow-pox,nature and treatment of, 128

Crackling, under the skin, nature of, $\ldots \ldots \ldots \ldots \ldots 85,212$

Croton Tiglii, its use as an occasional purgative,........ 44

Debility in sheep, on, ......234

Diaphragm, an account of the, 28
Diarrhœa, in calves, treatment of, 133 - cattle, treatment of, 61 - Jambs, treatment of, 199 sheep, treatment $\mathrm{cf}, 233$

Digestion, account of, . .....28

Disinfectant lotion, the composition of,............ 85

Diuretic drink for cattle, ..... 69

Downfall in the udder, ...... 68

Draining, under, the importance of,$\ldots \ldots \ldots \ldots \ldots \ldots \ldots 215$ reasons of its ac. casional failure, ib.

Dropping, after calving, nature and treatment of, ........ 77

Dysentery, on the, in cattle, ... 62

Ears, sore, in hogs, . . . . . . 244

Epidemic catarrh, on, ....... 48 of 1840 and $1841, \ldots 91$ - treatment of,.... 92 in sheep, ......99 in pigs,....... ib.

Epsom salts, the best purgative for cattle and sheep,....... 44

Ewe, the proper treatment of, while in lamb, .......... 194

Eye, diseases of the, in cattle, . 97 in sheep, .....2235

- cancer of the,......... 99 - inflammation of the,.... 98 lids, diseases of the, .... ib.

Falling down of calf-bed, . . 75, 196 Fardcl-bound, nature and treatment of . ............ 130

Fat, account of, ......... 23

Feeding, general observations on, 24! Feet of oxen, the proper form of, 22

, wounds in, ....... 116

Fellon, on, ............ 51

Fever drink for eattle,....... 46

Fistulous withers in oxen, ... 115

Flies on sheep, treatment of, . 230

Flukes in sheep, description of, 213

Fcetus, account of the,....... 36

Foot-rot, the,........... 218

- highly infectious, $219,22 \%$

- treatment of the,.....220

Fore-arm, description of the,... 22

Form of cattle, the proper, .... 2 
Foul in the foot, treatment of the, 123 Inflammation, internal, ...., . 4I

Fox-glove, poisonous for cattle, 112

Fractures, treatment of,...... 121 in sheep,......237

Gall lambs, what,.......... 197

Garget, on the, ........... 68

_ ointment for cattle, ... 69

Gargyse, nature and treatment of, 80

Gastric juice, account of the, .. 31

Giddiness in sheep, nature and trestment of, ...........204

Glands, description of the,.... 34

Glauber salts, a purgative for cattle,..................

Goggles in sheep, nature and treatment of, ..........206

Grub, the, in sheep, ........236

Gullet, account of the $\ldots \ldots \ldots 29$

Hair, account of the, ....... 23

Haw, inflammation of the, .... 100

Hawkes, nature and treatment of...$\ldots \ldots \ldots \ldots \ldots$. . .

Head, description of the,.....

Healing ointment, ..........

Heart, account of the, ........

Heifer, age of the, ..........

Hellebore, black, the root of, the best seton, ........... 46

Hemlock, poisonous for cattle, . 112

Hock, description of the, ..... 22

Hoose in calves, nature and treat. ment of,............. 137

cattle, nature and treatment of, ................

Hoove in cattle, nature and treat. ment of,.............. 101

- sheep, nature and treatment of,.............207

Hornet, treatment of the stings of, 114

Horn, broken, treatment of, ... 118

Horns, the, connected with the age, ..................

Humanity towards the sheep enforced, .............. 233

Hydatid on the brain, in sheep, 204

Hydrophobia in cattle, the nature and treatment of, ........ 130

Indigestion, on, in sheep, . . . . 234

Inflanumation, external,......
Inflammation, internal,...... 4 4l of the bladder, in cattle, ...... 94 neck of, ...... ib. bowels, in cattle, 59 - swine, 246 brain, in cattle, . 56 sheep, . 206 swine,. 242 eye,......... 98 kidneys in cuttle, 65 liver in cattle, .. 53 lungs, in cattle,. 50 sheep. .. 208 swine,.. 241

Inflammatory fever, in cattle,.. 82 - sheep, ........203 203

Influenza, on, .......... 47 - in sheep, ........ 208

Intestines, an account of the, .. 31

Iodine ointment,.......... 69

Jaundice, account of, in cattle, . 55 sheep, .......2 210

Joint-fellon, ............. 52

- wounds in the, treatment of,....... 114

Joints, humours about the, ....118

Kidneys, account of the, .... 35 - inflammation of the, . 65

Lacteals, account of the, .... 31

Lambing, the assistance which should be rendered in,..... 194

46

- signs of danger in, . 195 season, the duties of, 194 ewes should be sheltered then, 194 Lambs, young, the diseases of,. 198 the attention they require when dropped, . 196

Leech bitcs, treatment of, ..... 114

Leg, fore, description of the, . . 22 hind, description of the, ., ib Lice on cattle, how to destroy,. 126 shecp, how to destroy,. 22! Linseed oil, a good purgative,.. 44 Liver, account of the, ...... 32 inflammation of the, . . 53 Locked jaw in cattle,....... 110 
Lungs, inflammation of the, 50, 208

Mad-itch in catle, the cause of, 141

Mange in cattle, nature and treatmcnt of, ...........125 swine, nature and treatment of,....244 ointment, the best, .....125 Manyplus, account of the, .. 29, 30

Measles in swine, nature and treatment of, ..........243

Medicines should be given in a fluid form, ..............

Mesentery, account of the, ....

Milk, coagulation of the, in the lamb's stomach, ......... 198

- fever in cows, nature and treatment of, ....76, 140 should be all drawn at each milking,.......... 70 how to dry a cow of, .... 124 Murrain, nature and treatment of $, \ldots \ldots \ldots \ldots \ldots \ldots \ldots, 85,90$

Muscles, account of the,..... 24

Navel-string, bleeding from the, 133

INeat cuttle, number of, in each State,...................

Ncck, description of the,......

Nerves, account of the, ...... 24

Nose, discharge from the, in sheep,................207

Omentum, account of the,.... 35

Over-feeding, danger of, ..... 83 ___ young lambs, danger of, ....... 197

Ox, advantages from the use of the, .................. 142 — machine for shoeing the, .. 151

- shoe, description of the, .. 152

— skeleton of the,$\ldots \ldots \ldots \ldots 38$

- teams, compared with horseteams,............ 146

— treatment of the, ....... 162

- useful in teams for heavy draft,............. 148 — yoke for the, description of, 165

Pancreas, account of the, .... 33

Paunch, account of the,..... 29
Paunching, account of, .. 103, 209 Pelt of the dead lamb should never be the shepherd's perquisite, ............... 194

Periostcum, description of the, 20

Peritoneum, account of the, ... 35

Perspiration, account of the,... 34

Pestilential fever, nature and treatment of, ........... $\$ 5$

Phrensy in cattle, on, ....... 50 ó

Physicking, the object and $t_{2}$ fect of,................ 13

Pigging, directions concerning, 244 Poisons of cattle, account of the. $112,138,341$

Pregnancy, account of, ...... 35 Presentation, natural, in calving, 73 unnatural, means to be adopted, 73,195

Protrusion of the womb, treatment of, .......... 75, 196 Proud flesh, treatment of,.... 115 Pulse, account of the, ....... 26 Purgatives, the best, ..... 44, 140 —_ when useful, ..... 44 - doses of, .........207

Purging in calves, treatment of, 132 cattle, treatment of,. 61 drink, ........47, 200 for cattle, strong, 61 sheep, ......233

Quarter evil, nature and treatment of,.............. 82

Quey, age of the,$\ldots \ldots \ldots \ldots 21$

Quinsy in swine, nature and treatment of, ............245

Rabies, in cattle, nature and treatment of,.......... 130

Read Mr., his instrument for hoove,................. 104 patent pump recommended, . 106

Red-water in cattle,....... 65 important difference between its varieties, ........... ib. in sheep,........202

Rennet, account of the, ...... 31 Respiration, account of,...... 27 
Reticulum, account of the, ... 29 Staggers, ............ 58

Rheumatic drink, ...... 52,53 Staggers in lambs,........ 201

embrocation, ...... 52 Stone in the bladder, \&c..... 96

Rheumatism, description and treatment of,........... 51

Rot, the nature and treatment of, 211

Rottenness in cattle, on,.....6 63

Rising of the lights in swine, . 241

Rumen, account of the,..... 29

Ruminants, their distinguishing characteristics, ...........

Rumination, account of, .....

Salt, the use of it for cattle and sheep, ........44, 208, 217

Scab, the nature and treatment

of, .................223

ointment, the best,..... 224

Scouring-rot in cattle, on the,.. 62

Secretion, ............... 34

Setoning, ............. 45

Shape, inflammation of the,... 96

Sheep, diseases of, . . . . 168, 193

husbandry, .......... 168

different breeds of, their

characteristics,.. 175, 182

- their value,.... 182

number of, in each State, 187

Sore heads in sheep,........232

ears in swine, ........ 244

teats in cows, ....... 70

ointment for,... ib.

Strains, ............. 119

Sturdy in sheep,......... 204

Swimming in the head,..... 58

Swine, diseases of, ........241

Syringe, Read's patent veteri-

nary, ............... 104

Ticks in sheep, ......... 230

Trembles, cause of the,..... 138

T- account of the, .... 140

Tumours about the joints, .... 121

Udder, ............... 36

Ulcers, cancerous, ........ 121

Water in the head in sheep,... 204

Wool, growth in each Stute,... 187

value of different fleeces, 182

Woollen goods, manufactures of, in the United States, ....... 179

Womb, scirrhous state of its entrance prevents calving, .... 72 operation for,... 75

- inversion of, ....... 74

Wounds in cattle,........ 114 sheep, .........237

Yellows, ............. 55 in sheep, ........210 






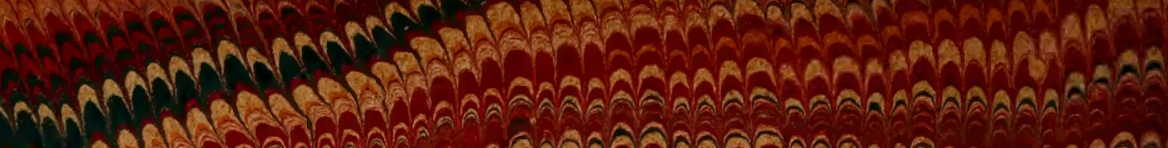

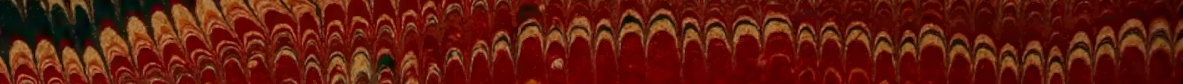

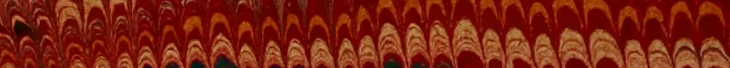

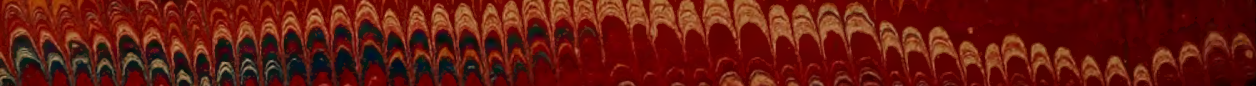
WhâA

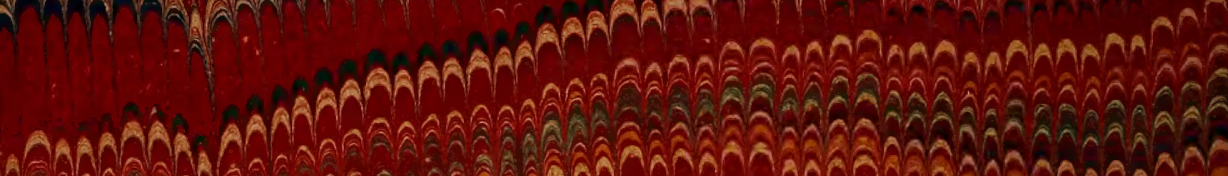
a) ThA

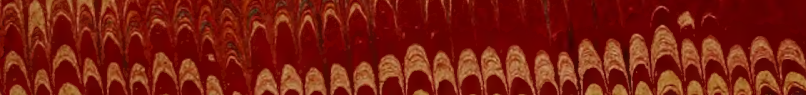
WWWhathanân

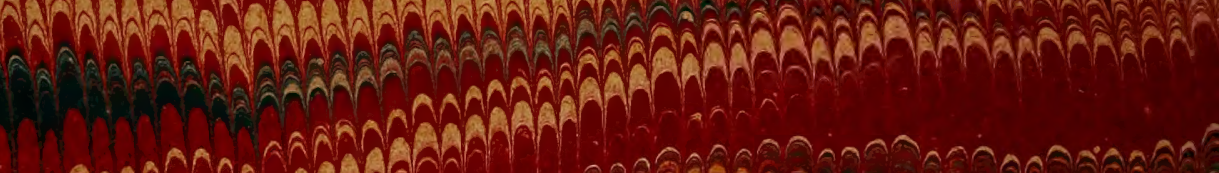

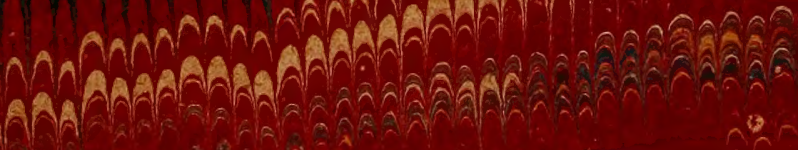

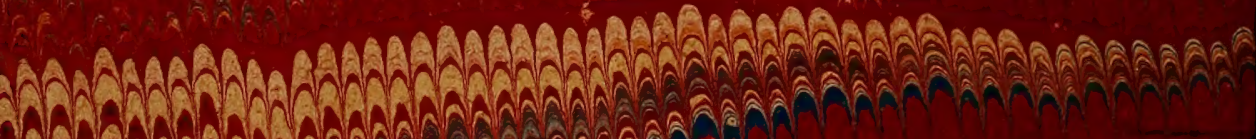

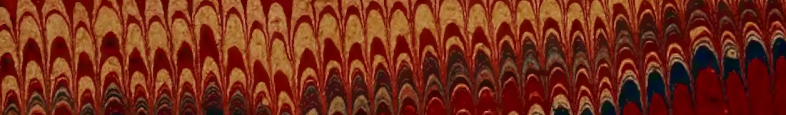

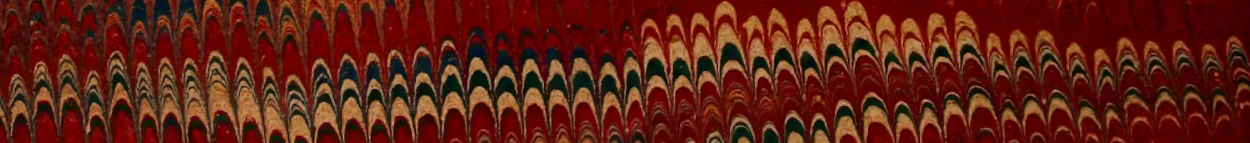

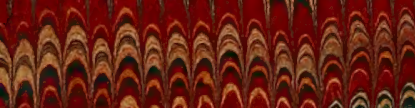

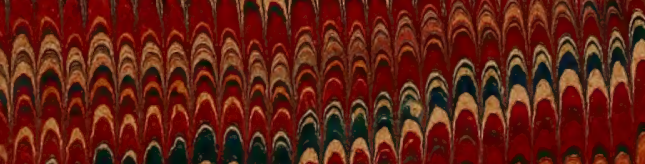

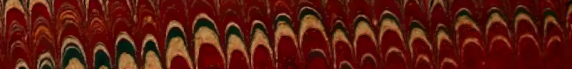

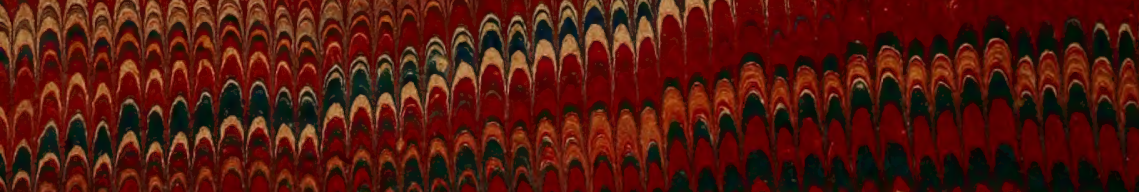

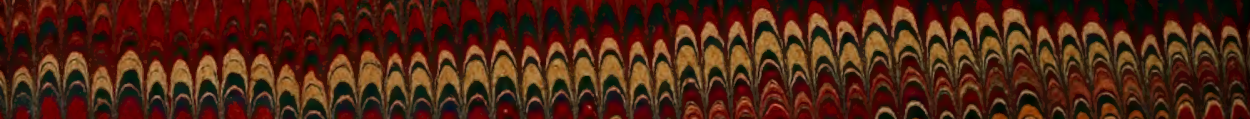

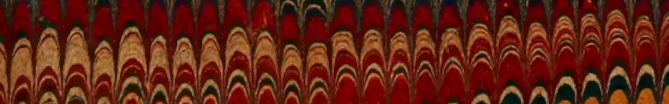

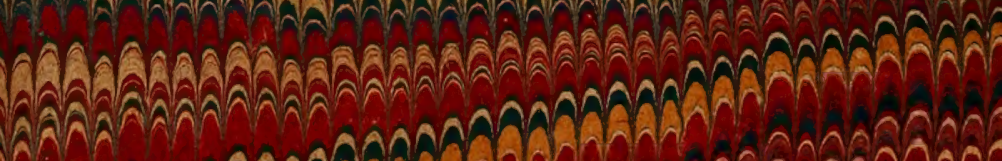

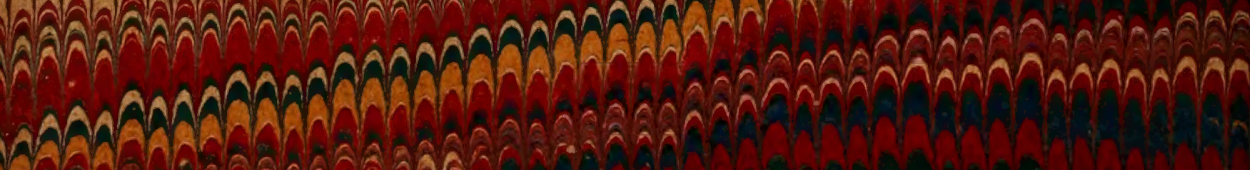




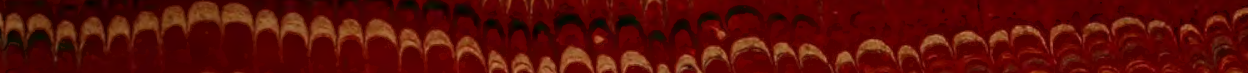

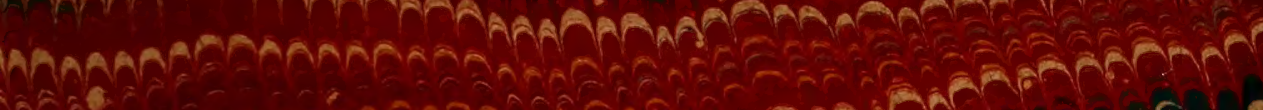

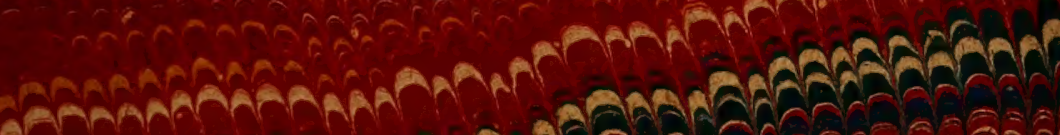
AAAA

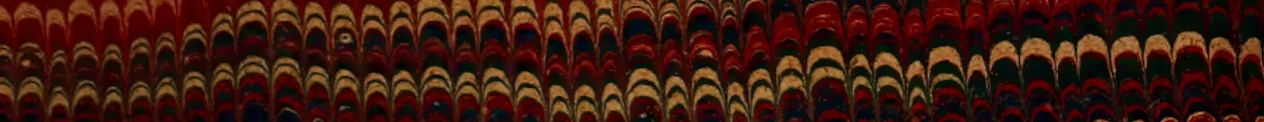

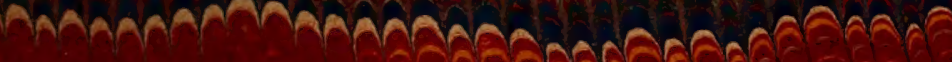

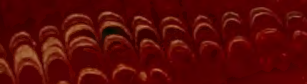

- inatinân

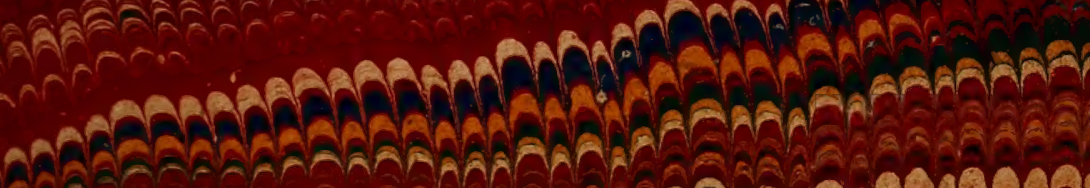

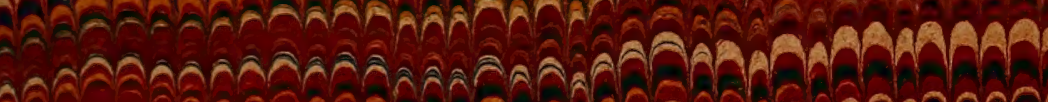

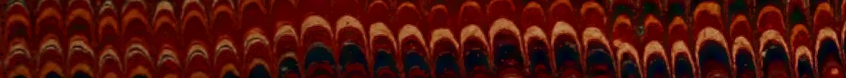

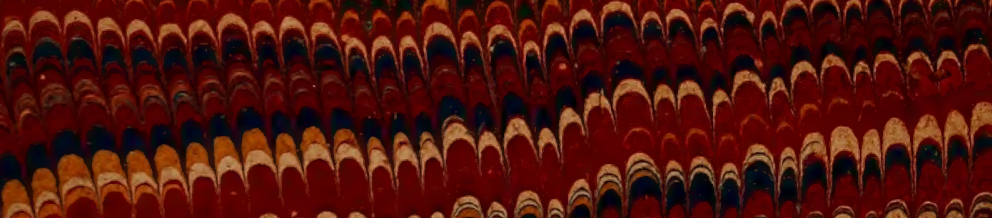
-

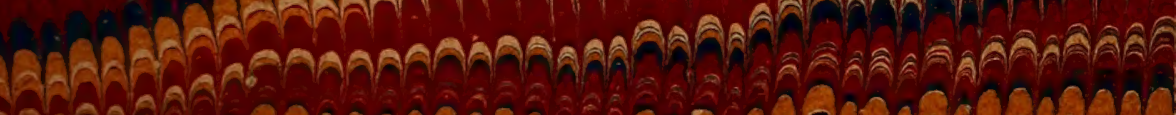

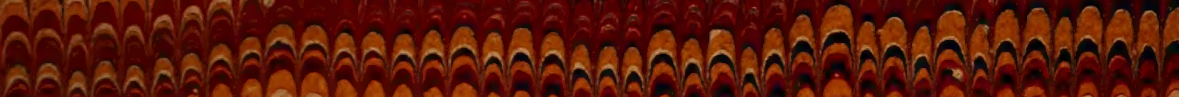

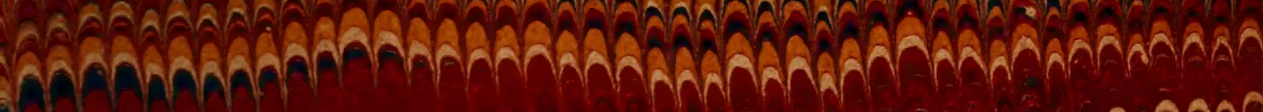

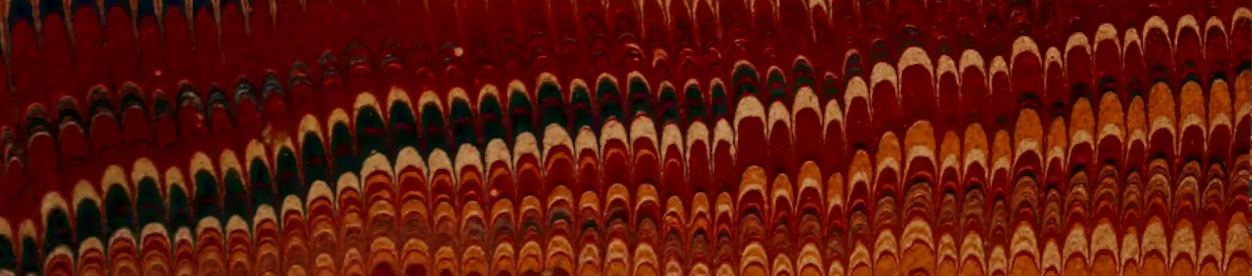

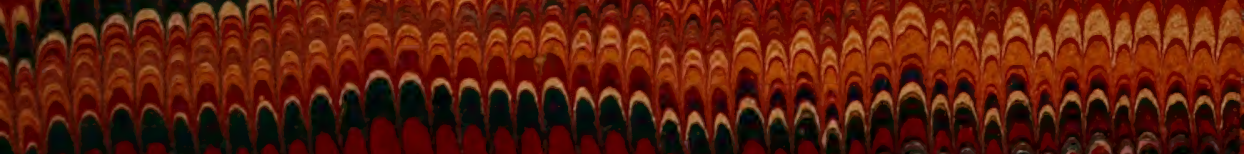

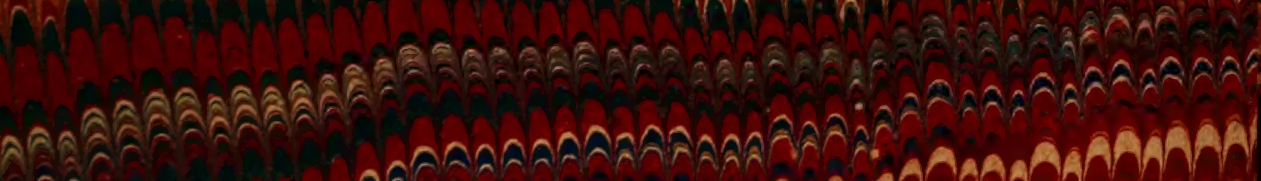

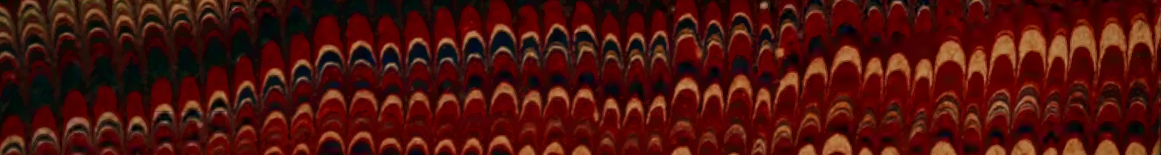
aลสิ

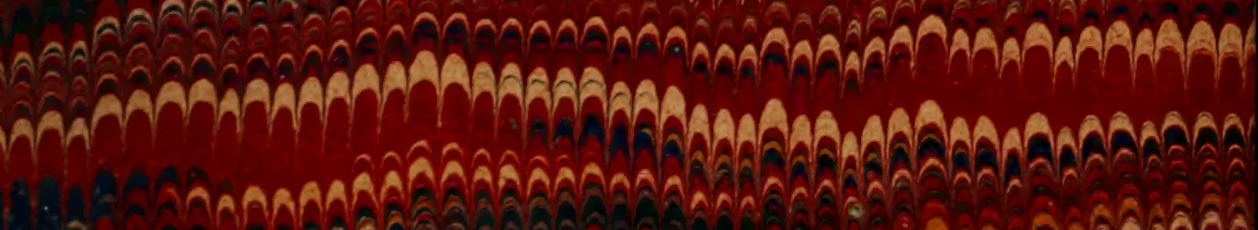

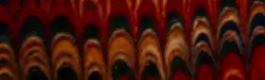


